\title{
UNIVERSIDADE FEDERAL DE MINAS GERAIS
}

PROGRAMA DE PÓS-GRADUAÇÃ̃ EM ENGENHARIA MECÂNICA

\section{PREDIÇÃO DE VIDA EM FADIGA DE UMA RODA DE CAÇAMBAS UTILIZANDO MECÂNICA DA FRATURA LINEAR ELÁSTICA}

BRUNO LOPES BARCELOS

Belo Horizonte, 17 de dezembro de 2018 


\author{
Bruno Lopes Barcelos
}

\title{
PREDIÇÃO DE VIDA EM FADIGA DE UMA RODA DE CAÇAMBAS UTILIZANDO MECÂNICA DA FRATURA LINEAR ELÁSTICA
}

Dissertação apresentada ao Programa de Pós-Graduação em Engenharia Mecânica da Universidade Federal de Minas Gerais, como requisito parcial para a obtenção do título de Mestre em Engenharia Mecânica.

Área de concentração: Projeto e Sistemas

Orientador: Prof. Dr. Ernani Sales Palma (UFMG)

Belo Horizonte

Escola de Engenharia da UFMG

2018 
Mecânica da Fratura Linear Elástica [manuscrito] / Bruno Lopes Barcelos. $-2018$.

135 f., enc.: il.

Orientador: Ernani Sales Palma.

Dissertação (mestrado) - Universidade Federal de Minas Gerais, Escola de Engenharia.

Anexos: f.114-135

Bibliografia: f.108-113.

1. Engenharia mecânica - Teses. 2. Juntas soldadas - Fadiga - Teses. 3. Mecânica da fratura - Teses. 4. Tensões residuais - Teses. I. Palma, Ernani Sales, 1959-. II. Universidade Federal de Minas Gerais. Escola de Engenharia. III. Título.

CDU: $621(043)$ 


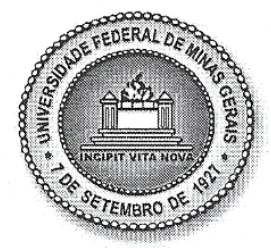

UNIVERSIDADE FEDERAL DE MINAS GERAIS

PROGRAMA DE PÓS-GRADUACÃO EM

ENGENHARIA MECÂNICA

Av. Antônio Carlos, 6627 - Campus Universitário

31270-901 - Belo Horizonte - MG

Tel.: +55313409.5145

E-mail: cpgmec@demec.ufmg.br

\section{"PREDIÇÃO DE VIDA EM FADIGA DE UMA RODA DE CAÇAMBAS UTILIZANDO MECÂNICA DA FRATURA LINEAR ELÁSTICA"}

\section{BRUNO LOPES BARCELOS}

Dissertação submetida à Banca Examinadora designada pelo Colegiado do Programa de Pós-Graduação em Engenharia Mecânica da Universidade Federal de Minas Gerais, como parte dos requisitos necessários à obtenção do título de "Mestre em Engenharia Mecânica", na área de concentração de "PROJETO E SISTEMAS".

Dissertação aprovada no dia 17 de dezembro de 2018.

Por:

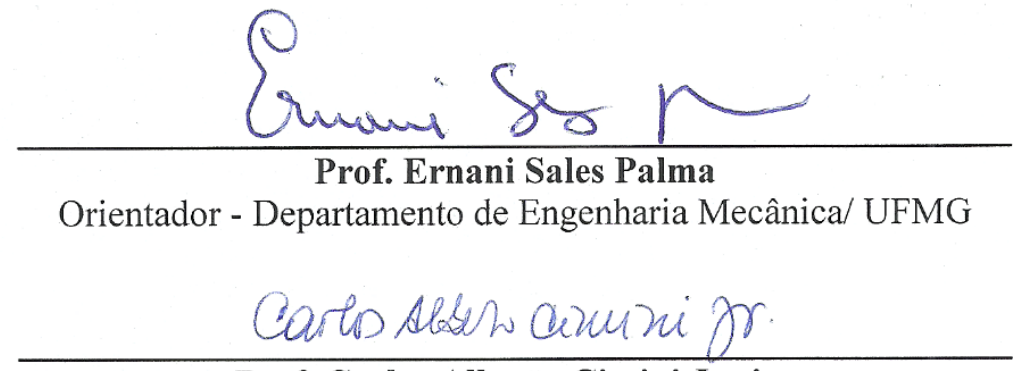

Prof. Carlos Alberto Cimini Junior

Departamento de Engenharia de Estruturas/ UFMG

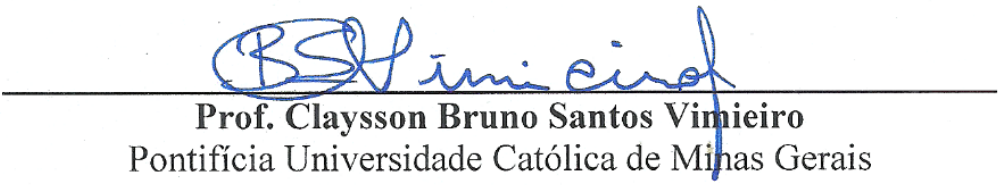




\section{AGRADECIMENTOS}

A Deus, por me dar forças, capacidade e sabedoria para completar mais essa jornada em minha carreira profissional.

Aos meus pais, Antônio e Leonarda, à minha irmã Agnes e ao meu cunhado Fabiano, pelo apoio incondicional e também pela compreensão nos momentos em que estive ausente em dedicação ao mestrado.

À Kotchergenko Engenharia Ltda., na pessoa do diretor Bruno Miranda, por gentilmente permitir a utilização das informações que serviram como ponto de partida para a realização deste estudo.

Ao Prof. Dr. Ernani Palma, pela disposição, suporte e orientação durante a elaboração deste trabalho.

Ao Eng..$^{\circ}$ Mecânico Frederico Mol, pelas conversas, conselhos e ensinamentos no campo da Mecânica da Fratura.

Aos Engenheiros Mecânicos Renée Ferreira e Ulisses Saffar, pelas valiosas dicas sobre a utilização do software Ansys ${ }^{\circledR}$.

À Eng. a de Produção Jacqueline Gurgel, que se prontificou em colaborar para a construção deste trabalho. Ao Eng..$^{\circ}$ Civil Roberto Gurgel, por solicitamente ceder parte de seu acervo iconográfico.

A todos, Muito Obrigado! 
"Suba o primeiro degrau com fé. Não é necessário que você veja toda a escada. Apenas dê o primeiro passo."

Martin Luther King Jr. 


\section{RESUMO}

Este trabalho apresenta o estudo de propagação de trinca na junta soldada de uma roda de caçambas que apresentou falha em campo após aproximadamente um ano de operação. Esta junta está localizada na transição entre o cubo do eixo de acionamento e a estrutura principal da roda de caçambas. Foram adotados os conceitos da Mecânica da Fratura Linear Elástica na análise. Os carregamentos resultantes do processo de escavação do material foram aplicados a um modelo de elementos finitos, a partir do qual se obtiveram as tensões atuantes na região fraturada. Alguns aspectos relacionados à junta soldada foram considerados na análise, tais como a ocorrência de tensões residuais na estrutura e o fator de amplificação do fator de intensidade de tensões devido à geometria da solda. Também foi levado em conta o fenômeno de fechamento de trinca, em função da presença de tensões compressivas no ciclo de carregamento. Devido à geometria peculiar da junta soldada, o fator de intensidade de tensões foi obtido de forma numérica para as trincas semielípticas e trincas passantes pela espessura consideradas, levando-se em conta a atuação de carregamentos de tração e de cisalhamento. A propagação foi avaliada tendo como direção preferencial tanto a profundidade quanto o comprimento da trinca, sendo adotada a equação de Walker (consideração do efeito da razão de tensões) para a determinação da taxa de propagação. Uma vida em fadiga coerente com a estimativa do número de ciclos até a falha da roda de caçambas foi obtida quando considerada a propagação de uma trinca preexistente na estrutura, em um campo de tensões residuais trativas através da espessura da chapa e ao longo do cordão de solda. Avaliou-se que a vida em fadiga com base em curvas S-N, para um detalhe de solda similar ao da junta soldada em estudo, foi superior ao número de ciclos estimado até a falha da roda de caçambas, indicando que algum defeito pode ter permanecido após a fabricação da roda e comprometido sua vida útil.

Palavras Chaves: Roda de caçambas, Mecânica da Fratura Linear Elástica, Propagação de trinca, Fadiga, Tensões residuais. 


\begin{abstract}
This work presents the study of crack propagation in the welded joint of a bucket wheel that failed in field after approximately one year of operation. This joint is located at the transition between the hub of the drive shaft and the main body of the bucket wheel. The concepts of Linear Elastic Fracture Mechanics were adopted in the analysis. The loads resulting from the material excavation process were applied to a finite element model, from which the stresses in the fractured region were obtained. Some aspects related to the welded joint were considered in the analysis, such as the occurrence of residual stresses in the structure and the magnification factor of the stress intensity factor due to the weld geometry. The crack closure phenomenon was also considered, due to the presence of compressive stresses in the loading cycle. Due to the peculiar geometry of the welded joint, the stress intensity factor was numerically obtained for the semi-elliptical cracks and through-thickness cracks considered, taking into account tensile and shear loads. The propagation was evaluated with the preferential direction of both the depth and the length of the crack, using the Walker equation (consideration of the stress ratio effect) for determining the propagation rate. A fatigue life consistent with the estimation of the number of cycles until the failure of the bucket wheel was obtained when considering the propagation of a preexisting crack in the structure in a field of residual tensile stresses across the thickness of the plate and along the weld bead. It was evaluated that fatigue life based on S$\mathrm{N}$ curves, for a weld detail similar to the weld joint under study, was higher than the estimated number of cycles until the bucket wheel failure, indicating that some defect may have remained after manufacture of the wheel and compromised its useful life.
\end{abstract}

Keywords: Bucket wheel, Linear Elastic Fracture Mechanics, Crack propagation, Fatigue, Residual stresses. 


\section{LISTA DE FIGURAS}

Figura 2-1 - Recuperadora de roda de caçambas.

Figura 2-2 - Fluxograma do processo de recuperação do material..........................................22

Figura 2-3 - Vista de parte frontal da lança de recuperadora................................................2 24

Figura 2-4 - Conexão típica entre o cubo do eixo de acionamento e a estrutura principal de uma roda de caçambas.

Figura 2-5 - Escavadora de roda de caçambas KWK-1400: (a) antes do colapso, (b) após o colapso e (c) região de fratura.

Figura 2-6 - Escavadora de roda de caçambas SchRs 630: (a) antes do colapso e (b) após o colapso.

Figura 2-7 - Trincas por fadiga no eixo de acionamento da roda de caçambas da escavadora KWK 1200. 27

Figura 2-8 - Trincas de fadiga no cubo de uma roda de caçambas........................................ 28

Figura 2-9 - Relação entre o crescimento da trinca e o intervalo de inspeção estrutural.

Figura 2-10 - Modos básicos de deslocamento entre duas superfícies na interface de uma trinca. 32

Figura 2-11 - Variação da tenacidade à fratura com a espessura............................................. 34

Figura 2-12 - Curva limite de fratura para modo misto no plano. ............................................. 35

Figura 2-13 - Tensões atuantes na ponta da trinca em coordenadas cartesianas e cilíndricas. 35 Figura 2-14 - Taxa de crescimento da trinca em função da variação do fator de intensidade de

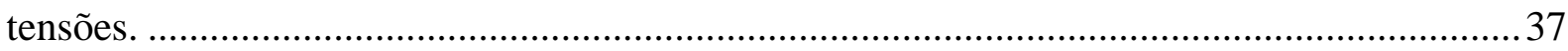

Figura 2-15 - Fechamento de trinca durante a propagação....................................................40

Figura 2-16 - Área sob a curva $d a / d N$ x a para um dado intervalo como estimado pela Regra de Simpson. 43

Figura 2-17 - Imperfeições e trincas em juntas soldadas. 45

Figura 2-18 - Distribuição típica de tensões residuais em juntas soldadas. 46

Figura 2-19 - Efeito de superposição das tensões residuais de tração sobre o range de tensões atuantes. 48

Figura 2-20 - Distribuição de tensões numa solda de topo solicitada à tração.

Figura 2-21 - Trinca semielíptica no pé de um cordão de solda. 50

Figura 2-22 - Superfícies de fratura com marcas de praia para tensão cíclica (à esquerda) e flexão cíclica (à direita). (a) Aço austeníticos; (b) Aço ferríticos; (c) Liga de alumínio. 
Figura 2-23 - Curvas de resistência S-N de aços sob atuação de tensões normais para uso em conjunto com a metodologia de acúmulo de danos.

Figura 2-24 - Detalhes de solda presentes nas recomendações do IIW.

Figura 2-25 - Modelo 3D (a) e localização das trincas (b) na roda de caçambas da escavadora SRs 1300 56

Figura 2-26 - Colapso da escavadora de roda de caçambas SRs 1760. 58

Figura 2-27 - Modelo tridimensional de uma trinca semielíptica em uma chapa plana. 59

Figura 2-28 - Zona plástica e a região de validade da Mecânica da Fratura Linear Elástica. .60 Figura 2-29 - Zona de validade dos resultados obtidos na modelagem da trinca por elementos finitos. 61

Figura 3-1 - Fluxograma de análise com base na Mecânica da Fratura. 62

Figura 3-2 - Fluxograma de análise com base nas recomendações do IIW. 63

Figura 3-3 - Estágios de propagação da trinca. 64

Figura 3-4 - Arranjo geral da roda de caçambas. 67

Figura 3-5 - Elemento bidimensional CQUAD8. 68

Figura 3-6: Elemento tridimensional SOLID 186.

Figura 3-7 - Representação das forças atuantes na roda de caçambas durante o processo de

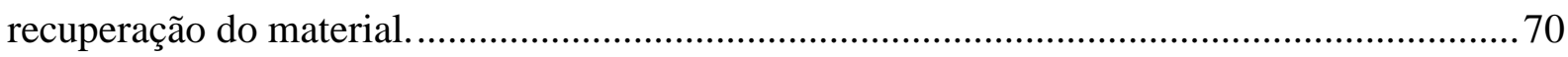

Figura 4-1 - Fratura observada na estrutura da roda de caçambas........................................ 72

Figura 4-2 - Localização da trinca na estrutura da roda de caçambas. ....................................73

Figura 4-3 - Dados experimentais de taxa de crescimento de trinca no aço Q345B..............75

Figura 4-4 - Modelo computacional da estrutura da roda de caçambas. ..................................76

Figura 4-5 - Detalhe da malha de elementos finitos utilizada no modelo. ............................. 77

Figura 4-6 - Variação das tensões normais e cisalhantes ao longo da circunferência da junta soldada em um ciclo. .77

Figura 4-7 - Distribuição de tensões normais e cisalhantes no modelo computacional da roda de caçambas. .78

Figura 4-8 - Tensões de von Mises no modelo computacional da roda de caçambas. .79

Figura 4-9 - Modelo computacional da chapa retangular - Trinca semielíptica. 80

Figura 4-10 - Modelo computacional da geometria da roda de caçambas - Trinca semielíptica.

Figura 4-11 - Parâmetros de definição da frente da trinca semielíptica. 81 
Figura 4-12 - Comparativo entre $K$ normalizado teórico e $K$ numérico para a trinca semielíptica sob tração: chapa retangular (a) e geometria da roda (b) - Direção da profundidade da trinca.

Figura 4-13 - Comparativo entre $K$ normalizado teórico e $K$ numérico para a trinca semielíptica sob tração: chapa retangular (a) e geometria da roda (b) - Direção do comprimento da trinca.

Figura 4-14 - $K$ normalizado numérico para a trinca semielíptica sob cisalhamento - Direção do comprimento da trinca.

Figura 4-15 - Variação de $\mathrm{K}_{\mathrm{I}}$ e $\mathrm{K}_{\mathrm{II}}$ ao longo da frente de uma trinca semielíptica $-a / c=0,5$ e $a / t=0,3$.

Figura 4-16 - Modelo computacional da chapa retangular - Trinca passante pela espessura. 85 Figura 4-17 - Modelo computacional da geometria da roda de caçambas - Trinca passante pela espessura.

Figura 4-18 - Comparativo entre $K$ normalizado teórico e o numérico para a trinca passante pela espessura sob tração.

Figura 4-19 - Comparativo entre o $K$ normalizado teórico e o numérico para a trinca passante pela espessura sob tração com razão c/b igual a 0,4 ......

Figura 4-20 - Fator de amplificação $M_{k}$ na direção da profundidade da trinca. 88

Figura 4-21 - Fator de amplificação $M_{k}$ na direção do comprimento da trinca. 88 Figura 4-22 - Vida em fadiga em função da presença de tensões residuais - Direção da profundidade da trinca.

Figura 4-23 - Comprimento da trinca em função da vida em fadiga - Direção da profundidade da trinca.

Figura 4-24 - Fator de intensidade de tensões equivalente em função do comprimento da trinca - Direção da profundidade da trinca.

Figura 4-25 - Recaracterização da trinca na transição entre os estágios de propagação. 91

Figura 4-26 - Influência da profundidade inicial da trinca sobre a vida em fadiga - Direção da profundidade da trinca.

Figura 4-27 - Vida em fadiga em função da presença de tensões residuais - Direção do comprimento da trinca.

Figura 4-28 - Comprimento da trinca em função da vida em fadiga - Direção do comprimento da trinca. . .94

Figura 4-29 - Fator de intensidade de tensões equivalente em função do comprimento da trinca - Direção do comprimento da trinca. 
Figura 4-30 - Perfil da trinca obtida para a propagação na direção do comprimento.

Figura 4-31 - Tensões residuais e comprimento crítico da trinca em função da profundidade inicial da trinca - Direção do comprimento da trinca.

Figura 4-32 - Relação entre o fator de intensidade de tensões equivalente e a curva limite de fratura.

Figura 4-33 - Comparativo entre o fator de amplificação $M_{k}$ para a direção da profundidade e para o comprimento da trinca. 98

Figura 4-34 - Dados de tensão residual obtidos experimentalmente em juntas " $T$ ". 99 Figura 4-35 - Pontos de medição de tensões residuais na roda de caçambas da escavadora SRs 1300.

Figura 4-36 - Comprimento da trinca em função da vida em fadiga considerando o perfil de tensões residuais proposto por Bate $e t$ al.

Figura 4-37 - Fator de intensidade de tensões equivalente em função do comprimento da trinca considerando o perfil de tensões residuais proposto por Bate et al.

Figura 4-38 - Comprimento da trinca em função da vida em fadiga desconsiderando a ocorrência de tensões residuais.

Figura 4-39 - Fator de intensidade de tensões em função do comprimento da trinca desconsiderando a ocorrência de tensões residuais. 102

Figura 4-40 - Classe de fadiga para o detalhe de solda analisado na roda de caçambas. .......103 Figura 4-41 - Plotagem dos resultados da análise sobre a curva de resistência em fadiga.... 104 Figura 4-42 - Avaliação do critério de Goodman para a vida em fadiga da roda de caçambas.

Figura A-1 - Principais dimensões de uma roda de caçambas.

Figura B-1 - Definições geométricas para uma trinca semielíptica.

Figura B-2 - Regressões polinomiais para $K$ normalizado numérico - Trinca semielíptica sob tração com razão a/c igual a 0,2 .

Figura B-3 - Regressões polinomiais para $K$ normalizado numérico - Trinca semielíptica sob tração com razão a/c igual a 0,5 .

Figura B-4 - Regressões polinomiais para $K$ normalizado numérico - Trinca semielíptica sob tração com razão a/c igual a 1,0.

Figura B-5 - Regressões polinomiais para $K$ normalizado numérico - Trinca semielíptica sob cisalhamento com razão a/c igual a 0,2 . 128

Figura B-6 - Regressões polinomiais para $K$ normalizado numérico - Trinca semielíptica sob cisalhamento com razão a/c igual a 0,5 . 
Figura B-7 - Regressões polinomiais para $K$ normalizado numérico - Trinca semielíptica sob cisalhamento com razão a/c igual a 1,0.

Figura B-8 - Definições geométricas para uma trinca passante pela espessura....................130

Figura B-9 - Definições geométricas para uma trinca semielíptica através da espessura. ....131

Figura C-1 - Modelo computacional utilizado para a obtenção do fator $\mathbf{M}_{\mathrm{k}}$. 133 


\section{LISTA DE TABELAS}

Tabela 2-1 - Tamanho de trinca detectáveis em função do método de ensaio não destrutivo. 30

Tabela 3-1 - Esforços atuantes considerados na análise.

Tabela 4-1 - Composição química e propriedades mecânicas do aço Q345B....................... 74

Tabela 4-2 - Composição química do eletrodo utilizado na soldagem da roda de caçambas. . 74

Tabela 4-3 - Estimativa das constantes das equações de Paris e de Walker........................... 75

Tabela 4-4 - Resumo das tensões consideradas na análise. .................................................... 78

Tabela 4-5 - Combinação entre tensões normais e cisalhantes........................................... 103

Tabela A-1 - Fatores de correção da força de corte em função da profundidade da caçamba.

Tabela A-2 - Resumo das variáveis envolvidas na memória de cálculo. 120 


\section{LISTA DE SIMBOLOS}

\section{Letras latinas}

$a$

$a_{c}$

$a_{f}$

$a_{i}$

$a_{o}$

$b$

$B_{f}$

$c$

C

$c_{f}$

$c_{i}$

$C_{1}$

$d a / d N$

$d c / d N$

FAT

$f(g)$

$I U$

K

$\Delta K$

$\Delta \bar{K}$

$K_{C}$

$\Delta K_{e f}$
Profundidade de uma trinca semielíptica [mm]

Tamanho crítico da trinca [mm]

Profundidade final de uma trinca semielíptica [mm]

Profundidade inicial de uma trinca semielíptica [mm]

Tamanho inicial da trinca $[\mathrm{mm}]$

Meia largura da chapa contendo a trinca [mm]

Número de repetições de um conjunto de ciclos até a falha [adimensional]

Meio comprimento da trinca $[\mathrm{mm}]$

Constante do material - equação de Paris $\left[\frac{\mathrm{mm} / \text { ciclo }}{(\mathrm{MPa} \sqrt{\mathrm{m}})^{\mathrm{m}}}\right]$

Comprimento final da trinca [mm]

Comprimento inicial da trinca [mm]

Constante do material - equação de Walker $\left[\frac{\mathrm{mm} / \text { ciclo }}{(\mathrm{MPa} \sqrt{\mathrm{m}})^{\mathrm{m}_{1}}}\right]$

Taxa de crescimento na direção da profundidade da trinca [mm/ciclo]

Taxa de crescimento na direção do comprimento da trinca [mm/ciclo]

Classe de fadiga conforme IIW

Fator de forma que depende da geometria do componente e da trinca [adimensional]

Índice de utilização [adimensional]

Fator de intensidade de tensões $[\mathrm{MPa} \sqrt{\mathrm{m}}]$

Variação do fator de intensidade de tensões $[\mathrm{MPa} \sqrt{\mathrm{m}}]$

Variação do fator de intensidade de tensões considerando o efeito da razão entre a tensão mínima e a máxima $[\mathrm{MPa} \sqrt{\mathrm{m}}]$

Tenacidade à fratura $[\mathrm{MPa} \sqrt{\mathrm{m}}]$

Variação do fator de intensidade de tensões efetivo [MPa $\sqrt{\mathrm{m}}]$ 


\section{Letras latinas (Continuação)}

$K_{e q} \quad$ Fator de intensidade de tensões equivalente $[\mathrm{MPa} \sqrt{\mathrm{m}}]$

$K_{\max } \quad$ Fator de intensidade de tensões máximo [MPa $\left.\sqrt{\mathrm{m}}\right]$

$K_{\min } \quad$ Fator de intensidade de tensões mínimo $[\mathrm{MPa} \sqrt{\mathrm{m}}]$

$K_{o p} \quad$ Fator de intensidade de tensões associado à abertura da trinca $[\mathrm{MPa} \sqrt{\mathrm{m}}]$

$K_{t} \quad$ Concentrador de tensões geométrico [adimensional]

$\Delta K_{t h} \quad$ Valor limite para que não haja propagação de trinca $[\mathrm{MPa} \sqrt{\mathrm{m}}]$

$K_{I}, K_{I I}, K_{I I I}$ Fator de intensidade de tensões para os modos I, II e III, respectivamente $[\mathrm{MPa} \sqrt{\mathrm{m}}]$

$K_{I C}, K_{I I C} \quad$ Tenacidade à fratura para o estado plano de deformações - Modos I e II, respectivamente $[\mathrm{MPa} \sqrt{\mathrm{m}}]$

$m \quad$ Inclinação da curva $d a / d N$ [adimensional]

$m_{1} \quad$ Constante do material - equação de Walker [adimensional]

$M_{k, a} \quad$ Fator de amplificação do fator de intensidade de tensões na direção da profundidade da trinca [adimensional]

$M_{k, c} \quad$ Fator de amplificação do fator de intensidade de tensões na direção do comprimento da trinca [adimensional]

$N \quad$ Vida em fadiga [ciclos]

$N_{f i} \quad$ Vida calculada para um determinado carregamento cíclico [ciclos]

$n_{i} \quad$ Número de ciclos atuante [ciclos]

$R \quad$ Razão entre a tensão mínima e a tensão máxima [adimensional]

$r_{k} \quad$ Região de validade do fator de intensidade de tensões [m]

$r_{p} \quad$ Tamanho da zona plástica [m]

$R_{\text {res }} \quad$ Razão de tensões em função da presença de tensões residuais [adimensional]

$t \quad$ Espessura da chapa [mm]

$U \quad$ Proporção do fator de intensidade de tensões para consideração do fenômeno de fechamento de trinca [adimensional] 


\section{Letras gregas}

$\gamma \quad$ Constante do material - equação de Walker [adimensional]

$\delta \quad$ Alongamento do material [adimensional]

$\theta \quad$ Ângulo de propagação da trinca [graus]

$\sigma \quad$ Tensão normal atuante [MPa]

$\Delta \sigma \quad$ Variação de tensões normais [MPa]

$\sigma_{a} \quad$ Tensão normal alternada [MPa]

$\Delta \sigma_{e q, S, d} \quad$ Variação de tensões normais equivalente solicitante de cálculo [MPa]

$\sigma_{m} \quad$ Tensão normal média [MPa]

$\sigma_{\max } \quad$ Tensão normal máxima atuante [MPa]

$\sigma_{\min } \quad$ Tensão normal mínima atuante [MPa]

$\Delta \sigma_{R, d} \quad$ Variação de tensões normais admissível em fadiga [MPa]

$\Delta \sigma_{R, k} \quad$ Valor característico da resistência à fadiga [MPa]

$\Delta \sigma_{S, d} \quad$ Variação de tensões normais solicitante de cálculo [MPa]

$\sigma_{u} \quad$ Limite de resistência [MPa]

$\sigma_{y} \quad$ Limite de escoamento [MPa]

$\tau \quad$ Tensão cisalhante atuante [MPa]

$\Delta \tau \quad$ Variação de tensões cisalhantes [MPa]

$\Delta \tau_{e q, S, d} \quad$ Variação de tensões cisalhantes equivalente solicitante de cálculo [MPa]

$\tau_{\max } \quad$ Tensão cisalhante máxima atuante [MPa]

$\tau_{\min } \quad$ Tensão cisalhante mínima atuante [MPa]

$\Delta \tau_{R, d} \quad$ Variação de tensões cisalhantes admissível em fadiga [MPa]

$\Delta \tau_{S, d} \quad$ Variação de tensões cisalhantes solicitante de cálculo [MPa] 


\section{SUMÁRIO}

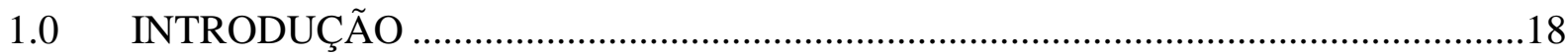

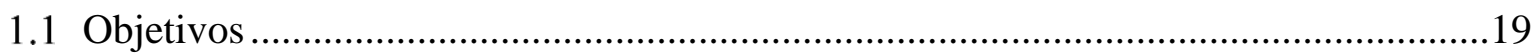

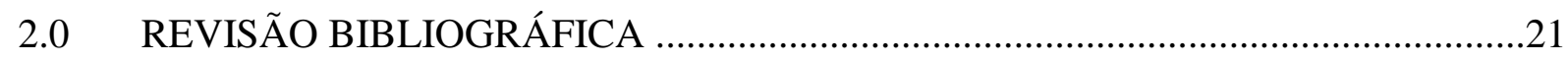

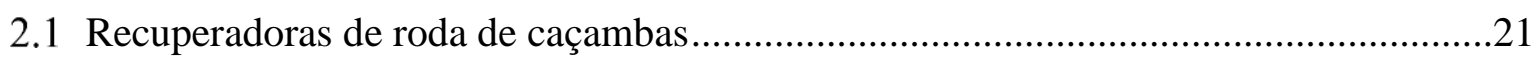

2.2 Falhas por fadiga em equipamentos para mineração ...............................................25

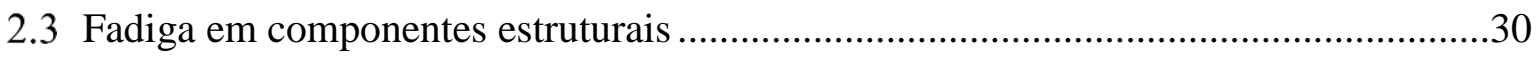

2.4 Mecânica da Fratura Linear Elástica (MFLE) .............................................................32

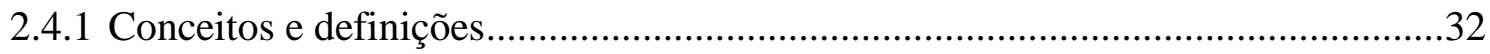

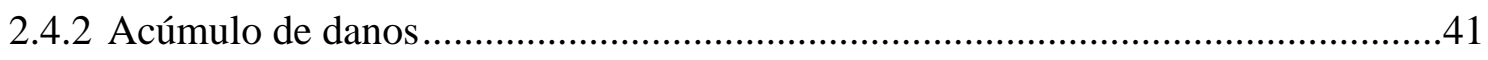

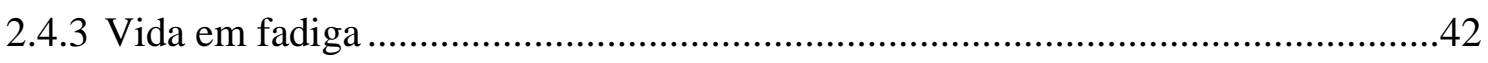

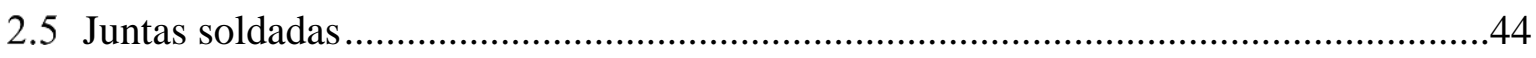

2.5.1 Defeitos e imperfeições em juntas soldadas........................................................4

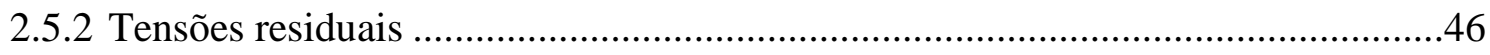

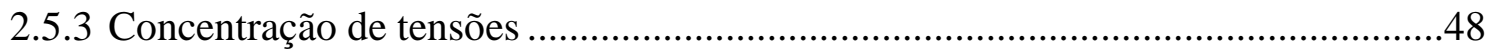

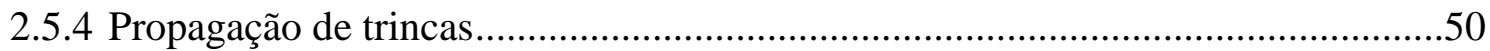

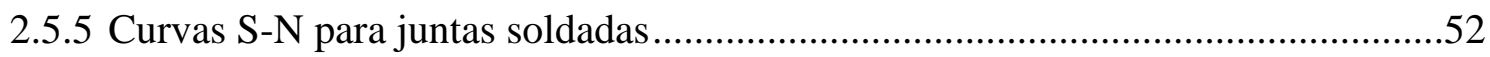

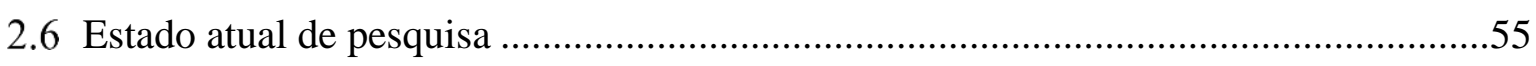

2.7 Métodos computacionais para propagação de trincas ..................................................58

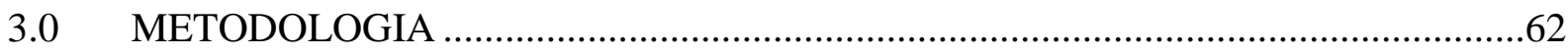

3.1 Vida em fadiga com base na Mecânica da Fratura Linear Elástica .............................63

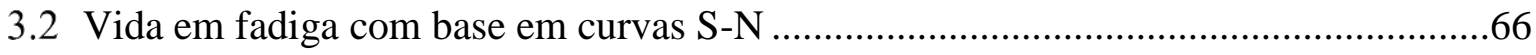

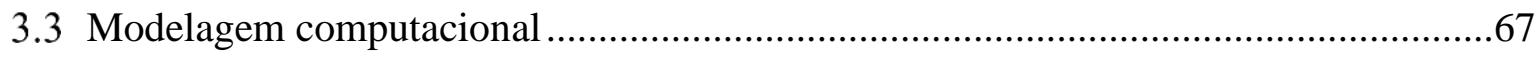

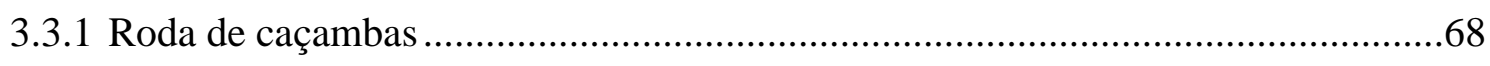

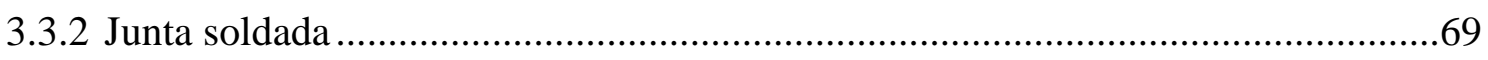

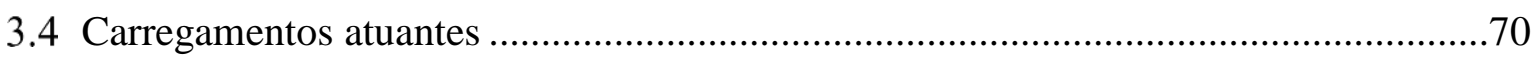

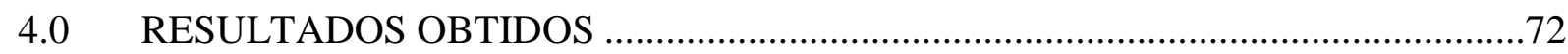

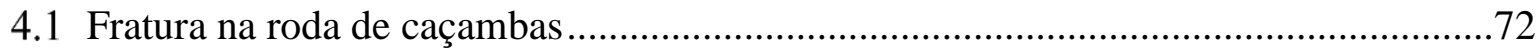

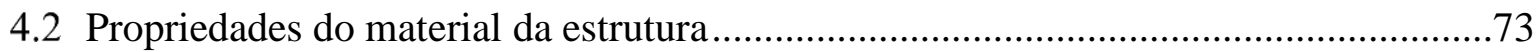

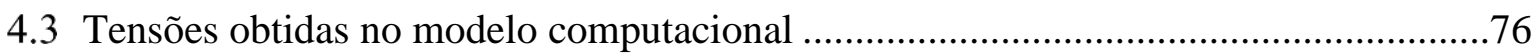

4.4 Verificação com base na Mecânica da Fratura Linear Elástica ...................................79 
4.4.1 Obtenção do Fator de Intensidade de Tensões numericamente

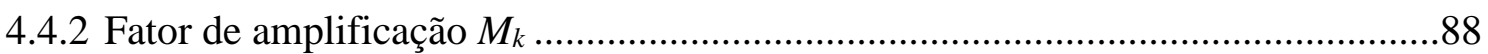

4.4.3 Propagação na direção da profundidade da trinca...............................................89

4.4.4 Propagação na direção do comprimento da trinca ..............................................92

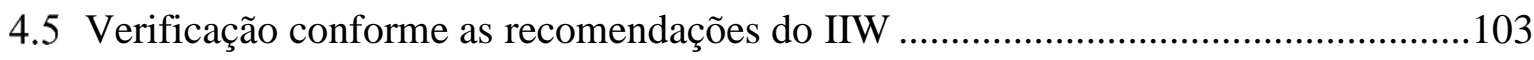

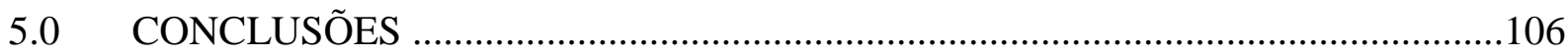

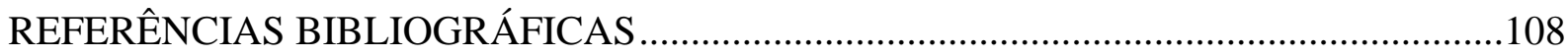

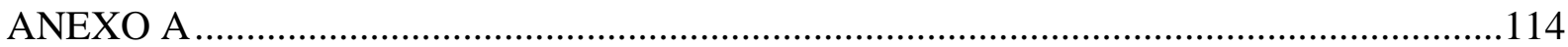

A.1 Determinação das cargas atuantes na roda de caçambas ...........................................114

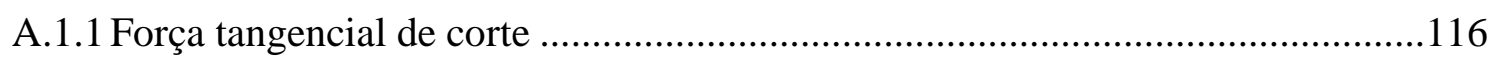

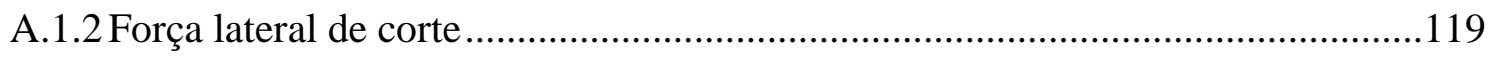

A.1.3 Força de elevação do material..........................................................................119

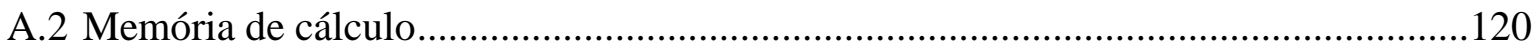

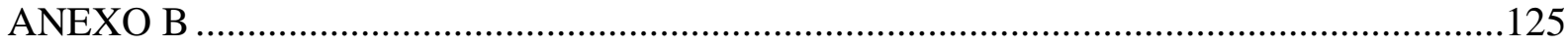

B.1 Formulação do Fator de Intensidade de Tensões de uma trinca semielíptica ..............125

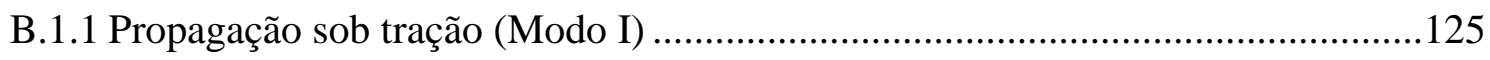

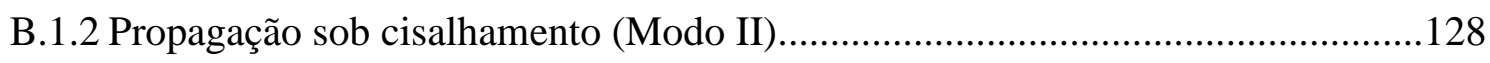

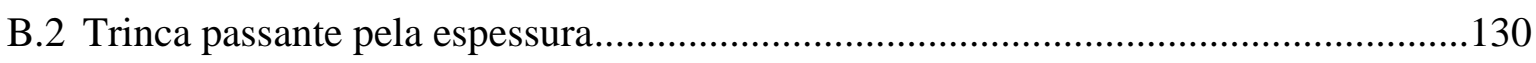

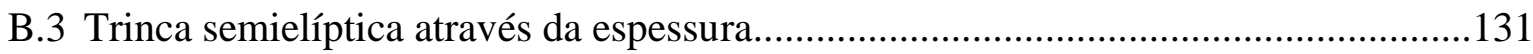

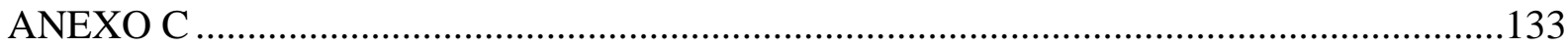

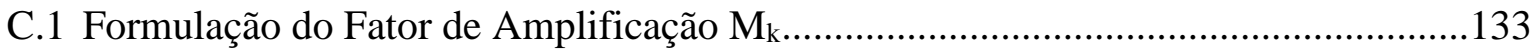




\subsection{INTRODUÇÃO}

A atividade mineradora tem participação fundamental na economia brasileira e corresponde a uma parcela significativa de toda a riqueza produzida no país. Para que este patamar fosse atingido, fez-se necessária a busca e o desenvolvimento de novas tecnologias que proporcionassem a fabricação de equipamentos eficientes e robustos para o manuseio de materiais a granel, além do estabelecimento de procedimentos adequados de manutenção preventiva e preditiva que proporcionem maior disponibilidade e maior vida útil do equipamento.

A cadeia de processamento de matérias-primas, desde a extração do minério bruto até o embarque para exportação do minério após o seu beneficiamento, envolve a atuação de diversos equipamentos, tais como transportadores de correia, empilhadeiras, carregadores de navios e recuperadoras de roda de caçambas.

Nesta cadeia de produção, recuperadoras de roda de caçambas desempenham um papel importante, sendo responsáveis pela remoção contínua do material de um pátio de estocagem e por destiná-lo à próxima etapa do processo produtivo. São equipamentos móveis geralmente compostos por estruturas metálicas com geometria complexa, que devem ser dimensionadas de forma que os esforços atuantes sejam adequadamente suportados pela estrutura e transferidos para os pontos de apoio, a fim de se garantir sua segurança operacional e performance satisfatória durante toda sua vida útil.

Devido à competitividade do mercado, tem-se exigido cada vez mais que o projeto de novos equipamentos tenha o menor custo de fabricação possível. Com isto, observa-se uma tendência de redução da espessura das chapas utilizadas, trabalhando-se com tensões muito próximas aos limites admissíveis do material empregado. Desta forma, a adoção de procedimentos confiáveis de dimensionamento torna-se de fundamental importância para que haja não prejuízos à integridade do equipamento. 
A falha estrutural de uma roda de caçambas pode envolver sérias consequências. Do ponto de vista econômico, paradas imprevistas para realização de manutenções corretivas acarretam prejuízo devido à indisponibilidade do equipamento e podem refletir até mesmo em atraso no embarque do material para exportação, gerando sobretaxas à mineradora pelo tempo em que o navio exceder sua estadia no porto (demurrage).

Em relação à segurança dos operadores e mantenedores do equipamento, acidentes fatais podem ocorrer, uma vez que a falha pode interferir diretamente no equilíbrio de massas da recuperadora, levando o equipamento ao colapso por perda de estabilidade caso a roda de caçambas se separe completamente do seu eixo de acionamento.

Neste sentido, propõe-se a análise no presente trabalho da estrutura de uma roda de caçambas, que apresentou falha prematura em campo com aproximadamente um ano de operação, utilizando os conceitos de Mecânica da Fratura Linear Elástica. Tal componente é um subconjunto de uma recuperadora de roda de caçambas e tem vida útil de projeto geralmente prevista em pelo menos 30 anos de operação.

Com relação à relevância do tema proposto, rodas de caçambas devem ser projetadas e fabricadas seguindo rigorosamente critérios normativos. Tal requisito não envolve somente questões econômicas, devido ao elevado custo de fabricação do componente, mas envolve principalmente a necessidade de se proporcionar segurança aos colaboradores que operam ou fazem manutenção de uma recuperadora.

\subsection{Objetivos}

Os objetivos gerais deste trabalho são:

- Avaliar se a vida estimada com base no tempo necessário para a falha da roda de caçambas pode ser atingida, considerando-se uma trinca preexistente na estrutura da roda;

- Determinar o comprimento limite desta trinca, para que o fator de intensidade de tensões $K$ tenha a mesma magnitude da tenacidade à fratura $K_{I C}$. 
Especificamente, pretende-se neste trabalho:

- Analisar o efeito de tensões residuais, do tamanho inicial da trinca e da proporção entre a profundidade e o comprimento da trinca semielíptica inicial considerada sobre o tempo de propagação da mesma;

- Fazer a previsão de vida em fadiga base em curvas S-N para juntas soldadas. 


\subsection{REVISÃO BIBLIOGRÁFICA}

\subsection{Recuperadoras de roda de caçambas}

Recuperadoras de roda de caçambas são equipamentos de grande porte destinados à remoção contínua de elevadas quantidades de material a granel. Geralmente, apresentam-se como máquinas complexas, dotadas de movimentos de translação, além de movimentos de giro e de basculamento da lança, podendo os mesmos ocorrer de forma simultânea.

O movimento de translação de uma recuperadora acontece normalmente sobre um caminho de rolamento formado por trilhos que se estendem ao longo de pátios de estocagem. Tal máquina recupera o material previamente empilhado por outro equipamento, que pode ser uma empilhadeira ou mesmo um transportador de correia móvel. A Figura 2-1 apresenta um exemplo de recuperadora de roda de caçambas para manuseio de minério de ferro, instalada em uma mina na África do Sul.

Figura 2-1 - Recuperadora de roda de caçambas.

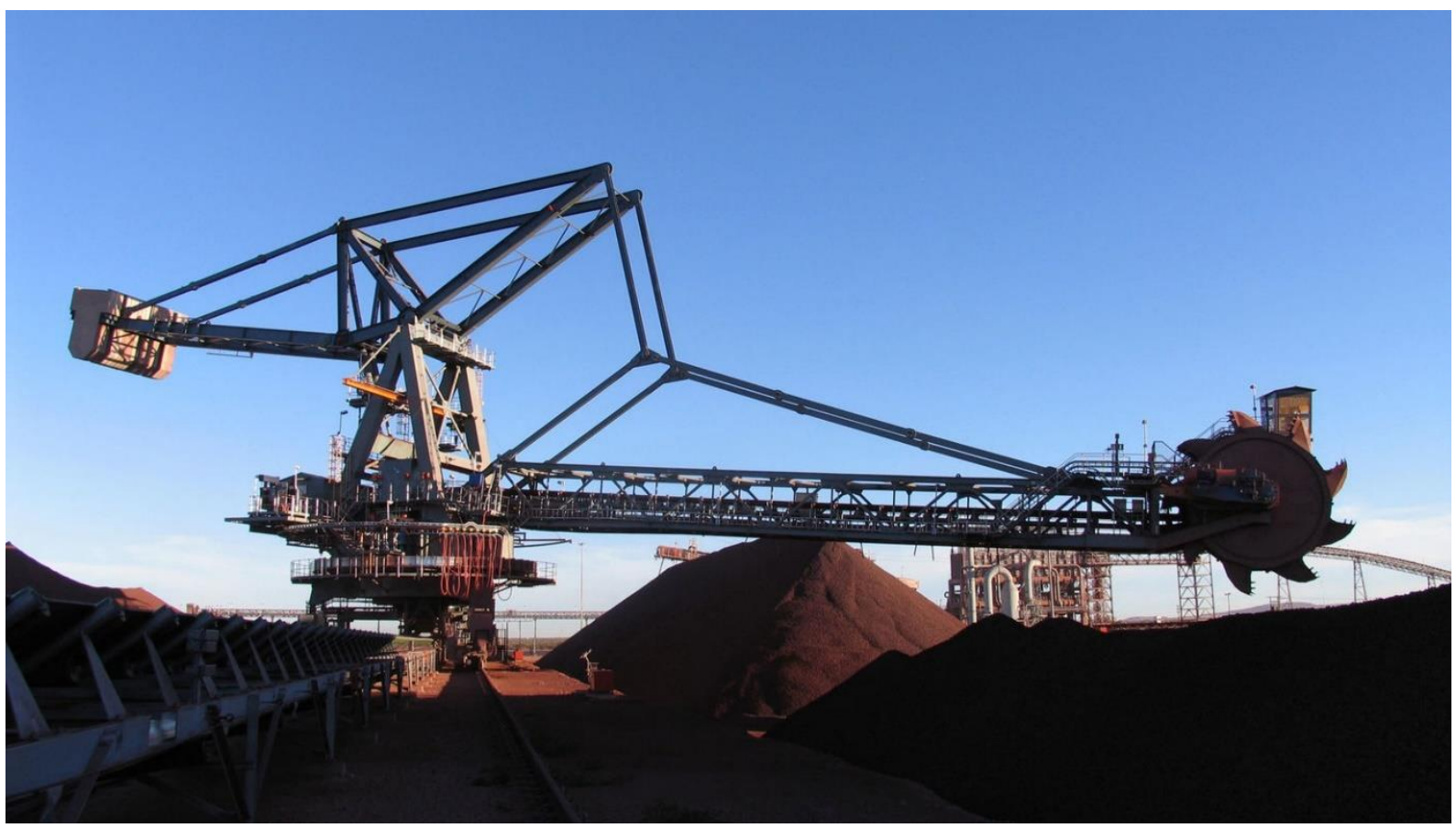

Fonte: Retirado de Tenova [1]. 
O processo de remoção do material ocorre de cima para baixo, ou seja, a roda de caçambas é primeiramente elevada o suficiente, de forma que a porção mais elevada da pilha possa ser removida, e evitando-se que haja desmoronamento da mesma sobre a máquina. A roda de caçambas, fixada na extremidade da lança, é então abaixada através do sistema de basculamento e direcionada para a próxima posição de corte ${ }^{(1)}$ através do mecanismo de translação. O corte é efetuado pela combinação do movimento de giro da lança com o movimento rotativo das caçambas alocadas ao longo do perímetro da roda. Esse processo é repetido até que a roda de caçambas atinja a base da pilha de estocagem.

O material removido pela roda de caçambas é descarregado em um transportador de correia localizado na lança, que encaminha o fluxo até a parte central da recuperadora, onde através de um chute de descarga, o material é transferido para outro transportador que passa por debaixo da recuperadora e está posicionado entre os trilhos do caminho de rolamento. Na Figura 2-2, pode ser visto o fluxograma do processo de recuperação do material.

Figura 2-2 - Fluxograma do processo de recuperação do material.

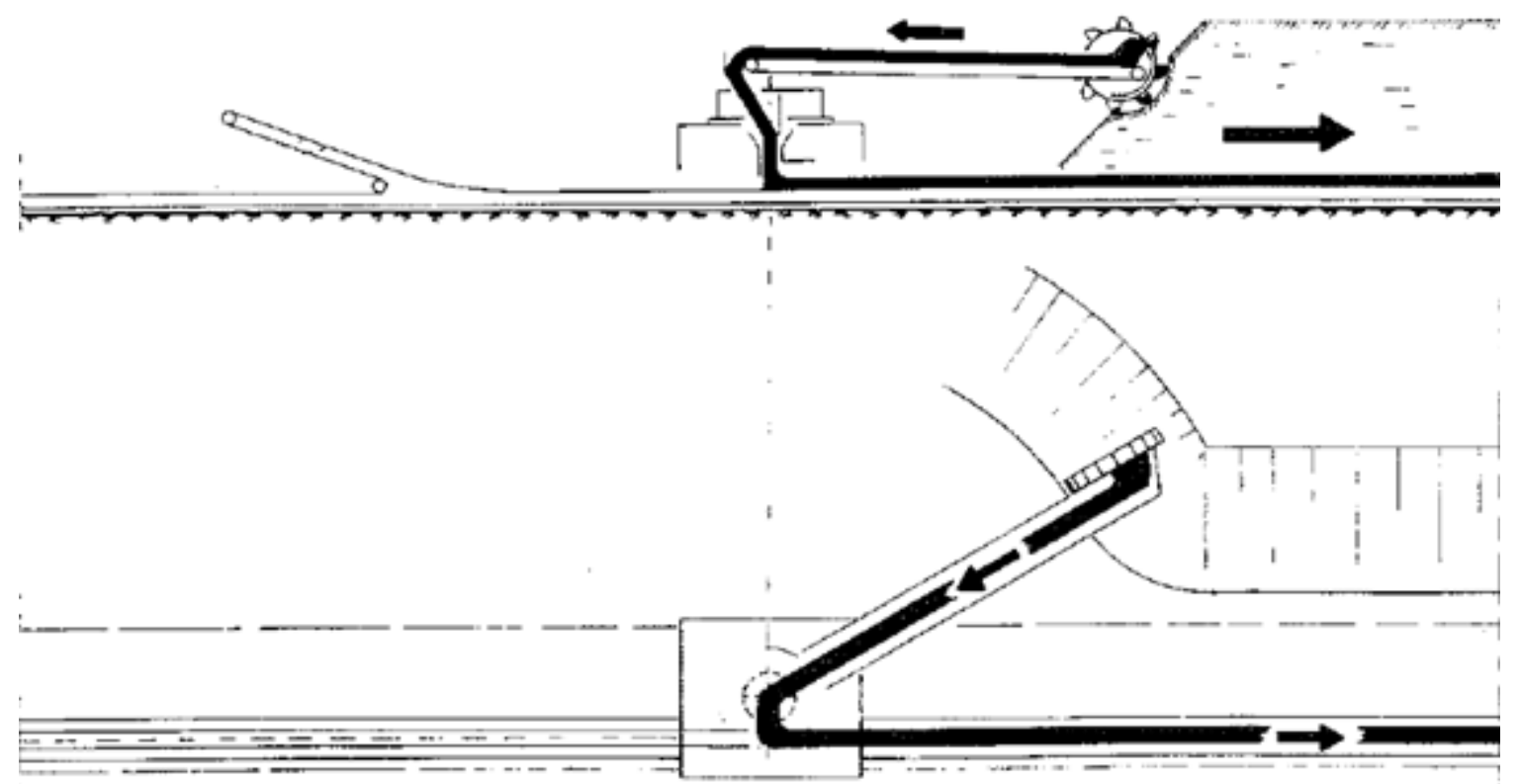

Fonte: Adaptado de Wöhlbier [2].

\footnotetext{
${ }^{1} \mathrm{O}$ termo "corte" é utilizado para designar o processo de cisalhamento do material durante sua extração da pilha de estocagem.
} 
Recuperadoras são geralmente compostas por vários subsistemas formados por estruturas metálicas e componentes mecânicos, elétricos ou eletrônicos, que em conjunto permitem o funcionamento adequado do equipamento. Dentre estes subsistemas, a roda de caçambas será o objetivo de estudo deste trabalho e um maior detalhamento a seu respeito será apresentado aqui.

Segundo Wöhlbier [2], a roda de caçambas é o componente diretamente responsável pela recuperação de material empilhado no pátio de estocagem. É composta por uma estrutura metálica em formato circular onde são fixadas as caçambas ao longo do perímetro da roda, que escavam a pilha e se enchem com o material recuperado. As caçambas possuem formato de cunha com duas faces abertas: uma face se localiza nas bordas principais, onde se efetua o corte de material (essencialmente radial), e a outra se localiza onde a caçamba é fixada à roda para permitir a descarga de material (essencialmente tangencial).

Tanto a roda de caçambas quanto seu sistema de acionamento são fixados na viga porta-roda. Esta estrutura tem a função de resistir os esforços de escavação atuantes na roda de caçambas, além do peso próprio dos componentes nela fixados, como por exemplo, a calha de recebimento do material descarregado pelas caçambas e o impacto gerado pela queda deste material.

O acionamento da roda de caçambas pode ser hidráulico (acionado por motor hidráulico) ou eletromecânico (acionado por um conjunto motor-redutor), sendo que, em ambos os casos, o acionamento deve ser dimensionado para superar as resistências de corte, elevação e enchimento da caçamba, além de eventuais sobrecargas geradas por erros operacionais ou durante a partida do sistema. Embora cada vez mais em desuso devido ao elevado peso do conjunto, caso um acionamento eletromecânico seja adotado, a utilização de acoplamentos hidrodinâmicos tipo turbina é extremamente recomendada para limitação das sobrecargas atuantes no sistema. 
A Figura 2-3 ilustra a vista de uma roda de caçambas e de suas estruturas auxiliares na parte frontal de uma recuperadora.

Figura 2-3 - Vista de parte frontal da lança de recuperadora

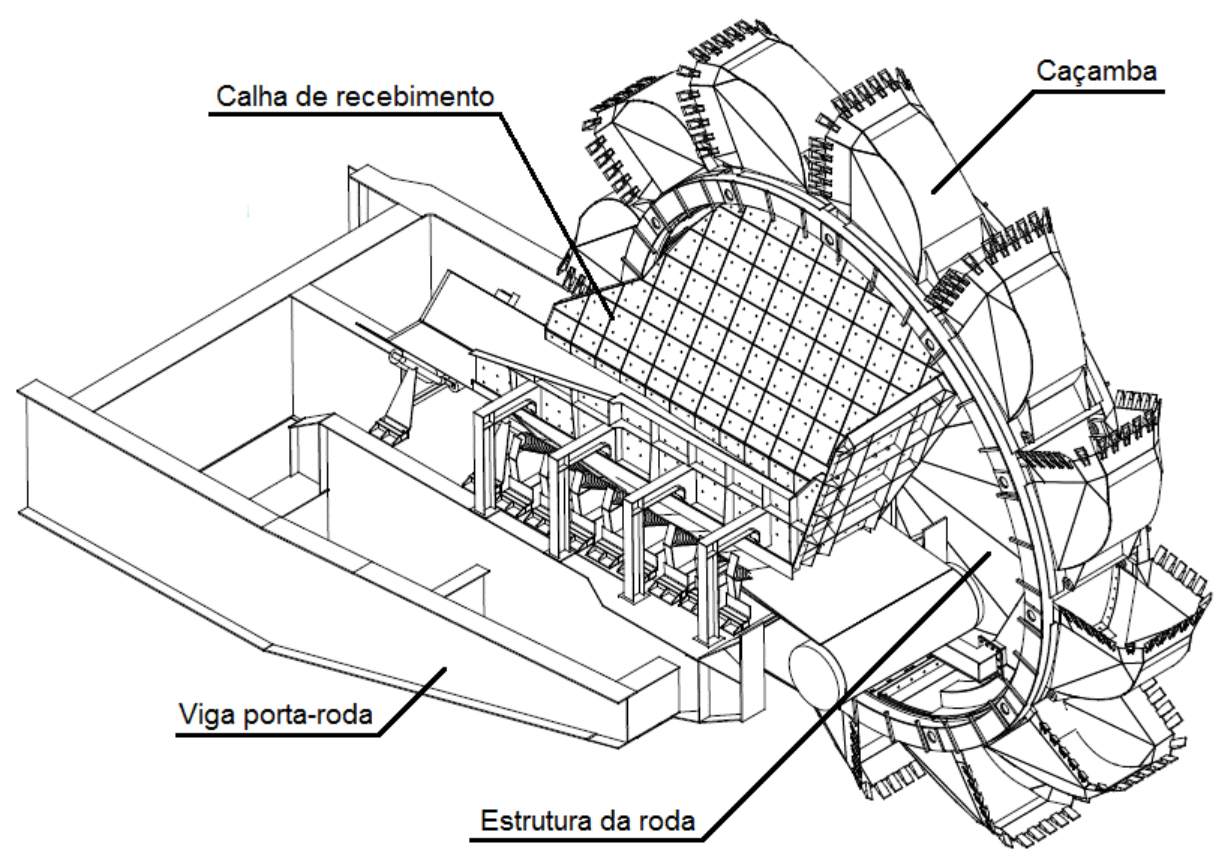

Fonte: Adaptado de Kotchergenko Engenharia [3].

Com relação à parte estrutural da roda de caçambas, a conexão entre o cubo do eixo de acionamento com a estrutura principal da roda é a parte do componente mais suscetível à fadiga, sendo frequente a presença de danos por fadiga segundo Rusiński et al. [4].

Tal conexão é feita geralmente por meio de soldagem e está sujeita a esforços cíclicos de magnitude elevada, uma vez que o torque gerado pelas cargas atuantes nas caçambas durante o processo de escavação do material é máximo na região onde se localiza a solda. Além disso, tais esforços apresentam amplitude variável em função da forma de trabalho adotada pelo operador da recuperadora, fazendo com que a junta soldada também esteja sujeita à fadiga. $\mathrm{Na}$ Figura 2-4, pode ser vista em detalhe a conexão soldada acima citada. 
Figura 2-4 - Conexão típica entre o cubo do eixo de acionamento e a estrutura principal de uma roda de caçambas.

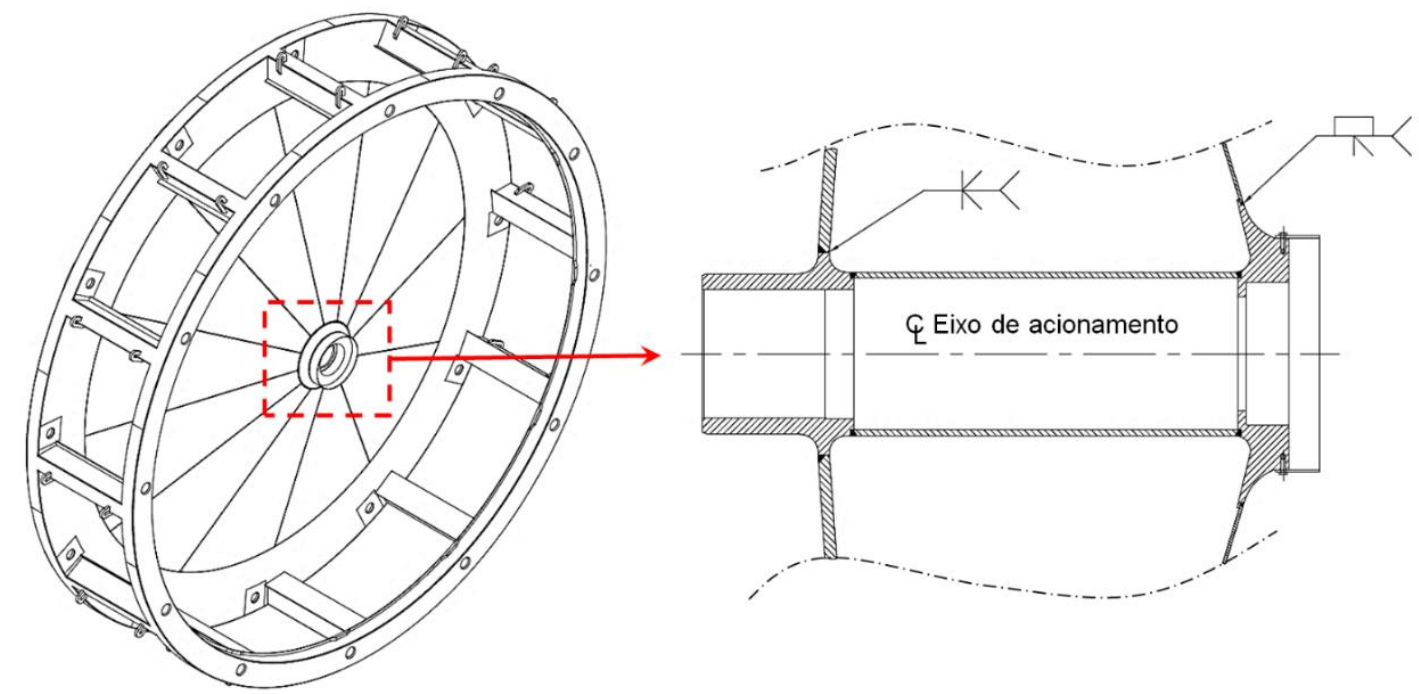

Fonte: Adaptado de Kotchergenko Engenharia [3].

Cabe ao projetista selecionar adequadamente o material da estrutura da roda e a classe do eletrodo, além do processo de soldagem, com base nas solicitações estáticas, e principalmente levando em consideração a condição de fadiga da estrutura. Além disso, de acordo com Wöhlbier [2], é prática comum para o projeto de componentes estruturais sujeitos à fadiga fazer com que o range de tensões seja dependente do número de ciclos a que o componente será submetido durante sua vida útil.

\subsection{Falhas por fadiga em equipamentos para mineração}

Equipamentos utilizados em mineração devem satisfazer a requisitos normativos com relação à resistência estrutural sob atuação de carregamentos estáticos e de natureza variável que possam levar a estrutura à falha por fadiga, sendo tais equipamentos comumente projetados para operação por longos períodos. Ainda que tais equipamentos sejam dimensionados em acordo com as normas aplicáveis, a presença de defeitos ou trincas na estrutura em algum momento de sua vida útil, seja em função do processo de fabricação ou decorrente de fadiga do material, não pode ser negligenciada. 
Neste aspecto, a adoção de procedimentos de manutenção capazes de detectar trincas no início da fase de propagação e de monitorar sua evolução durante a operação do equipamento é de vital importância para evitar a ocorrência de falhas catastróficas, como a falha ocorrida com a escavadora $^{2}$ de roda de caçambas KWK-1400 ilustrada na Figura 2-5. Tal máquina está alocada em uma mina de carvão na Polônia e apresentou uma fratura por fadiga em um dos tirantes da contralança (lança do contrapeso) após 28 anos de operação, levando ao colapso do equipamento, conforme Rusiński et al. [5].

Figura 2-5 - Escavadora de roda de caçambas KWK-1400: (a) antes do colapso, (b) após o colapso e (c) região de fratura.

(a)

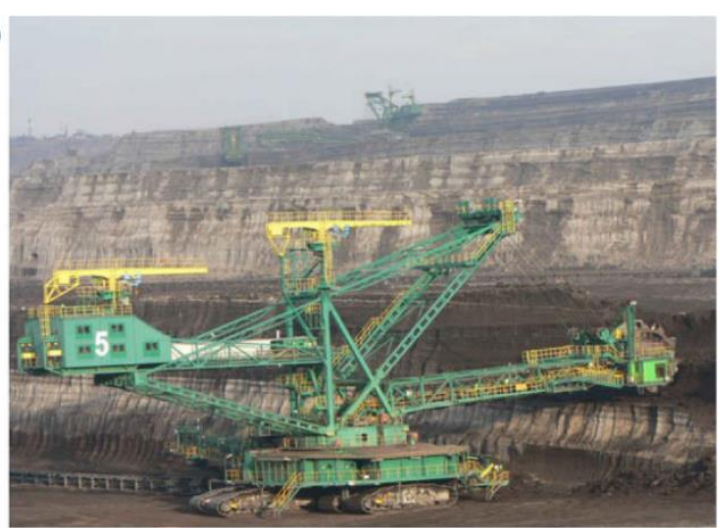

(b)

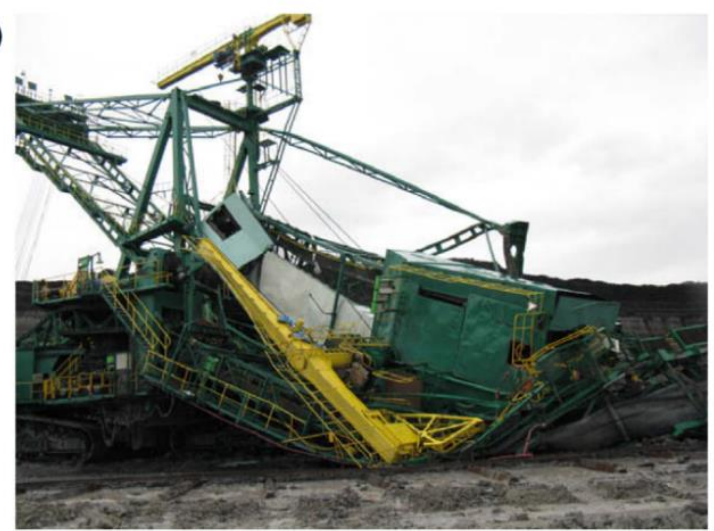

(c)

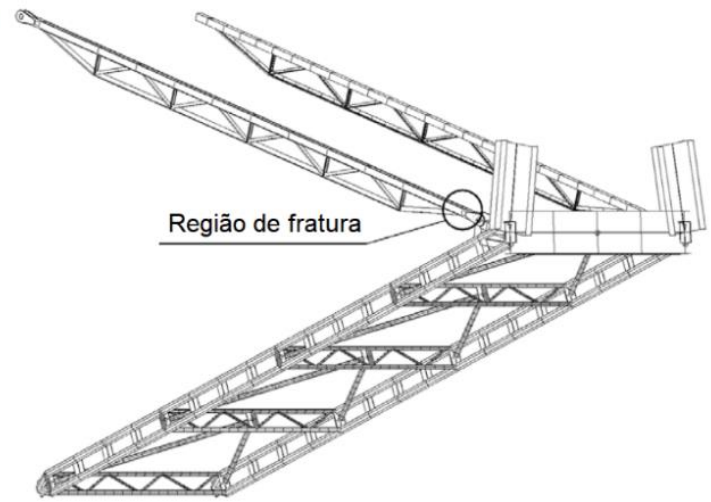

Fonte: Adaptado de Rusiński et al. [5].

Outra falha catastrófica a ser destacada é a ocorrida com a escavadora de roda de caçambas SchRs 630. Segundo Daničić et al. [6], a máquina sofreu colapso estrutural devido à propagação de uma trinca por fadiga nucleada em pontos de concentração de tensões próximos a enrijecedores do mastro. A Figura 2-6 ilustra tal escavadora.

\footnotetext{
2 A denominação "escavadora" é geralmente dada a máquinas que escavam o material bruto em minas de superfície, enquanto que o termo "recuperadora" se refere a máquinas que recolhem (recuperam) um material a granel previamente empilhado por outro equipamento.
} 
Figura 2-6 - Escavadora de roda de caçambas SchRs 630: (a) antes do colapso e (b) após o colapso.

(a)

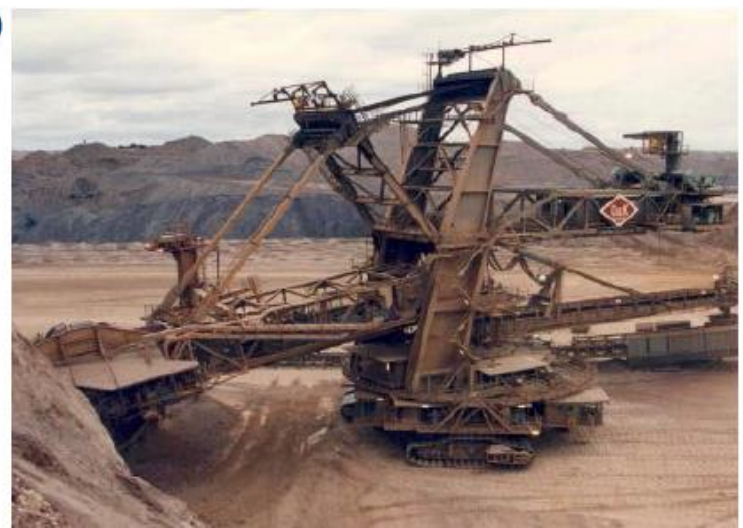

(b)

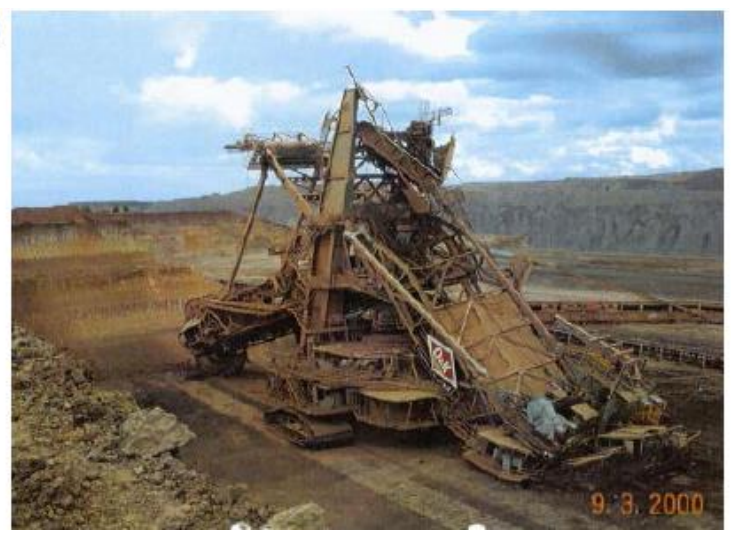

Fonte: Adaptado de Daničić et al. [6].

A estrutura da roda de caçambas e seu eixo de acionamento são componentes submetidos a esforços variáveis devido ao seu movimento de rotação e ao modo de operação intermitente de escavação do material. Possuem velocidade de rotação típica entre 4,5 e $5 \mathrm{rpm}$, o que implica na atuação de um ciclo de carregamento aproximadamente a cada 12 segundos, tornando tais componentes bastante suscetíveis à ocorrência de fadiga. Como resultado, trincas podem ser nucleadas após curtos períodos de tempo em relação à vida útil esperada para uma recuperadora.

A Figura 2-7 ilustra trincas ocorridas por fadiga no eixo de acionamento da roda de caçambas da escavadora KWK 1200M, conforme apresentado por Rusiński et al. [4]. A Figura 2-8 apresenta trincas de fadiga na região do cubo de uma roda de caçambas de uma recuperadora.

Figura 2-7 - Trincas por fadiga no eixo de acionamento da roda de caçambas da escavadora KWK 1200.
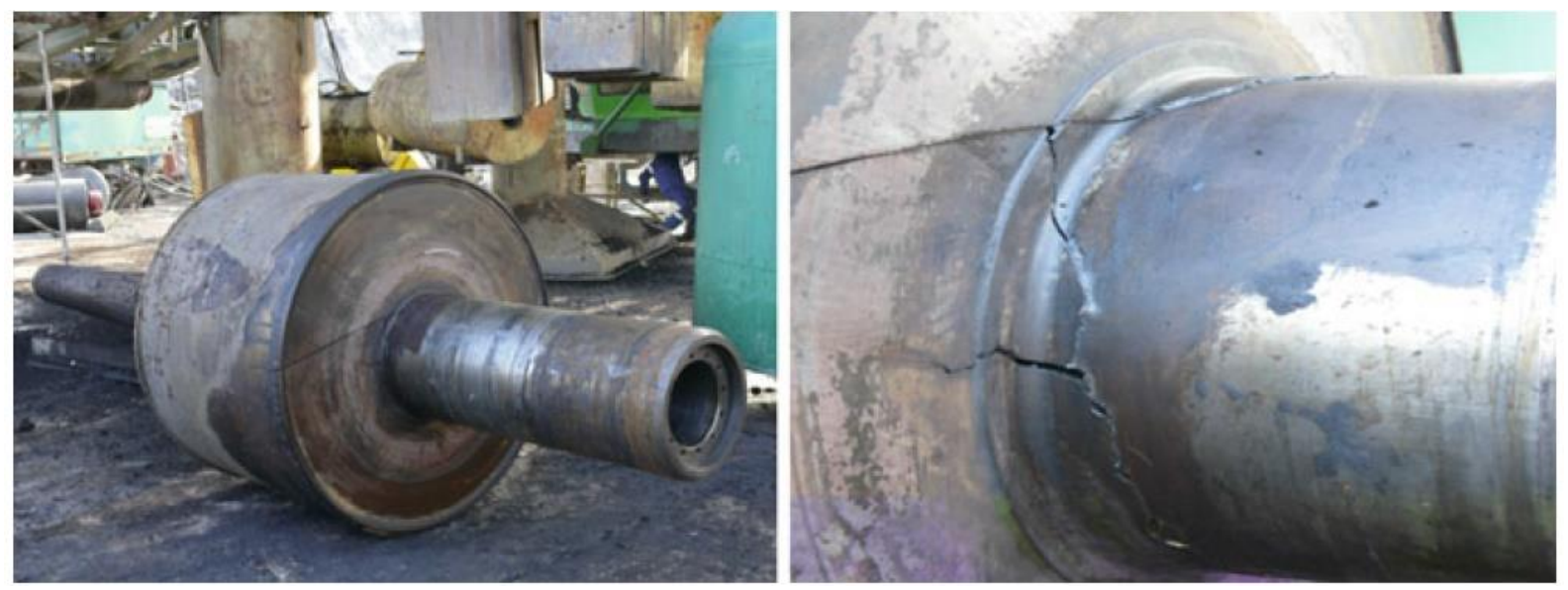

Fonte: Retirado de Rusiński et al. [4]. 
Figura 2-8 - Trincas de fadiga no cubo de uma roda de caçambas.

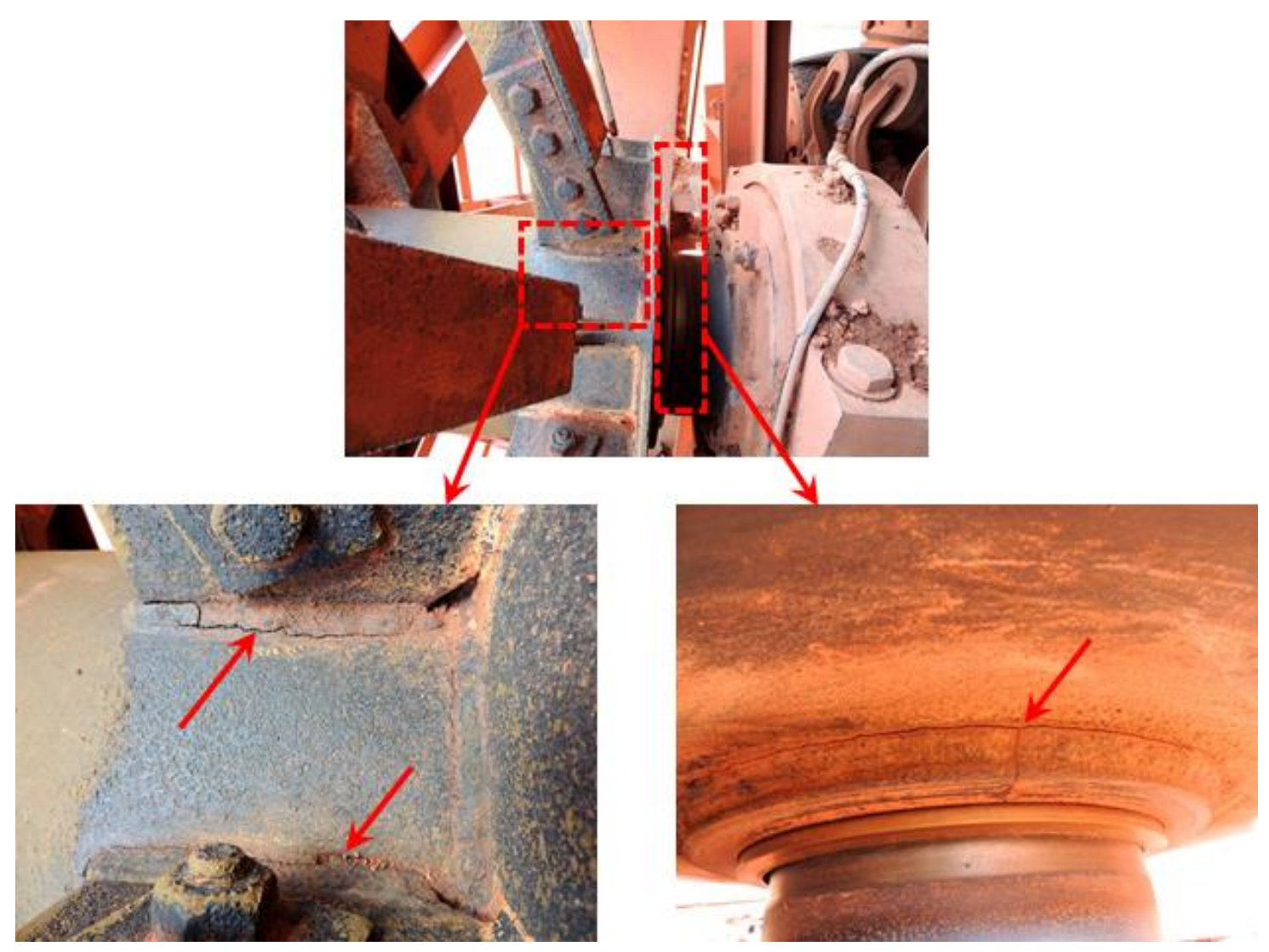

Fonte: Adaptado de Souza [7].

De acordo com Branco et al. [8], com o desenvolvimento da Mecânica da Fratura, tornou-se crescente a adoção de projetos em que a estrutura deve apresentar uma falha segura, sendo tal filosofia de projeto denominada Fail Safe Design. Este método se baseia na hipótese de que a estrutura possui algum defeito, mas terá que continuar em operação de forma satisfatória mesmo com o defeito presente, até que o mesmo seja detectado e reparado.

Além disso, a Mecânica da Fratura tornou-se uma ferramenta importante quando aliada à execução de uma manutenção preditiva eficiente, permitindo a prevenção de falhas catastróficas e o acompanhamento da propagação de trincas. Baseando-se no tempo necessário para que uma trinca existente na estrutura propague de maneira instável, permite-se a determinação de intervalos apropriados de manutenção, o que promove a redução de paradas inesperadas do equipamento, aumenta sua disponibilidade e confiabilidade, e consequentemente reduz os custos com o equipamento fora de operação. 
Broek [9] recomenda que pelo menos duas inspeções periódicas sejam realizadas entre um tamanho inicial de trinca $a_{o}$, que pode ou não ser detectável pelo método de inspeção adotado, e o tamanho crítico da trinca $a_{c}$. Isto tem por objetivo garantir que a trinca seja descoberta e eliminada antes que a falha aconteça. A Figura 2-9 ilustra tal relação entre o crescimento da trinca e o intervalo de inspeção estrutural.

Figura 2-9 - Relação entre o crescimento da trinca e o intervalo de inspeção estrutural.

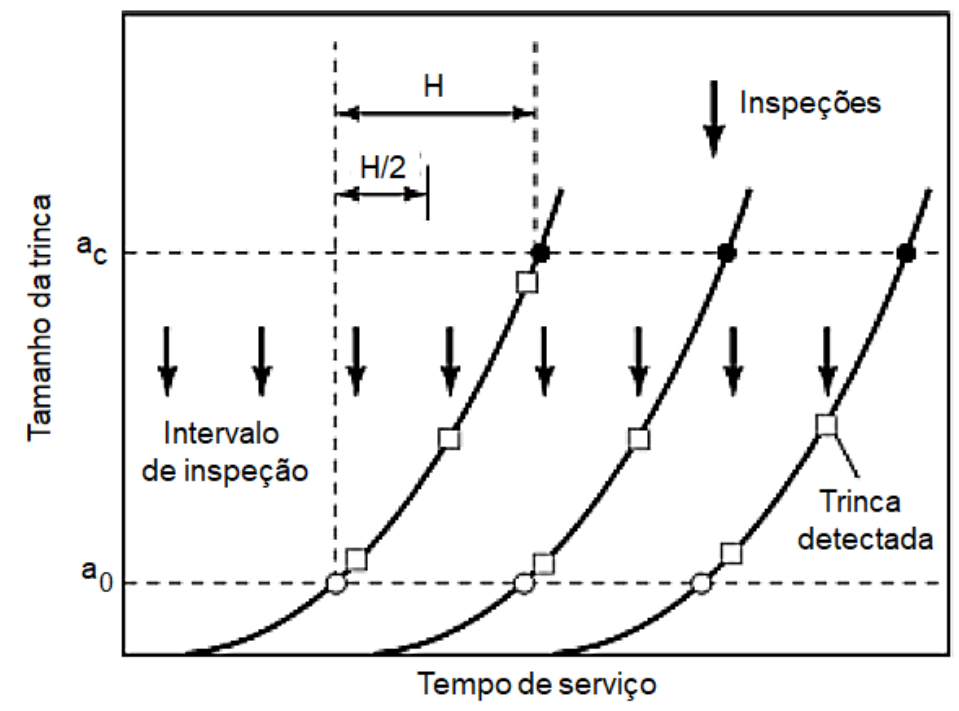

Fonte: Adaptado de Broek [9].

Daničić et al. [6] defende a adoção de uma manutenção proativa no ambiente de mineração, em que parâmetros chave são monitorados com o objetivo de estabelecer fatores operacionais críticos denominados "raízes da fratura". Quando estes fatores se tornam instáveis, ações devem ser tomadas antes do início da falha. Daničić et al. [6] ainda destacam que tal método de manutenção é baseado, por um lado, no aperfeiçoamento de técnicas de diagnóstico de falhas, e por outro, no desenvolvimento de análises mais elaboradas pelas normas técnicas.

Timmins [10] relata que os avanços nos últimos anos nas técnicas e equipamentos de ensaios não destrutivos tem levado a uma melhora na capacidade de detecção de defeitos decorrentes do processo de fabricação de um componente. Anderson [11] destaca que a Mecânica da Fratura caminha em conjunto com a realização de ensaios não destrutivos em procedimentos de controle de fratura, uma vez que tais ensaios fornecem dados de entrada para a análise, que em troca permite definir intervalos de inspeção. 
Tamanhos de trinca detectáveis são apresentados na Tabela 2-1 em função dos métodos de ensaio não destrutivos mais comuns para aplicação em campo, conforme indicação de Shanmugham e Liaw [12]. A aplicação de cada ensaio é descrita por Timmins [10].

Tabela 2-1 - Tamanho de trinca detectáveis em função do método de ensaio não destrutivo.

\begin{tabular}{c|c|c}
\hline Método de ensaio & Aplicação do ensaio & $\begin{array}{c}\text { Tamanho de trinca } \\
\text { detectável [mm] }\end{array}$ \\
\hline Líquidos penetrantes & $\begin{array}{c}\text { Procedimento simples para localização de } \\
\text { trincas superficiais }\end{array}$ & $0,025-0,25$ \\
\hline Ultrassom & $\begin{array}{c}\text { Detecção de defeitos internos, porosidade, } \\
\text { falta de fusão e trincas }\end{array}$ & 0,050 \\
\hline Emissão acústica & $\begin{array}{c}\text { Monitoramento da iniciação e propagação } \\
\text { de trincas e defeitos sob tensão em metais }\end{array}$ & 0,1 \\
\hline Partículas magnéticas & $\begin{array}{c}\text { Localização de trincas e inclusões } \\
\text { superficiais e subsuperficiais }\end{array}$ & 0,5 \\
\hline Radiografia & $\begin{array}{c}\text { Detecção de trincas e defeitos por meio de } \\
\text { raios X ou raios gama }\end{array}$ & $\begin{array}{c}2 \% \text { da espessura do } \\
\text { componente }\end{array}$ \\
\hline
\end{tabular}

Fonte: Adaptado de Shanmugham e Liaw [12] e Timmins [10].

A detecção de trincas maiores que o tamanho de trinca detectável não é uma garantia, podendo ser afetada por muitos fatores, tais como a habilidade do inspetor, a acessibilidade ao local de inspeção, possível presença de produtos de corrosão na região avaliada, entre outros. (Broek [9])

\subsection{Fadiga em componentes estruturais}

A norma ASTM E1823 [13] define "Fadiga" como o processo progressivo de mudança estrutural permanente localizada que ocorre em um material sujeito a condições que produzem tensões e deformações flutuantes em um ou mais pontos e que podem culminar em trincas ou em fratura completa após um número suficiente de flutuações. Na maioria dos casos, as tensões envolvidas em falhas por fadiga são baixas se comparadas ao limite de escoamento do material, embora em alguns casos estas falhas sejam decorrentes da atuação de tensões elevadas que geram deformações plásticas localizadas no componente. 
Basicamente, são três os métodos disponíveis na literatura para a determinação da vida em fadiga de um componente estrutural: fadiga controlada por tensão (método S-N), fadiga controlada por deformação (método $\varepsilon-\mathrm{N}$ ) e a Mecânica da Fratura Linear Elástica (MFLE). Segundo Bannantine et al. [14], não há um método genérico que é a melhor abordagem para todas as situações, pois cada técnica tem suas próprias vantagens e limitações, e a seleção do método deve se basear no material, tipo de carregamento, ambiente, geometria do componente e consequências da falha em serviço.

O método de fadiga controlada por tensão é principalmente utilizado na análise de componentes submetidos a um elevado número de ciclos onde as tensões e as deformações atuantes se localizam no regime elástico do material. Não é recomendado para aplicações de baixo ciclo em que as deformações plásticas tenham parcela significativa. Além disso, o método não faz distinção entre a fase de nucleação e de propagação de uma trinca (Bannantine et al. [14]).

O método de fadiga controlada por deformação permite uma análise mais detalhada da região sujeita à fadiga, levando em consideração a possibilidade de ocorrência de escoamento localizado e de deformações plásticas. Conforme Bannantine et al. [14], o método envolve um nível mais complexo de análise, sendo necessária a utilização de algumas ferramentas para determinação das deformações em um entalhe, tais como o Método dos Elementos Finitos e o uso de medições por extensômetros.

Em contraste aos dois métodos acima mencionados, a Mecânica da Fratura Linear Elástica parte do conceito de que todo componente possui inevitavelmente imperfeições e defeitos. Devido aos processos de fabricação, defeitos tais como porosidade, inclusões ou trincas iniciais estão presentes em um material. Além disso, defeitos podem surgir em função da condição de serviço empregada (Kuna [15]). Isto representa um avanço em relação aos métodos tradicionais de análise de fadiga, que não consideram os efeitos de trincas preexistentes no material. 


\subsection{Mecânica da Fratura Linear Elástica (MFLE)}

\subsection{1 $\quad$ Conceitos e definições}

Segundo Bannantine [14], a Mecânica da Fratura Linear Elástica (MFLE) é baseada na aplicação na teoria da elasticidade a corpos que contenham trincas ou defeitos. As hipóteses usadas na elasticidade também são inerentes à teoria da MFLE, a saber, pequenos deslocamentos e linearidade entre tensões e deformações. Uma vez que os materiais se deformam plasticamente quando o limite de escoamento é excedido, uma zona plástica se formará perto da extremidade da trinca. A base da Mecânica da Fratura Linear Elástica permanece válida se essa região plastificada permanecer pequena em relação às dimensões totais da trinca e do corpo trincado.

O deslocamento relativo entre duas superfícies na interface de uma trinca pode acontecer basicamente de três modos distintos em função do tipo de carregamento atuante, como ilustrado na Figura 2-10. Estes modos recebem numeração romana, sendo o Modo I definido pela abertura da trinca por tração, o Modo II definido pelo deslizamento das superfícies por cisalhamento numa direção perpendicular à frente da trinca e o Modo III definido pelo rasgamento das superfícies por cisalhamento numa direção paralela à frente da trinca. Tais modos podem ocorrer isoladamente ou combinados em um modo misto.

Figura 2-10 - Modos básicos de deslocamento entre duas superfícies na interface de uma trinca.

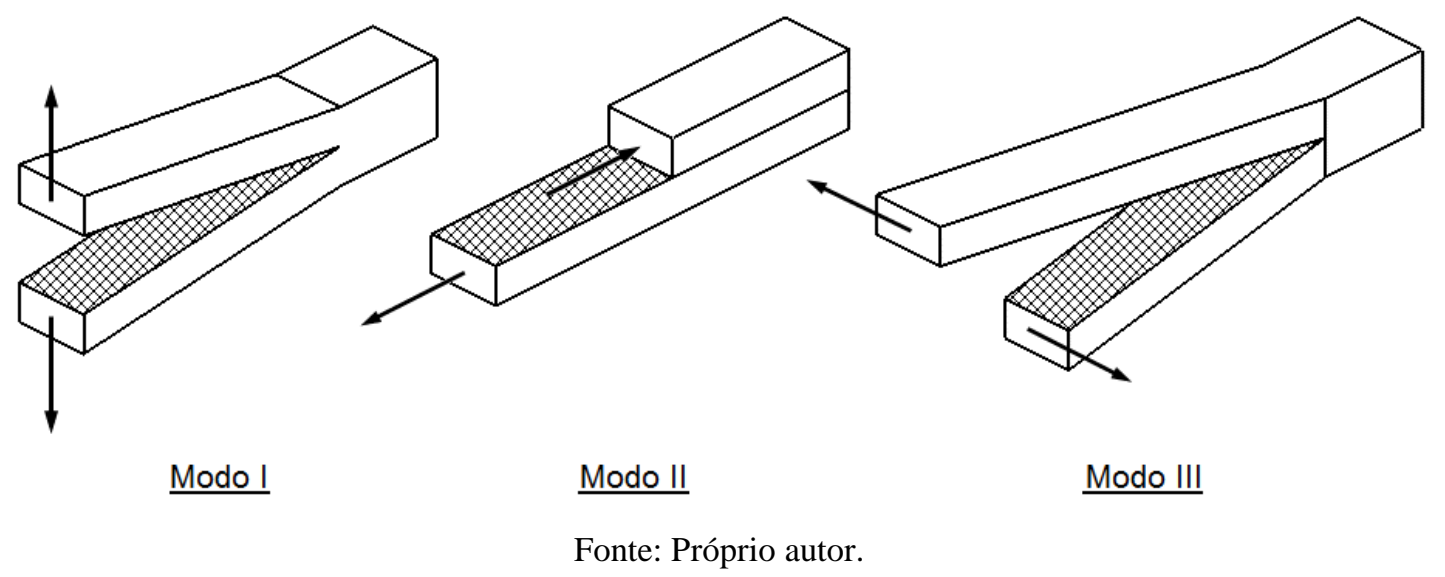


Para descrever a magnitude das tensões envolvidas em torno de uma trinca, define-se o Fator de Intensidade de Tensões $K$, que segundo Tada et al. [16] pode ser considerado como a representação da intensidade da distribuição das tensões linear-elásticas em torno da frente da trinca, onde pequenas não linearidades estão incorporadas no campo de tensões e não interferem significativamente no mesmo. Como o processo de fratura de um material pode ser relacionado a este campo de tensões na frente da trinca, o fator de intensidade de tensões desempenha papel importante como parâmetro para análise de uma fratura na prática.

O fator de intensidade de tensões $K$ depende do tipo de tensão $\sigma$ aplicada, da dimensão da trinca $a$ e da geometria do componente analisado, que é contabilizada por meio de um fator de forma $f(g)$. Em função dos modos de deslocamento anteriormente citados recebe as denominações $K_{I}$, $K_{I I}$ ou $K_{I I I}$. A Equação (2.1) apresenta a forma geral do cálculo do fator de intensidade de tensões:

$$
K=f(g) \sigma \sqrt{\pi a}
$$

A medida que a trinca evolui, o fator de intensidade de tensões pode atingir um limite acima do qual a trinca propagará de maneira instável. Tal limite é denominado Tenacidade à Fratura $K_{C}$ do material e pode ser obtido por meio de ensaios tais como os previstos na norma ASTM E399 [17].

A tenacidade à fratura é definida por Campbell [18] como a medida de resistência de um material à fratura frágil quando o mesmo possui uma trinca. Para corpos relativamente finos, em que o estado plano de tensões (EPT) será mais pronunciado, o valor de $K_{C}$ dependerá da espessura do componente ensaiado. À medida que a espessura aumenta, há uma transição do estado plano de tensões para o estado plano de deformações (EPD), no qual a tenacidade à fratura $K_{C}$ atinge um valor constante que independe da espessura do componente, passando a receber a denominação $K_{I C}$. A Figura 2-11 ilustra a variação da tenacidade à fratura com a espessura. 
Figura 2-11 - Variação da tenacidade à fratura com a espessura.

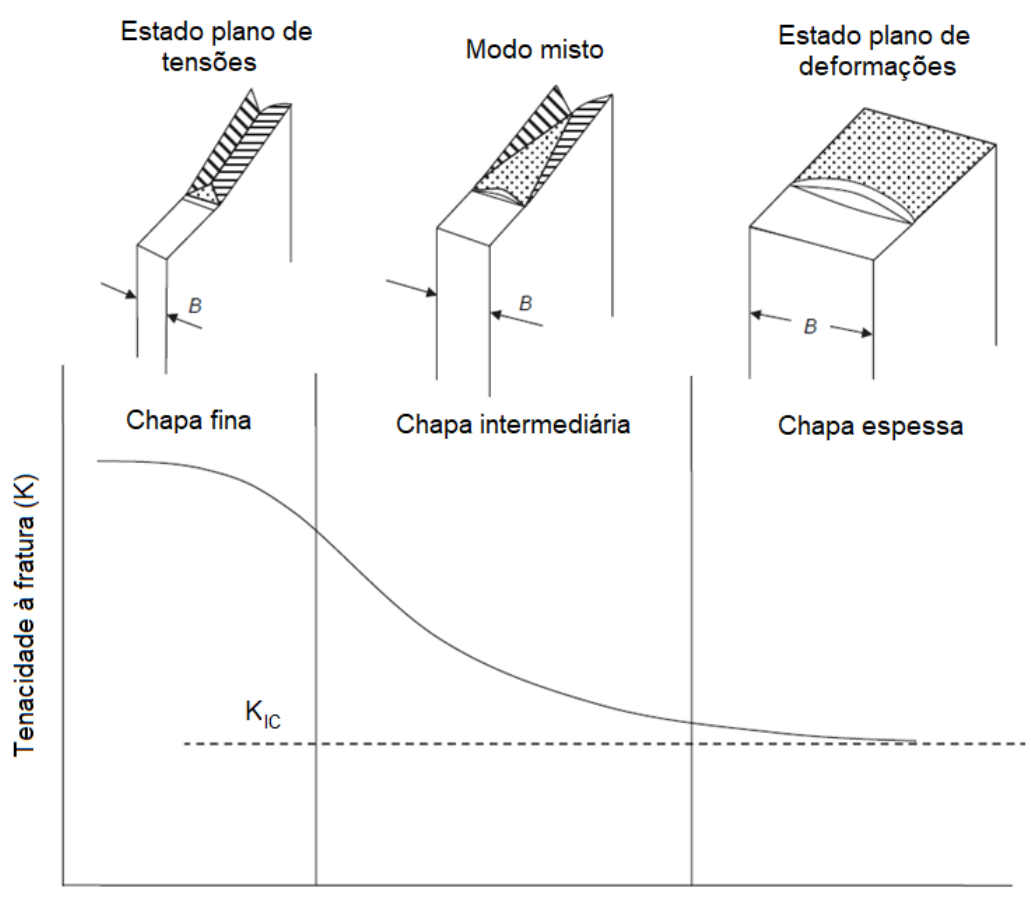

Fonte: Adaptado de Campbell [18].

De acordo com Dowling [19], se uma trinca não possui direção normal à tensão aplicada ou se há um estado de tensões complexo, a combinação dos modos I, II e III pode acontecer. Tal ocorrência exige uma análise mais detalhada porque a trinca pode mudar de direção e propagar em um plano diferente de seu plano original, e além disso os modos de fratura não agem de forma independente, mas interagem entre si.

Dowling [19] ainda argumenta que a obtenção de uma metodologia que avalie a combinação entre os modos de fratura é análoga à necessidade de um critério de escoamento para tensões combinadas. Existem diversos critérios para análise de uma fratura em que há combinação entre os modos, mas não há um consenso sobre qual destes critérios oferece a melhor abordagem para o problema.

Para ser considerado adequado, Dowling [19] afirma que um critério para combinação entre os modos deve realizar um ajuste de curva empírico em forma de elipse, como ilustrado na Figura 2-12. Conforme Richard et al. [20], em qualquer ponto localizado abaixo da curva de ajuste não é esperada a propagação instável da trinca, ao passo que pontos sobre a curva ou acima dela apresentarão instabilidade no crescimento da trinca. 
Figura 2-12 - Curva limite de fratura para modo misto no plano.

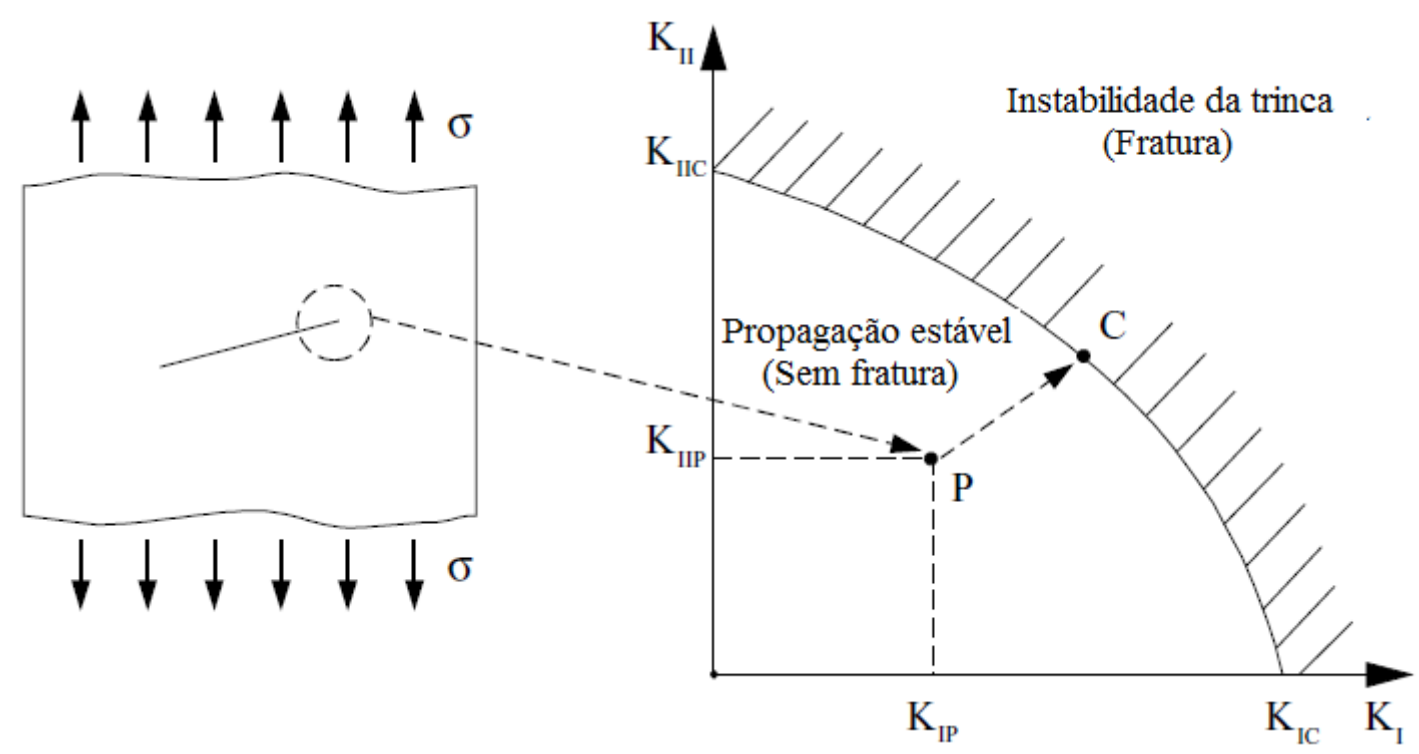

Fonte: Adaptado de Richard et al. [20].

Erdogan e Sih [21] propuseram um critério no qual a propagação da trinca ocorrerá em uma direção radial em relação à extremidade da trinca com um ângulo $\theta=\theta_{o}$ que define um plano perpendicular à tensão tangencial máxima. A Figura 2-13 ilustra as tensões atuantes na ponta da trinca com o referencial em um sistema cartesiano e em um sistema cilíndrico.

Figura 2-13 - Tensões atuantes na ponta da trinca em coordenadas cartesianas e cilíndricas.
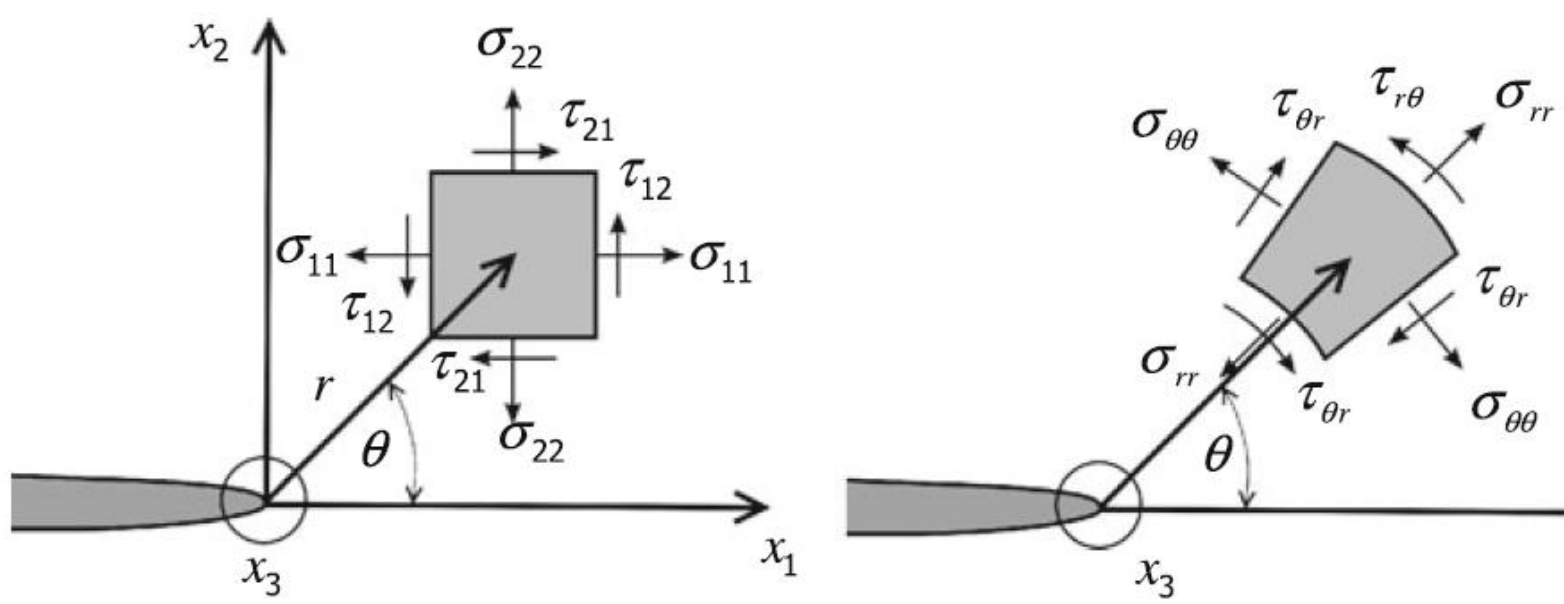

Fonte: Retirado de Kuna [15]. 
Se uma trinca é solicitada combinando-se os modos I e II, as tensões $\sigma_{\theta \theta}$ e $\tau_{r \theta}$ na ponta da trinca são dadas pelas equações abaixo:

$$
\begin{aligned}
\sigma_{\theta \theta} & =\frac{1}{\sqrt{2 r}} \cos \frac{\theta}{2}\left[K_{I} \cos ^{2} \frac{\theta}{2}-\frac{3}{2} K_{I I} \operatorname{sen} \theta\right] \\
\tau_{r \theta} & =\frac{1}{2 \sqrt{2 r}} \cos \frac{\theta}{2}\left[K_{I} \operatorname{sen} \theta+K_{I I}(3 \cos \theta-1)\right]
\end{aligned}
$$

A tensão tangencial $\sigma_{\theta \theta}$ será máxima quando a tensão cisalhante $\tau_{r \theta}$ for nula. Igualando-se a Eq. (2.3) a zero e achando sua solução, pode-se obter o ângulo $\theta_{o}$ que define a direção de propagação da trinca:

$$
K_{I} \operatorname{sen} \theta_{o}+K_{I I}\left(3 \cos \theta_{o}-1\right)=0
$$

Uma trinca apresentará comportamento instável quando a tensão cisalhante for nula e a parcela da tensão tangencial dada pela Eq. (2.2) que depende do ângulo da direção de propagação da trinca for equivalente à tenacidade à fratura para o modo I:

$$
\cos \frac{\theta_{o}}{2}\left[K_{I} \cos ^{2} \frac{\theta_{o}}{2}-\frac{3}{2} K_{I I} \operatorname{sen} \theta_{o}\right]=K_{I C}
$$

Richard et al. [20] definem um fator de intensidade de tensões equivalente, que pode ser comparado a uma tensão equivalente no estado plano de tensões, que depende dos fatores de intensidade de tensões $K_{I}$ e $K_{I I}$ :

$$
K_{e q}=\frac{K_{I}}{2}+\frac{1}{2} \sqrt{K_{I}^{2}+4\left(\alpha_{1} K_{I I}\right)^{2}}
$$

A propagação instável da trinca ocorrerá caso o fator de intensidade de tensões equivalente exceda a tenacidade à fratura para o modo $\mathrm{I}\left(K_{I C}\right)$. Este critério possui boa compatibilidade com a curva limite de fratura do critério da tensão tangencial máxima proposto por Erdogan e Sih [21] se o parâmetro do material $\alpha_{1}$ for igual a 1,155. Tal parâmetro é referente à razão entre as tenacidades à fratura do modo I e do modo II, ou seja, $K_{I C} / K_{I I C}=1,155$. 
Para a determinação do ângulo de propagação da trinca, Richard et al. [20] definem a expressão abaixo obtida de forma experimental:

$$
\theta_{o}=\mp\left(155,5^{\circ} \frac{\left|K_{I I}\right|}{\left|K_{I}\right|+\left|K_{I I}\right|}\right)-83,4^{\circ}\left(\frac{\left|K_{I I}\right|}{\left|K_{I}\right|+\left|K_{I I}\right|}\right)^{2}
$$

A evolução do comprimento da trinca pode ser analisada por meio de um gráfico que mostra a taxa de crescimento da trinca $d a / d N$ em função da variação do fator de intensidade de tensões $\Delta K$, que pode ser visualizado em escala log-log na Figura 2-14.

Figura 2-14 - Taxa de crescimento da trinca em função da variação do fator de intensidade de tensões.

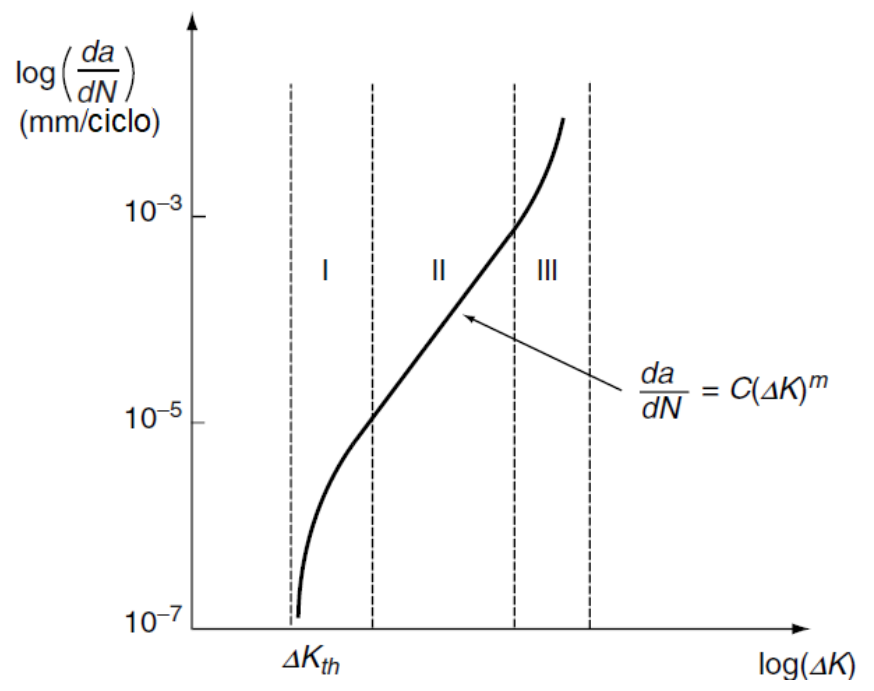

Fonte: Adaptado de Lee et al. [22].

Três regiões podem ser observadas neste gráfico: na região I, sob tensões com baixa magnitude, o comportamento da trinca é associado ao limite $\Delta K_{t h}$, abaixo do qual não há propagação da trinca; na região II, a propagação da trinca ocorre de maneira estável e a taxa de crescimento pode ser aproximada de forma linear; na região III, a propagação da trinca ocorre rapidamente e será instável caso a tenacidade à fratura seja ultrapassada.

De acordo com a norma ASTM E1823 [13], o limite $\Delta K_{t h}$ é definido como o valor assintótico de $\Delta K$ no qual a taxa de crescimento da trinca se aproxima de zero (valor arbitrário igual a $10^{-10} \mathrm{~m} /$ ciclo para a maioria dos materiais). Barsom e Rolfe [23] explicam que muitos fatores podem influenciar o valor do limite $\Delta K_{t h}$, tais como limite de escoamento, tamanho de grão, presença de tensões residuais, módulo de elasticidade entre outros fatores. 
A partir de dados obtidos experimentalmente por diversos pesquisadores, Barsom e Rolfe [23] apresentam estimativas conservadoras de $\Delta K_{\text {th }}$ para diversos tipos de aços, como pode ser visto na Eq. (2.8). Tais estimativas são dependentes da razão entre a tensão mínima e a tensão máxima atuantes $\left(R=\sigma_{\min } / \sigma_{\max }\right)$.

$$
\Delta K_{t h}=\left\{\begin{array}{c}
7(1-0,85 R) M P a \sqrt{m} ; R \geq 0,1 \\
6 M P a \sqrt{m} ; R<0,1
\end{array}\right.
$$

Valores de referência para o limite $\Delta K_{\text {th }}$ para aços também são apresentados pela norma BS 7910 [24] e podem ser vistos na Eq. (2.9):

$$
\Delta K_{t h}=\left\{\begin{array}{c}
2 M P a \sqrt{m} ; R \geq 0,5 \\
(5,38-6,77 R) M P a \sqrt{m} ; 0 \leq R<0,5 \\
5,38 M P a \sqrt{m} ; R<0
\end{array}\right.
$$

Para a região II, onde a taxa de crescimento da trinca é aproximadamente linear, um ajuste de curva para tal comportamento foi proposto por P. C. Paris no início da década de 1960, sendo o modelo mais aceito no meio acadêmico, conforme Bannantine et al. [14]. Tal ajuste é expresso por meio da Eq. (2.10):

$$
\frac{d a}{d N}=C(\Delta K)^{m}=C\left(K_{\max }-K_{\min }\right)^{m}
$$

onde $C$ é uma constante e $m$ é a inclinação da curva $d a / d N \times \Delta K$.

A equação de Paris não leva em consideração a razão entre a tensão mínima e a tensão máxima. Segundo Dowling [19], o valor da razão $R$ influencia a taxa de crescimento da trinca de maneira análoga aos efeitos observados em curvas S-N para diferentes valores da razão $R$ ou da tensão média. Para uma dada variação $\Delta K$, um aumento na razão $R$ proporciona o aumento da taxa de crescimento, sendo este efeito mais significativo em materiais frágeis.

Para levar em consideração o efeito da razão entre a tensão mínima e a tensão máxima, Walker [25] propôs uma modificação no cálculo da variação do fator de intensidade de tensões indicada pela Eq. (2.11): 


$$
\Delta \bar{K}=K_{\max }(1-R)^{\gamma}
$$

Reescrevendo a Eq. (2.11) em função de $\Delta K$ e substituindo a expressão na equação de Paris (Eq. (2.10)), pode-se obter a formulação expressa pela Eq. (2.12), denominada aqui como equação de Walker:

$$
\frac{d a}{d N}=C_{1}[\Delta \bar{K}]^{m_{1}}=C_{1}\left[\frac{\Delta K}{(1-R)^{1-\gamma}}\right]^{m_{1}}
$$

As constantes do material $C$ e $m$ indicadas na Eq. (2.10) podem ser reescritas da seguinte forma:

$$
C=\frac{C_{1}}{(1-R)^{m_{1}(1-\gamma)}}, \quad m=m_{1}
$$

onde $C_{l}, m_{l}$ e $\gamma$ são parâmetros relacionados ao material.

De acordo com Dowling [19], a constante $\gamma$ possui valor típico igual a 0,5 para vários metais, e pode variar entre 0,3 e aproximadamente 1,0 . Um valor de $\gamma=1$ indica que a razão de tensões $R$ não influencia na taxa de propagação da trinca e uma redução nos valores de $\gamma$ implica em um efeito significativo da razão $R$. Em carregamentos que envolvem compressão $(R<0)$, podese assumir que a parcela de compressão do carregamento cíclico não tem efeito sobre a trinca através da utilização de $\gamma=0$. Tal consideração se baseia na lógica de que a trinca se fecha no momento em que a carga é nula e não se comporta como uma trinca quando submetida a carregamentos compressivos.

Para Gross e Lampman [26], o fechamento de uma trinca de fadiga é um efeito importante a ser considerado porque altera a relação entre o fator de intensidade de tensões aplicado (calculado a partir das tensões aplicadas e do comprimento da trinca) e o fator realmente atuante na extremidade da trinca. 
Elber [27] estudou o fenômeno de fechamento de trinca na década de 1970 e verificou que trincas em corpos de prova permaneciam fechadas durante uma parcela significativa dos ciclos de carregamento, mesmo sob atuação de cargas trativas, apresentando rigidez similar à de um corpo de prova sem trinca, como pode ser visto na Figura 2-15. Tal fenômeno estaria relacionado à formação de zonas plasticamente deformadas deixadas para trás à medida que a trinca propaga, que induzem o contato entre as superfícies da trinca, mantendo-a fechada.

Figura 2-15 - Fechamento de trinca durante a propagação.

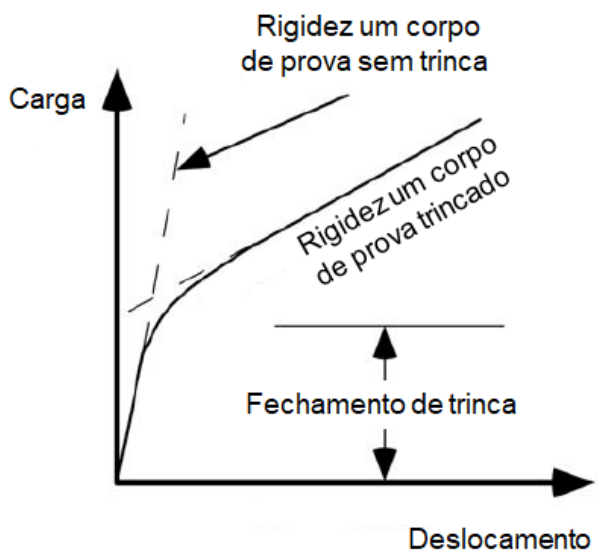

a) Comportamento da rigidez do corpo de prova

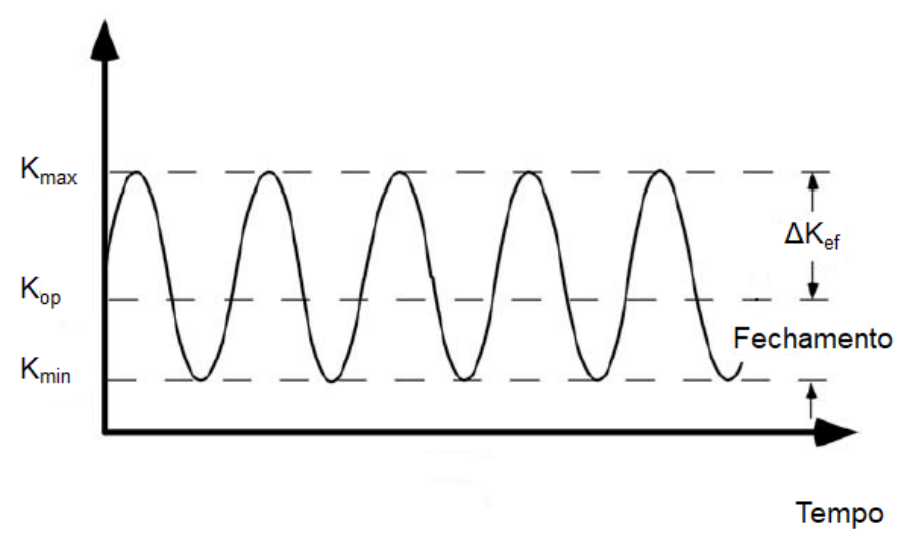

b) Definição do fator de intensidade de tensões efetivo

Fonte: Adaptado de Anderson [11].

De acordo com o Elber [27], somente haverá propagação de uma trinca quando a mesma estiver totalmente aberta, a partir da aplicação de um fator de intensidade de tensões $K_{o p}$ associado a uma carga capaz de abrir a trinca. Uma vez que somente a parcela acima da carga de abertura da trinca é responsável pela propagação, foi desenvolvido o conceito de fator de intensidade de tensões efetivo, que representa uma proporção $U$ do fator de intensidade de tensões calculado:

$$
U=\frac{\Delta K_{e f}}{\Delta K}=\frac{K_{\max }-K_{o p}}{K_{\max }-K_{\min }}
$$

Elber [27] propôs uma formulação experimental da relação entre a razão de tensão para abertura da trinca $U$ e a razão de tensões $R$ :

$$
U=0,5+0,4 R ;-0,1 \leq R \leq+0,7
$$


Schijve [28] também propôs uma expressão para a razão $U$, a qual é válida para uma maior faixa de razão de tensões $R$ do que a formulação proposta por Elber [27]:

$$
U=0,55+0,35 R+0,1 R^{2} ;-1 \leq R \leq+1
$$

Kurihara et al. [29] avaliaram o efeito da razão de tensões $R$ juntamente com o comportamento de fechamento de trinca através de experimentos em aços para fabricação de vasos de pressão submetidos a uma ampla faixa de razões de tensões $(-5$ até $+0,8)$, sendo obtida a expressão da Eq. (2.17) por meio de ajustes de curva dos dados experimentais:

$$
U=\left\{\begin{array}{cc}
\frac{1}{1,5-R} ; & -5 \leq R \leq+0,5 \\
1 ; & R>0,5
\end{array}\right.
$$

\subsection{2 $\quad$ Acúmulo de danos}

Segundo Lee et al. [22], o processo de fadiga de um componente envolve os seguintes estágios: (1) nucleação da trinca, (2) propagação da microtrinca, (3) propagação da macrotrinca, e (4) fratura final. Tais estágios geram danos à estrutura que, acumulados devido à continuidade dos carregamentos cíclicos, proporcionam a redução da área resistente e a consequente fratura do componente.

De acordo com Dowling [19], uma forma de se levar em consideração o acúmulo de danos em uma estrutura sujeita à fadiga, principalmente sob atuação de carregamentos de amplitude variável, é a utilização de técnicas como a regra de dano cumulativo linear de Palmgren-Miner. Tal regra foi proposta por Palmgren na década de 1920 para predição de vida em rolamentos de esferas e, posteriormente, foi desenvolvida por Miner em 1945.

A regra de Palmgren-Miner, expressa pela Eq. (2.18), consiste em somar as parcelas de vida consumida, dada pela razão entre o número de ciclos atuante $n_{i}$ e a vida calculada $N_{f i}$ para um determinado carregamento cíclico, e comparar esta soma a um limite usualmente tomado como 1, que representa $100 \%$ da vida útil do componente. Uma falha por fadiga é esperada caso o somatório de danos ultrapasse tal limite. 


$$
\frac{n_{1}}{N_{f 1}}+\frac{n_{2}}{N_{f 2}}+\cdots=\sum \frac{n_{i}}{N_{f i}}=1
$$

A repetição de carregamentos com amplitude variável pode ocorrer em um determinado histórico de carregamento. Neste caso, é conveniente realizar a soma do dano acumulado em uma repetição e multiplicar este dano pelo número de repetições $B_{f}$ que ocorrerão até a falha do componente, como ilustrado na Eq. (2.19):

$$
B_{f}\left[\sum \frac{N_{i}}{N_{f i}}\right]_{1 \text { repetição }}=1
$$

\subsubsection{Vida em fadiga}

Para carregamentos com amplitude variável, o número de ciclos necessários para que uma trinca propague de maneira instável pode ser obtido por meio de integração numérica. Tal método possui maior abrangência, uma vez que o mesmo pode ser utilizado para casos em que o fator de forma do fator de intensidade de tensões varia significativamente durante a propagação da trinca.

Anderson [11] propõe o cálculo do número de ciclos $N$ a partir da soma de incrementos no comprimento da trinca sob a atuação de carregamentos com amplitude variável que se repetem periodicamente. Considerando um caso onde uma trinca está sujeita a uma tensão cíclica $\Delta \sigma_{I}$ durante $N_{l}$ ciclos e assim sucessivamente até $N_{n}$ ciclos, o comprimento total da trinca pode ser estimado pela Eq. (2.20):

$$
\Delta a=\left(\frac{d a}{d N}\right)_{1} N_{1}+\left(\frac{d a}{d N}\right)_{2} N_{2}+\cdots+\left(\frac{d a}{d N}\right)_{n} N_{n}=\sum_{i=1}^{n}\left(\frac{d a}{d N}\right)_{i} N_{i}
$$


Segundo Anderson [11], a metodologia de acúmulo de danos pode ser generalizada através do cálculo de uma taxa média de crescimento da trinca para um dado espectro de carregamentos por meio da Eq. (2.21). O número total de ciclos $N_{\text {tot }}$ deve incluir todos os ciclos de carga a que o componente está submetido durante uma repetição do espectro de carregamento:

$$
\frac{d \bar{a}}{d N}=\frac{\Delta a}{N_{t o t}}=\frac{1}{N_{t o t}} \sum_{i=1}^{n}\left(\frac{d a}{d N}\right)_{i} N_{i}
$$

A vida em fadiga com base na Mecânica da Fratura pode ser obtida através da integração do inverso da taxa média de propagação da trinca partindo de um tamanho inicial $a_{i}$ até o tamanho final $a_{f}$ :

$$
N=\int_{a_{i}}^{a_{f}}\left(\frac{d \bar{a}}{d N}\right)^{-1} d a
$$

Dowling [19] propõe a obtenção do número de ciclos utilizando integração numérica por meio da Regra de Simpson. No método proposto, o número de ciclos é dado pela área sob a curva $d a / d N$ x a para um dado intervalo do tamanho da trinca, como pode ser observado na Figura 2-16. Entre os tamanhos $a_{j}$ e $a_{j+2}$, a área sob a curva $y=d a / d N$ é estimada assumindo-se que uma parábola passa pelos três pontos $\left(a_{j}, y_{j}\right),\left(a_{j+1}, y_{j+1}\right)$ e $\left(a_{j+2}, y_{j+2}\right)$.

Figura 2-16 - Área sob a curva $d a / d N$ x a para um dado intervalo como estimado pela Regra de Simpson.

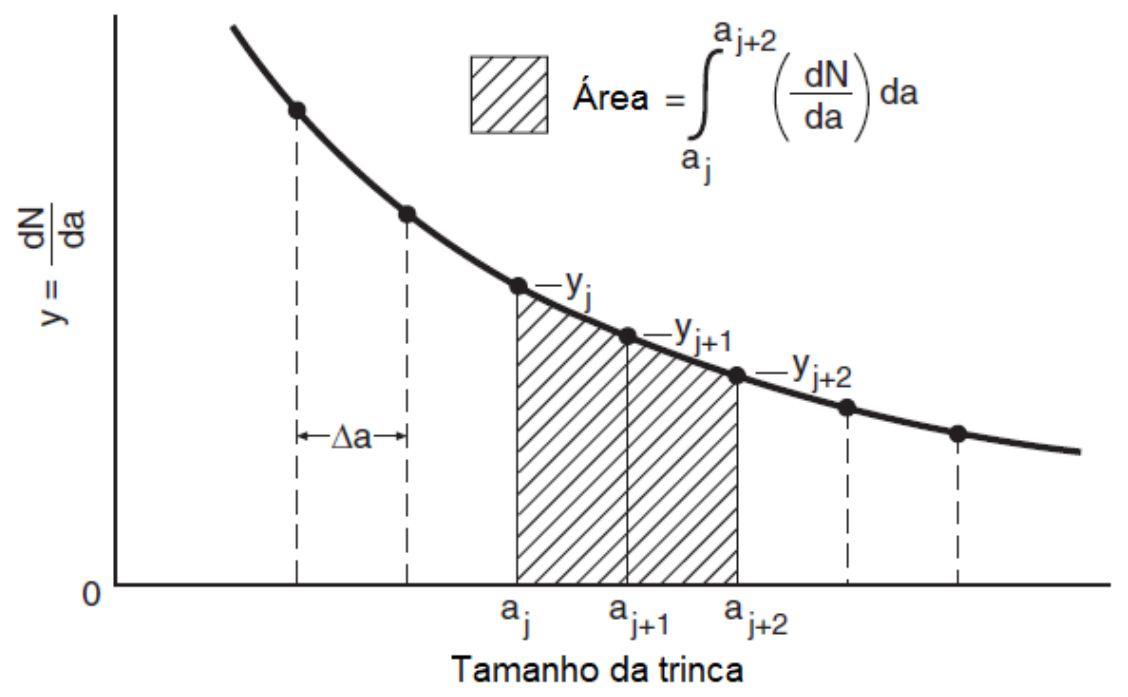

Fonte: Adaptado de Dowling [19]. 


\subsection{Juntas soldadas}

Segundo Barsom e Rolfe [23], a utilização de processos de soldagem para união entre componentes metálicos tem proporcionado um impacto significativo no desenvolvimento da indústria, sendo um método efetivo para redução dos custos de fabricação, podendo ser mecanizado, computadorizado e incorporado em linhas de montagem.

Embora este desenvolvimento tenha sido acompanhado de uma evolução nas diretrizes fornecidas por normas da área de soldagem, estruturas metálicas nas quais são adotadas juntas soldadas não estão isentas de falhas mesmo naquelas projetadas, fabricadas e inspecionadas de acordo com alguma norma de referência.

Baseado em análise dos dados disponíveis na literatura sobre falhas estruturais ocorridas em um período de 50 anos, Jutla [30] afirma que juntas soldadas são o ponto mais crítico do ponto de vista de desempenho de componentes e estruturas soldadas. A introdução de uma solda em um material metálico proporciona características prejudiciais, as quais podem incluir mudanças na microestrutura e nas propriedades mecânicas, introdução de tensões residuais, amplificação local da tensão aplicada devido à presença de descontinuidades geométricas e a introdução de defeitos e imperfeições na solda.

\subsubsection{Defeitos e imperfeições em juntas soldadas}

Vários tipos de descontinuidades, trincas e imperfeições, suas causas e métodos para eliminálos tem sido o objeto de pesquisa em muitas publicações. Em geral, estas descontinuidades em soldas podem ser causadas por: (1) projeto inadequado que restringe a acessibilidade para soldagem; (2) seleção incorreta do processo ou dos parâmetros de soldagem; (3) armazenamento inadequado do eletrodo ou do fluxo, ou ambos; e (4) outras razões, incluindo o desempenho do soldador. (Barsom e Rolfe [23])

A norma BS 7910 [24] classifica defeitos em juntas soldadas em três categorias, conforme indicado a seguir. Na Figura 2-17, é apresentada uma representação esquemática de imperfeições e trincas em juntas soldadas. 
a) Defeitos planos: Trincas, falta de fusão ou penetração, concavidades e sobreposição em soldas;

b) Defeitos não planos: Cavidades (bolsas de gás, porosidade interna) e inclusões de sólidos (escória, fluxo, óxidos metálicos);

c) Imperfeições de forma: Mordeduras, desalinhamento; perfil de solda imperfeito.

Figura 2-17 - Imperfeições e trincas em juntas soldadas.

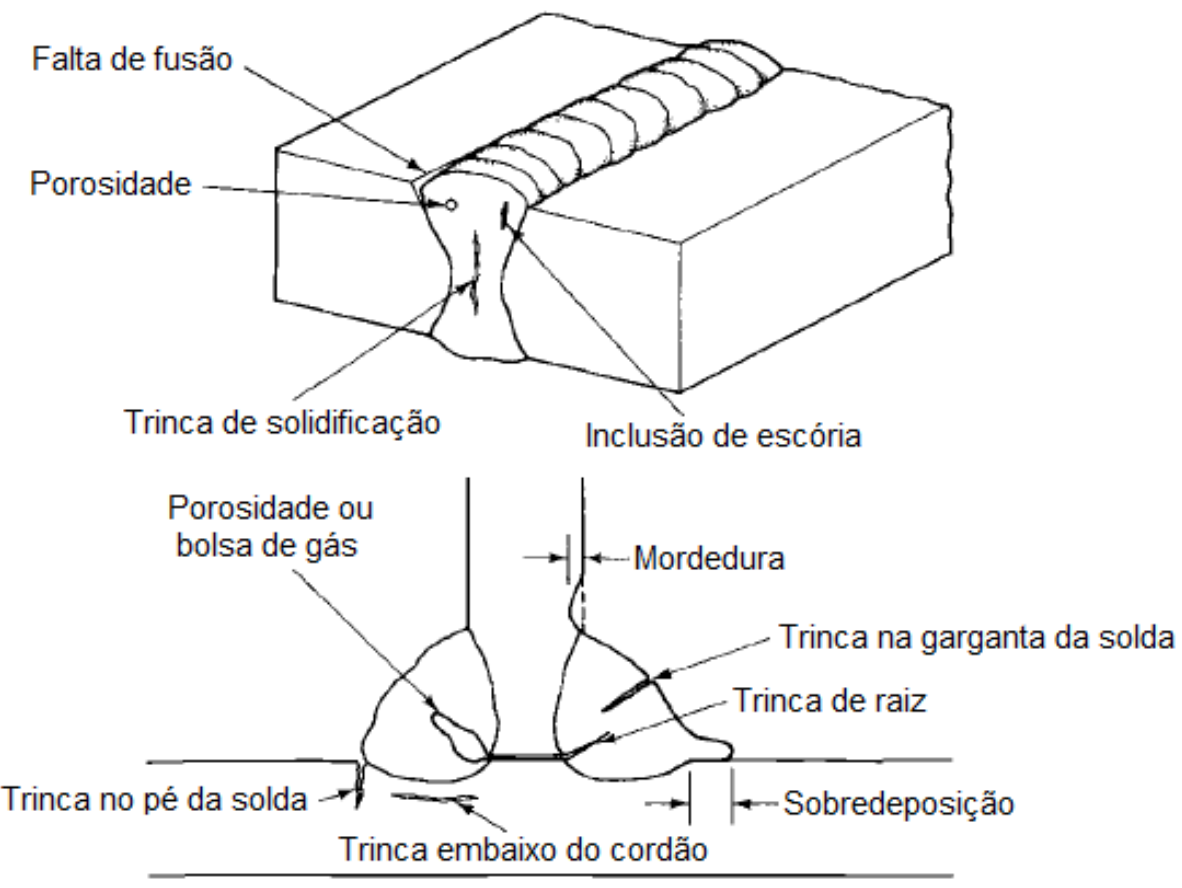

Fonte: Adaptado de Barsom e Rolfe [23].

Branco et al. [8] indicam que trincas de fadiga se iniciam geralmente no cordão de solda, numa zona em que a concentração de tensões seja mais elevada, ou num local onde haja defeitos na solda. A propagação da trinca faz-se pelo metal de base, metal depositado ou zona termicamente afetada, dependendo da geométrica da junta, estado metalúrgico do material, tensões residuais e condições de solicitação.

Cary e Helzer [31] afirmam que trincas são talvez o mais sério dos defeitos que podem ocorrer em juntas soldadas. São consideradas um risco porque proporcionam uma redução significativa da resistência do material, podendo causar a falha repentina do componente. Particularmente em casos em que a solda está sujeita à operação em baixas temperaturas, impacto e tensões reversíveis, ou quando a falha da junta soldada coloca vidas humanas em risco, trincas não devem ser aceitas no material. 
Em uma junta soldada, existem três zonas distintas: o metal de solda, a zona termicamente afetada (ZTA) e o metal de base. Trincas podem ocorrer em qualquer uma destas três regiões, sendo mais predominantes a presença de trincas na solda e na ZTA, embora trincas nucleadas nestas regiões possam propagar através do metal de base (Miller [32]).

\subsubsection{Tensões residuais}

De acordo com Branco et al. [8], tensões residuais podem ser definidas como tensões que existem num dado componente na ausência de qualquer solicitação exterior, sendo o resultado de deformações de origem térmica ou mecânica acompanhadas de escoamento do material. No caso de juntas soldadas, as tensões criadas em tais juntas são devidas a deformações inelásticas não uniformes geradas por efeito do ciclo térmico da solda.

Jutla [30] destaca que tensões residuais são normalmente encontradas em estruturas soldadas, e podem ser tão elevadas quanto o limite de escoamento do material. Branco et al. [8] afirma que as dilatações e contrações térmicas do metal depositado e do metal de base adjacente daí decorrentes poderão não ser acomodadas sem que o limite de escoamento do material seja excedido, do que resultam por vezes deformações permanentes e tensões residuais nas peças. A Figura 2-18 ilustra a distribuição típica de tensões residuais em juntas soldadas.

Figura 2-18 - Distribuição típica de tensões residuais em juntas soldadas.

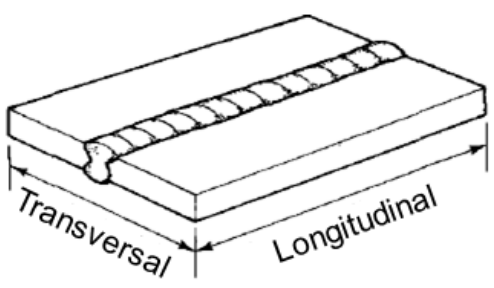

(a) Chapa soldada por penetração total

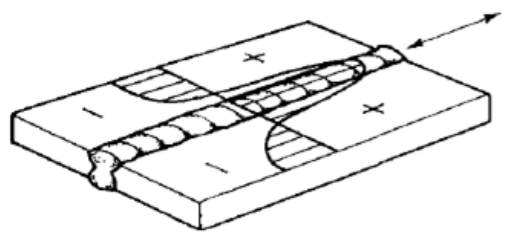

(b) Tensão residual longitudinal

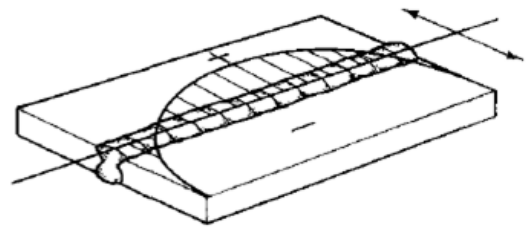

(c) Tensão residual transversal

Fonte: Adaptado de Barsom e Rolfe [23]. 
O efeito de tensões residuais sobre fraturas instáveis tem sido analisado utilizando-se os conceitos da mecânica da fratura. Esta análise indica que tais fraturas podem ocorrer a partir de pequenas trincas que normalmente seriam estáveis se tensões residuais não estivessem presentes. Quando uma pequena trinca subcrítica se localiza em uma região com tensões residuais compressivas, estas tensões não contribuem para o aumento das tensões na ponta da descontinuidade. Entretanto, caso as tensões residuais sejam trativas, tais tensões serão adicionadas às tensões atuantes, podendo causar a propagação da trinca até que sua extremidade esteja fora do campo de tensões residuais. Neste ponto, a trinca pode parar ou continuar a crescer, dependendo de seu comprimento e da intensidade das tensões na frente da trinca. (Welding Handbook [33])

Quando um componente soldado em que estão presentes tensões residuais é solicitado, verificase uma interação entre as tensões residuais presentes nas juntas soldadas e as tensões resultantes das cargas aplicadas. Como resultado dessa interação, é observada uma alteração da razão de tensões $R=\sigma_{\min } / \sigma_{\max }$ efetivamente presente na junta soldada, principalmente na região da junta onde ocorrem tensões residuais de tração. (Branco et al. [8])

A alteração na razão de tensões em função da presença de tensões residuais pode ser refletida na Eq. (2.23), apresentada em termos do fator de intensidade de tensões $K$ na frente da trinca. Destaca-se que a norma BS-7910 [24] indica a utilização da mesma formulação de $K$ da tensão máxima $K_{\max }$ e da tensão mínima $K_{\min }$ para o cálculo de $K$ das tensões residuais $K_{\text {res: }}$ :

$$
R_{\text {res }}=\frac{K_{\text {min }}+K_{\text {res }}}{K_{\text {max }}+K_{\text {res }}}
$$

Na Figura 2-19, pode-se observar graficamente a superposição do campo de tensões residuais de tração sobre as tensões aplicadas no ciclo de carregamento. De acordo com Jutla [30], devido a esta superposição, o range de tensões irá flutuar entre o limite de escoamento $\sigma_{y}$, que será a tensão máxima atuante, e uma tensão mínima igual a $\sigma_{y}-\Delta \sigma$. Desta forma, haverá um deslocamento no valor da tensão média atuante, fazendo com que ciclos de tensão parcialmente ou totalmente em compressão gerem danos de fadiga equivalentes a ciclos de tensão totalmente em tração, mantendo-se o mesmo range de tensões. 
Figura 2-19 - Efeito de superposição das tensões residuais de tração sobre o range de tensões atuantes.

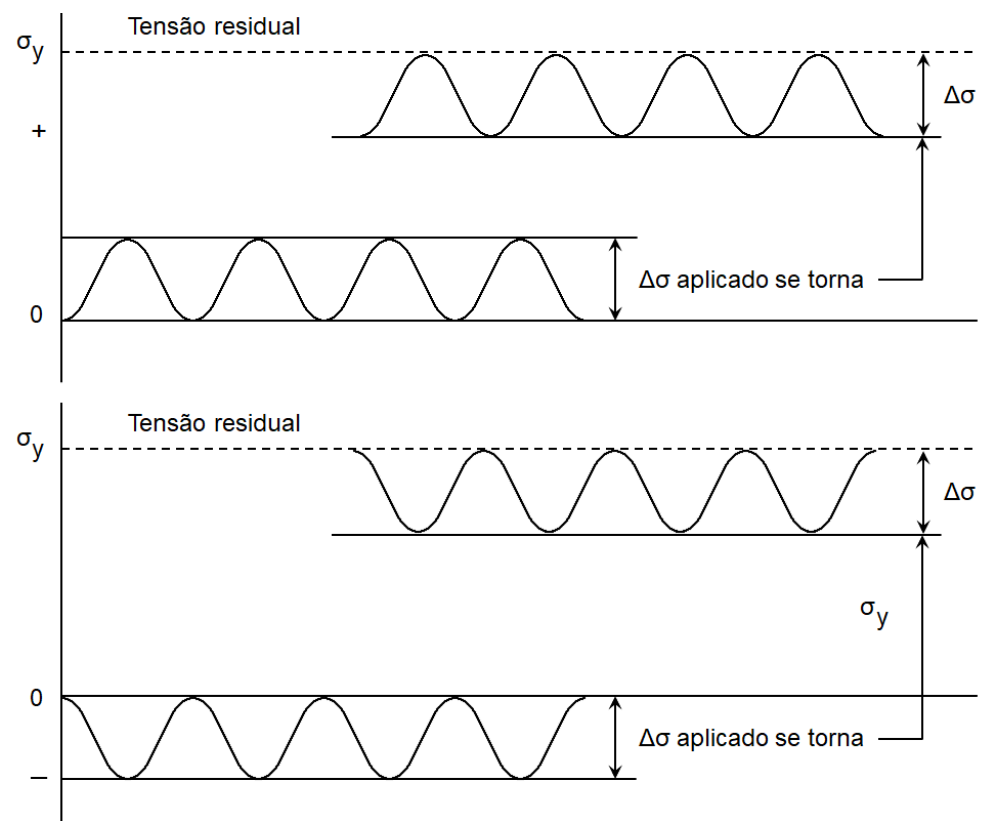

Fonte: Adaptado de Jutla [30].

A distribuição de tensões residuais em um componente soldado nem sempre está disponível no momento da análise de propagação de trincas. Nesse caso, perfis de tensão residual em juntas soldadas obtidos experimentalmente, como os disponíveis na norma BS-7910 [24], podem ser utilizados. Segundo esta norma, uma abordagem conservadora também pode ser adotada considerando-se tensões residuais de tração com magnitude constante e igual ao menor valor entre os limites de escoamento do metal de base e do metal de solda. Martinsson [34] destaca que esta abordagem não leva em consideração a redistribuição do campo de tensões residuais durante o processo de crescimento da trinca.

\subsubsection{Concentração de tensões}

Segundo Barsom e Rolfe [23], trincas de fadiga ocorrem preferencialmente na região do pé ou em terminações do cordão de solda do que em imperfeições internas (porosidades, inclusões) geradas pelo processo de soldagem. Branco et al. [8] afirmam que a iniciação e propagação de trincas de fadiga em juntas soldadas é bastante facilitada pela concentração de tensões induzida pela descontinuidade geométrica causada pelo cordão de solda. Consequentemente, a resistência à fadiga de uma junta soldada será menor que a da mesma peça lisa (sem descontinuidade). A Figura 2-20 ilustra a concentração de tensões gerada pelo cordão de solda. 
Figura 2-20 - Distribuição de tensões numa solda de topo solicitada à tração.

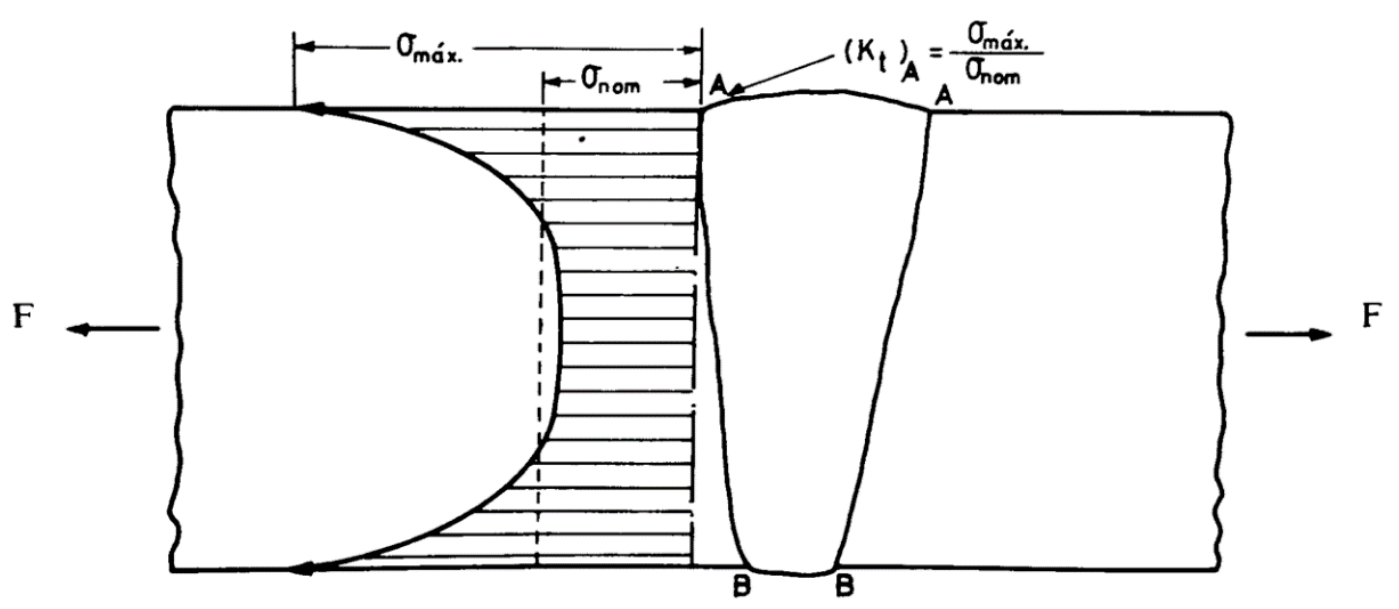

Fonte: Retirado de Branco et al. [8].

Maddox [35] estudou o efeito da concentração de tensões sobre o fator de intensidade de tensões $K$ em uma trinca e observou que a consideração de um concentrador geométrico $K_{t}$ para amplificação do fator de intensidade de tensões, independentemente do comprimento da trinca, leva a uma superestimativa de $K$, uma vez que há uma redução em $K_{t}$ à medida que a trinca propaga. Desta forma, Maddox [35] propôs a utilização um fator de amplificação $M_{k}$, definido como a razão entre o fator de intensidade de tensões numa junta soldada e o fator de intensidade de tensões para uma geometria análoga, mas sem o cordão de solda:

$$
M_{k}=\frac{K_{\text {junta soldada }}}{K_{\text {geometria sem } a \text { solda }}}
$$

Normalmente, o fator de amplificação $M_{k}$ diminui à medida que a trinca se afasta da região de concentração de tensões no pé da solda, e conforme a norma BS 7910 [24] um valor unitário para o fator $M_{k}$ avaliado na direção da profundidade de uma trinca semielíptica é tipicamente atingido quando a trinca possui uma profundidade igual a $30 \%$ da espessura do componente soldado.

Estudos sobre a variação do fator de amplificação $M_{k}$ durante a propagação de trinca podem ser obtidos em trabalhos disponíveis na literatura para juntas soldadas com geometrias mais usuais, tais como os resultados presentes em Hobbacher [36] e em Bowness e Lee [37]. Para casos específicos em que não há dados disponíveis, o fator $M_{k}$ pode ser estimado computacionalmente através do Método dos Elementos Finitos (MEF). 


\subsubsection{Propagação de trincas}

Como destacado anteriormente, trincas em juntas soldadas nucleiam-se com maior frequência na região do pé de uma solda devido à presença de concentradores de tensão. De acordo com Branco et al. [8], trincas nucleadas nesta região possuem o formato de uma semielipse como configuração habitual.

Neste tipo de trinca, é necessário definir duas dimensões $a$ e $c$, paralelas aos eixos da semielipse que caracteriza a trinca. A dimensão $a$ representa a profundidade enquanto que a dimensão $2 c$ representa o comprimento da trinca medido na superfície. A Figura 2-21 ilustra a configuração de uma trinca semielíptica no pé de um cordão de solda.

Figura 2-21 - Trinca semielíptica no pé de um cordão de solda.

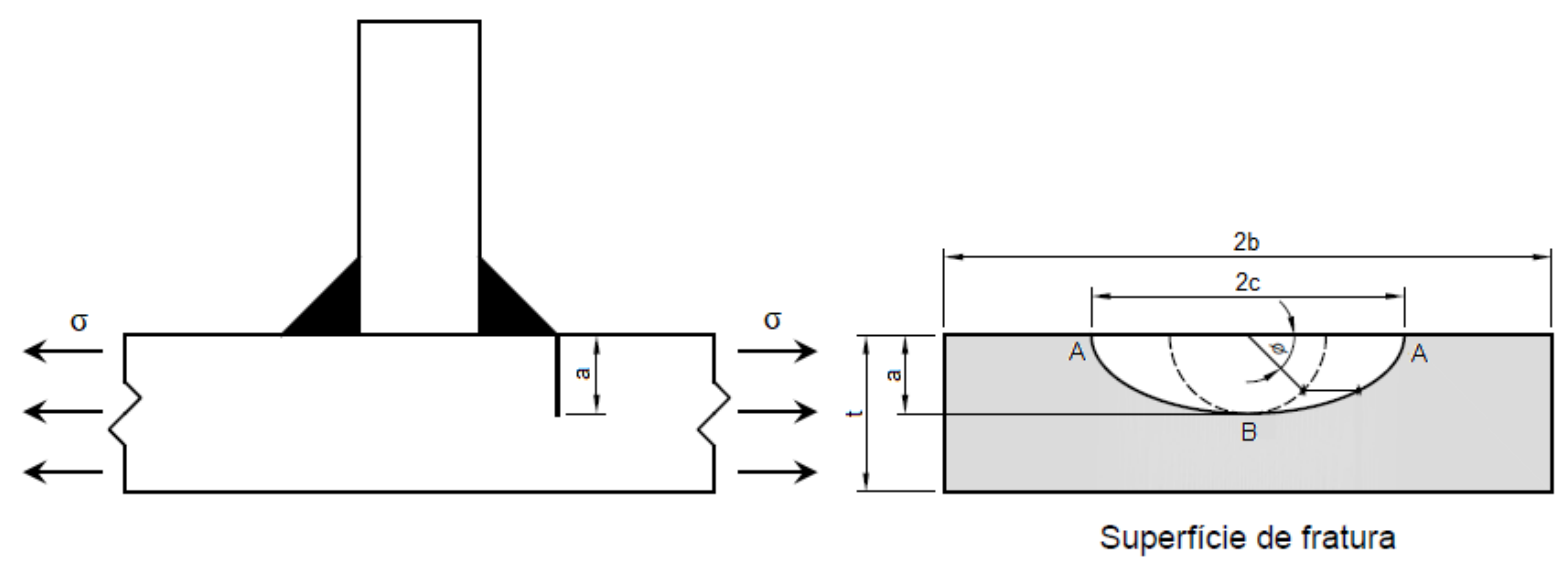

Fonte: Adaptado de Branco et al. [8].

Branco et al. [8] destacam que em uma trinca com a configuração semielíptica, quando a profundidade da trinca ultrapassa a espessura da chapa, a mesma passa a se comportar como uma trinca passante com a frente reta, mas propagando segundo a direção da largura da chapa.

Maddox [35] analisou a propagação de trincas semielípticas em soldas de filete e Newman e Raju [38] avaliaram a propagação de trincas elípticas e semielípticas em diversas posições em chapas finitas maciças e com furos passantes. Em análise das formulações para o fator de intensidade de tensões propostas pelos dois autores, é possível observar que a proporção $a / c$ que define a trinca pode alterar-se durante a propagação, uma vez que a taxa de crescimento da trinca é diferente à superfície e no interior da mesma, havendo uma tendência de que a forma semielíptica se aproxime de uma forma semicircular. 
Müller et al. [39] estudaram a extensão de uma trinca semielíptica em chapas fabricadas em aços austeníticos, em aços ferríticos e em ligas de alumínio sob carregamentos de tração e de flexão. Os resultados experimentais obtidos por tais autores mostraram que trincas sob tração apresentaram maior crescimento na direção da profundidade (ponto B da trinca da Figura 2-21) do que na direção do comprimento (ponto A da trinca da Figura 2-21), enquanto que trincas sob flexão apresentaram comportamento inverso. Superfícies de fratura obtidas por Müller et al. [39] são apresentadas na Figura 2-22.

Figura 2-22 - Superfícies de fratura com marcas de praia para tensão cíclica (à esquerda) e flexão cíclica (à direita). (a) Aço austeníticos; (b) Aço ferríticos; (c) Liga de alumínio.

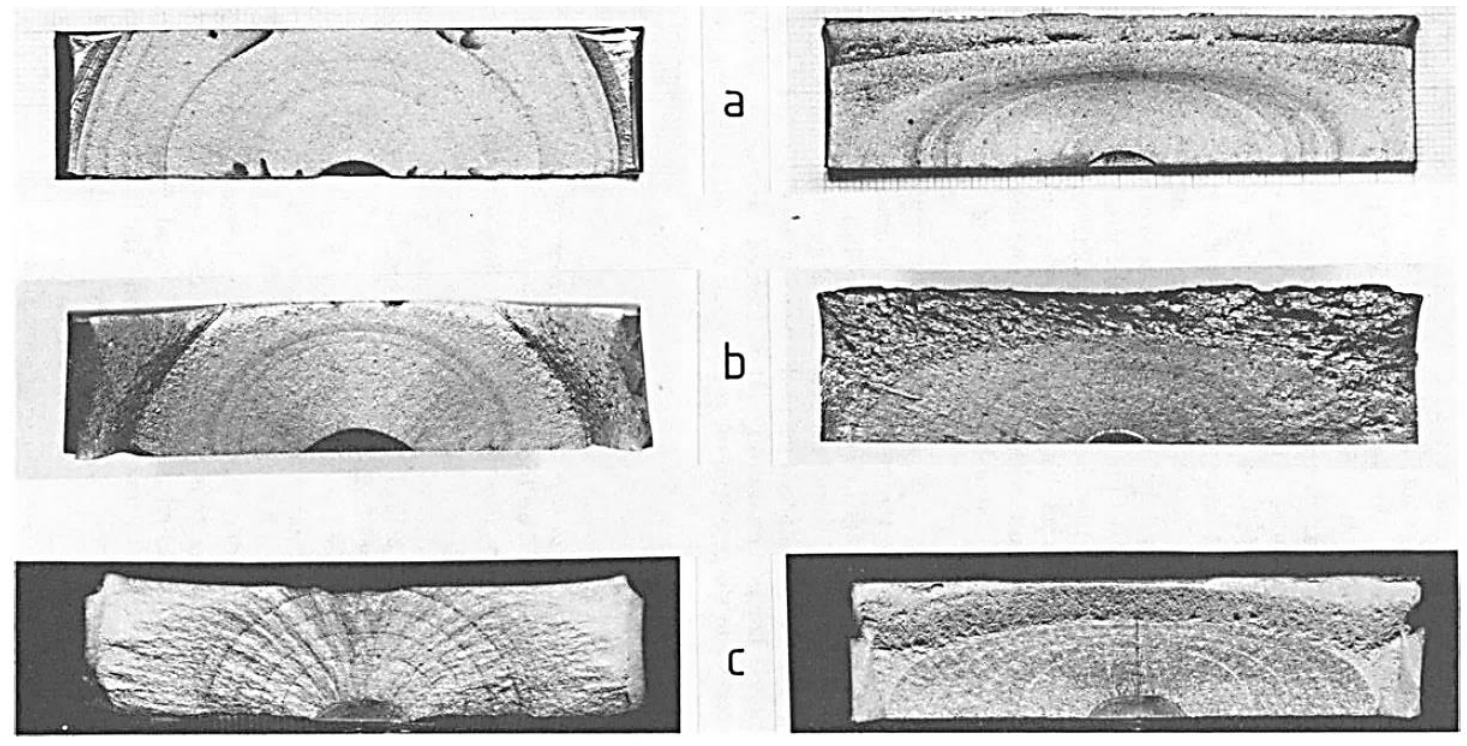

Fonte: Retirado de Müller et al. [39].

Como predição para a mudança de forma de uma trinca semielíptica durante a sua propagação, Müller et al. [39] utilizaram a definição de que embora cada ponto do contorno da semielipse esteja submetido a uma taxa de propagação de trinca distinta, devido à atuação de fatores de intensidade de tensões também distintos, o tempo necessário para a propagação de cada ponto da trinca permanece inalterado.

Aplicando a equação de Paris (Eq. (2.10)) para a propagação da trinca na direção da profundidade ( $d a / d N$ no ponto B da Figura 2-21) e na direção do comprimento ( $d c / d N$ no ponto A da Figura 2-21), a mudança de forma da trinca pode ser expressa pela Eq. (2.25).

$$
\frac{d a}{d c}=\left(\frac{\Delta K_{B}}{\Delta K_{A}}\right)^{m}
$$




\subsubsection{Curvas S-N para juntas soldadas}

De acordo com Dowling [19], a presença de defeitos e de aspectos complexos associados à geometria e à microestrutura em soldas torna difícil determinar fatores de concentração de tensão em estruturas soldadas e correlacionar o comportamento destas estruturas com o de um componente não soldado. Como resultado disso, normas e práticas de engenharia que cobrem estruturas soldadas em seu escopo, tais como o Eurocode EN 1993-1-9 [40], a norma BS 7910 [24], a prática DNVGL-RP-C203 [41] e o International Institute of Welding (IIW) [42], adotam curvas S-N baseadas em ensaios de componentes soldados para a análise de fadiga.

Dentre as referências destacadas acima, as recomendações do IIW [42] e a norma EN 1993-19 [40] são as que fornecem maior abrangência no que se refere ao número de ciclos coberto na análise ( $10^{9}$ ciclos), sendo que as demais referências são limitadas a $10^{8}$ ciclos. Tal abrangência torna-se um ponto favorável principalmente para a análise de componentes rotativos, que consumem um grande número de ciclos em relativamente baixos períodos de operação.

As recomendações do IIW [42] são aplicáveis a aços com limite de escoamento máximo de 960 $\mathrm{MPa}$, sujeitos a uma variação de tensões nominais de no máximo 1,5 vezes o limite de escoamento. Tais tensões consideram efeitos macrogeométricos do componente avaliado, excluindo concentrações de tensão geradas pela geometria da junta soldada. Branco et al. [8] destaca que a resistência à fadiga dependerá basicamente da variação de tensões normais solicitante de cálculo $\Delta \sigma_{S, d}$ e do concentrador de tensões gerado pelo detalhe de solda. Com base nesses dois parâmetros, é possível determinar o número de ciclos conforme a Eq. (2.26):

$$
N=\frac{A}{\Delta \sigma_{S, d}{ }^{B}}
$$

De acordo com o IIW [42], a constante $A$ e o parâmetro $B$ da Eq. (2.26) são obtidos a partir das curvas S-N de aços para uso em conjunto com a metodologia de acúmulo de danos, ilustradas na Figura 2-23. Para cada curva, é associado um valor característico de resistência à fadiga $\Delta \sigma_{R, k}$ ou classe de fadiga $F A T$, que leva em conta diversos aspectos relativos à solda, dentre eles a concentração local de tensões devido à geometria do cordão de solda e a presença de elevadas tensões residuais. Dividindo-se a classe de fadiga FAT por um fator de segurança para o 
material, pode-se obter a variação de tensões admissível em fadiga $\Delta \sigma_{R, d}$ para uma vida $N$ igual a $2 \times 10^{6}$ ciclos, com uma confiabilidade de $95 \%$. Caso a vida em fadiga requerida seja diferente de $2 \times 10^{6}$ ciclos, $\Delta \sigma_{R, d}$ deve ser corrigido com base na curva S-N. Com relação ao parâmetro $B$, o mesmo representa a inclinação da curva de resistência em fadiga em um gráfico com escala $\log -\log$.

Figura 2-23 - Curvas de resistência S-N de aços sob atuação de tensões normais para uso em conjunto com a metodologia de acúmulo de danos.

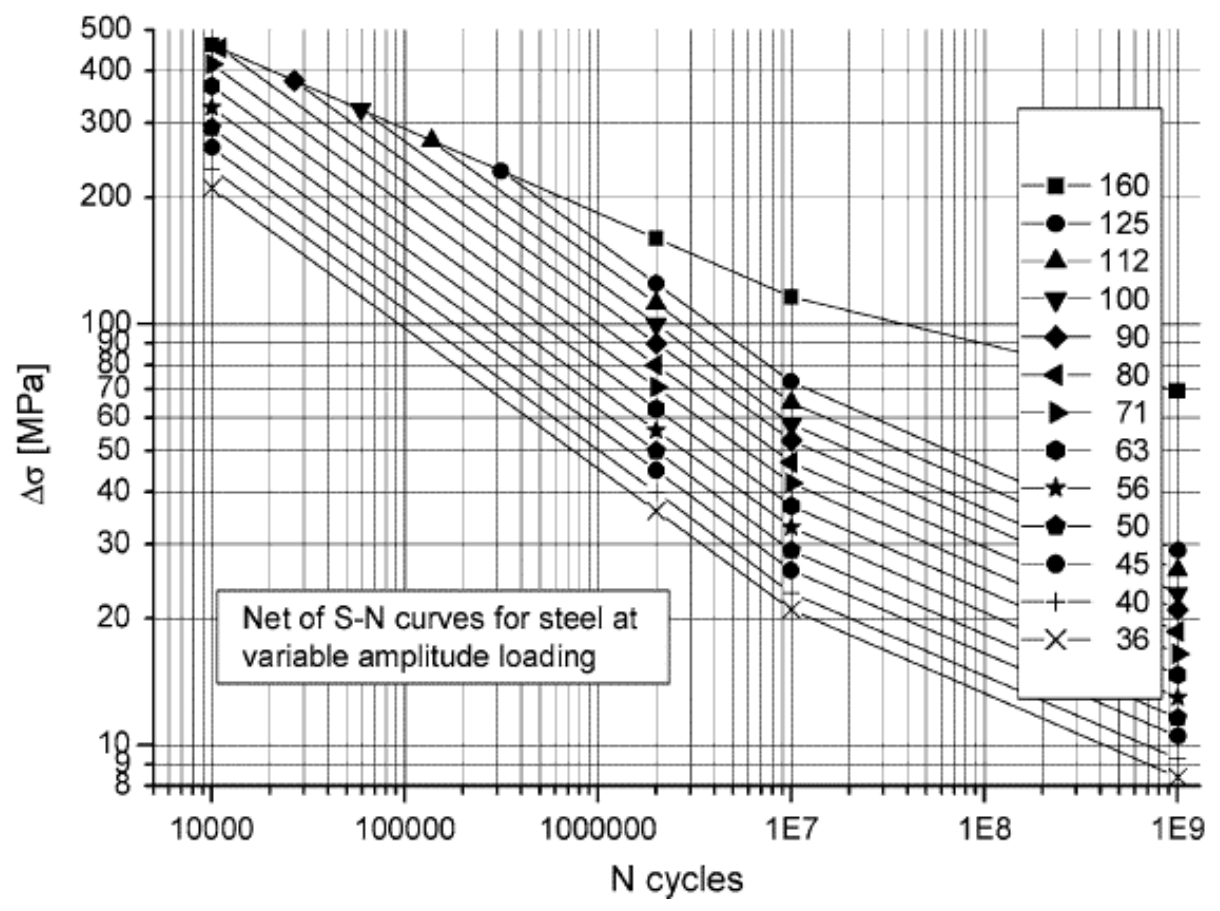

Fonte: Retirado de IIW [42].

O ponto de transição (knee point) das curvas de resistência é dado para uma vida $N$ igual a $10^{7}$ ciclos para tensões normais e igual a $10^{8}$ ciclos para tensões cisalhantes. A partir deste ponto de transição, o IIW [42] considera que a resistência à fadiga permanece decrescendo até uma vida de $10^{9}$ ciclos para aplicações de elevado número de ciclos e descarta a existência do tradicional patamar no qual o limite de resistência à fadiga é constante. Tal consideração é um diferencial em relação à norma EN 1993-1-9 [40], que considera a ocorrência do patamar de resistência à fadiga constante a partir de $10^{8}$ ciclos. Segundo Niemi et al. [43], tem-se discutido a existência deste patamar devido à observância de falhas por fadiga abaixo do nível constante de resistência à fadiga para elevados números de ciclos. 
Conforme o IIW [42], as curvas S-N para os detalhes de solda são referentes a modos específicos de falha, geralmente crescimento de trincas no interior do cordão de solda ou nas regiões do metal de base adjacentes à solda, sendo importante levar em conta na análise todos os possíveis modos de falha para um dado detalhe de solda na direção de atuação do carregamento.

Na Figura 2-24, são exemplificados alguns detalhes de solda, com base na atuação de tensões nominais, presentes nas recomendações do IIW [42].

Figura 2-24 - Detalhes de solda presentes nas recomendações do IIW.

\begin{tabular}{l|l|l}
\hline No. & Structural Detail & $\begin{array}{l}\text { Description } \\
\text { St. = steel; Al. = aluminium })\end{array}$ \\
\hline 412 & $\begin{array}{l}\text { Cruciform joint or T-joint, K-butt welds, full } \\
\text { penetration, potential failure from weld toe } \\
\text { Single sided T-joints }\end{array}$ \\
\hline 413 & $\begin{array}{l}\text { Cruciform joint or T-joint, fillet welds or partial } \\
\text { penetration K-butt welds, potential failure from } \\
\text { weld toe } \\
\text { Single sided T-joints }\end{array}$ \\
\hline
\end{tabular}

Fonte: Retirado de IIW [42].

Para o cálculo da vida em fadiga sob atuação de carregamentos com amplitude variável, Dowling [19] e as recomendações do IIW [42] convergem para a definição de uma variação de tensões normais equivalente solicitante de cálculo $\Delta \sigma_{e q, S, d}$, em substituição à variação de tensões normais $\Delta \sigma_{S, d}$ na Eq. (2.26), para comparação direta com as curvas $\mathrm{S}-\mathrm{N}$ que se baseiam em ciclos de carregamento com amplitude constante. A Equação (2.27) apresenta o cálculo desta variação de tensões equivalente, que representa uma espécie de média ponderada das tensões atuantes, onde o fator multiplicativo (peso) é o número de ciclos associado a um carregamento cíclico.

$$
\Delta \sigma_{e q, S, d}=\sqrt[m]{\frac{\sum_{i}^{j}\left(n_{i} \cdot \Delta \sigma_{i, S, d}^{m}\right)}{\sum_{i}^{j} n_{i}}}
$$


O IIW [42] indica que caso as tensões normais atuantes sofram variação em fase com as tensões de cisalhamento atuantes na estrutura, ou quando a direção da máxima tensão principal não sofre alterações significativas $\left(<20^{\circ}\right)$ durante o ciclo, a variação da máxima tensão principal pode ser usada na verificação de fadiga. Neste caso, é recomendado que a direção da máxima tensão principal esteja em uma faixa de $\pm 60^{\circ}$ em relação à direção perpendicular ao cordão de solda. Também pode ser feita a verificação do efeito combinado de tensões normais e cisalhantes por meio de um índice de utilização $I U$, conforme a Eq. (2.28).

$$
I U=\left(\frac{\Delta \sigma_{e q, S, d}}{\Delta \sigma_{R, d}}\right)^{2}+\left(\frac{\Delta \tau_{e q, S, d}}{\Delta \tau_{R, d}}\right)^{2} \leq 1
$$

De forma análoga às tensões normais, $\Delta \tau_{e q, S, d}$ e $\Delta \tau_{R, d}$ representam, respectivamente, a variação de tensões cisalhantes equivalente solicitante de cálculo e a resistência em fadiga por cisalhamento para uma vida $N$ igual a $2 \times 10^{6}$ ciclos. A variação $\Delta \tau_{e q, S, d}$ pode ser calculada por meio da Eq. (2.27) expressa em termos da variação de tensões cisalhantes $\Delta \tau_{S, d}$.

\subsection{Estado atual de pesquisa}

Arsić et al. [44] investigaram a fratura de juntas soldadas da roda de caçambas da escavadora SRs 1300, observada após apenas 1800 horas de operação. Tais autores apontam como principal causa da fratura a presença de elevadas tensões residuais medidas nas proximidades das juntas soldadas, uma vez que foram obtidos níveis de tensão residual da ordem do limite de escoamento do material (355 MPa). Tais tensões foram atribuídas pelos autores ao uso impróprio da tecnologia da soldagem, através do aquecimento e resfriamento não controlados da estrutura. Nenhuma inconsistência entre as propriedades teóricas do material da estrutura e os ensaios realizados em amostras foi encontrada.

Com relação às máximas tensões atuantes na estrutura, as mesmas são baixas e tem magnitude da ordem de $15 \%$ do limite de escoamento do material. Também foi realizada uma análise de fadiga com base no critério de Goodman, e Arsić et al. [44] apontam que o aumento na tensão média causado pela superposição das tensões residuais sobre as tensões atuantes proporcionou a redução na vida útil da estrutura da roda de caçambas. A localização das trincas na roda de caçambas é apresentada na Figura 2-25. 
Figura 2-25 - Modelo 3D (a) e localização das trincas (b) na roda de caçambas da escavadora SRs 1300.

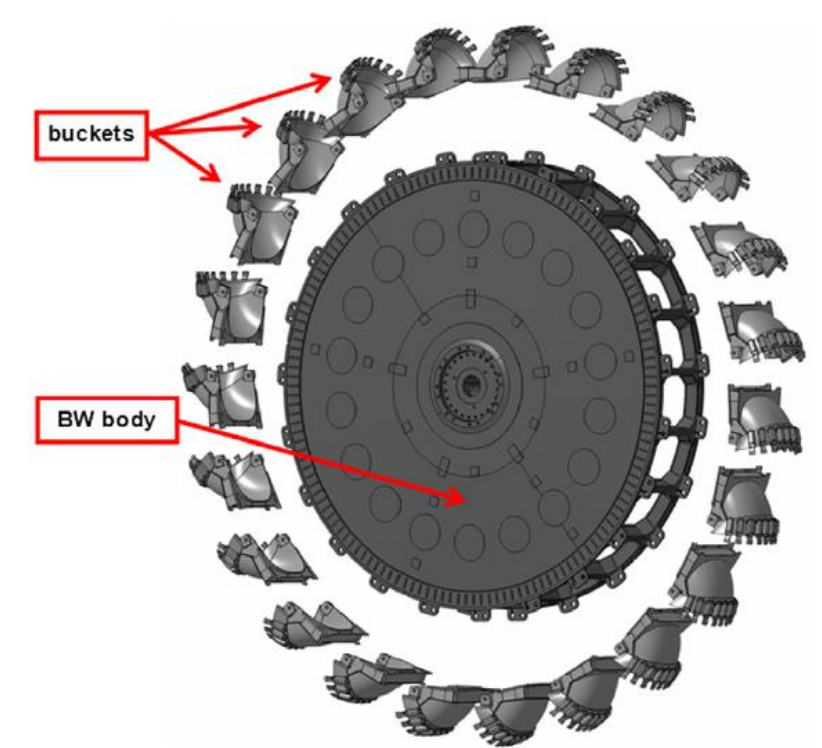

(a)

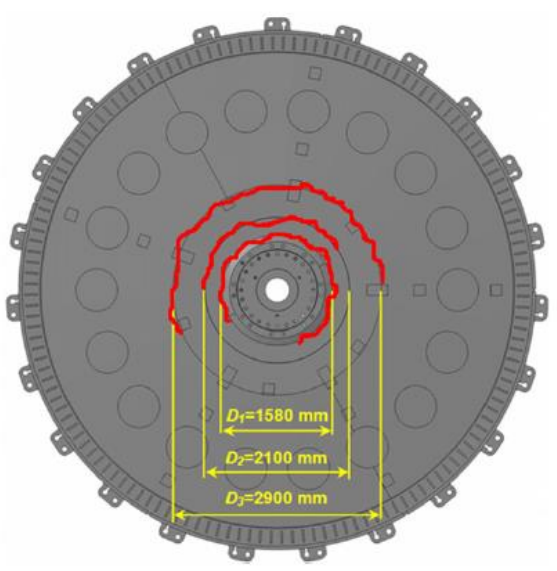

(b)

Fonte: Adaptado de Arsić et al. [44].

Bošnjak et al. [45] estudaram a falha estrutural de caçambas da escavadora de roda de caçambas SRs 470, e concluíram que a adoção de um projeto subdimensionado (design-in defects), associado à utilização de um aço com baixo limite de escoamento e à geometria incorreta das caçambas, foi a causa principal da falha. Além disso, foi observada a ocorrência de tensões residuais e de trincas a frio nas soldas de união da estrutura com os dentes de corte do material (manufacturing-in defects). A combinação entre os aspectos relacionados ao projeto e à fabricação do componente, levaram à nucleação e propagação de trincas por fadiga na estrutura das caçambas.

Rusiński et al. [46] analisaram a fratura da junta soldada entre o eixo de acionamento e a estrutura da roda de caçambas da escavadora KWK 1200 (veja fratura previamente apresentada na Figura 2-7). Uma análise de fadiga foi realizada, sendo observada uma "vida infinita" para o componente considerando-se as cargas previstas no projeto. Entretanto, quando levados em conta os esforços atuantes na roda de caçambas durante sua operação na mina (registrados por meio de medição em tempo real), verificou-se uma redução na vida em fadiga. 
A análise metalográfica da superfície de fratura da junta soldada corroborou com a hipótese de falha por fadiga, sendo encontrados diversos pontos de nucleação de trincas de fadiga, característicos em eixos expostos a esforços combinados de torção e flexão. Inclusões de escória decorrentes de um processo de forjamento inadequado também foram observadas, e podem ter sido o gatilho para a propagação inicial das trincas no eixo.

Bošnjak et al. [47] estimaram a vida remanescente da solda entre o olhal e o tirante de sustentação da lança da escavadora de roda de caçambas SRs 1301, com base na utilização dos conceitos da Mecânica da Fratura Linear Elástica. Ensaios por radiografia e por ultrassom foram realizados, sendo detectado um defeito inicial igual a 2,92 $\mathrm{mm}$. A partir deste defeito e do ciclo operacional da máquina, foi estimada uma vida remanescente de 4,5 anos até o defeito atinja um tamanho crítico em que ocorra propagação instável e a consequente ruptura do tirante.

Cernescu et al. [48] determinaram intervalos periódicos de inspeção na estrutura do tirante de sustentação da lança da escavadora de roda de caçambas ESRC 470, a partir de um estudo de propagação de trinca no furo do olhal do tirante. Para tal estudo, foi realizada a determinação do fator de intensidade de tensões na frente da trinca de forma computacional, sendo empregado o Método dos Elementos de Contorno através da utilização do software Franc $3 \mathrm{D}^{\circledR}$. A partir do comprimento e da geometria iniciais da trinca, foi possível estimar a vida remanescente do olhal do tirante em aproximadamente 12 anos. Um plano de inspeções foi definido até que ocorra a substituição do componente ao final da vida estimada, de forma a garantir a integridade estrutural e a disponibilidade operacional da escavadora.

Daničić et al. [49] investigaram as causas do colapso da escavadora de roda de caçambas SRs 1760 após 17 anos de operação em uma mineração de superfície na Sérvia. A análise demonstrou que trincas por fadiga se iniciaram em pontos de concentração de tensão em uma das soldas do suporte da contralança, levando a máquina ao colapso por instabilidade como ilustrado na Figura 2-26. 
Figura 2-26 - Colapso da escavadora de roda de caçambas SRs 1760.

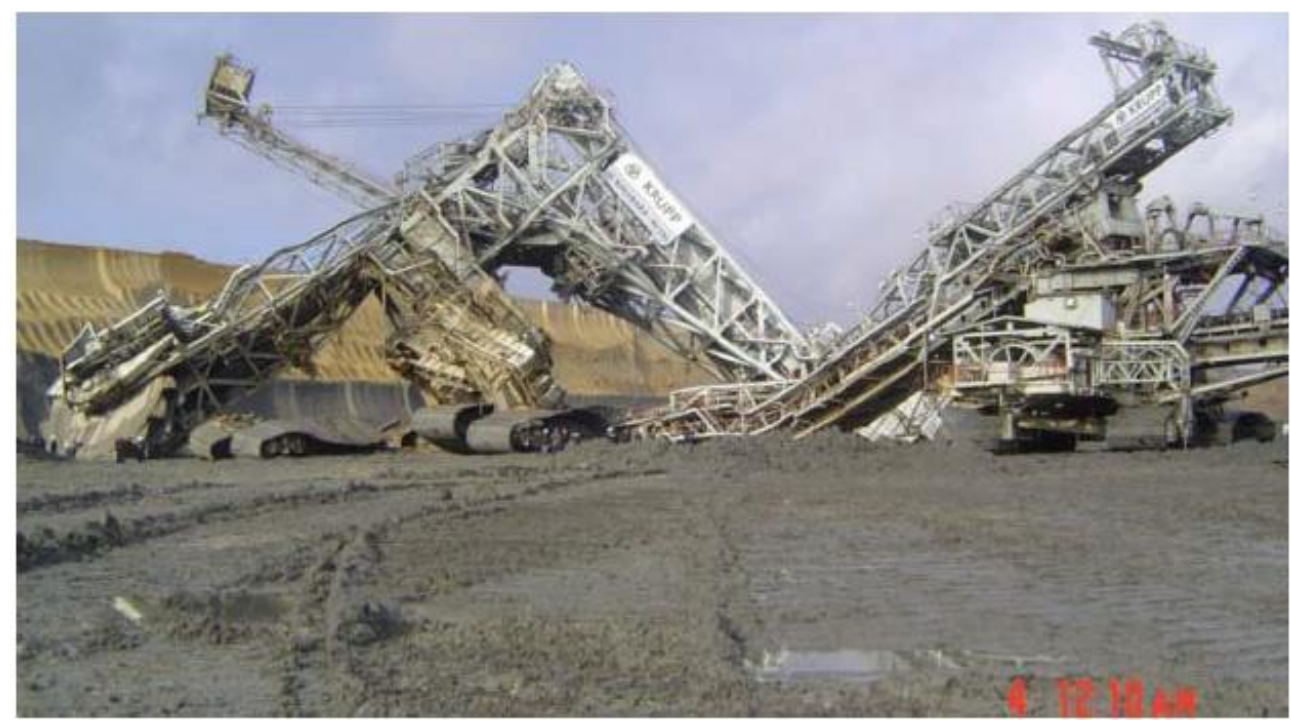

Fonte: Retirado de Daničić et al. [49].

Segundo Daničić et al. [49], o surgimento de tais trincas também podem estar associado à uma microestrutura heterogênea, com regiões de baixa tenacidade à fratura, e à presença de defeitos na região de fratura, tais como a penetração incompleta na raiz da solda. Marcas de catraca, marcas de praia e estriações foram observadas na superfície de fratura, sendo tais características típicas em falhas por fadiga.

\subsection{Métodos computacionais para propagação de trincas}

A aplicação do Método dos Elementos Finitos na determinação do campo de tensões na ponta da trinca tem experimentado um rápido progresso. $\mathrm{O}$ método tem grande versatilidade, pois permite a análise de geometrias complexas (estruturas parafusadas e soldadas), o tratamento de problemas tridimensionais e o uso de elementos para avaliação de plasticidade na frente da trinca. (Broek [50])

Basicamente, duas diferentes abordagens podem ser adotadas para determinação do fator de intensidade de tensões através do método dos elementos finitos. A primeira é um método direto no qual $K$ é obtido a partir do campo de tensões ou deslocamentos na ponta da trinca. A segunda abordagem é um método indireto no qual $K$ é determinado por meio da relação com outros parâmetros tais como flexibilidade, taxa de liberação de energia ou a integral J. (Broek [50]) 
Na modelagem computacional de trincas, Anderson [11] afirma que a configuração da malha em forma de "teia de aranha" representa a forma mais eficiente de se caracterizar a ponta da trinca. Tal configuração consiste na formação de anéis concêntricos de elementos com seção quadrilateral que se dispõem em torno da região da ponta da trinca. Uma vez que esta região contém gradientes acentuados de tensões e de deformações, deve-se utilizar um grande refinamento da malha.

Anderson [11] também ressalta que a configuração em forma de teia de aranha permite uma transição suave de uma malha fina na ponta da trinca para uma malha grosseira em pontos afastados da trinca. Além disso, a configuração resulta em uma série de domínios concêntricos de integração (contornos) para determinação da integral J e de integrais de volume denominadas integrais de interação, sendo estas últimas utilizadas na solução de problemas tridimensionais em softwares comerciais, tais como o Ansys ${ }^{\circledR}$.

Na Figura 2-27, é apresentado um modelo numérico tridimensional de uma trinca semielíptica em uma chapa plana. A face da trinca é destacada em cinza e podem ser vistos os contornos em torno da frente da trinca, utilizados no processo de integração para determinação do fator de intensidade de tensões de forma indireta.

Figura 2-27 - Modelo tridimensional de uma trinca semielíptica em uma chapa plana.

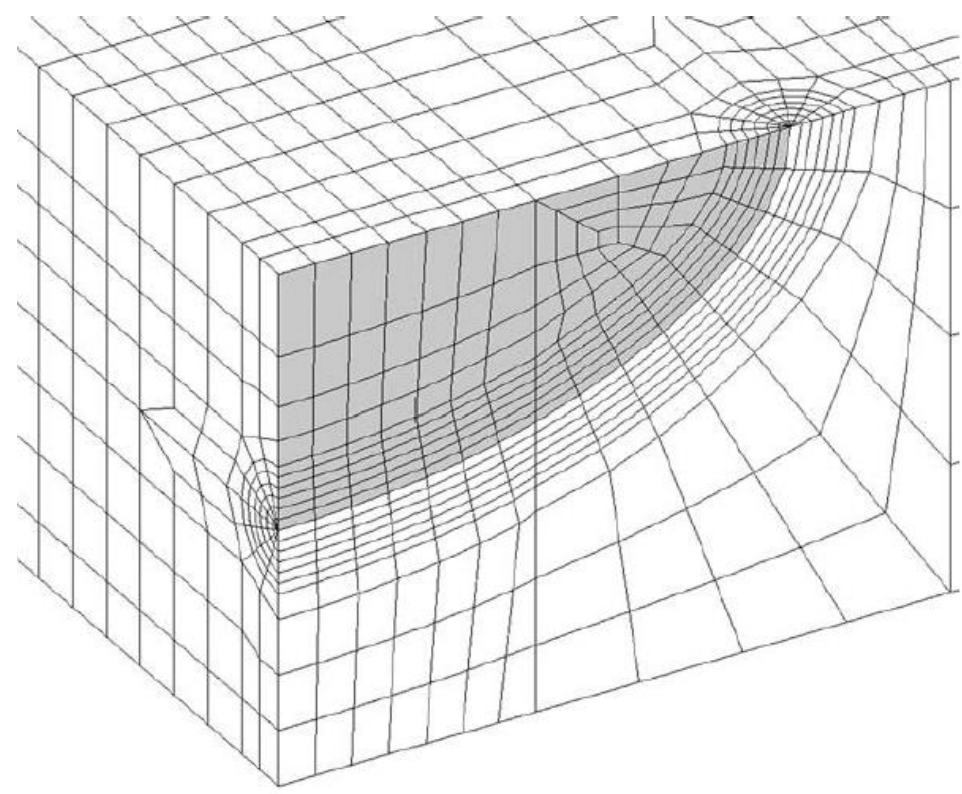

Fonte: Retirado de Anderson [11]. 
Avaliar a proporção da zona plástica na ponta da trinca em relação à região de validade do fator de intensidade de tensões é de suma importância para se estabelecer a confiabilidade dos resultados obtidos numericamente. Kuna [15] afirma que do ponto de vista macroscópico, deformações plásticas muito pequenas surgem em um material sob fadiga e o crescimento de trincas nestas condições ocorre em um domínio controlado pelo fator de intensidade de tensões, de forma que a Mecânica da Fratura Linear Elástica é aplicável. Na Figura 2-28, é ilustrada a relação desejável entre a zona plástica e a região de validade da MFLE.

Figura 2-28 - Zona plástica e a região de validade da Mecânica da Fratura Linear Elástica.

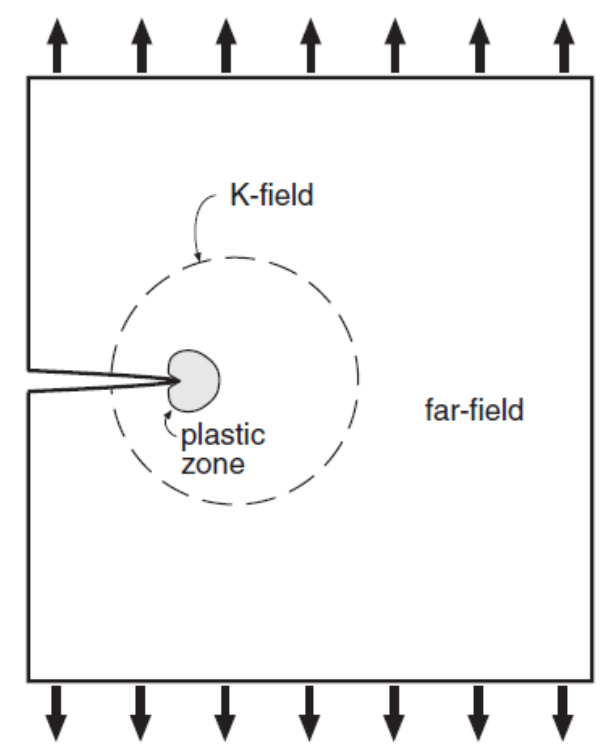

Fonte: Retirado de Dowling [19].

Considerando-se um estado plano de tensões, a equação abaixo apresenta o cálculo do tamanho da zona plástica, conforme Dowling [19]. Esta zona plástica representa a distância a frente da trinca onde a distribuição de tensões excede o critério de escoamento.

$$
r_{p}=\frac{1}{2 \pi}\left(\frac{K}{\sigma_{y}}\right)^{2}
$$

Dowling [19] reitera que para que a teoria da MFLE seja aplicável, é necessário que a zona plástica seja pequena se comparada com a distância a partir da ponta da trinca até qualquer borda livre do componente. Uma região definida por um raio $r_{k}$ igual a 8 vezes o tamanho da zona plástica $r_{p}$ é considerada suficiente para se estimar a região de domínio do fator de intensidade de tensões. 
Kuna [15] apresenta algumas recomendações com relação à modelagem computacional de trincas para a obtenção de resultados válidos. Segundo o autor, os menores elementos finitos na extremidade da trinca devem ter um tamanho consideravelmente inferior ao raio $r_{k}$ do domínio de validade do fator de intensidade de tensões, sendo que o tamanho deste raio pode ser aproximado entre 1/50 e 1/10 do tamanho da trinca.

Com relação à interpretação dos resultados obtidos na análise por elementos finitos, a Figura 2-29 identifica três domínios definidos em relação à distância a partir da ponta da trinca. Segundo Kuna [15], os elementos muito próximos à ponta da trinca podem somente representar a singularidade de forma imprecisa, sendo que o valor de $K$ obtido computacionalmente é inferior à solução exata de $K$. Na região média do gráfico, a qualidade da solução por elementos finitos é suficiente. Fora da região de domínio de $K\left(r>r_{k}\right)$, os resultados perdem sua justificativa.

Figura 2-29 - Zona de validade dos resultados obtidos na modelagem da trinca por elementos finitos.

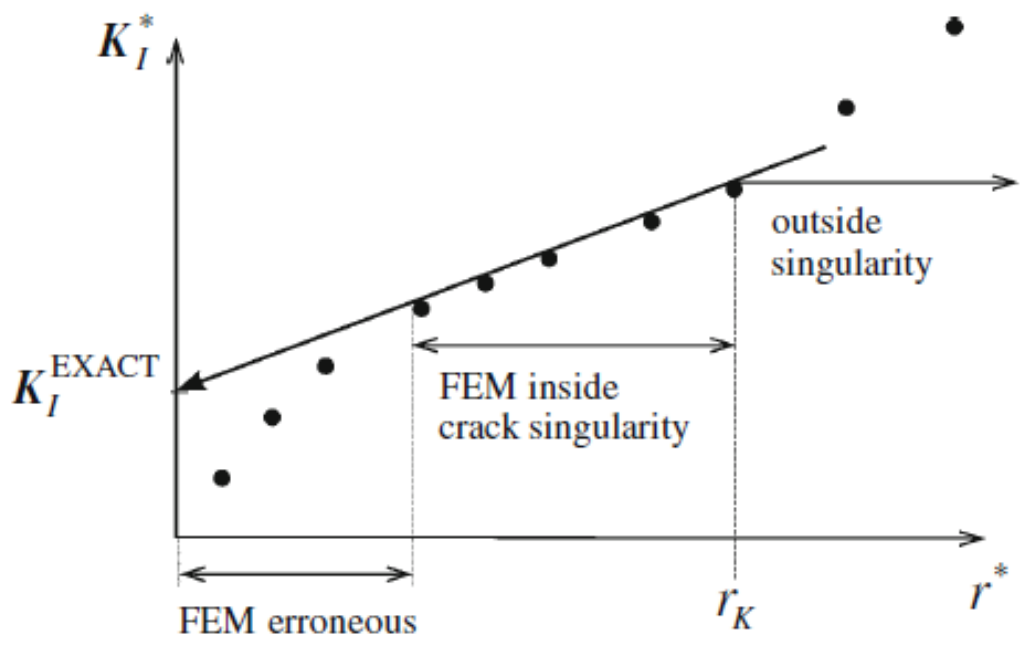

Fonte: Retirado de Kuna [15]. 


\subsection{METODOLOGIA}

Este item descreve a metodologia empregada, assim como todas as considerações adotadas, para a realização do estudo da propagação de trinca na estrutura da roda de caçambas que apresentou falha prematura em campo. A análise a ser realizada consistirá em duas etapas: a primeira corresponde à análise da estrutura com base na Mecânica da Fratura Linear Elástica, enquanto a segunda etapa considera as recomendações indicados pelo International Institute of Welding (IIW) [42].

Na análise baseada na Mecânica da Fratura Linear Elástica, será avaliado o comprimento da trinca para que a mesma apresente propagação instável e o número de ciclos necessários para que este fato ocorra, conforme o fluxograma de análise apresentado na Figura 3-1.

Figura 3-1 - Fluxograma de análise com base na Mecânica da Fratura.

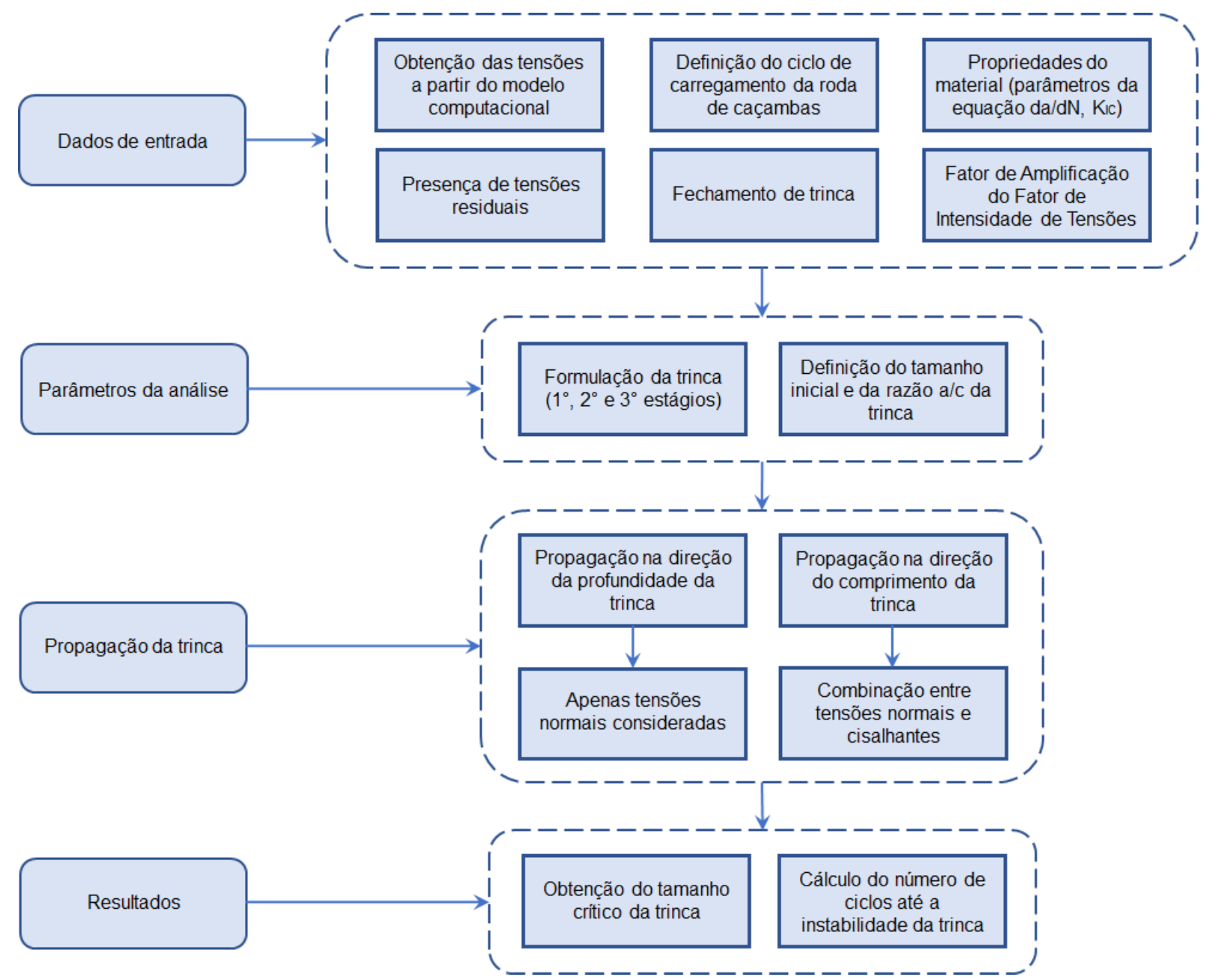

Fonte: Próprio autor. 
$\mathrm{Na}$ análise baseada nas recomendações do IIW [42], serão utilizadas curvas S-N relativas ao detalhe de solda em que se enquadra a junta, onde ocorreu a fratura na roda de caçambas. Assim, a vida em fadiga da estrutura será determinada conforme o fluxograma ilustrado na Figura 3-2.

Figura 3-2 - Fluxograma de análise com base nas recomendações do IIW.

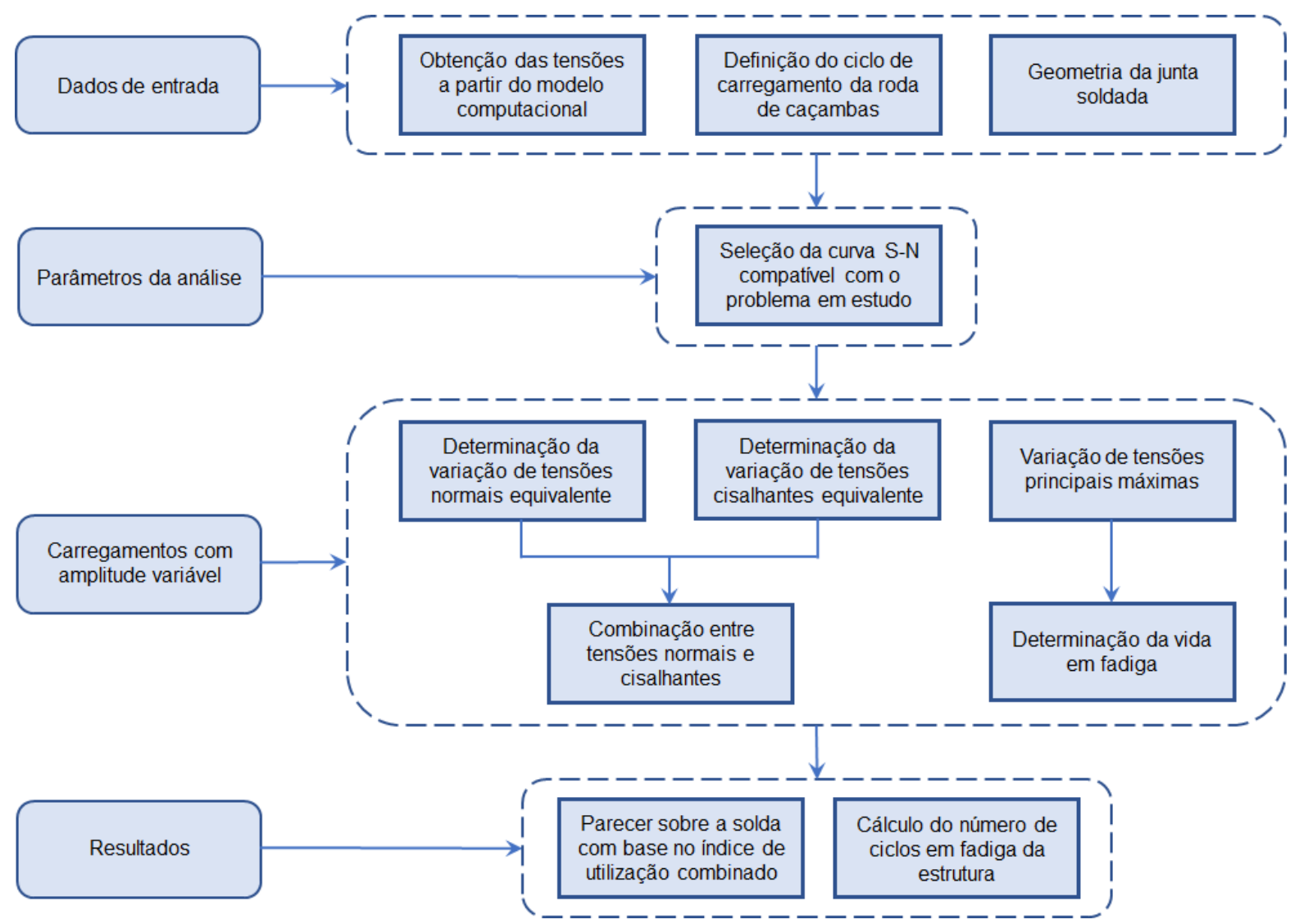

Fonte: Próprio autor.

\subsection{Vida em fadiga com base na Mecânica da Fratura Linear Elástica}

A propagação se dará em três estágios, sendo composta inicialmente por uma trinca semielíptica caracterizada por uma profundidade $a$ e um meio comprimento $c$ ( $1^{\circ}$ estágio). Quando a profundidade da trinca ultrapassa a espessura $t$ da chapa da estrutura principal (18 $\mathrm{mm}$ ), a trinca terá uma forma semielíptica através da espessura ( $2^{\circ}$ estágio). Esta última será considerada como completamente passante pela espessura se a diferença entre os comprimentos da trinca de ambos os lados da chapa for inferior a $1 \%$ do maior comprimento ( $3^{\circ}$ estágio). 
Não será considerada a mudança de forma da trinca semielíptica do $1^{\circ}$ estágio durante a propagação, ou seja, a proporção $a / c$ será considerada constante. Os estágios de propagação da trinca são apresentados na Figura 3-3.

Figura 3-3 - Estágios de propagação da trinca.

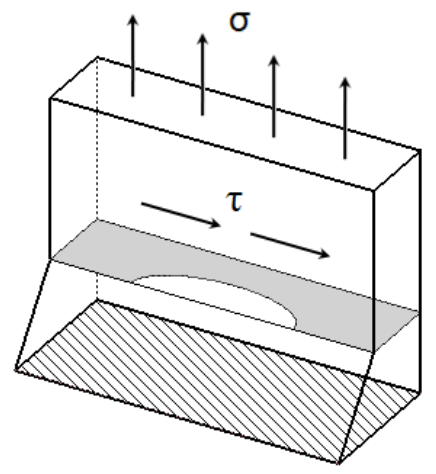

a) Trinca semielíptica $\left(1^{\circ}\right.$ Estágio $)$

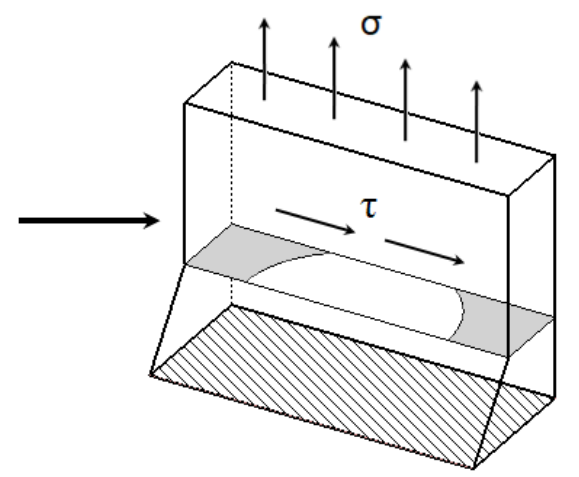

b) Trinca semielíptica através da espessura ( $2^{\circ}$ Estágio)

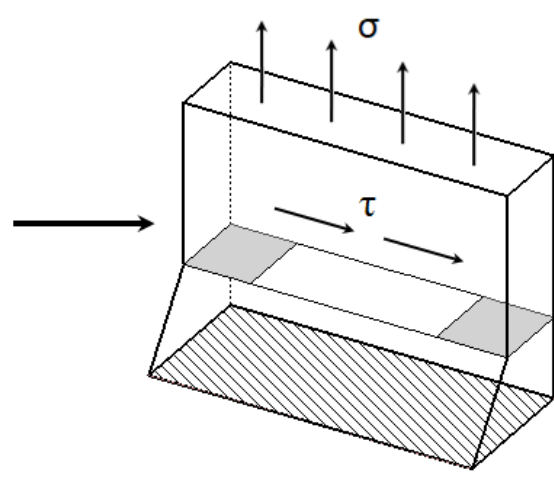

c) Trinca passante pela espessura ( $3^{\circ}$ Estágio)

Fonte: Próprio autor.

As formulações para o fator de intensidade de tensões em cada estágio de propagação da trinca foram obtidas numericamente através de simulações computacionais no software Ansys ${ }^{\circledR}$. Para trincas semielípticas sob tração e trincas passantes pela espessura sob tração e cisalhamento, existem formulações na literatura para a determinação de $K$ (vide ANEXO B), sendo realizada nestes casos a avaliação da validade destas formulações na geometria da junta soldada em estudo. Para trincas semielípticas sob cisalhamento, a formulação foi obtida numericamente.

O crescimento da trinca semielíptica será avaliado tendo como direção principal de propagação tanto a profundidade, onde apenas tensões normais são relevantes para a progressão da trinca, quanto o comprimento da trinca, em que a combinação entre tensões normais e cisalhantes é relevante para a propagação da trinca. Tal combinação se dará por meio da determinação do fator de intensidade de tensões equivalente $K_{e q}$ apresentado na Eq. (2.6), em função da formação de um modo misto entre os modos I e II, conforme a metodologia proposta por Richard et al. [20].

O efeito de concentração de tensões gerado pela descontinuidade geométrica causada pelo cordão de solda será levado em conta. Isto se dará através do fator de amplificação $M_{k}$, aplicável somente à trinca semielíptica do $1^{\circ}$ estágio, cuja formulação foi obtida em Bowness e Lee [37] para uma junta soldada com geometria similar à do problema em questão. Tal formulação é apresentada em detalhes no ANEXO C. 
A presença de tensões residuais na região de localização da trinca será considerada por meio da alteração na razão de tensões $R$, em função da superposição das tensões residuais sobre as tensões resultantes das cargas aplicadas. A razão de tensões alterada $R_{\text {res }}$ pode ser calculada através da aplicação da Eq. (2.23). Na ausência de informações sobre o valor das tensões residuais na junta soldada em estudo, serão adotados vários valores para estas tensões, computados como uma proporção do limite de escoamento do metal de base, e avaliada a influência das tensões residuais sobre a propagação da trinca.

O fenômeno de fechamento de trinca será incluso no estudo de propagação, em função da ocorrência de tensões compressivas no ciclo de carregamento. A variação de um fator de intensidade de tensões efetivo $\Delta K_{\text {ef }}$ será adotada, que representa uma proporção $U$ da variação do fator de intensidade de tensões equivalente $\Delta K_{e q}$. Combinando a Eq. (2.17) e a Eq. (2.23), a influência da razão de tensões alterada pela presença de tensões residuais sobre o fator $U$ pode ser calculada através da Eq. (3.1):

$$
U=\left\{\begin{array}{cc}
\frac{1}{1,5-R_{\text {res }}} ; & -5 \leq R_{\text {res }} \leq+0,5 \\
1 ; & R_{\text {res }}>0,5
\end{array}\right.
$$

A taxa de crescimento da trinca na direção da profundidade $d a / d N$ e na direção do comprimento $d c / d N$ será calculada através da equação de Paris modificada para consideração do efeito da razão de tensões (equação de Walker). Para inclusão dos efeitos dos fatores de amplificação $M_{k, a}$ e $M_{k, c}$, do fenômeno de fechamento de trinca e da presença de tensões residuais, a Eq. (2.12) será modificada conforme apresentado pela equação abaixo:

$$
\frac{d a}{d N}=C_{1}\left[\frac{M_{k, a} \Delta K_{e f}}{\left(1-R_{r e s}\right)^{1-\gamma}}\right]^{m_{1}} ; \frac{d c}{d N}=C_{1}\left[\frac{M_{k, c} \Delta K_{e f}}{\left(1-R_{r e s}\right)^{1-\gamma}}\right]^{m_{1}}
$$

A Regra de Palmgren-Miner (Eq. (2.18)) será adotada para a consideração do acúmulo de danos na estrutura da roda de caçambas sob a atuação de carregamentos com amplitude variável. Tais carregamentos se devem ao giro da lança da recuperadora, que pode ocorrer tanto no sentido horário quanto no sentido anti-horário. Isto será feito através da determinação de uma taxa média de crescimento da trinca $d \bar{a} / d N$ e $d \bar{c} / d N$ utilizando-se a Eq. (2.21). 
A vida em fadiga $N$ será obtida por meio de integração numérica utilizando o método proposto por Dowling [19] e apresentado no item 2.4.3. Tal método consiste na integração do inverso de $d \bar{a} / d N$ e de $d \bar{c} / d N$, partindo de um tamanho de trinca inicial até um tamanho final. A Equação (3.3) expressa o cálculo da vida em fadiga.

$$
N=\int_{a_{i}}^{a_{f}}\left(\frac{d \bar{a}}{d N}\right)^{-1} d a ; \quad N=\int_{c_{i}}^{c_{f}}\left(\frac{d \bar{c}}{d N}\right)^{-1} d c
$$

O tamanho final da trinca será obtido quando a tenacidade à fratura $K_{I C}$ do material é atingida. Para o aço de fabricação da roda de caçambas, será adotado o valor de $126 \mathrm{MPa} \sqrt{\mathrm{m}}$ para $K_{I C}$.

\subsection{Vida em fadiga com base em curvas $\mathrm{S}-\mathrm{N}$}

A metodologia consiste na aplicação das recomendações do IIW [42] à roda de caçambas em estudo. Será selecionado um detalhe de solda compatível geometricamente e em relação aos esforços atuantes (normais ou cisalhantes) dentre os detalhes de solda disponíveis.

Para o detalhe de solda selecionado, o IIW atribui uma curva S-N associada a uma classe de solda FAT para uma vida $N$ igual a $2 \times 10^{6}$ ciclos. Como este trabalho trata da análise de uma falha já ocorrida em campo, será admitido um valor unitário para o fator de segurança do material, o que leva a obtenção de uma variação de tensões normais admissível $\Delta \sigma_{R, d}$ e de uma variação de tensões cisalhantes admissível $\Delta \tau_{R, d}$ igual aos seus respectivos $F A T$ s.

Em função da atuação de carregamentos com amplitude variável, será calculada a variação de tensões normais equivalente $\Delta \sigma_{e q, S, d}$ e a variação de tensões cisalhantes $\Delta \tau_{e q, S, d}$ equivalente com base na Eq. (2.27). Realizado este cálculo, duas verificações podem ser feitas para a junta soldada em estudo.

A primeira verificação consistirá na avaliação do efeito combinado de tensões normais e cisalhantes conforme apresentado pela Eq. (2.28). Trata-se da obtenção de um índice de utilização da junta soldada, que deve ser comparado a um limite admissível unitário. Índices de 
utilização abaixo da unidade indicam a aprovação, enquanto que valores acima do limite admissível demonstram a reprovação da junta soldada na análise de fadiga.

A segunda verificação visa a determinar a vida em fadiga com base na Eq. (2.26). Conforme indicação do IIW [42], será verificado se a direção da tensão principal máxima sofre alterações inferiores a $20^{\circ}$ durante o ciclo de carregamento e se esta direção está em uma faixa de $\pm 60^{\circ}$ em relação à direção perpendicular ao cordão de solda. Caso ambos requisitos sejam atendidos, a variação da máxima tensão principal será usada na verificação de fadiga. Em caso contrário, a vida em fadiga será avaliada separadamente para tensões normais e para tensões cisalhantes.

\subsection{Modelagem computacional}

Na Figura 3-4, pode ser visualizado o arranjo geral da roda de caçambas. A partir dos desenhos de projeto, foram elaborados modelos em elementos finitos para a estrutura da roda de caçambas e para o estudo de propagação da trinca na junta soldada.

Figura 3-4 - Arranjo geral da roda de caçambas.
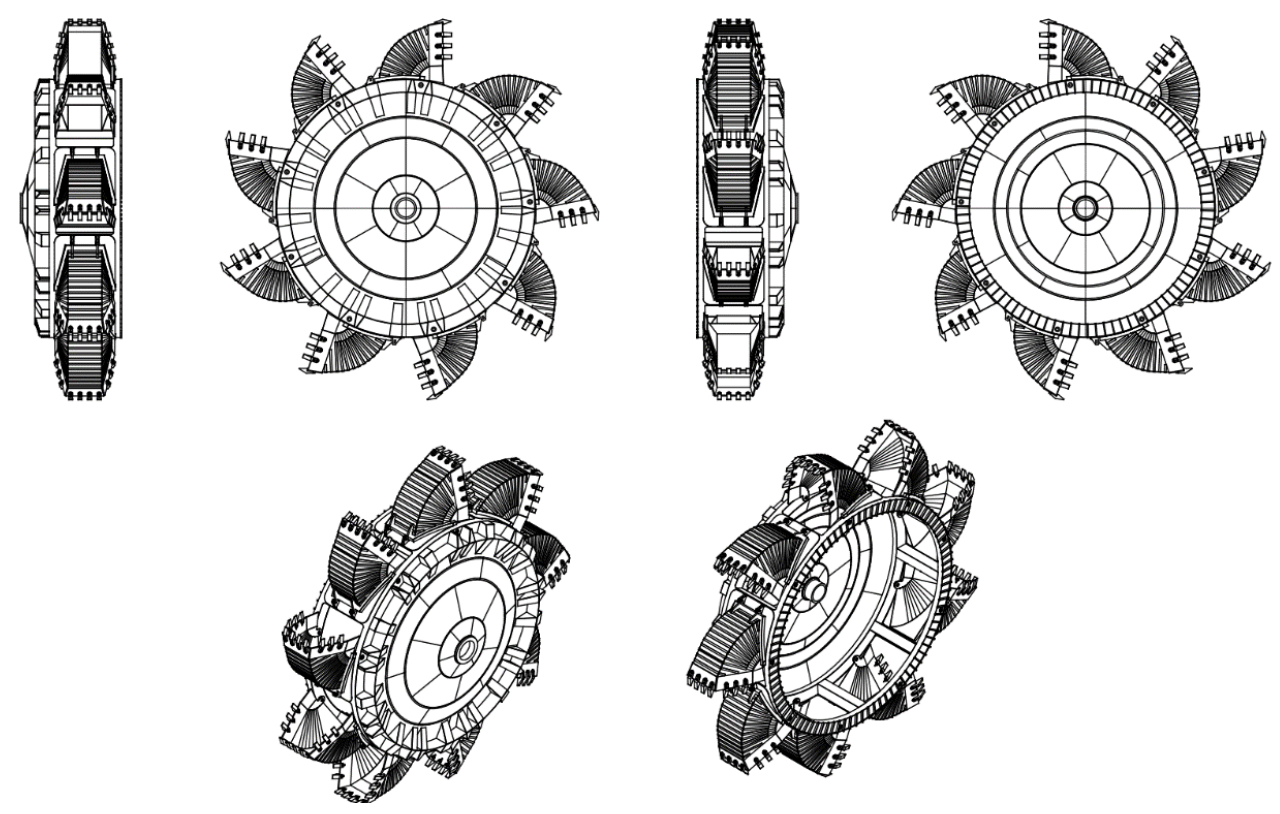

Fonte: Próprio autor. 


\subsection{1 $\quad$ Roda de caçambas}

Para a obtenção das tensões atuantes na estrutura da roda de caçambas, foi criado um modelo computacional em elementos finitos. Tal modelo foi elaborado utilizando o software Femap ${ }^{\circledR}$ v.11.0.1 em conjunto com o solver NX Nastran v.8.5.1, a partir dos desenhos de detalhamento da estrutura.

No modelo computacional, foram utilizados elementos sólidos tetraédricos (CTETRA) para a modelagem do cubo do eixo de acionamento, elementos de massa pontual (CONM2) para a representação da massa das caçambas conectadas à estrutura da roda e elementos rígidos interpolados (RBE3) que permitem a aplicação das cargas atuantes durante o processo de escavação do material. A estrutura principal da roda de caçambas, onde serão obtidas as tensões para a determinação da vida em fadiga, foi modelada utilizando elementos bidimensionais de segunda ordem (CQUAD8). A seguir, são fornecidos maiores detalhes a respeito deste tipo de elemento.

O tipo CQUAD8 é um elemento finito bidimensional com formato quadrilateral composto por 8 nós. Segundo a biblioteca de elementos do solver NX Nastran [51], CQUAD8 é um elemento de segunda ordem que inclui nós no centro das arestas (mid-side nodes), além dos nós existentes nos vértices do elemento (corner nodes). A Figura 3-5 ilustra o elemento CQUAD8 e as tensões calculadas para tal elemento.

Figura 3-5 - Elemento bidimensional CQUAD8.

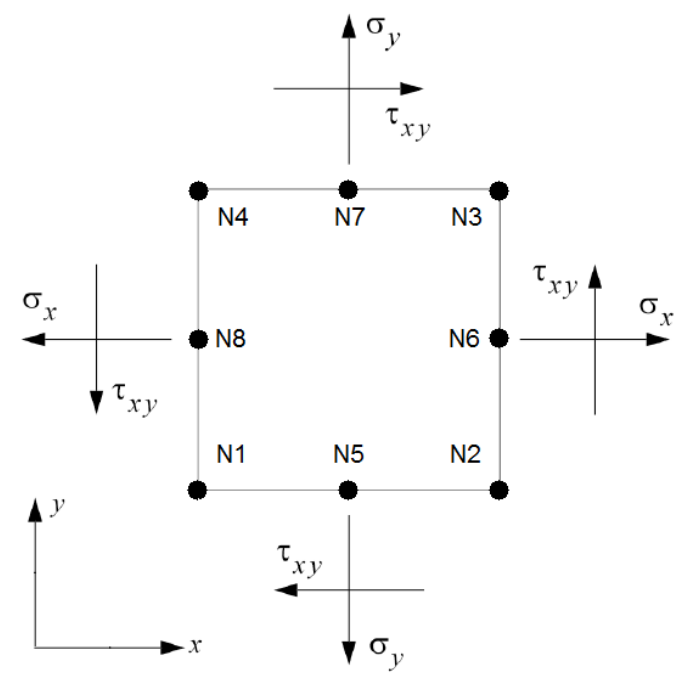

Fonte: Adaptado de NX Nastran [51]. 


\subsubsection{Junta soldada}

Modelos em elementos finitos foram elaborados no software Ansys ${ }^{\circledR}$ R19.1 para a obtenção do fator de intensidade de tensões na frente da trinca de forma computacional. Geometrias retangulares foram utilizadas para um comparativo com as soluções teóricas de $K$, além de permitir a calibração da malha a ser adotada no modelo da geometria da roda. Este segundo modelo, tem por objetivo avaliar a validade das formulações de $K$ apresentadas na literatura na geometria da junta soldada em estudo, uma vez que tais formulações foram obtidas em geometrias específicas e afastadas de qualquer concentrador de tensões geométrico.

No modelo computacional da junta soldada contendo a trinca, foi utilizado o elemento finito tridimensional SOLID 186. Conforme a documentação do Ansys ${ }^{\circledR}$ [52], SOLID 186 é elemento de segunda ordem definido por 20 nós, contendo três graus de liberdade de translação por nó. A Figura 3-6 ilustra tal elemento finito.

Figura 3-6: Elemento tridimensional SOLID 186.
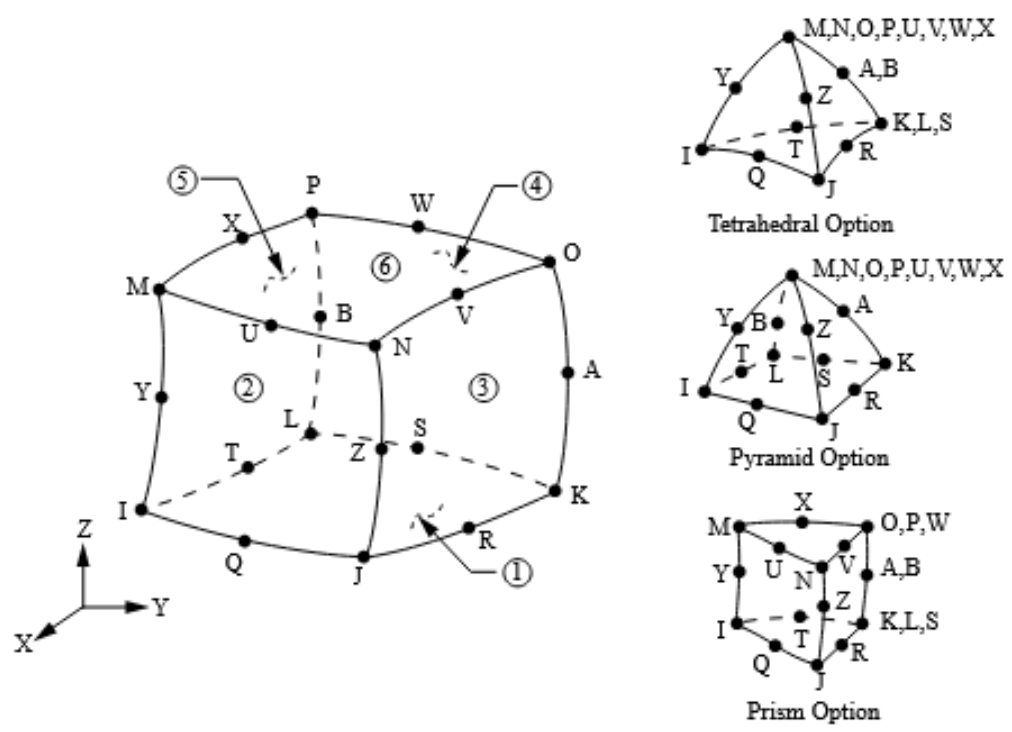

Fonte: Retirado de Ansys [52].

A rotina de cálculo CINT do software Ansys ${ }^{\circledR}$ foi utilizada para o cálculo do fator de intensidade tensões. Parâmetros relacionados à trinca serão definidos, tais como o raio da região de domínio de $K$, o número de elementos ao longo da frente da trinca, o número de divisões circunferenciais e o número de contornos da teia de aranha ao redor da trinca. 


\subsection{Carregamentos atuantes}

Devido ao modo de operação da recuperadora, atuam na roda de caçambas forças de escavação, denominadas comumente como forças de corte nas direções tangencial e lateral à roda de caçambas, e forças de elevação do material escavado. Para o cálculo da força de corte tangencial e da força de elevação, foi empregada a metodologia proposta por Rasper [53], enquanto que a força de corte lateral foi assumida como $30 \%$ da força de corte tangencial, conforme indicação da norma ISO 5049-1 [54]. A Figura 3-7 mostra a representação esquemática dos esforços atuantes na roda de caçambas.

Figura 3-7 - Representação das forças atuantes na roda de caçambas durante o processo de recuperação do material.

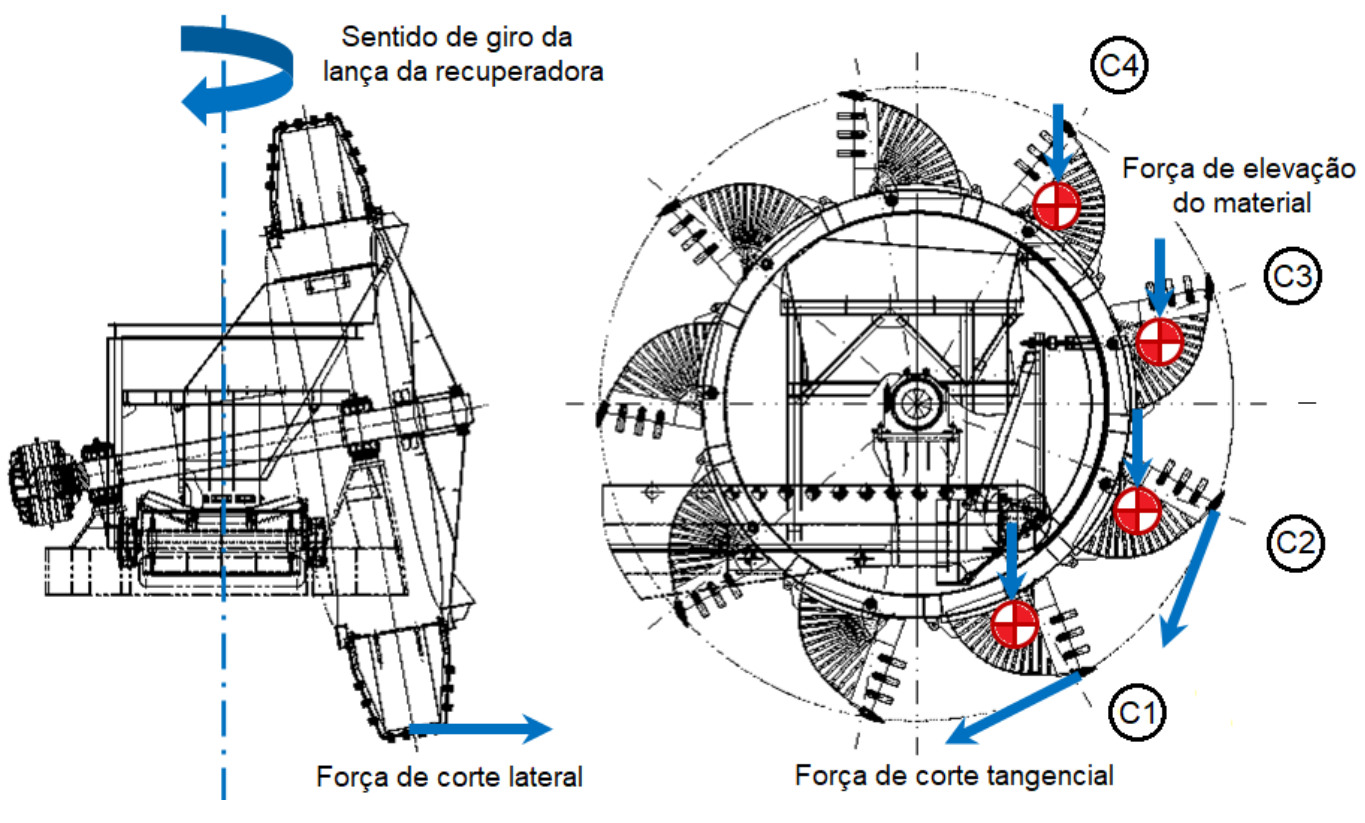

Fonte: Adaptado de Kotchergenko Engenharia [3].

A determinação dos esforços atuantes durante a operação da roda de caçambas foi feita considerando-se a condição de operação normal do equipamento (foram desconsideradas eventuais sobrecargas operacionais). A Tabela 3-1 apresenta os esforços considerados na análise. 
Tabela 3-1 - Esforços atuantes considerados na análise.

\begin{tabular}{c|c|c|c}
\hline $\mathrm{N}^{\circ}$ da caçamba & $\begin{array}{c}\text { Força de corte } \\
\text { tangencial [N] }\end{array}$ & $\begin{array}{c}\text { Força de corte } \\
\text { lateral [N] }\end{array}$ & $\begin{array}{c}\text { Força de } \\
\text { elevação [N] }\end{array}$ \\
\hline 1 & 40064 & 12019 & 6652 \\
\hline 2 & 40064 & 12019 & 16630 \\
\hline 3 & \multicolumn{2}{|c|}{ Não aplicável } & 21620 \\
\hline 4 & \multicolumn{2}{|c|}{ Não aplicável } & 21620 \\
\hline
\end{tabular}

Fonte: Próprio autor.

Além dos carregamentos apresentados na Tabela 3-1, considerou-se a atuação das cargas de peso próprio da estrutura da roda $(166,8 \mathrm{kN})$ e das caçambas $(185,4 \mathrm{kN})$, totalizando um peso próprio de $352,2 \mathrm{kN}$.

No ANEXO A, é apresentada com maior detalhamento a metodologia empregada para a determinação dos esforços indicados na Tabela 3-1, além da memória de cálculo indicando todas as formulações utilizadas nos cálculos. 


\subsection{RESULTADOS OBTIDOS}

Este item descreve os resultados obtidos nas análises realizadas para a roda de caçambas. Primeiramente, a fratura ocorrida em campo é apresentada, sendo dados maiores detalhes a respeito da localização e do tempo necessário para a propagação da trinca. São descritas as propriedades do material de fabricação da roda e indicadas as tensões obtidas no modelo computacional da estrutura. Por fim, os resultados da análise com base nos conceitos da Mecânica da Fratura Linear Elástica e a partir das recomendações do IIW [42] são apresentados.

\subsection{Fratura na roda de caçambas}

A roda de caçambas em estudo neste trabalho apresentou uma trinca prematura em campo após aproximadamente um ano de operação. Esta roda é parte integrante de uma recuperadora de roda de caçambas que manuseia minério de ferro com uma densidade de 2,3 t/m a uma capacidade de projeto de $11620 \mathrm{t} / \mathrm{h}$. A roda de caçambas possui uma rotação de $5 \mathrm{rpm}$, o que corresponde à ocorrência de 5 ciclos de carregamento por minuto. Além disso, a lança da recuperadora é capaz de rotacionar tanto para o sentido horário quanto para o anti-horário. A Figura 4-1 ilustra a fratura observada na estrutura da roda de caçambas.

Figura 4-1 - Fratura observada na estrutura da roda de caçambas.
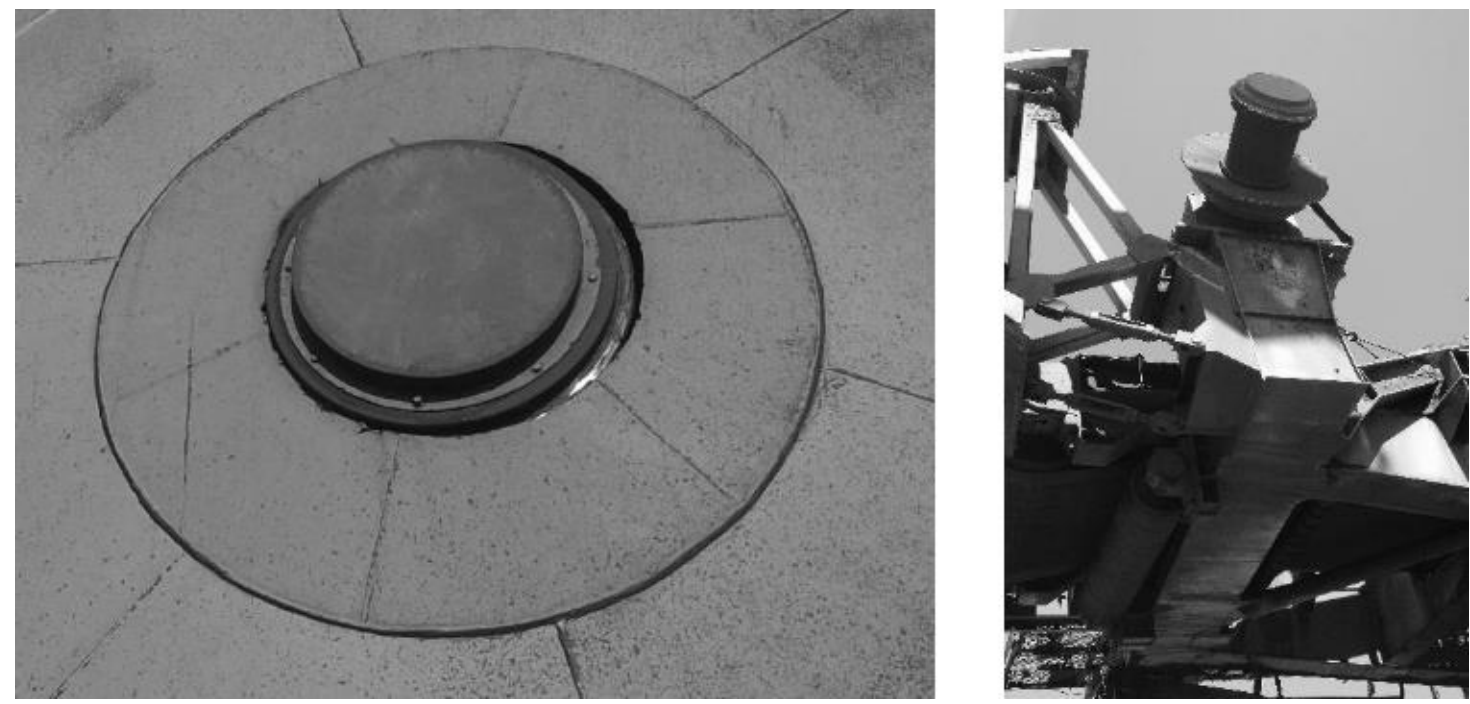

Fonte: Acervo pessoal. 
A trinca está localizada no topo do cordão de solda que une o cubo do eixo de acionamento e a estrutura principal da roda, e proporcionou a separação completa entre os dois componentes, como pode ser visto na Figura 4-1. A trinca final observada em campo possui comprimento de aproximadamente $2600 \mathrm{~mm}$, valor igual ao perímetro do cordão de solda empregado. Na Figura 4-2, pode ser vista a localização da trinca.

Figura 4-2 - Localização da trinca na estrutura da roda de caçambas.

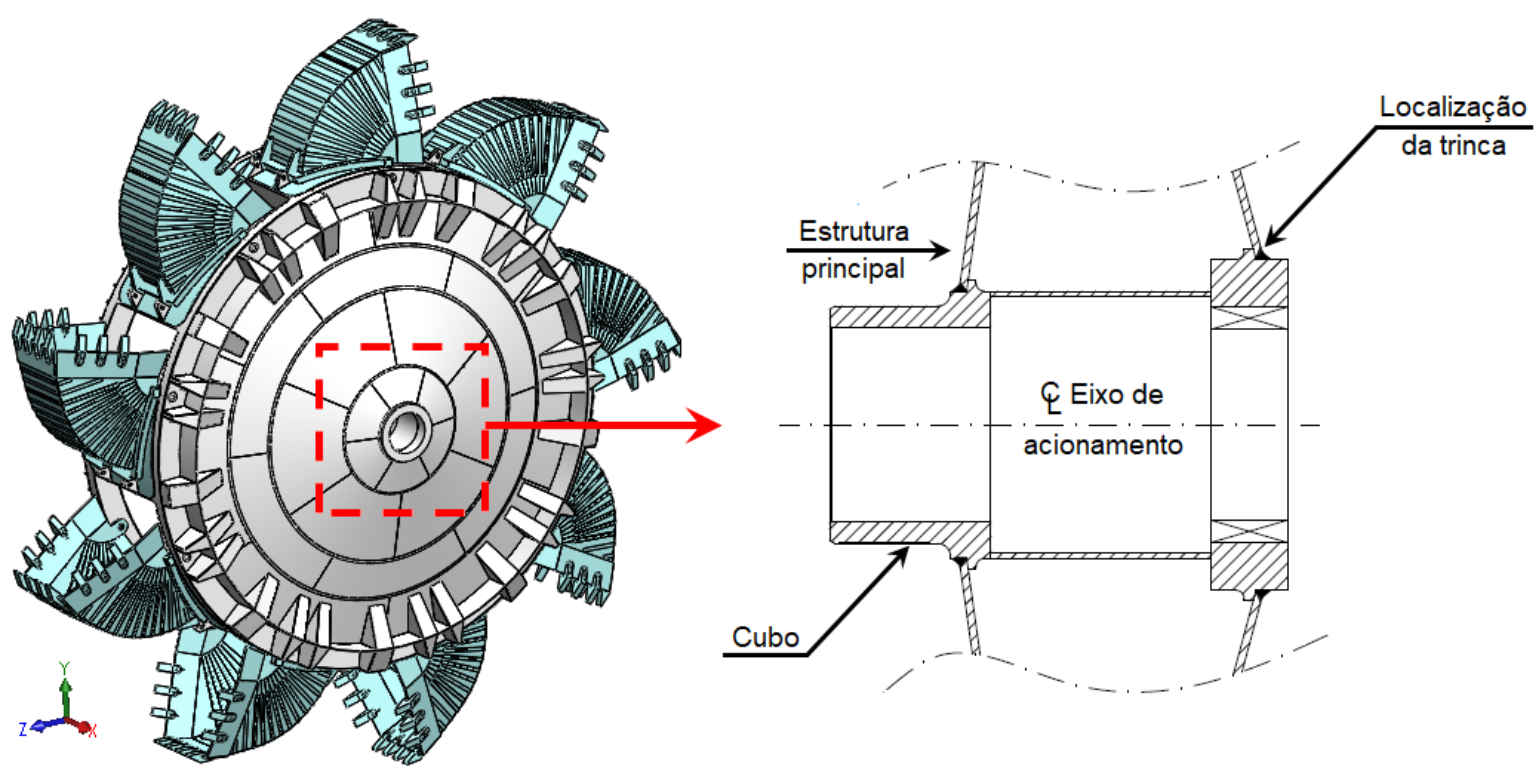

Fonte: Próprio autor.

Não foi possível obter o histórico operacional do equipamento antes da ocorrência de falha. Desta forma, uma disponibilidade operacional de $90 \%$ será atribuída à recuperadora, o que implica na estimativa de 2,37 × $10^{6}$ ciclos até a falha da estrutura em aproximadamente um ano de operação. Metade desta ciclagem estará associada ao giro da lança no sentido horário e os $50 \%$ restantes associados ao giro da lança no sentido anti-horário.

\subsection{Propriedades do material da estrutura}

O material de fabricação da estrutura principal da roda de caçambas é o aço de especificação chinesa Q345B. Destaca-se que não foi possível obter amostras do material utilizado na roda para a realização de ensaios, e, portanto, serão utilizados dados obtidos na literatura para o aço. Com relação à solda entre a estrutura principal e o cubo do eixo de acionamento, foi utilizada a combinação fluxo-eletrodo F4A2-H10Mn2, própria para soldagem por arco submerso (SAW). 
De acordo com a norma GB/T 1591 [55], o aço Q345B possui limite de escoamento mínimo igual a $335 \mathrm{MPa}$ e limite de resistência mínimo igual a $470 \mathrm{MPa}$ para uma chapa com $18 \mathrm{~mm}$ de espessura (espessura da chapa onde houve propagação da trinca). A composição química e as propriedades mecânicas do aço Q345B, conforme norma GB/T 1591 [55], são apresentadas na Tabela 4-1.

Tabela 4-1 - Composição química e propriedades mecânicas do aço Q345B.

\begin{tabular}{c|c|c|c|c|c|c|c}
\hline \multicolumn{3}{c|}{ Composição química [\% em peso] } & $\begin{array}{c}\text { Limite de } \\
\text { escoamento, } \\
\sigma_{\mathrm{y}}[\mathrm{MPa}]\end{array}$ & $\begin{array}{c}\text { Limite de } \\
\text { resistência, } \\
\sigma_{\mathrm{u}}[\mathrm{MPa}]\end{array}$ & $\begin{array}{c}\text { Alongamento, } \\
\delta[\%]\end{array}$ \\
\cline { 1 - 4 } $\mathrm{C}$ & $\mathrm{Mn}$ & $\mathrm{Si}$ & $\mathrm{S}$ & $\mathrm{P}$ & $\geq 335$ & $470-630$ & $\geq 20$ \\
\hline$\leq 0,20$ & $\leq 0,50$ & $\leq 1,70$ & $\leq 0,035$ & $\leq 0,035$ & $\geq 35$ & $\geq$ \\
\hline
\end{tabular}

Fonte: Retirado de GB/T 1591 [55].

A composição química e as propriedades mecânicas da combinação fluxo-eletrodo F4A2H10Mn2, conforme norma GB/T 5293 [56], são apresentadas na Tabela 4-2. Tal eletrodo possui composição química similar ao AWS EH 14.

Tabela 4-2 - Composição química do eletrodo utilizado na soldagem da roda de caçambas.

\begin{tabular}{c|c|c|c|c|c|c|c}
\hline \multicolumn{4}{c|}{ Composição química [\% em peso] } & \multirow{2}{*}{$\begin{array}{c}\text { Limite de } \\
\text { escoamento, } \\
\sigma_{\mathrm{y}}[\mathrm{MPa}]\end{array}$} & $\begin{array}{c}\text { Limite de } \\
\text { resistência, } \\
\sigma_{\mathrm{u}}[\mathrm{MPa}]\end{array}$ & $\begin{array}{c}\text { Alongamento, } \\
\delta[\%]\end{array}$ \\
\hline $\mathrm{C}$ & $\mathrm{Mn}$ & $\mathrm{Si}$ & $\mathrm{S}$ & $\mathrm{P}$ & $\geq 330$ & $415-550$ & $\geq 22$ \\
\hline
\end{tabular}

Fonte: Retirado de GB/T 5293 [56].

Devido à impossibilidade de realização de ensaios com corpos de prova do aço da estrutura da roda de caçambas, procurou-se obter na literatura as propriedades do aço Q345B necessárias para a realização deste estudo. Xiong e Hu [57] estudaram a propagação de trincas no aço Q345B em diversos corpos de prova soldados com o eletrodo H10Mn2, sendo obtida a taxa de crescimento $d a / d N$ tanto para o metal de base quanto para a solda. Cabe ressaltar que a composição química e as propriedades dos materiais ensaiados são compatíveis com os requisitos normativos apresentados na Tabela 4-1 e na Tabela 4-2.

A partir dos dados experimentais, foi possível extrair as coordenadas dos pontos medidos por meio do software WebPlotDigitizer ${ }^{\circledR}$ [58]. Na Figura 4-3, é apresentada a taxa de crescimento de trinca em pontos dos corpos de prova utilizados por Xiong e Hu [57], considerando-se uma razão de tensões $R$ igual a $+0,5$. 
Figura 4-3 - Dados experimentais de taxa de crescimento de trinca no aço Q345B.

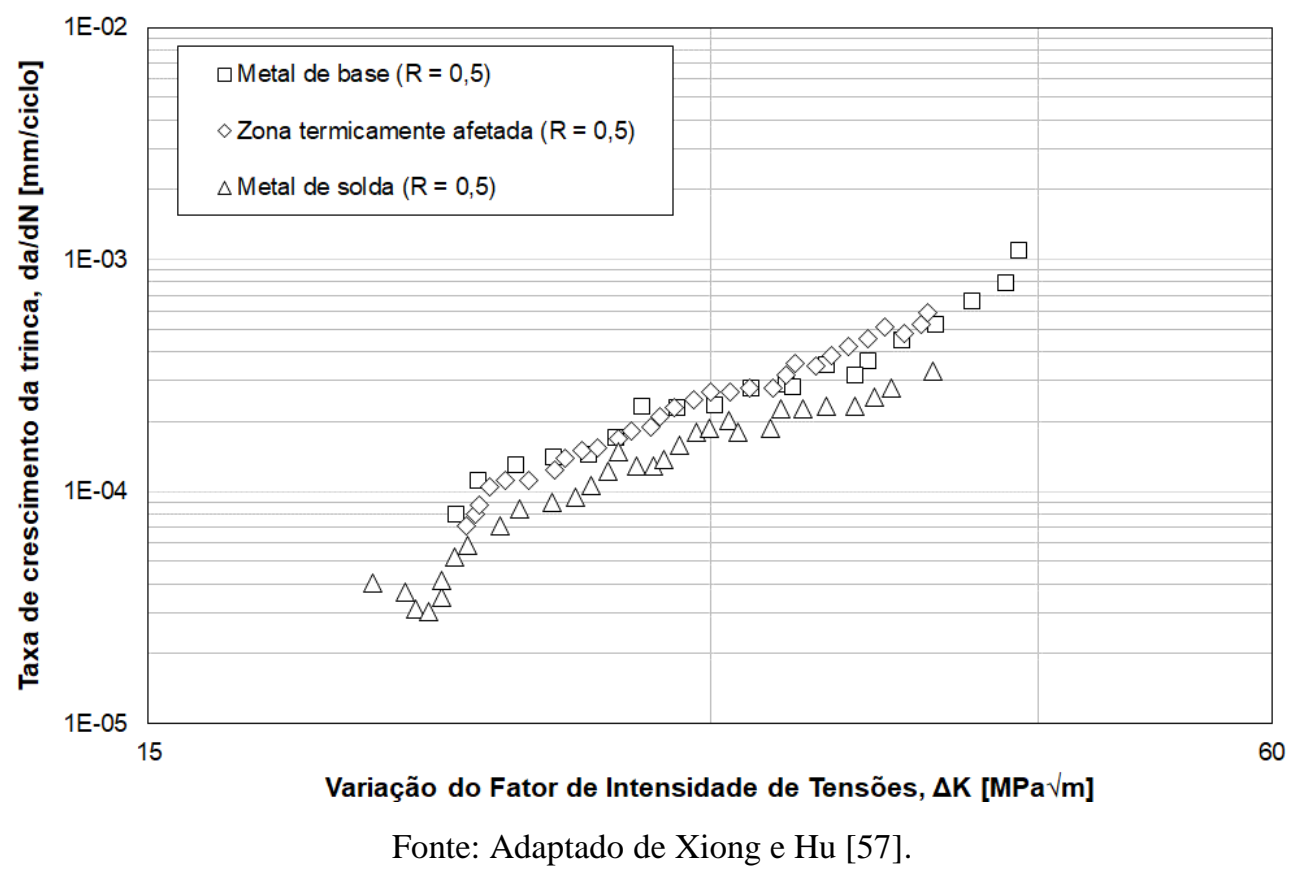

Regressões foram realizadas utilizando-se os dados experimentais obtidos por Xiong e Hu [57], permitindo estimar as constantes $C$ e $m$ da equação de Paris (Eq. (2.10)) para uma razão de tensões $R$ igual a $+0,5$. Com base nestes parâmetros, as constantes $C_{l}$ e $m_{l}$ foram calculadas por meio da Eq. (2.13) considerando-se a constante $\gamma$ igual a 0,5, conforme recomendado por Dowling [19] para $R>0$. Os resultados estão apresentados na Tabela 4-3. Destaca-se que os valores das constantes $C$ e $m$ para o metal de base do aço Q345B apresentam ordem de grandeza similar aos valores apresentados por Stephens et al. [59] para o aço ASTM A572 (aço com propriedades mecânicas similares ao Q345B).

Tabela 4-3 - Estimativa das constantes das equações de Paris e de Walker.

\begin{tabular}{c|c|c|c|c}
\hline $\begin{array}{c}\text { Ponto ensaiado no } \\
\text { corpo de prova (Xiong e Hu) }\end{array}$ & $\mathrm{C}\left[\frac{\mathrm{mm} / \mathrm{ciclo}}{(\mathrm{MPa} \sqrt{\mathrm{m}})^{\mathrm{m}}}\right]$ & $\mathrm{C}_{1}\left[\frac{\mathrm{mm} / \mathrm{ciclo}}{(\mathrm{MPa} \sqrt{\mathrm{m}})^{\mathrm{m}_{1}}}\right]$ & $\mathrm{m} / \mathrm{m}_{1}$ & $\gamma$ \\
\hline Metal de base & $7,92 \mathrm{E}-09$ & $2,77 \mathrm{E}-09$ & 3,03 & \multirow{2}{*}{0,5} \\
\hline Zona termicamente afetada & $2,98 \mathrm{E}-09$ & $9,43 \mathrm{E}-10$ & 3,32 \\
\hline Metal de solda & $1,09 \mathrm{E}-09$ & $3,25 \mathrm{E}-10$ & 3,49 & \\
\hline
\end{tabular}

Fonte: Adaptado de Xiong e $\mathrm{Hu}$ [57].

Na análise do presente trabalho, serão considerados os dados apresentados na Tabela 4-3 para a zona termicamente afetada devido à proximidade da trinca com o cordão de solda entre o cubo e a estrutura principal da roda de caçambas. Desta forma, $C_{1}$ é igual a 9,43 x $10^{-10}$ $(\mathrm{mm} /$ ciclo $) /(\mathrm{MPa} \sqrt{\mathrm{m}})^{\mathrm{m}_{1}}$ e $\mathrm{m}_{1}$ é igual a 3,32 
A tenacidade à fratura $K_{I C}$ considerada para o aço Q345B possui valor médio igual a $126 \mathrm{MPa} \sqrt{ } \mathrm{m}$, conforme recomendado por Wang et al. [60] a partir de uma coletânea de dados de ensaios de tenacidade à fratura do aço Q345B realizados por pesquisadores chineses. Tal valor foi obtido considerando-se uma temperatura ambiente de $+20^{\circ} \mathrm{C}$.

Wang et al. [61] determinaram o deslocamento de abertura da ponta de trincas (CTOD) em chapas do aço Q345B soldadas com um eletrodo similar ao utilizado na roda de caçambas, e não foram observadas diferenças significativas para a tenacidade à fratura no metal de base, na zona termicamente afetada e no metal de solda em relação aos dados de CTOD também apresentados por Wang et al. [60].

\subsection{Tensões obtidas no modelo computacional}

A Figura 4-4 ilustra o modelo computacional criado no software Femap ${ }^{\circledR}$ para a estrutura da roda de caçambas. Foram utilizados quatro diferentes tipos de elementos finitos, conforme detalhado no item 3.3.1. Em relação às condições de contorno, restrições de deslocamento em $\mathrm{X}, \mathrm{Y}$ e $\mathrm{Z}$ foram aplicadas no contato entre o cubo e o eixo de acionamento da roda. $\mathrm{O}$ modelo computacional conta com um total de 222236 elementos e 298992 nós.

Figura 4-4 - Modelo computacional da estrutura da roda de caçambas.
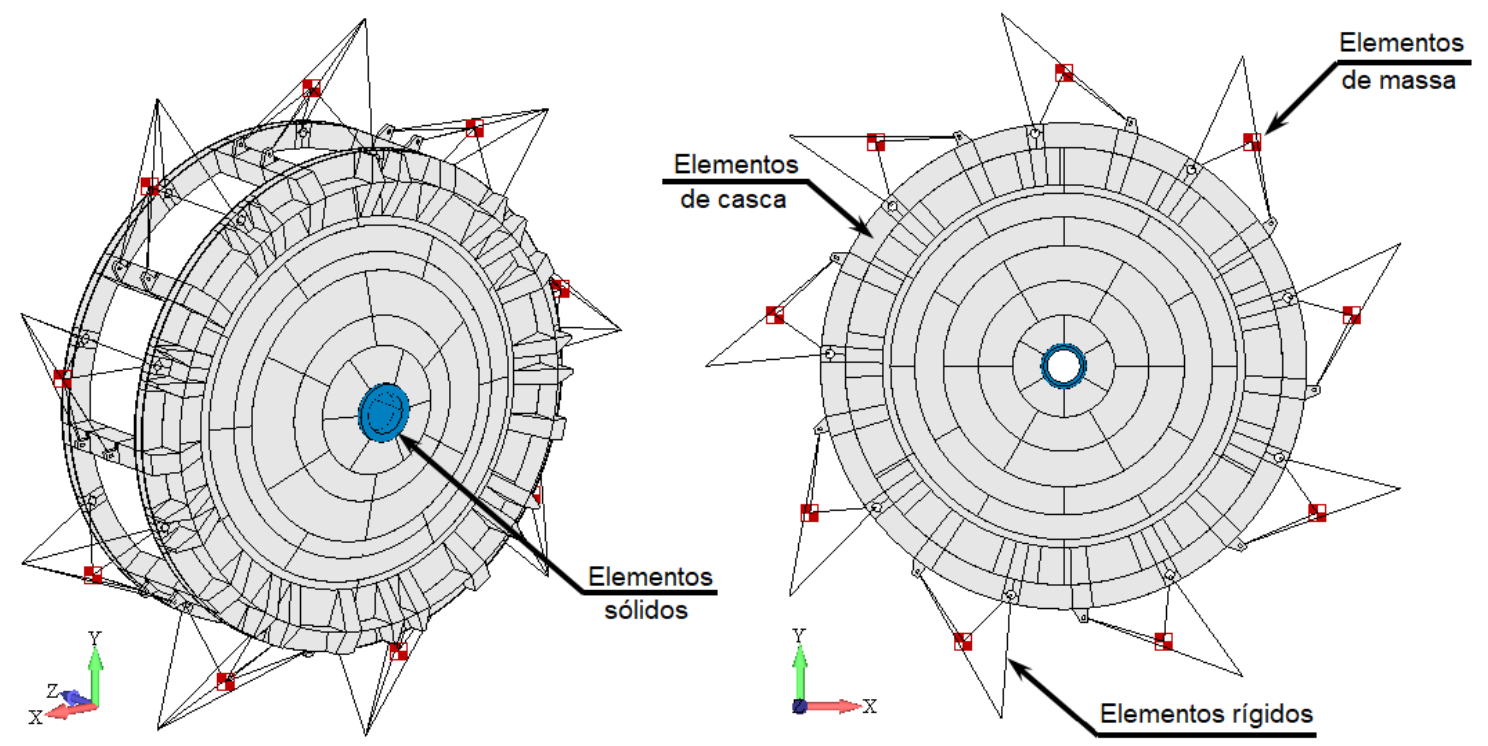

Fonte: Próprio autor. 
No modelo da roda de caçambas, as tensões atuantes foram obtidas em elementos bidimensionais de segunda ordem, com tamanho médio da aresta igual à espessura da chapa $(18 \mathrm{~mm})$. A adoção destas definições segue como referência a indicação do IIW [42] para a modelagem de regiões com gradientes de tensões abruptos. Na Figura 4-5, pode ser vista em detalhe a malha de elementos finitos utilizada na região em análise no modelo computacional.

Figura 4-5 - Detalhe da malha de elementos finitos utilizada no modelo.

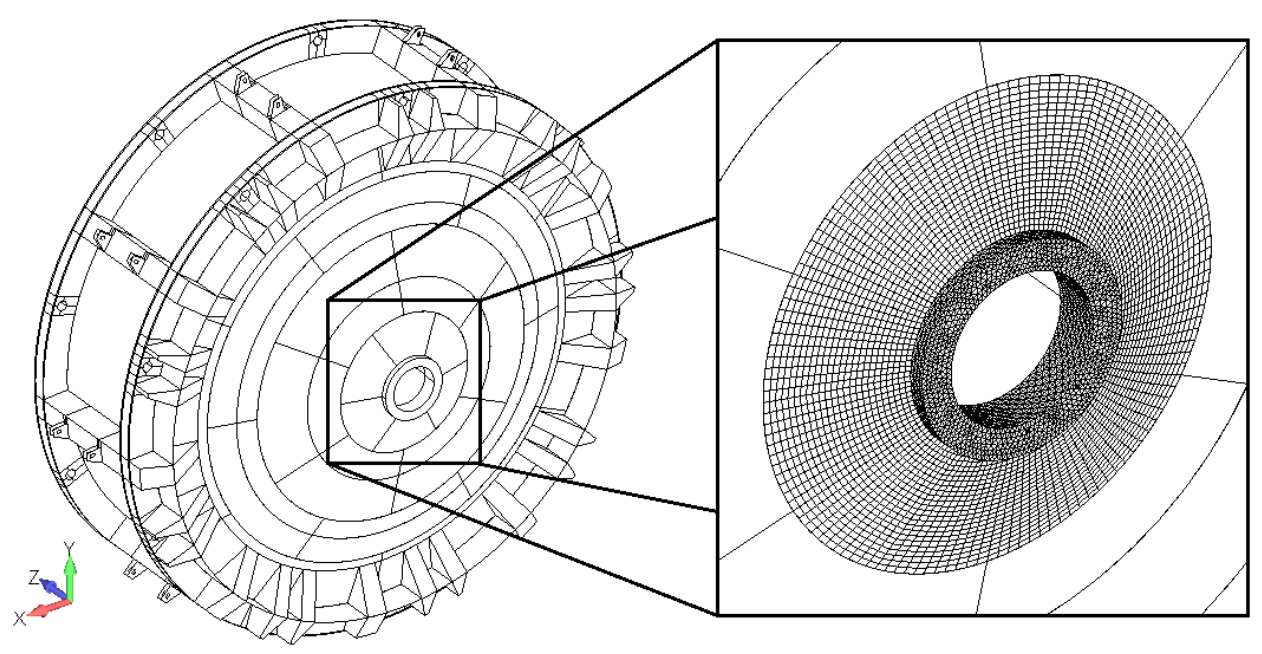

Fonte: Próprio autor.

A Figura 4-6 ilustra a variação das tensões normais e cisalhantes atuantes ao longo da circunferência da junta soldada durante um ciclo de rotação da roda de caçambas. Ressalta-se que o sentido de giro da recuperadora influencia na magnitude das tensões atuantes.

Figura 4-6 - Variação das tensões normais e cisalhantes ao longo da circunferência da junta soldada em um ciclo.

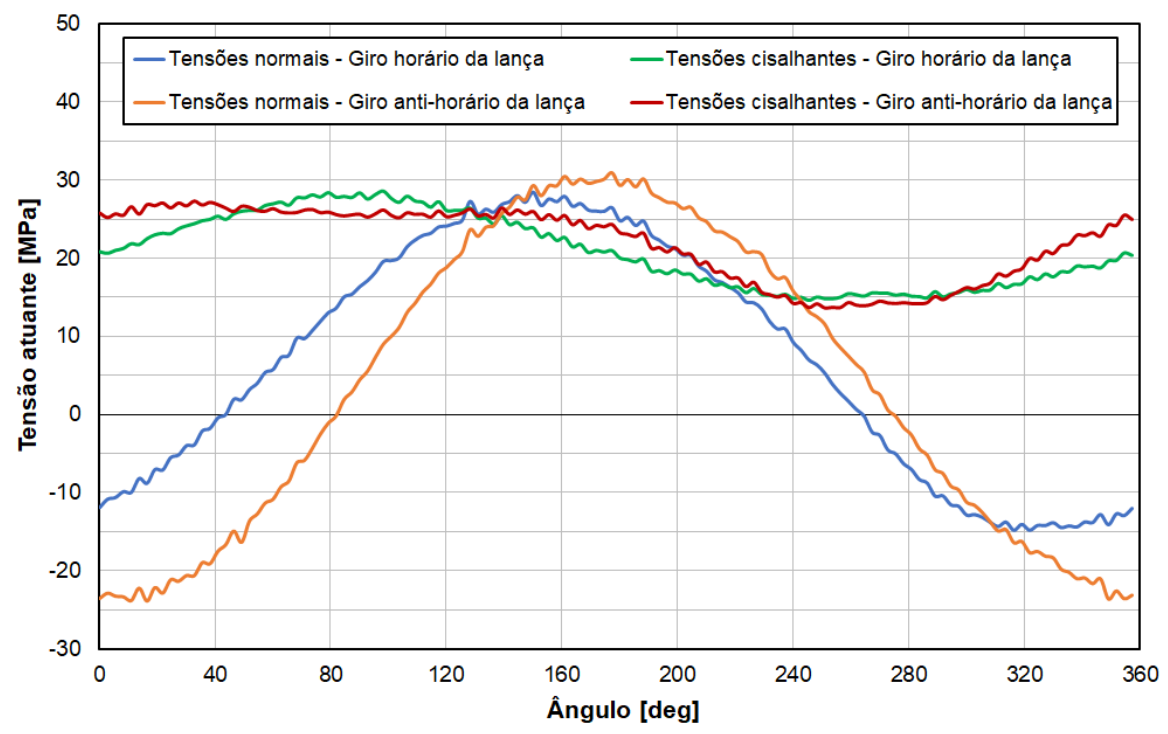

Fonte: Próprio autor. 
A Figura 4-7 mostra a distribuição destas tensões no modelo computacional, sendo que as mesmas foram obtidas após a aplicação dos carregamentos listados na Tabela 3-1.

Figura 4-7 - Distribuição de tensões normais e cisalhantes no modelo computacional da roda de caçambas.

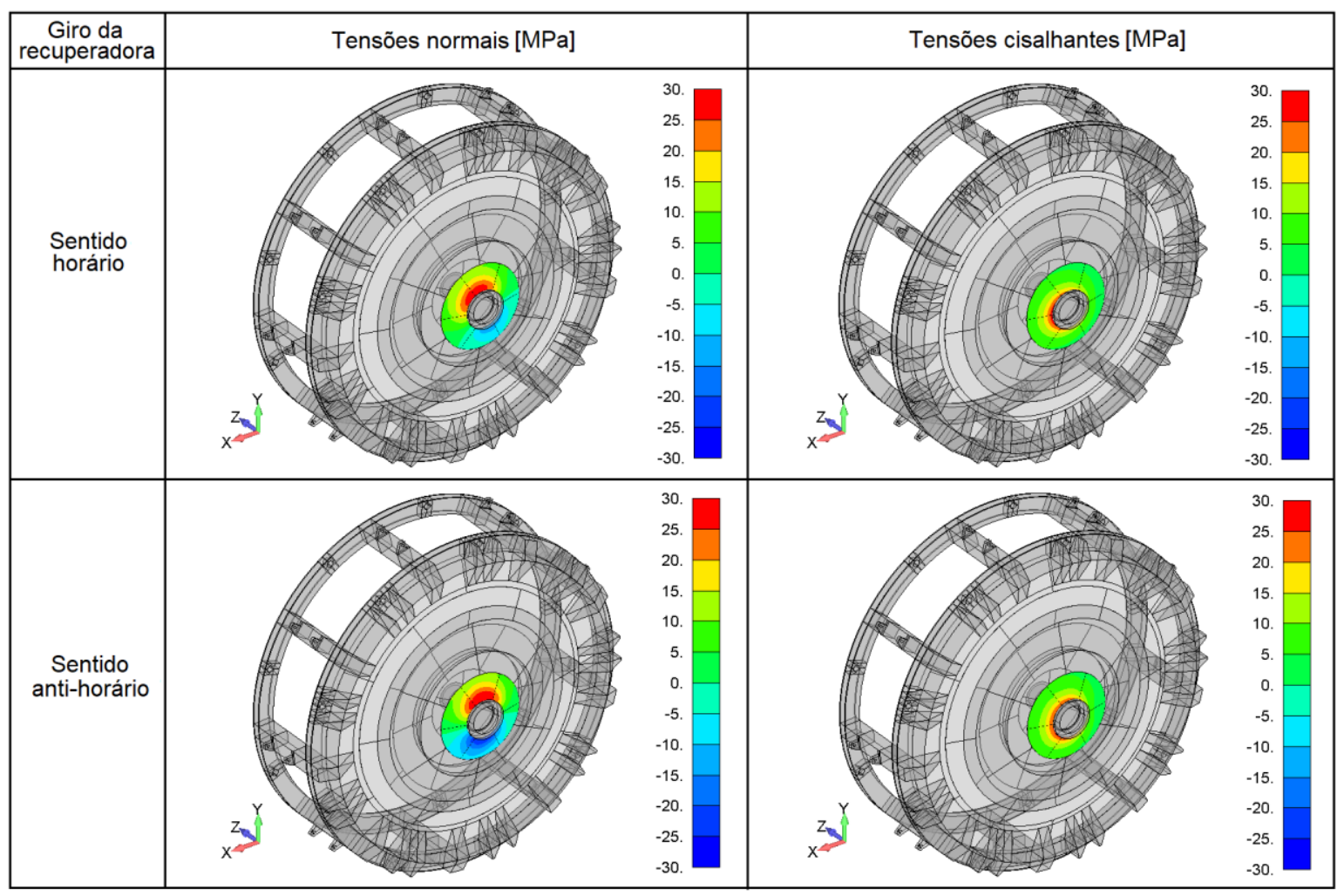

Fonte: Próprio autor.

A Tabela 4-4 apresenta o resumo das tensões normais e cisalhantes que foram consideradas nas análises. Também são indicadas as variações de tensões e a razão de tensões mínimas e máximas.

Tabela 4-4 - Resumo das tensões consideradas na análise.

\begin{tabular}{c|c|c|c}
\hline \multirow{2}{*}{ Tensões } & Parâmetro & $\begin{array}{c}\text { Giro horário da } \\
\text { lança }\end{array}$ & $\begin{array}{c}\text { Giro anti-horário } \\
\text { da lança }\end{array}$ \\
\hline \multirow{4}{*}{ Normais } & Tensão máxima, $\sigma_{\max }[\mathrm{MPa}]$ & 28,5 & 31,0 \\
\cline { 2 - 4 } & Tensão mínima, $\sigma_{\min }[\mathrm{MPa}]$ & $-14,8$ & $-23,9$ \\
\cline { 2 - 4 } & Variação de tensões, $\Delta \sigma[\mathrm{MPa}]$ & 43,3 & 54,9 \\
\cline { 2 - 4 } & Razão de tensões, $\mathrm{R}$ & $-0,52$ & $-0,77$ \\
\hline \multirow{4}{*}{ Cisalhantes } & Tensão máxima, $\tau_{\max }[\mathrm{MPa}]$ & 28,6 & 27,4 \\
\cline { 2 - 4 } & Tensão mínima, $\tau_{\min }[\mathrm{MPa}]$ & 14,6 & 13,7 \\
\cline { 2 - 4 } & Variação de tensões, $\Delta \tau[\mathrm{MPa}]$ & 14,0 & 13,7 \\
\cline { 2 - 4 } & Razão de tensões, $\mathrm{R}$ & 0,51 & 0,50 \\
\hline
\end{tabular}

Fonte: Próprio autor. 
A Figura 4-8 ilustra a distribuição de tensões equivalentes de von Mises no modelo computacional. A tensão máxima observada na região da junta soldada em estudo é igual a 50,8 $\mathrm{MPa}$, valor correspondente a 15,2\% do limite de escoamento do aço Q345B.

Figura 4-8 - Tensões de von Mises no modelo computacional da roda de caçambas.
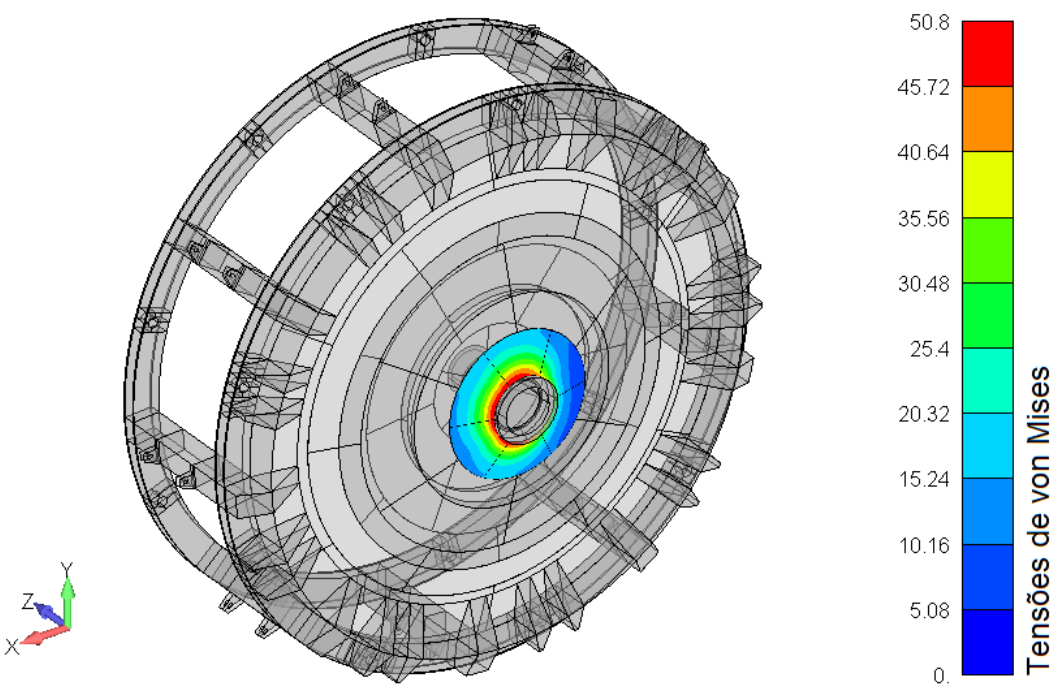

Fonte: Próprio autor.

\subsection{Verificação com base na Mecânica da Fratura Linear Elástica}

\subsubsection{Obtenção do Fator de Intensidade de Tensões numericamente}

As formulações para o fator de intensidade de tensões apresentadas por Newman e Raju [38] para trincas semielípticas submetidas à tração e por Tada et al. [16] para trincas passantes pela espessura sob tração e cisalhamento foram obtidas para geometrias específicas, sendo definidas limitações dimensionais em que os resultados obtidos são válidos.

Uma vez que a geometria do local onde houve propagação de trinca na roda de caçambas não é totalmente compatível em seu dimensional com as geometrias utilizadas pelos autores supracitados, modelos computacionais no software Ansys ${ }^{\circledR}$ para trincas semielípticas e para trincas passantes pela espessura foram elaborados para a obtenção do fator de intensidade de tensões de forma numérica. Trincas semielípticas através da espessura não foram modeladas, sendo aproximado o fator de intensidade de tensões destas trincas a partir dos resultados para trincas passantes pela espessura. 
Para a avaliação de trincas semielípticas, dois modelos computacionais foram criados: o primeiro, ilustrado na Figura 4-9, é composto por uma chapa retangular com geometria semelhante à utilizada por Newman e Raju [38]. onde a largura e a altura da chapa são iguais a 5 vezes o comprimento da trinca. Este modelo foi utilizado para comparação entre a solução teórica e a solução numérica, além de permitir a calibração da malha adotada. O segundo modelo, visto na Figura 4-10, representa a geometria da roda de caçambas, que será empregada para avaliar se a solução teórica é válida no problema em estudo.

Figura 4-9 - Modelo computacional da chapa retangular - Trinca semielíptica.

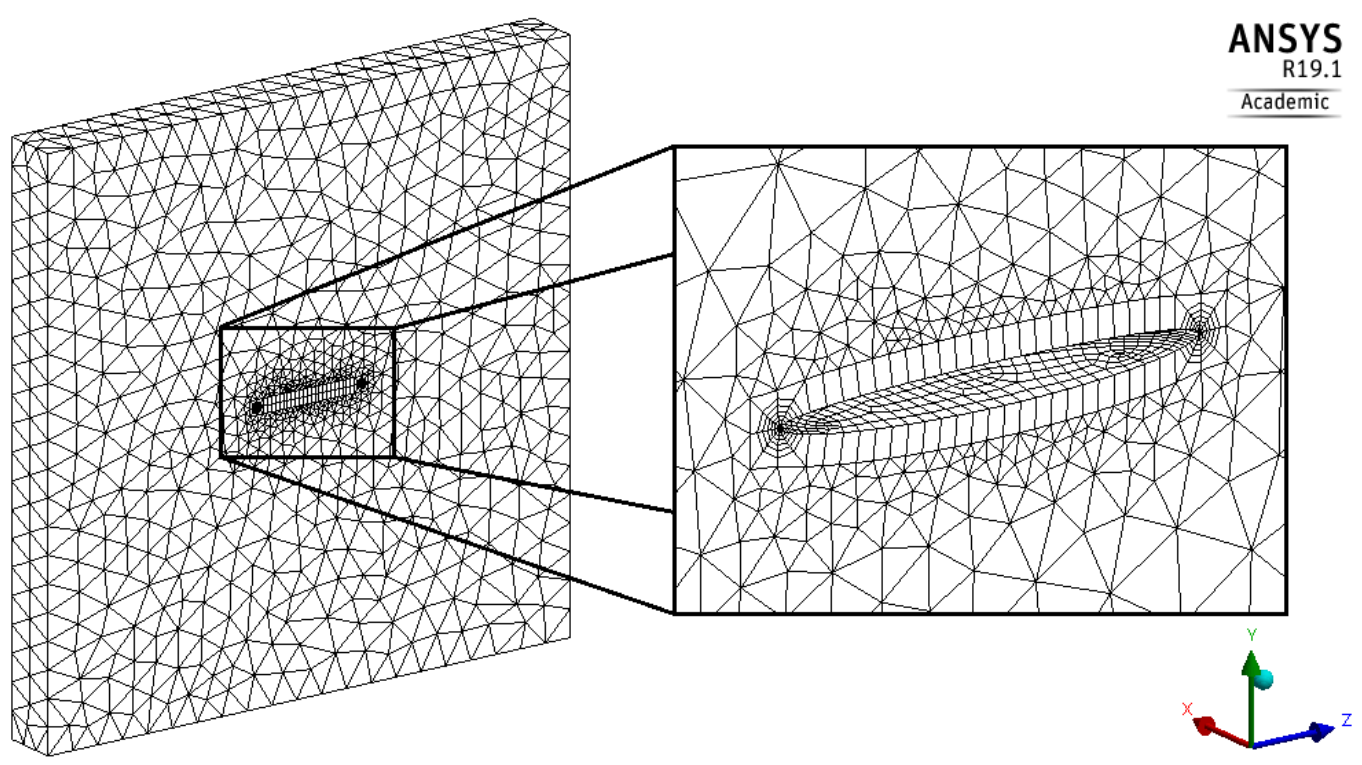

Fonte: Próprio autor.

Figura 4-10 - Modelo computacional da geometria da roda de caçambas - Trinca semielíptica.

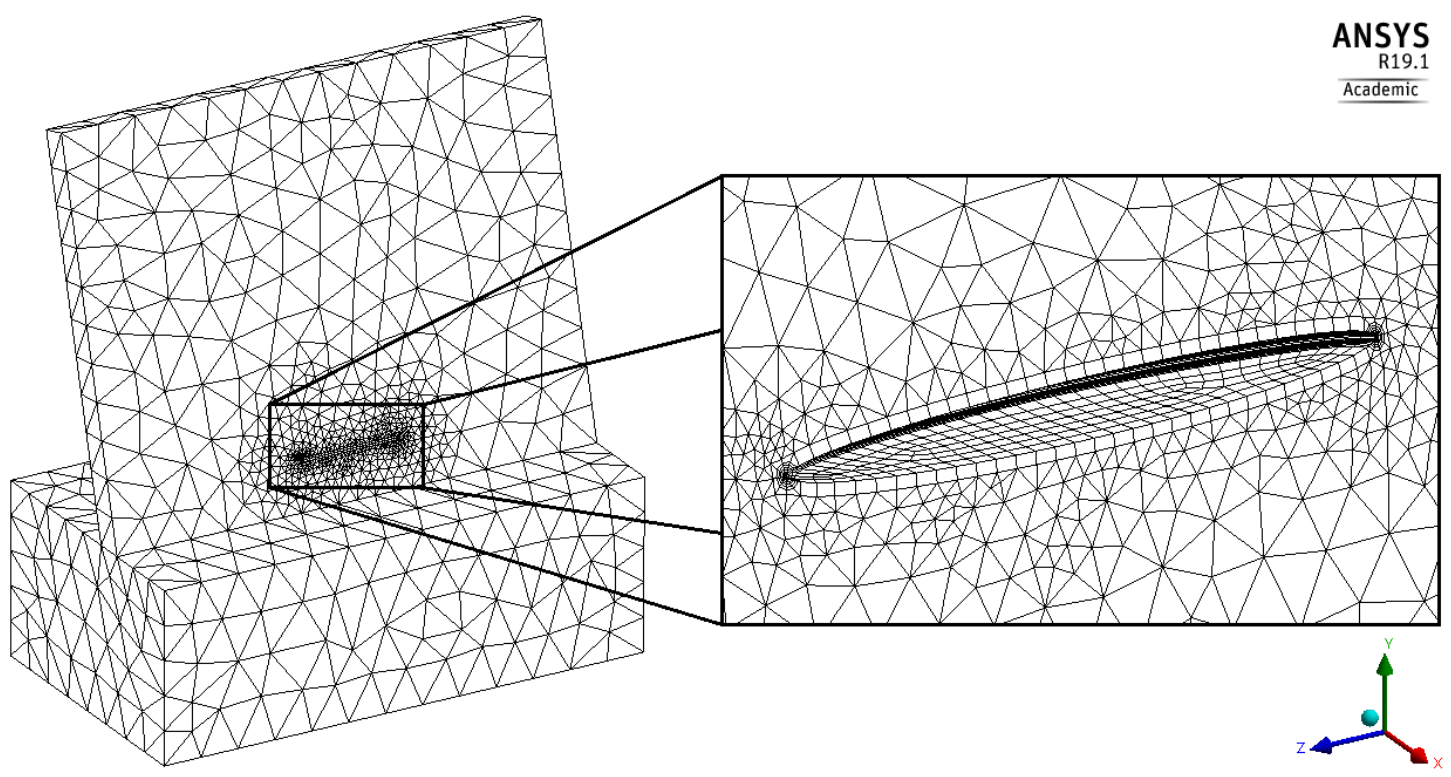

Fonte: Próprio autor. 
Em função da utilização de uma versão educacional do software Ansys ${ }^{\circledR}$, a qual é limitada no uso máximo de 32000 nós/elementos, procurou-se realizar a otimização da malha em regiões afastadas da trinca, permitindo a adoção de uma malha mais refinada na frente da trinca. São quatro os parâmetros que definem a trinca no software: raio da região de domínio de $K$, número de elementos ao longo da frente da trinca, de divisões circunferenciais e de contornos da teia de aranha ao redor da trinca.

O raio da região de domínio de $K$ foi definido em acordo com o indicado por Kuna [15], ou seja, entre 1/50 e 1/10 do comprimento da trinca, sendo escolhida a proporção que melhor se adapte à malha adotada em cada trinca avaliada. Ao longo da frente da trinca, foram adotados 36 elementos de segunda ordem, o que representa a presença de 73 nós onde são obtidos os resultados de $K$. Com relação à teia de aranha ao redor da trinca, foram adotadas 8 divisões circunferenciais e 6 contornos para integração numérica. $O$ fator de intensidade de tensões adotado será igual à média do $2^{\circ}$ ao $6^{\circ}$ contorno, uma vez que o $1^{\circ}$ contorno, por estar muito próximo à trinca, fornece resultados muito divergentes em relação aos demais contornos. Os parâmetros de definição da trinca semielíptica estão mostrados na Figura 4-11.

Figura 4-11 - Parâmetros de definição da frente da trinca semielíptica.

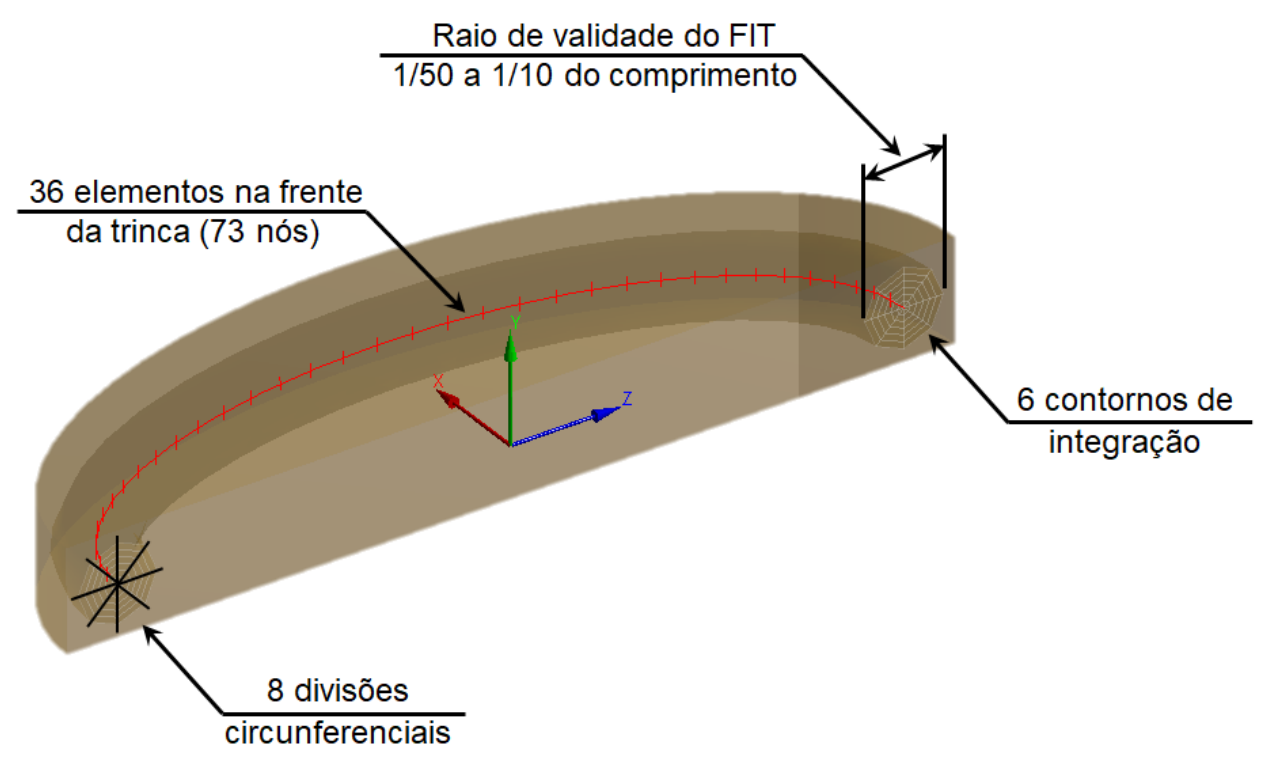

Fonte: Próprio autor.

A Figura 4-12 e a Figura 4-13 apresentam comparativos entre o fator de intensidade de tensões teórico e o numérico para a trinca semielíptica sob tração, considerando a propagação na direção da profundidade e do comprimento da trinca, respectivamente. De forma a facilitar a apresentação dos resultados e a utilização dos mesmos nas análises subsequentes, o fator de 
intensidade de tensões é indicado em sua forma normalizada $K /(\sigma \sqrt{ } \pi a)$ para razões $a / t$ que variam de 0,02 a 0,9 , representando o fator de forma $f(g)$ da geometria analisada.

Figura 4-12 - Comparativo entre $K$ normalizado teórico e $K$ numérico para a trinca semielíptica sob tração: chapa retangular (a) e geometria da roda (b) - Direção da profundidade da trinca.

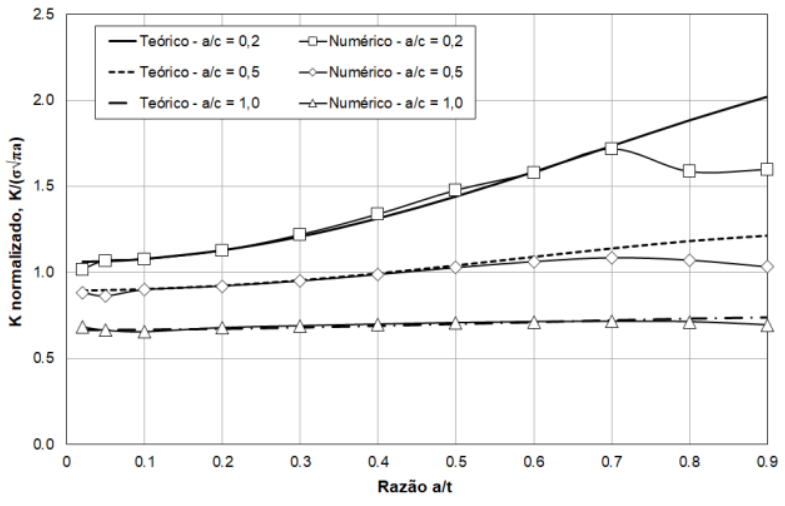

(a)

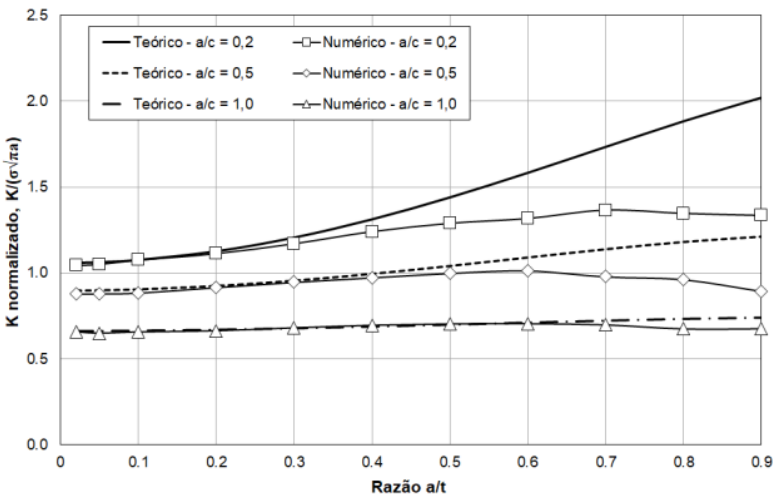

(b)

Fonte: Próprio autor.

Figura 4-13 - Comparativo entre $K$ normalizado teórico e $K$ numérico para a trinca semielíptica sob tração: chapa retangular (a) e geometria da roda (b) - Direção do comprimento da trinca.

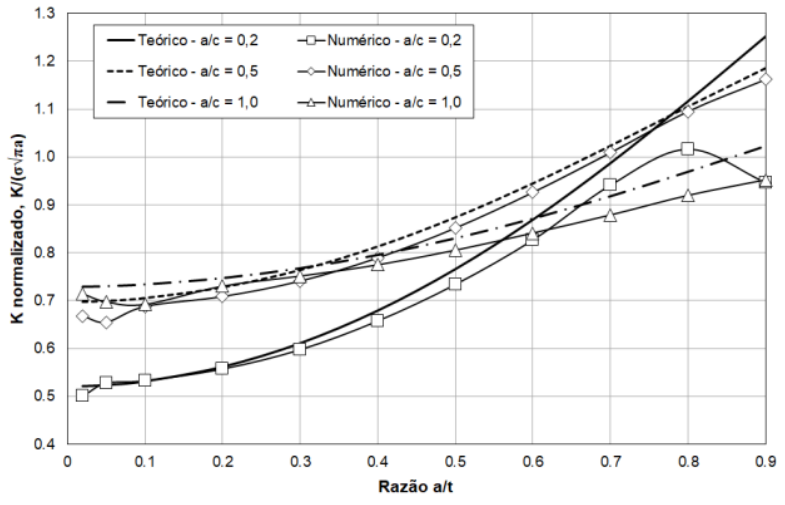

(a)

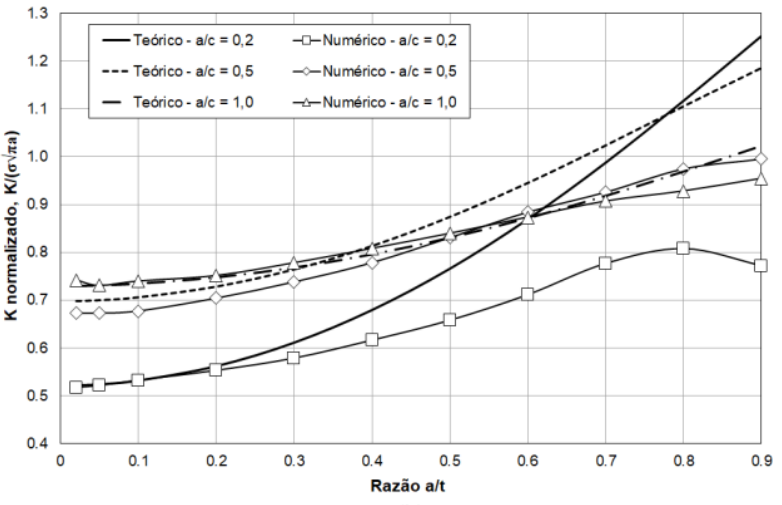

(b)

Fonte: Próprio autor.

Nos resultados apresentados, pode-se observar que $K$ numérico possui boa compatibilidade com $K$ teórico para a chapa retangular, sendo observado um erro máximo igual a $-6,39 \%$ até uma razão $a / t$ igual a 0,7 . Para trincas profundas a partir desta razão $a / t$, os resultados numéricos divergem da solução em até $-24,3 \%$ para uma razão $a / t$ igual a 0,9 avaliando-se $K$ na direção do comprimento da trinca. Resultados semelhantes foram obtidos por Bransen [62], e Newman e Raju [38] indicam que para trincas com razão $a / t$ superior a 0,8 , a formulação apresentada pelos autores indica apenas uma boa estimativa para o fator de intensidade de tensões. Desta forma, os resultados para a chapa retangular foram considerados satisfatórios e indicam que a malha é representativa para a avaliação de $K$ na geometria da roda. 
Com relação à geometria da roda, verifica-se que há uma maior divergência entre a solução teórica e os resultados numéricos, principalmente para a razão $a / c$ igual a 0,2 . Acredita-se que esta divergência esteja relacionada à perda de rigidez na chapa trincada em função da presença do cubo da estrutura da roda de caçambas, que restringe a abertura da trinca e ocasiona uma redução no valor de $K$. A partir dos dados obtidos, regressões polinomiais foram realizadas para a obtenção de curvas para o fator de forma $f(g)$, sendo as mesmas apresentadas no item B.1.1.

A Figura 4-14 apresenta o fator de intensidade de tensões numérico para a trinca semielíptica sob cisalhamento considerando a propagação na direção do comprimento da trinca.

Figura 4-14 - K normalizado numérico para a trinca semielíptica sob cisalhamento - Direção do comprimento da trinca.

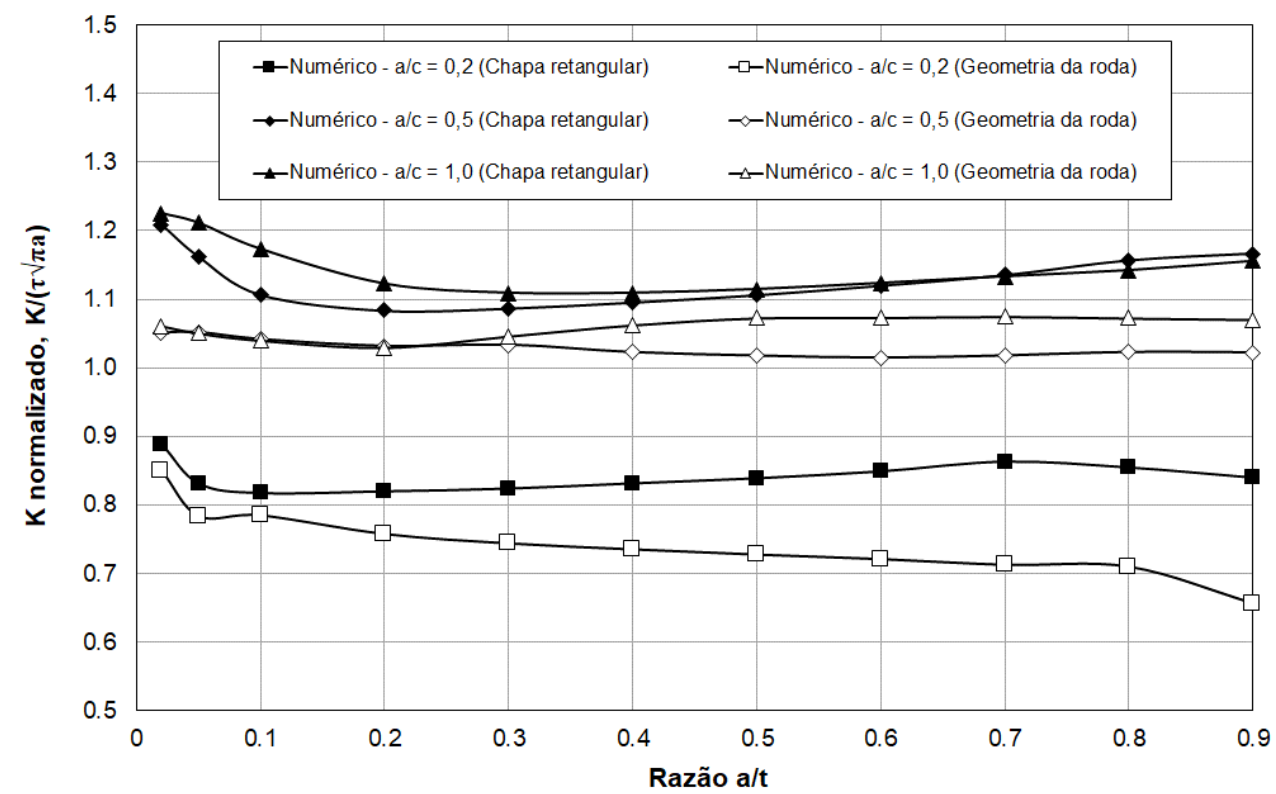

Fonte: Próprio autor.

Na literatura, não foram encontradas soluções específicas para trincas semielípticas submetidas ao cisalhamento em corpos finitos. He e Hutchinson [63] e Noda e Kagita [64] estimaram soluções para trincas semielípticas sob cisalhamento em corpos semi-infinitos a partir da solução para trincas elípticas em sólidos infinitos estudadas por Kassir e Sih [65]. Como a geometria da roda é peculiar, decidiu-se por obter a solução de $K$ de forma inteiramente numérica, sendo consideradas não aplicáveis para o caso em estudo as soluções propostas pelos autores indicados acima. A partir do fator de intensidade de tensões normalizado $K /(\tau \sqrt{ } \pi a)$ apresentado na Figura 4-14, regressões polinomiais foram realizadas para a obtenção de curvas para o fator de forma $f(g)$, sendo as mesmas apresentadas no item B.1.2. 
Na Figura 4-15, são plotadas as curvas de variação de $K$ numérico para o modo I e para o modo II de propagação ao longo da frente de uma trinca semielíptica com proporções $a / c$ de 0,5 e $a / t$ igual a 0,3 . Verifica-se que $K_{I}$ apresenta pequena variação em relação à posição angular avaliada na frente da trinca, tendo seu valor máximo alocado na direção da profundidade $\left(\phi=90^{\circ}\right)$. Já $K_{I I}$ possui valor máximo na direção do comprimento da trinca $\left(\phi=0^{\circ}\right)$, sendo nulo na direção da profundidade $\left(\phi=90^{\circ}\right)$. Uma vez que tais perfis de variação de $K$ ao longo da frente da trinca são típicos, conclui-se que carregamentos de cisalhamento induzem o crescimento da trinca semielíptica apenas na direção do comprimento, enquanto que carregamentos de tração proporcionam a propagação da trinca em ambas as direções.

Figura 4-15 - Variação de $\mathrm{K}_{\mathrm{I}}$ e $\mathrm{K}_{\mathrm{II}}$ ao longo da frente de uma trinca semielíptica $-a / c=0,5$ e $a / t=0,3$.

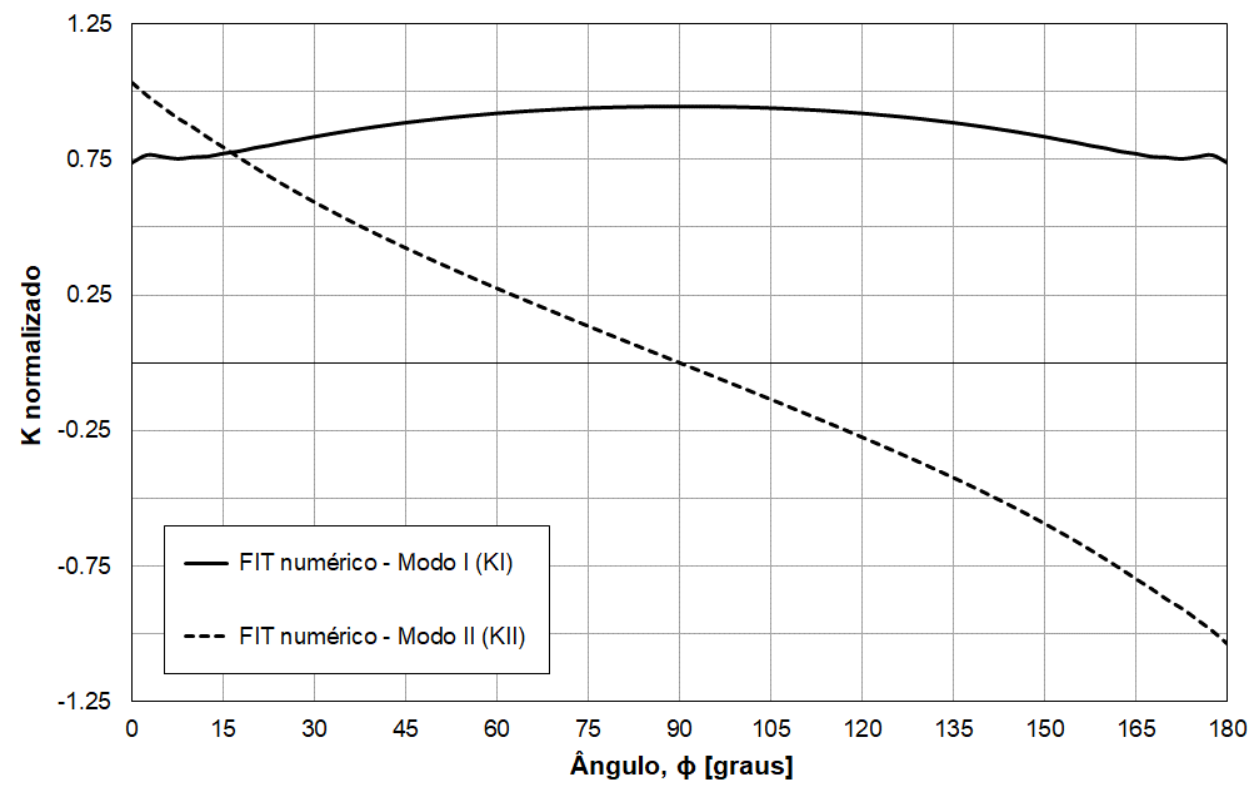

Fonte: Próprio autor.

Para a avaliação de trincas passantes pela espessura, dois modelos computacionais foram elaborados de forma semelhante para trincas semielípticas. O modelo contendo a chapa retangular para comparação entre a solução teórica apresentada por Tada et al. [16] e a solução numérica é apresentado na Figura 4-16, e o modelo da geometria da roda para avaliação da validade da solução teórica no problema em estudo é ilustrado na Figura 4-17. 
Figura 4-16 - Modelo computacional da chapa retangular - Trinca passante pela espessura.

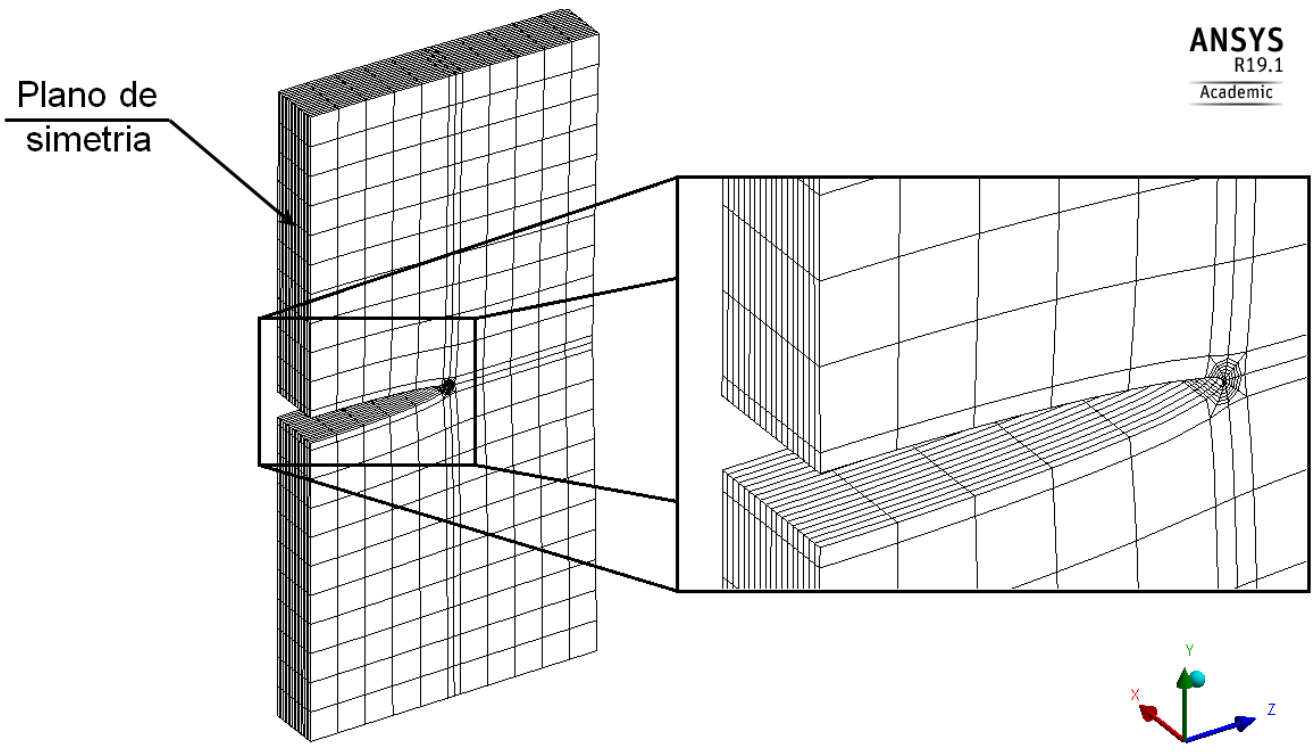

Fonte: Próprio autor.

Figura 4-17 - Modelo computacional da geometria da roda de caçambas - Trinca passante pela espessura.

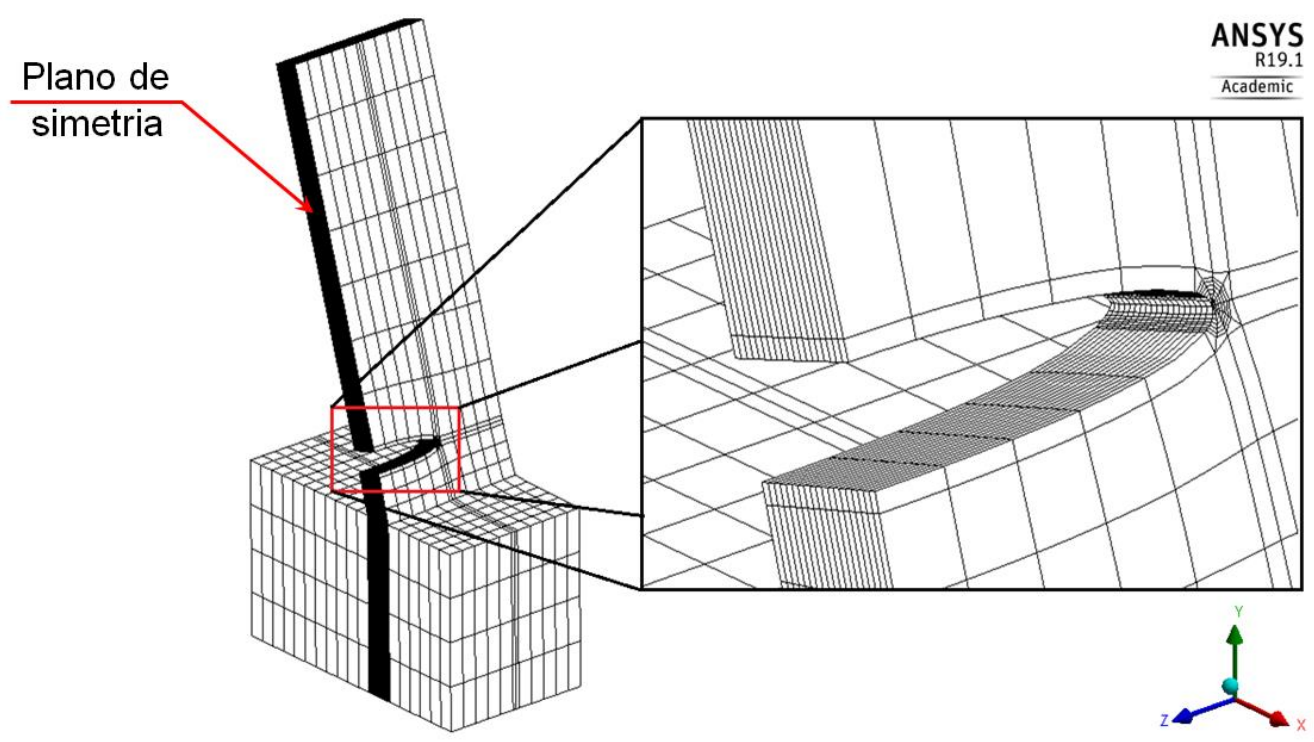

Fonte: Próprio autor.

Nos modelos acima apresentados, a condição de simetria da trinca foi utilizada, uma vez que o software Ansys $^{\circledast}$ não permite a utilização de duas frentes para uma mesma trinca. De forma semelhante à trinca semielíptica, foram adotadas 8 divisões circunferenciais e 6 contornos de integração numérica e obtenção de $K$ para a teia de aranha ao redor da trinca. Novamente, o fator de intensidade de tensões a ser considerado é média do $2^{\circ}$ ao $6^{\circ}$ contorno. 
$\mathrm{O}$ raio da região de domínio de $K$ foi fixado em $2 \mathrm{~mm}$ para todos os tamanhos de trinca simulados, sendo que tal dimensão para o raio se encaixa na recomendação de Kuna [15]. Ao longo da frente da trinca, foram adotados 18 elementos de segunda ordem, o que representa a presença de 37 nós onde são obtidos o fator de intensidade de tensões.

A Figura 4-18 ilustra o comparativo entre o fator de intensidade de tensões teórico e o numérico para a trinca passante pela espessura sob tração. Semelhantemente à trinca semielíptica, o fator de intensidade de tensões é indicado em sua forma normalizada $K /(\sigma \sqrt{ } \pi a)$, porém variando-se agora a razão $c / b$ (meio comprimento da trinca / meia largura da chapa). Os resultados representam, portanto, o fator de forma $f(g)$ da geometria analisada.

Figura 4-18 - Comparativo entre $K$ normalizado teórico e o numérico para a trinca passante pela espessura sob tração.

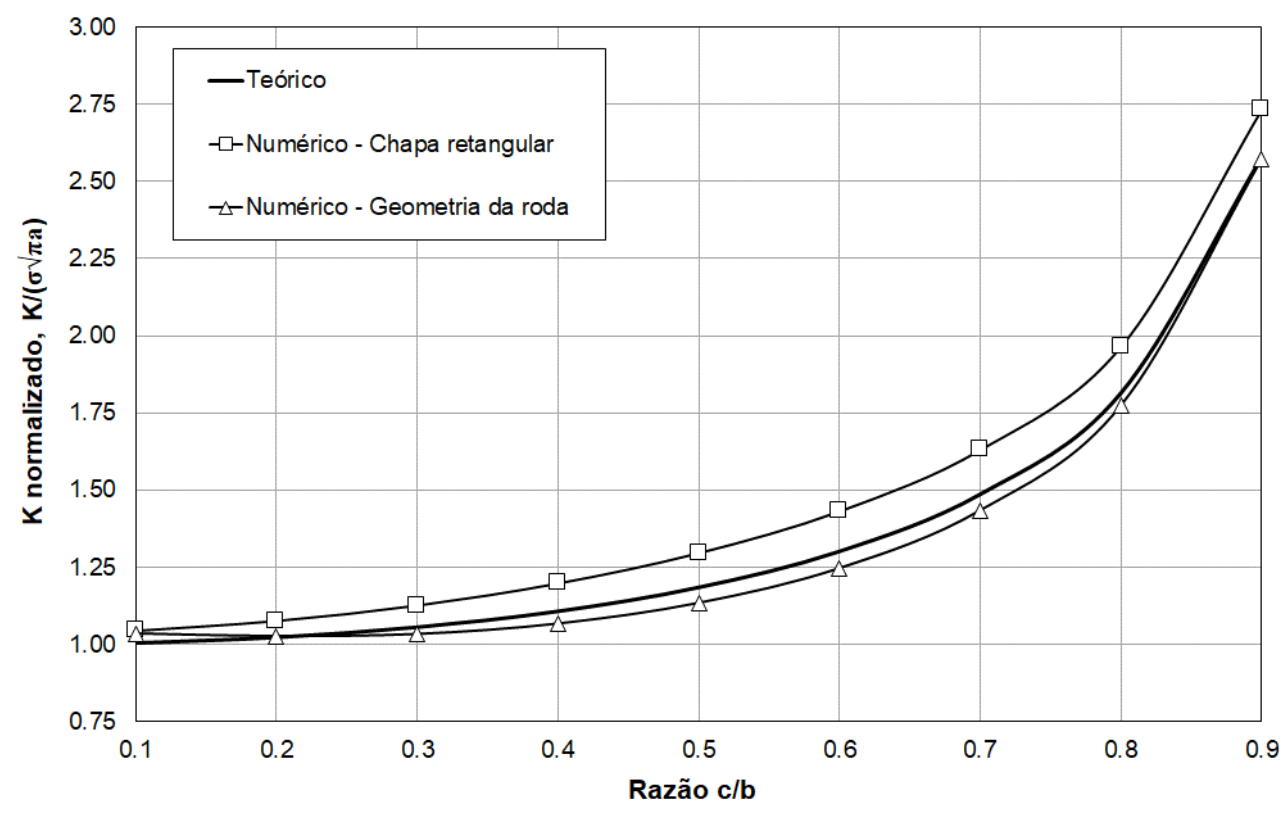

Fonte: Próprio autor.

Nos resultados apresentados na Figura 4-18, observa-se, através do paralelismo entre as curvas da solução teórica e de $K$ numérico, que os resultados numéricos são compatíveis com a formulação proposta por Tada et al. [16]. O máximo erro encontrado é igual a $+9,89 \%$ para a chapa retangular e igual a $-4,46 \%$ para a geometria da roda. Valores inferiores para o fator de intensidade de tensões da geometria da roda em relação à chapa retangular podem ser explicados de forma semelhante à trinca semielíptica, em função da restrição de abertura da trinca proporcionada pelo cubo. 
Devido à coerência entre a solução teórica e os resultados obtidos numericamente para carregamentos de tração, a condição de tensões cisalhantes atuando na trinca não será avaliada, uma vez que a formulação de $K$ para trincas sob tração e cisalhamento é idêntica conforme apresentado por Tada et al. [16]. Desta forma, a formulação de $K$ proposta por Tada et al. [16] será utilizada na análise de propagação de trinca na roda de caçambas, sem a necessidade de uso de regressões para determinação de um fator de forma específico para a geometria da roda.

Na Figura 4-19, é ilustrado o comparativo entre o fator de intensidade de tensões teórico e o numérico para uma trinca passante pela espessura com razão $c / b$ igual a 0,4 , sendo tal comparativo realizado em pontos ao longo da espessura da chapa .É possível observar que $K$ não se mantém constante ao longo da espessura da chapa, tanto para a chapa retangular quanto para a geometria da roda. A explicação para este efeito pode estar relacionada à baixa triaxialidade nas bordas livres da trinca, devido à liberdade de deformação das bordas na direção transversal da chapa.

Figura 4-19 - Comparativo entre o $K$ normalizado teórico e o numérico para a trinca passante pela espessura sob tração com razão c/b igual a 0,4 .

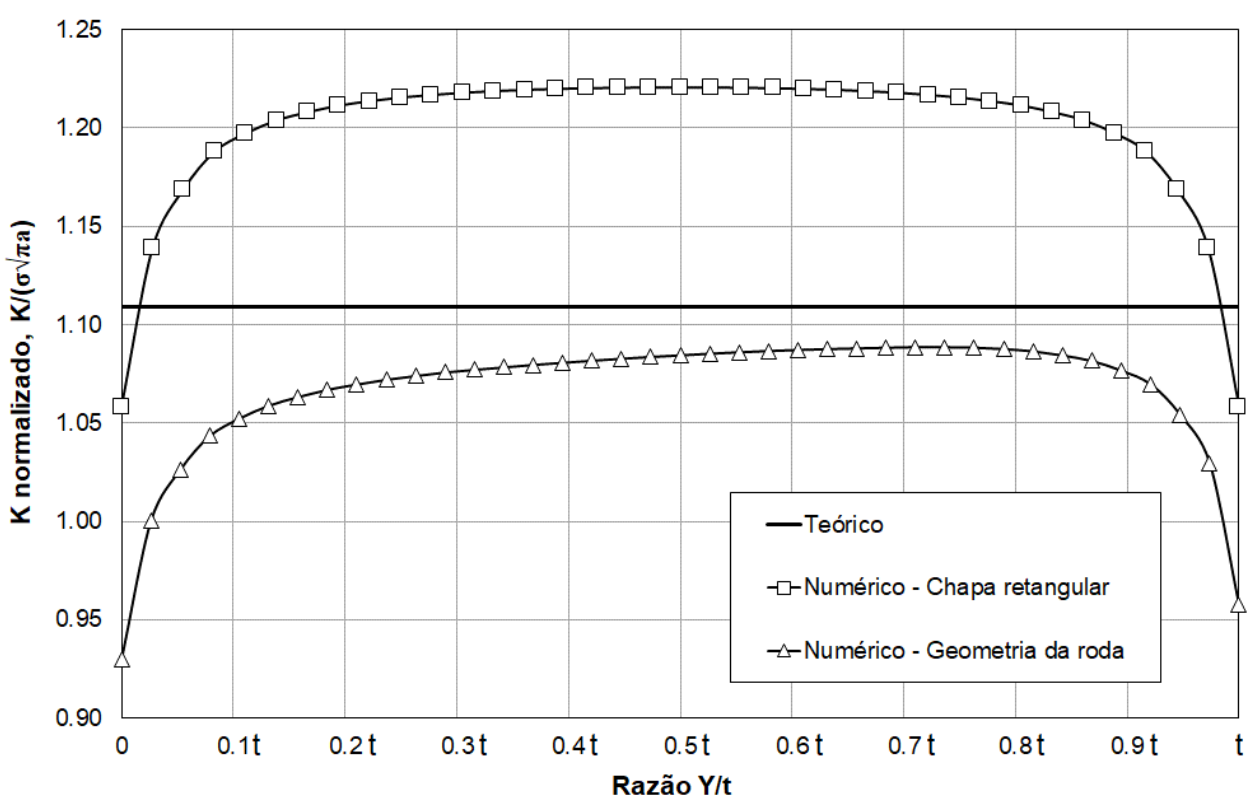

Fonte: Próprio autor. 


\subsection{2 $\quad \underline{\text { Fator de amplificação } M_{k}}$}

A Figura 4-20 e a Figura 4-21 apresentam o fator de amplificação $M_{k}$ do fator de intensidade de tensões na direção da profundidade e do comprimento da trinca, respectivamente. A partir da formulação proposta por Bowness e Lee [37], foram obtidas curvas para três proporções $a / c$ da trinca semielíptica do $1^{\circ}$ estágio em função da razão $a / t$. Tal formulação é apresentada em detalhes no ANEXO C.

Figura 4-20 - Fator de amplificação $M_{k}$ na direção da profundidade da trinca.

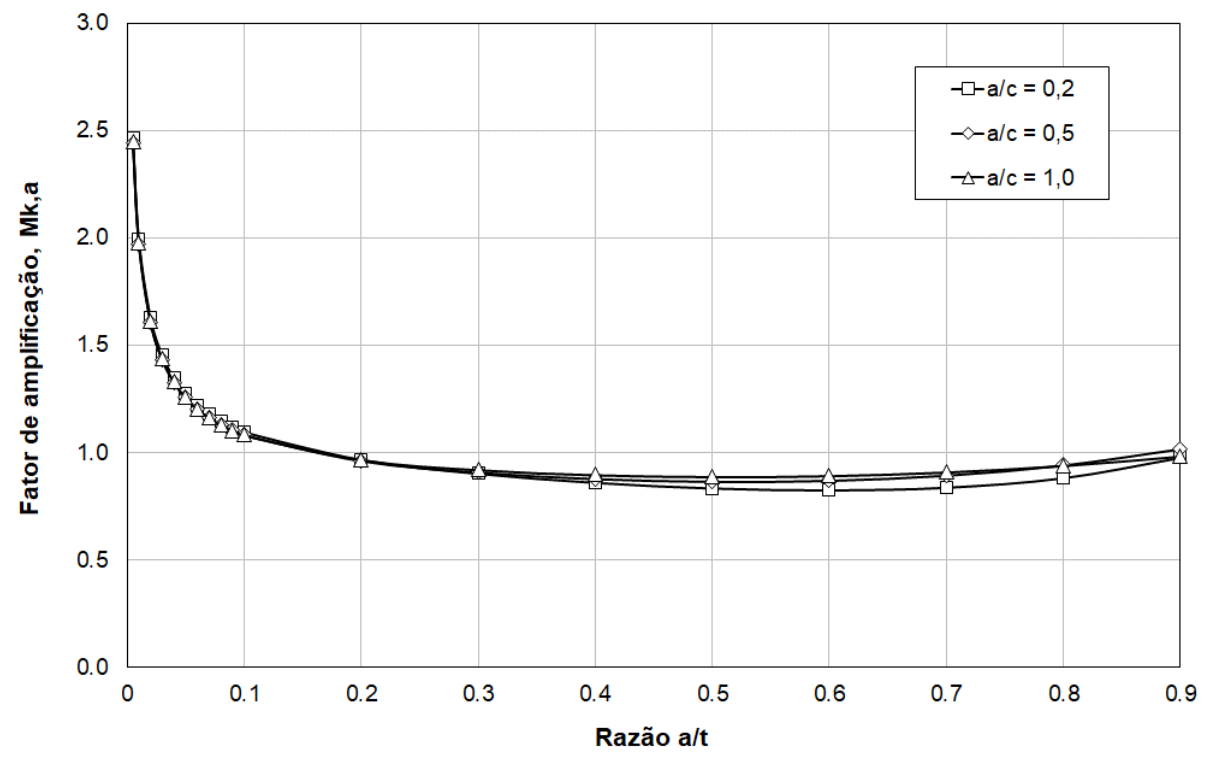

Fonte: Adaptado de Bowness e Lee [37].

Figura 4-21 - Fator de amplificação $M_{k}$ na direção do comprimento da trinca.

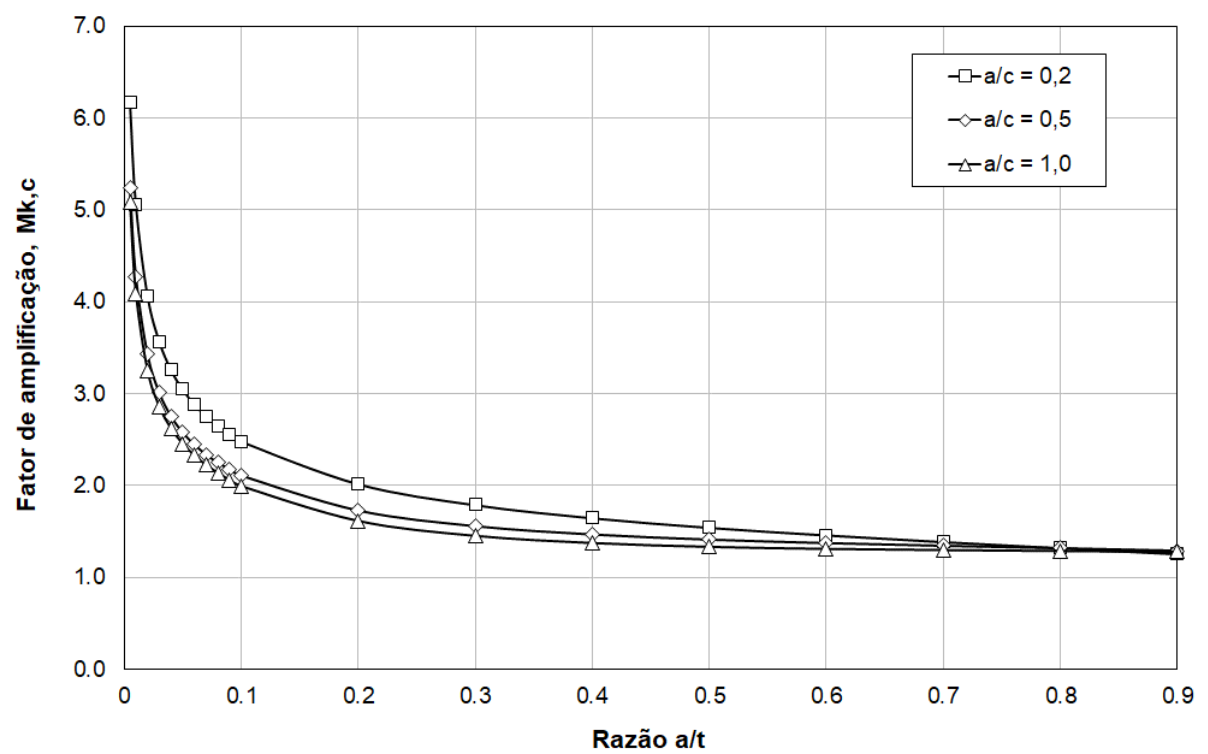

Fonte: Adaptado de Bowness e Lee [37]. 
A partir dos gráficos apresentados, verifica-se que em função da maior magnitude do fator $M_{k, c}$ (propagação na direção do comprimento) em relação ao fator $M_{k, a}$ (propagação na direção da profundidade), há uma tendência de que a trinca cresça preferencialmente ao longo do cordão de solda. Além disso, não há distinção significativa para os valores de $M_{k}$ em função da proporção $a / c$ na propagação em ambas as direções.

\subsubsection{Propagação na direção da profundidade da trinca}

No estudo de propagação na direção da profundidade da trinca na roda de caçambas, será estimada uma trinca semielíptica com uma profundidade inicial $a_{i}$ de $0,5 \mathrm{~mm}$, com base nas recomendações da prática DNVGL-RP-C203 [41] para trincas localizadas na transição entre a solda e o metal de base. Três proporções entre a profundidade $a$ e o meio comprimento $c$ da trinca semielíptica inicial foram consideradas: 0,2, 0,5 e 1,0. Como indicado anteriormente, estima-se 2,37 x $10^{6}$ ciclos até a falha da estrutura em aproximadamente um ano de operação.

Adotadas as considerações feitas acima, a Figura 4-22 apresenta a variação da vida em fadiga em função da presença de tensões residuais de tração na região fraturada. Tais tensões são expressas através de um percentual do limite de escoamento do aço Q345B (335 MPa), sendo consideradas constantes na direção transversal ao cordão de solda.

Figura 4-22 - Vida em fadiga em função da presença de tensões residuais - Direção da profundidade da trinca.

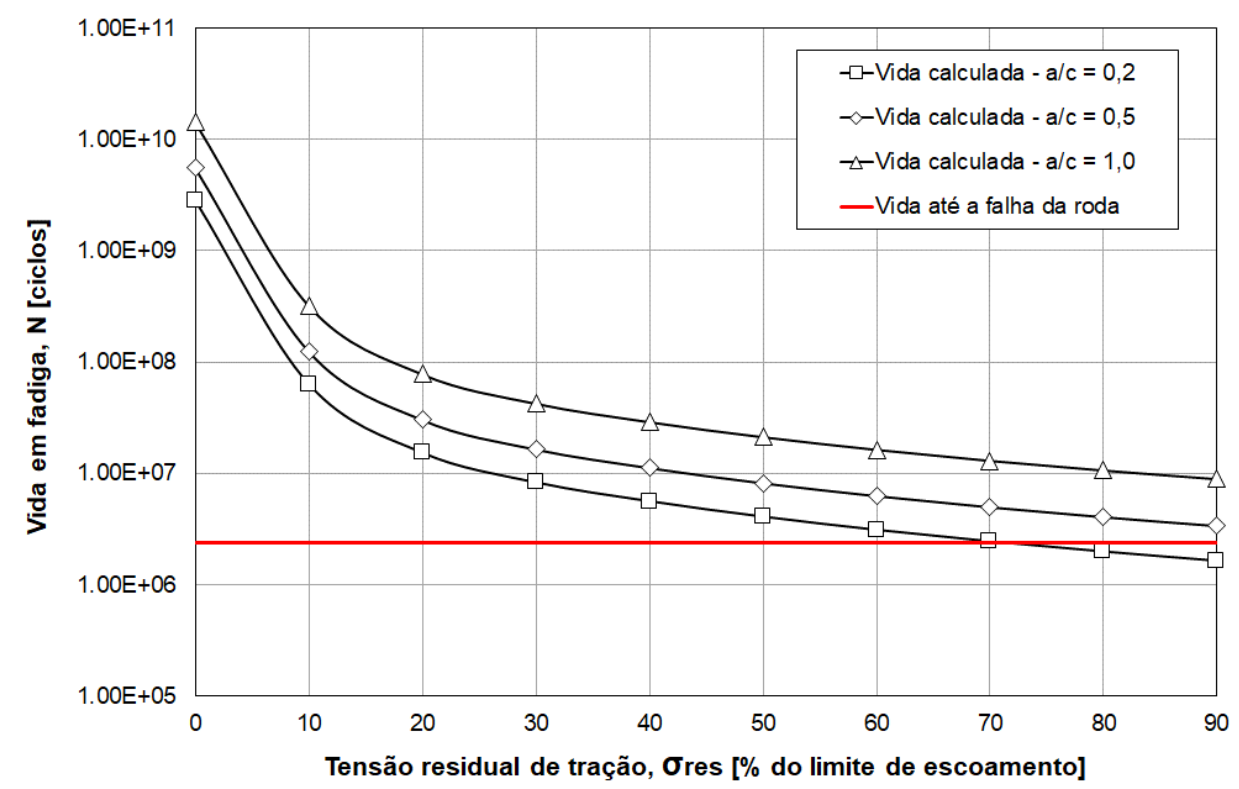

Fonte: Próprio autor. 
Verifica-se que a vida em fadiga na qual a roda de caçambas apresentou falha em campo pode ser obtida apenas para a proporção $a / c$ de 0,2 quando considerada uma tensão residual de tração igual a $239 \mathrm{MPa}$, valor correspondente a 71,3\% do limite de escoamento do aço da estrutura da roda. Para as proporções $a / c$ iguais a 0,5 e 1,0, a vida até a falha não é atingida nas condições avaliadas.

O comprimento crítico da trinca obtido para a condição supracitada é de $227 \mathrm{~mm}(8,7 \%$ do comprimento do cordão de solda entre o cubo e a estrutura principal) para que a tenacidade à fratura $K_{I C}$ de $126 \mathrm{MPa} \sqrt{ } \mathrm{m}$ seja atingida na frente da trinca. Após este valor de $K_{I C}$ ser alcançado, a trinca propagará de maneira instável causando a separação completa entre o cubo e a estrutura principal da roda de caçambas (tamanho final da trinca de aproximadamente $2600 \mathrm{~mm}$ ). Destaca-se que nas condições acima citadas, o $3^{\circ}$ estágio de propagação da trinca não foi alcançado, ocorrendo a propagação instável da mesma a partir do $2^{\circ}$ estágio.

A evolução do comprimento da trinca $2 c$ em função da vida em fadiga $N$ pode ser vista na Figura 4-23. A variação do fator de intensidade de tensões equivalente $K_{e q}$ em função do comprimento da trinca $2 c$ é apresentada na Figura 4-24.

Figura 4-23 - Comprimento da trinca em função da vida em fadiga - Direção da profundidade da trinca.

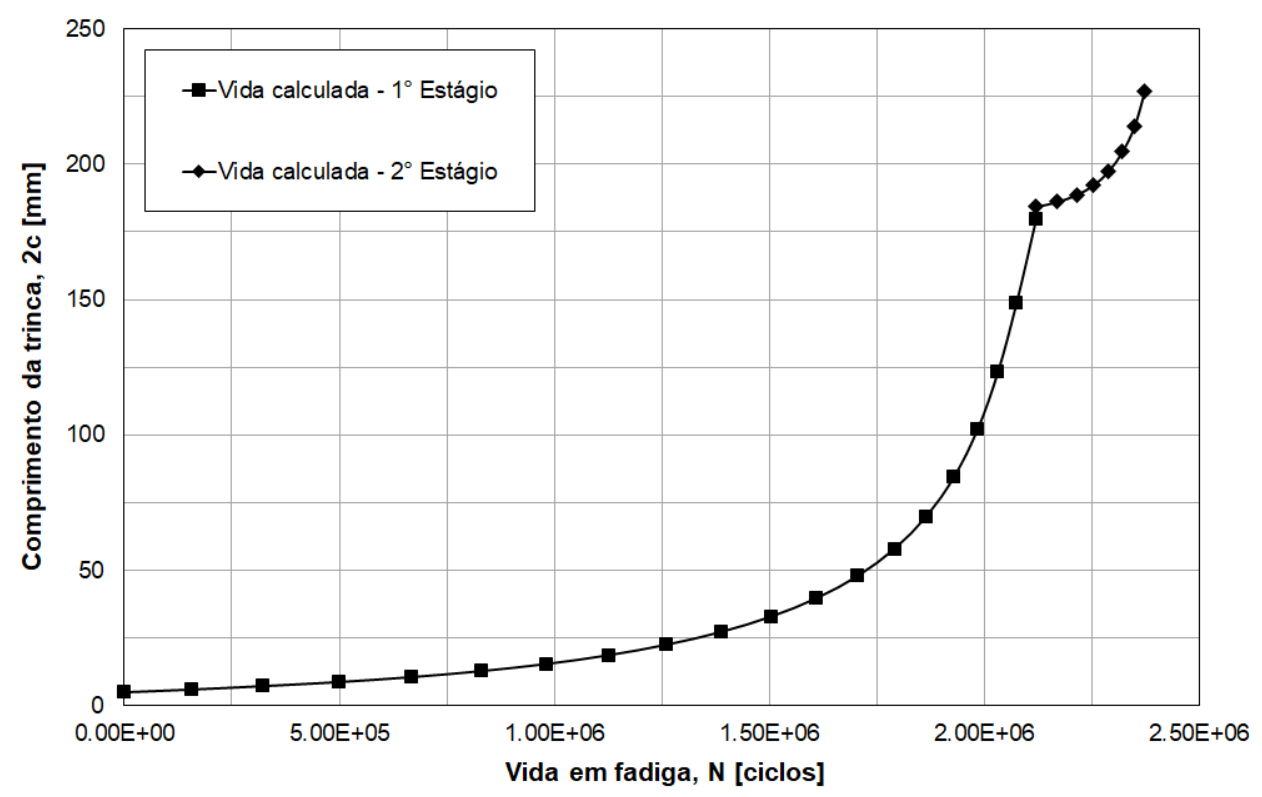

Fonte: Próprio autor. 
Figura 4-24 - Fator de intensidade de tensões equivalente em função do comprimento da trinca - Direção da profundidade da trinca.

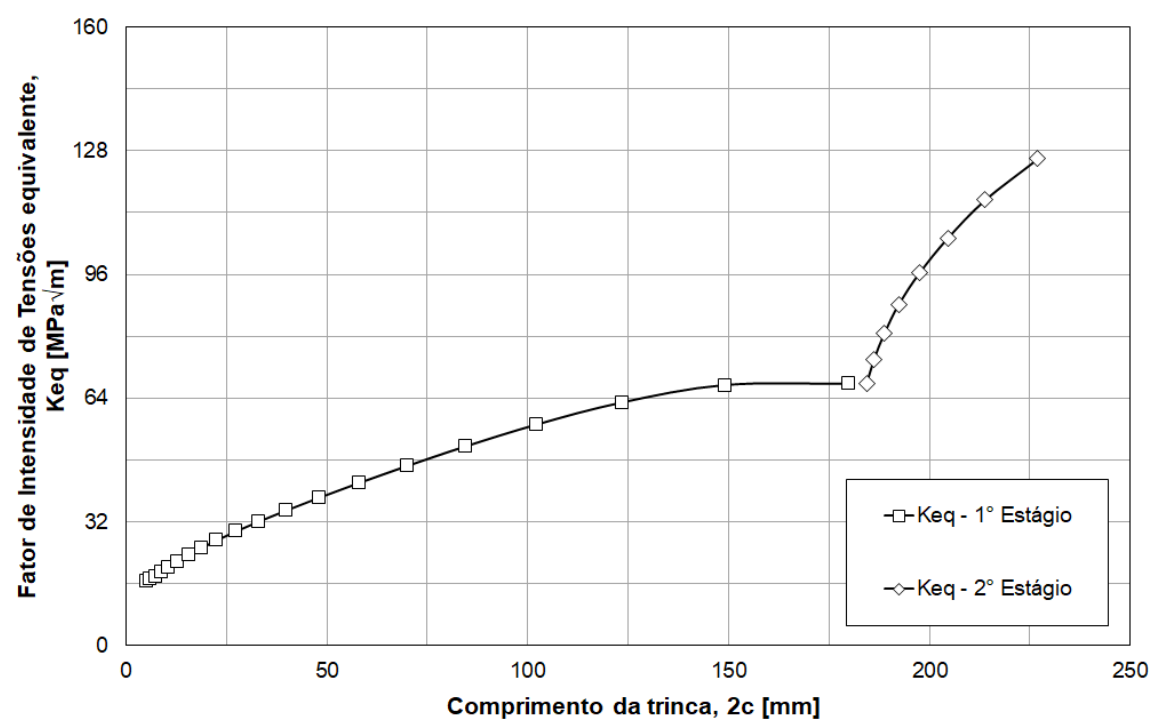

Fonte: Próprio autor.

A descontinuidade nas curvas apresentadas na Figura 4-23 e na Figura 4-24 se deve às diferentes formulações para o fator de intensidade de tensões adotadas para o $1^{\circ}$ estágio (trinca semielíptica) e o $2^{\circ}$ estágio (trinca semielíptica através da espessura) de propagação da trinca. Além disso, na transição entre os estágios, foi necessário recaracterizar o perfil da trinca no momento em que a mesma ultrapassa a espessura da chapa. Neste instante, o comprimento da trinca na direção do cordão de solda é nulo. Desta forma, definiu-se um comprimento que gerasse um fator de intensidade de tensões igual ao da profundidade da trinca semielíptica antes do avanço da mesma pela espessura. A recaracterização da trinca é ilustrada na Figura 4-25.

Figura 4-25 - Recaracterização da trinca na transição entre os estágios de propagação.

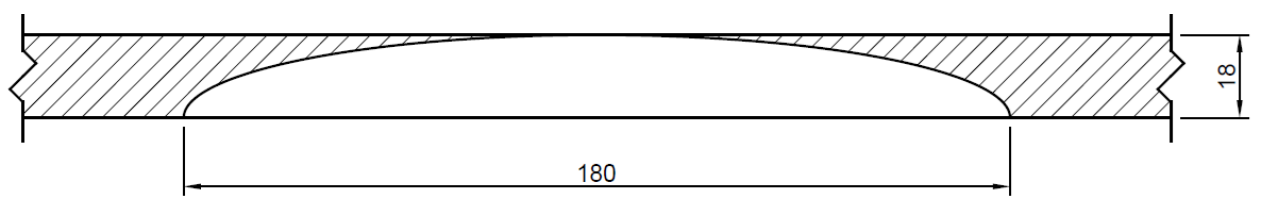

$\underline{\text { Trinca semielíptica }}$

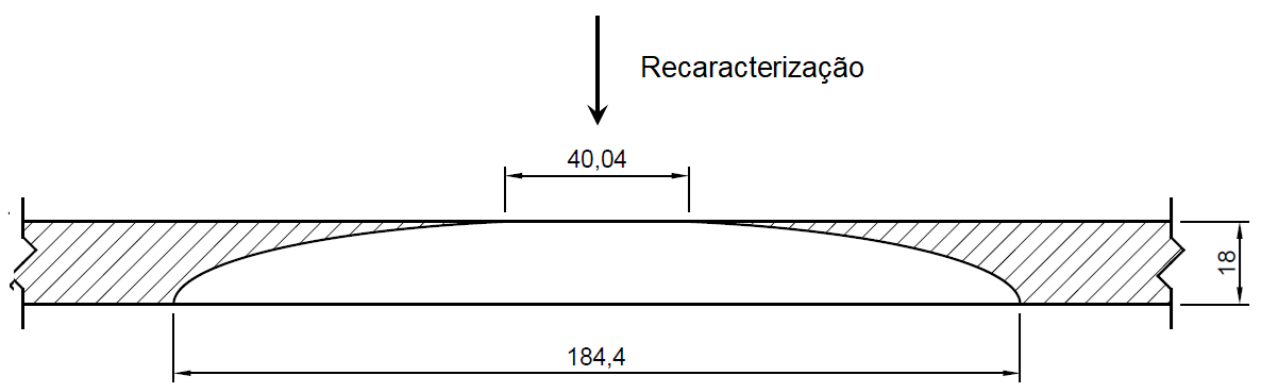

Trinca semielíptica através da espessura

Fonte: Próprio autor. 
A influência do tamanho inicial da trinca sobre a vida em fadiga também foi estudada e pode ser visualizada na Figura 4-26. Avaliando-se os dados obtidos, observa-se uma redução média de $44 \%$ na vida quando variada a profundidade inicial da trinca de $0,1 \mathrm{~mm}$ até 1,0 $\mathrm{mm}$, indicando uma grande sensibilidade da vida em fadiga com a variação do tamanho inicial da trinca, semelhantemente ao indicado por Bannantine et al. [14]. Vê-se também, devido ao paralelismo entre as curvas plotadas, que a presença de tensões residuais não influi na variação percentual da vida em fadiga.

Figura 4-26 - Influência da profundidade inicial da trinca sobre a vida em fadiga - Direção da profundidade da trinca.

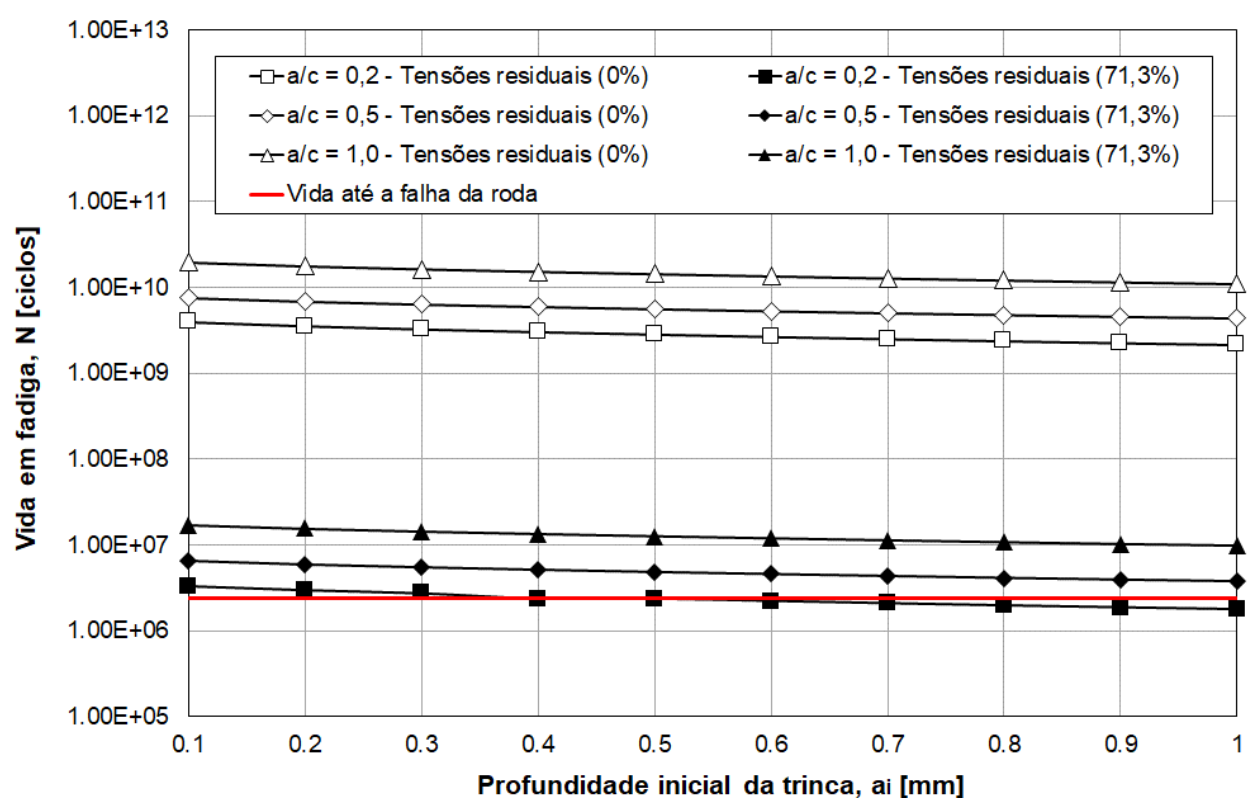

Fonte: Próprio autor.

\subsubsection{Propagação na direção do comprimento da trinca}

Para o estudo de propagação na direção do comprimento da trinca, serão adotadas as mesmas considerações feitas no item 4.4.3 para a direção da profundidade: trinca semielíptica com profundidade inicial $a_{i}$ de $0,5 \mathrm{~mm}$ e avaliação das proporções $a / c$ iguais a 0,2, 0,5 e 1,0.

A Figura 4-27 apresenta a influência das tensões residuais trativas sobre a vida em fadiga na região fraturada da roda de caçambas. Tais tensões são expressas através de um percentual do limite de escoamento do aço Q345B (335 MPa), sendo consideradas constantes na direção transversal ao cordão de solda. 
Pode-se observar que é possível atingir a vida até a falha para as três proporções avaliadas considerando a presença de tensões residuais. Entretanto, o menor valor de tensão residual é igual a $145,7 \mathrm{MPa}(43,5 \%$ do limite de escoamento) para a proporção $a / c$ igual a 0,5 . As tensões residuais são iguais a 189,3 $\mathrm{MPa}$ e a $152,4 \mathrm{MPa}$ para as proporções a/c de 0,2 e 1,0, respectivamente, para que a vida de $2,37 \times 10^{6}$ ciclos seja obtida.

Figura 4-27 - Vida em fadiga em função da presença de tensões residuais - Direção do comprimento da trinca.

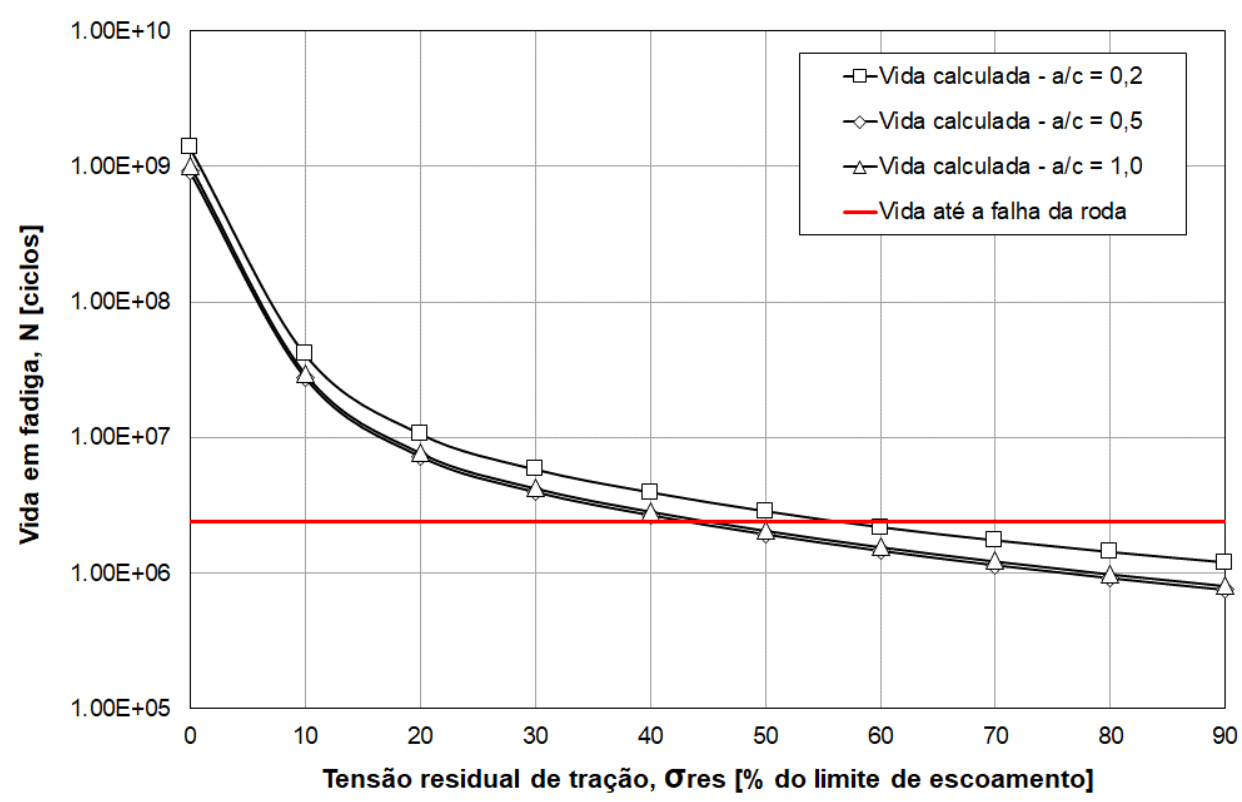

Fonte: Próprio autor.

Quando considerada a tensão residual de $145,7 \mathrm{MPa}$, a tenacidade à fratura $K_{I C}$ de $126 \mathrm{MPa} \sqrt{\mathrm{m}}$ é atingida na frente da trinca para um comprimento de trinca $2 c$ de 299,6 mm, que representa 11,5\% do comprimento do cordão de solda. Após este comprimento, a trinca apresentará um comportamento instável a partir do $2^{\circ}$ estágio, ocorrendo a separação completa entre o cubo e a estrutura principal da roda de caçambas.

A evolução do comprimento da trinca $2 c$ em função da vida em fadiga $N$ pode ser vista na Figura 4-28. A variação do fator de intensidade de tensões equivalente $K_{e q}$ em função do comprimento da trinca $2 c$ é apresentada na Figura 4-29. 
Figura 4-28 - Comprimento da trinca em função da vida em fadiga - Direção do comprimento da trinca.

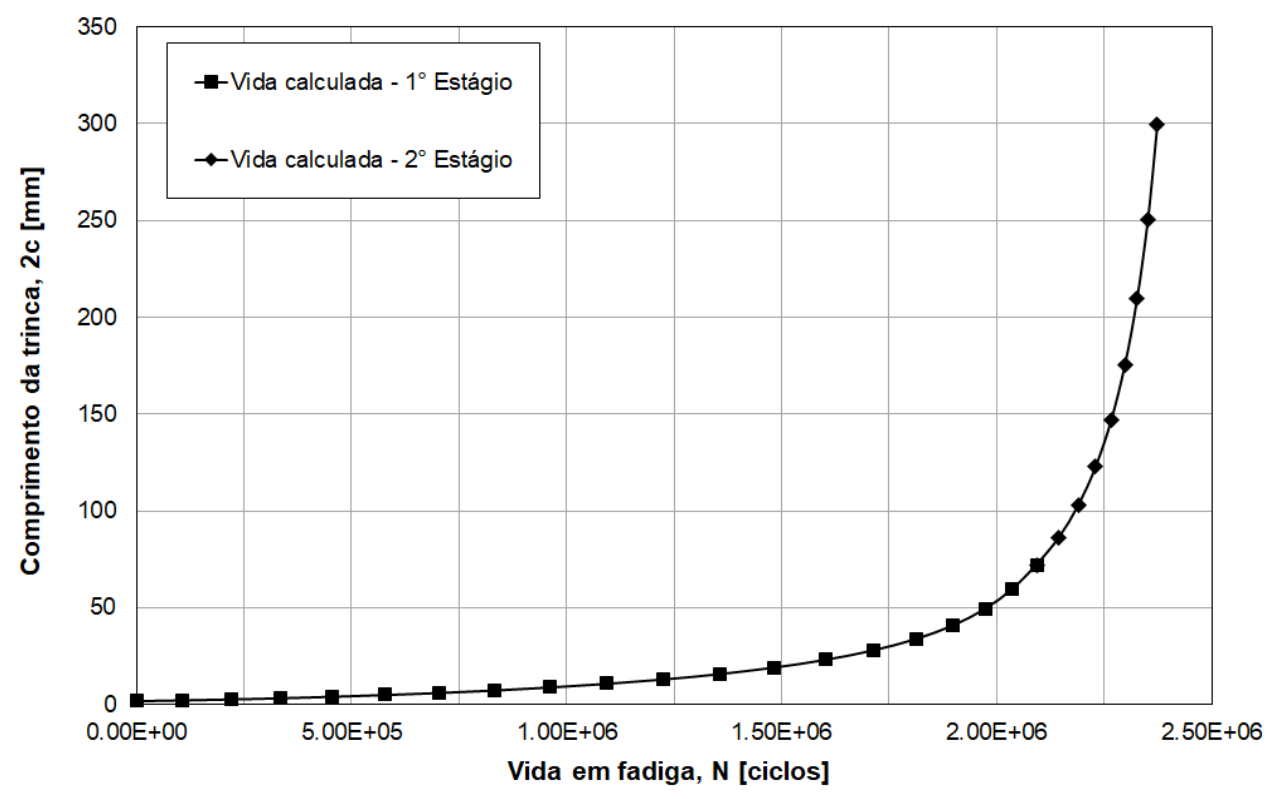

Fonte: Próprio autor.

Figura 4-29 - Fator de intensidade de tensões equivalente em função do comprimento da trinca - Direção do comprimento da trinca.

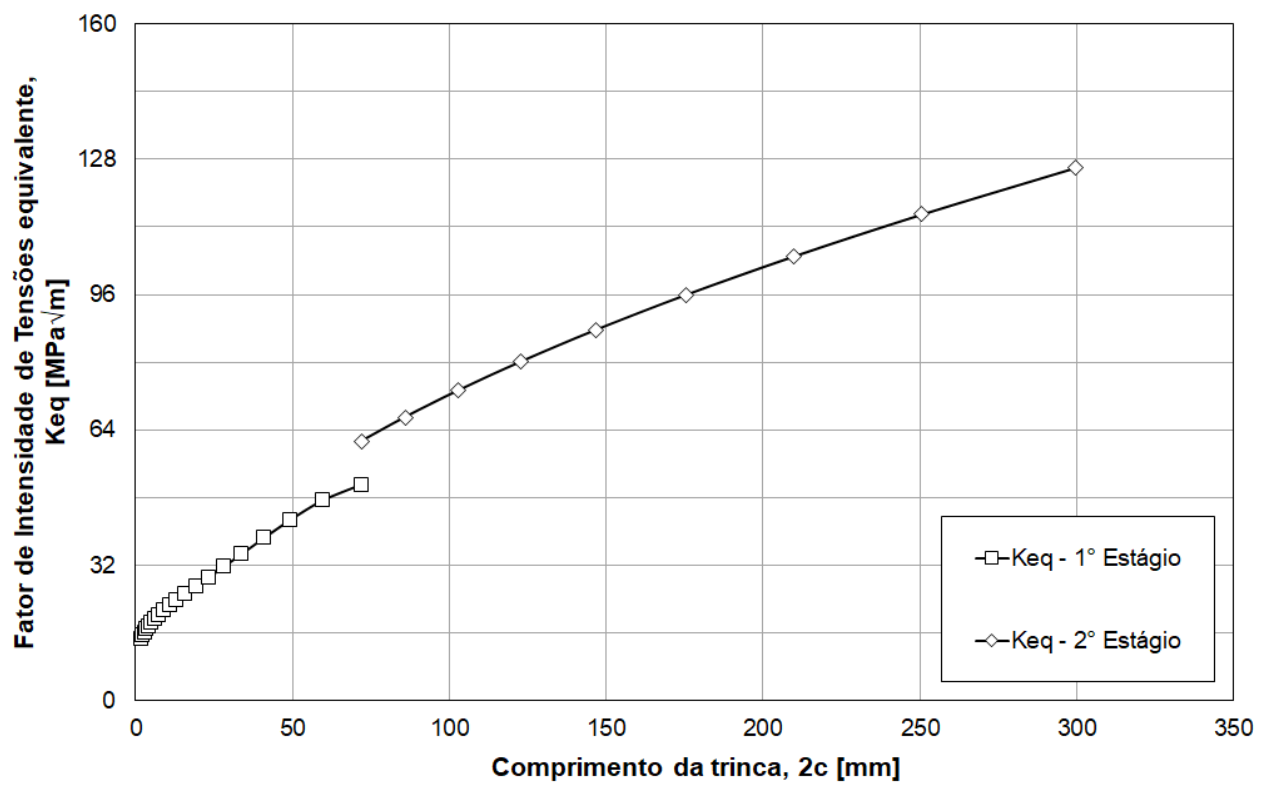

Fonte: Próprio autor.

Assim como para a propagação na direção da profundidade, a curva do fator de intensidade de tensões para a propagação na direção do comprimento apresenta uma descontinuidade em função das diferentes formulações adotadas para a trinca semielíptica do $1^{\circ}$ estágio e para a trinca semielíptica através da espessura do $2^{\circ}$ estágio. Como a avaliação de $K$ ocorre diretamente no comprimento da trinca, seu crescimento é contínuo, sendo desnecessário recaracterizar a trinca. O perfil da trinca obtida é ilustrado na Figura 4-30. 
Figura 4-30 - Perfil da trinca obtida para a propagação na direção do comprimento.

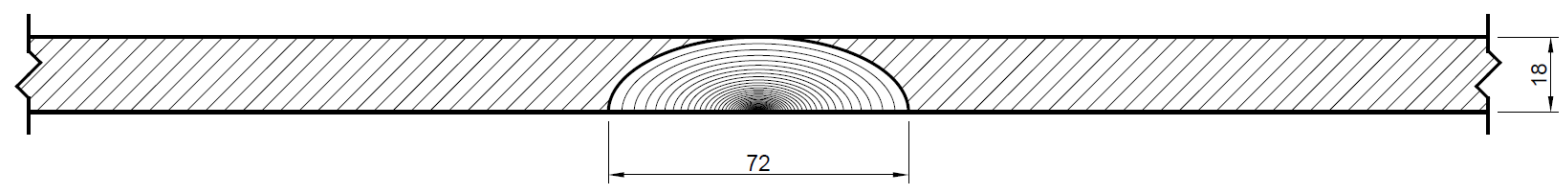

Trinca semielíptica $\left(1^{\circ}\right.$ Estágio)

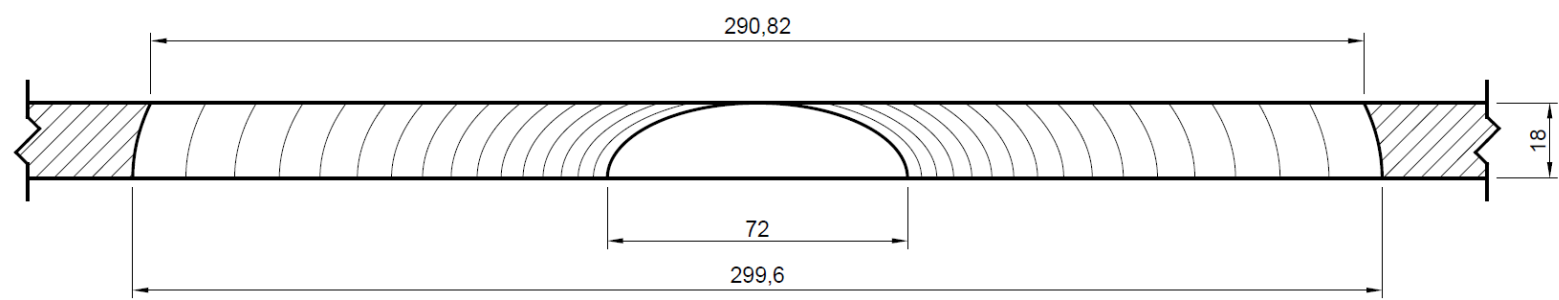

Trinca semielíptica através da espessura $\left(2^{\circ}\right.$ Estágio)

Fonte: Próprio autor.

A variação das tensões residuais e do comprimento crítico da trinca em função da profundidade inicial da trinca semielíptica pode ser observada na Figura 4-31. Considerando a proporção $a / c$ de 0,5 , se a profundidade é alterada de 0,1 até $1,0 \mathrm{~mm}$, as tensões residuais necessárias para a ocorrência da falha em 2,37 x $10^{6}$ ciclos estarão compreendidas entre 52,8\% (176,9 MPa) e $38,1 \%$ (127,6 MPa) do limite de escoamento, enquanto o comprimento crítico da trinca estará entre $221,7 \mathrm{~mm}$ e $363,9 \mathrm{~mm}$. Desta forma, quanto menor a profundidade inicial da trinca, maior será o nível de tensões residuais necessário para que a vida estimada até a falha seja atingida. Consequentemente, um menor comprimento crítico para a trinca será obtido.

Figura 4-31 - Tensões residuais e comprimento crítico da trinca em função da profundidade inicial da trinca Direção do comprimento da trinca.

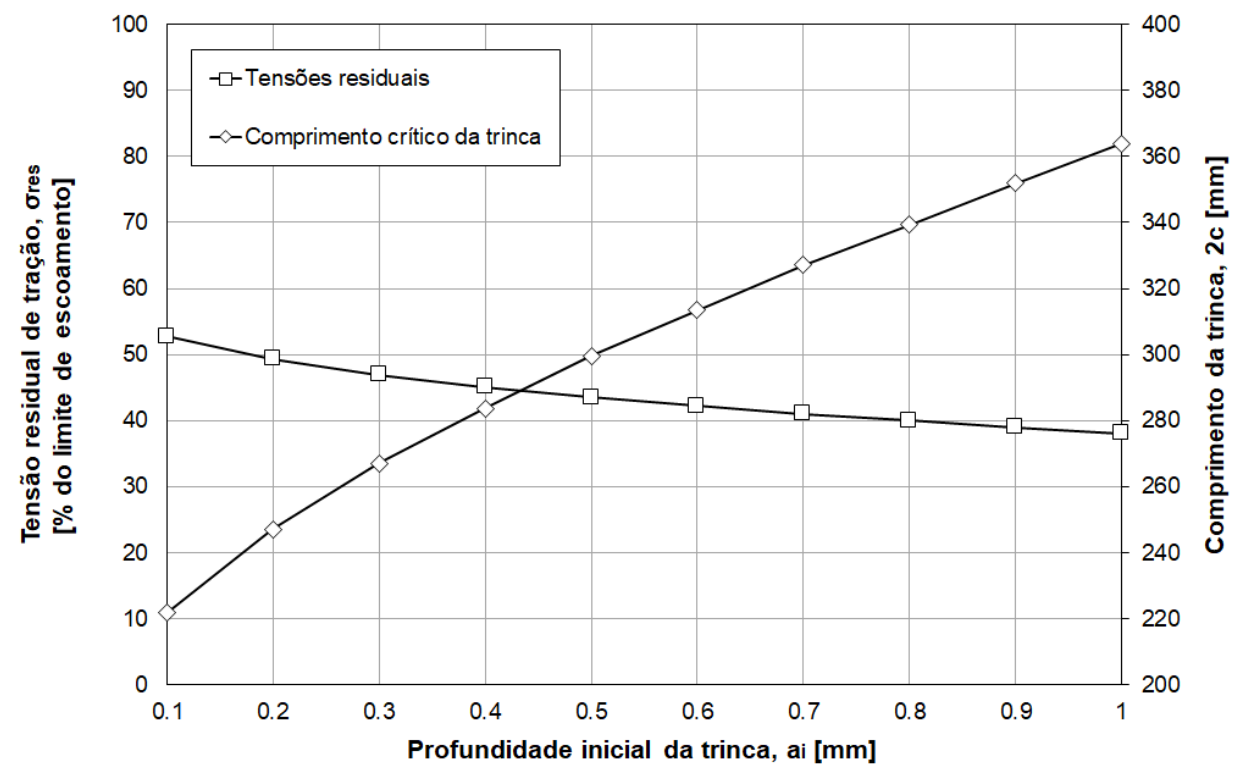

Fonte: Próprio autor. 
Nas análises realizadas, verifica-se que o efeito de superposição das tensões residuais sobre as tensões atuantes contribui diretamente na determinação do comprimento crítico da trinca, uma vez que o fator de intensidade de tensões para este comprimento depende da tensão máxima atuante. Por outro lado, tensões residuais não são cíclicas e, desta forma, sua única influência sobre a variação do fator de intensidade de tensões efetivo está relacionada ao parâmetro $U$, relativo ao fenômeno de fechamento de trinca. A variação de tensões atuantes não se altera em função da presença de tensões residuais.

Observa-se também que baixos níveis de tensão residual de tração (da ordem de 10\% do limite de escoamento) são capazes de anular as tensões de compressão atuantes na estrutura, e fazer com que a razão de tensões se torne positiva. Este efeito é prejudicial para a vida em fadiga da estrutura, uma vez que o fenômeno de fechamento da trinca passa a ter um impacto menos significativo ou mesmo nulo durante a propagação da trinca.

Quando comparada a vida em fadiga para a propagação na direção da profundidade (Figura 4-22) e do comprimento (Figura 4-27), observa-se que, para um mesmo nível de tensões residuais, a trinca cresce de forma mais acelerada na direção do comprimento. Este fato está relacionado a dois fatores: o fator de intensidade de tensões equivalente $K_{e q}$ e o fator de amplificação $M_{k}$.

Como mostrado na Figura 4-15, $K_{I}$ influencia o crescimento da trinca tanto na direção da profundidade quanto na direção do comprimento, enquanto que $K_{I I}$ induz o crescimento apenas na direção do comprimento. Desta forma, um modo misto de tração e cisalhamento será formado somente nesta direção, levando à obtenção de um fator de intensidade de tensões equivalente superior às parcelas $K_{I}$ e $K_{I I}$. A Figura 4-32 ilustra a relação entre o fator de intensidade de tensões equivalente e a curva limite de fratura proposta por Richard et al. [20] para a representação de um modo misto, considerando a proporção $a / c$ de 0,5 . Pontos sobre a curva apresentam $K$ equivalente igual à tenacidade à fratura $K_{I C}$. 
Figura 4-32 - Relação entre o fator de intensidade de tensões equivalente e a curva limite de fratura.

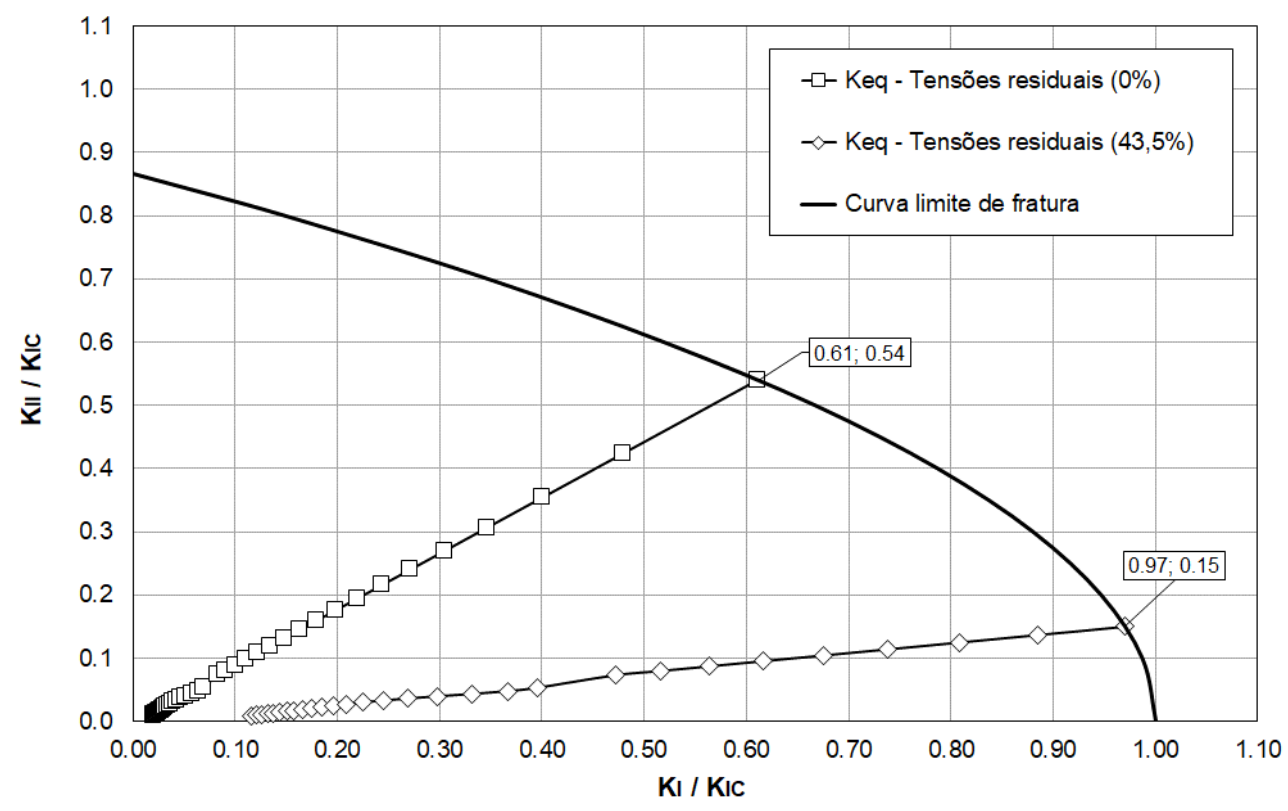

Fonte: Próprio autor.

Para o estado de tensões observado na roda de caçambas (veja Figura 4-7 e Tabela 4-4), constata-se que o efeito da combinação entre os modos de tração e de cisalhamento é mais pronunciado na ausência de tensões residuais, uma vez que a presença destas desequilibra a proporção das tensões normais em relação às tensões cisalhantes.

Com relação ao fator de amplificação $M_{k}$, observa-se que o fator para uma proporção $a / c$ de 0,5 na direção do comprimento $M_{k, c}$ é superior ao fator para uma proporção $a / c$ de 0,2 na direção da profundidade $M_{k, a}$ desde trincas muito pequenas até trincas profundas em relação à espessura da chapa (veja comparativo na Figura 4-33). Isto faz com que o tempo necessário para o crescimento da trinca semielíptica na direção do comprimento seja menor, independentemente do nível de tensões residuais considerado. Como mais de $80 \%$ da vida em fadiga é consumida ainda no $1^{\circ}$ estágio de propagação, o efeito do fator $M_{k}$ torna-se ainda mais representativo na avaliação por mecânica da fratura. 
Figura 4-33 - Comparativo entre o fator de amplificação $M_{k}$ para a direção da profundidade e para o comprimento da trinca.

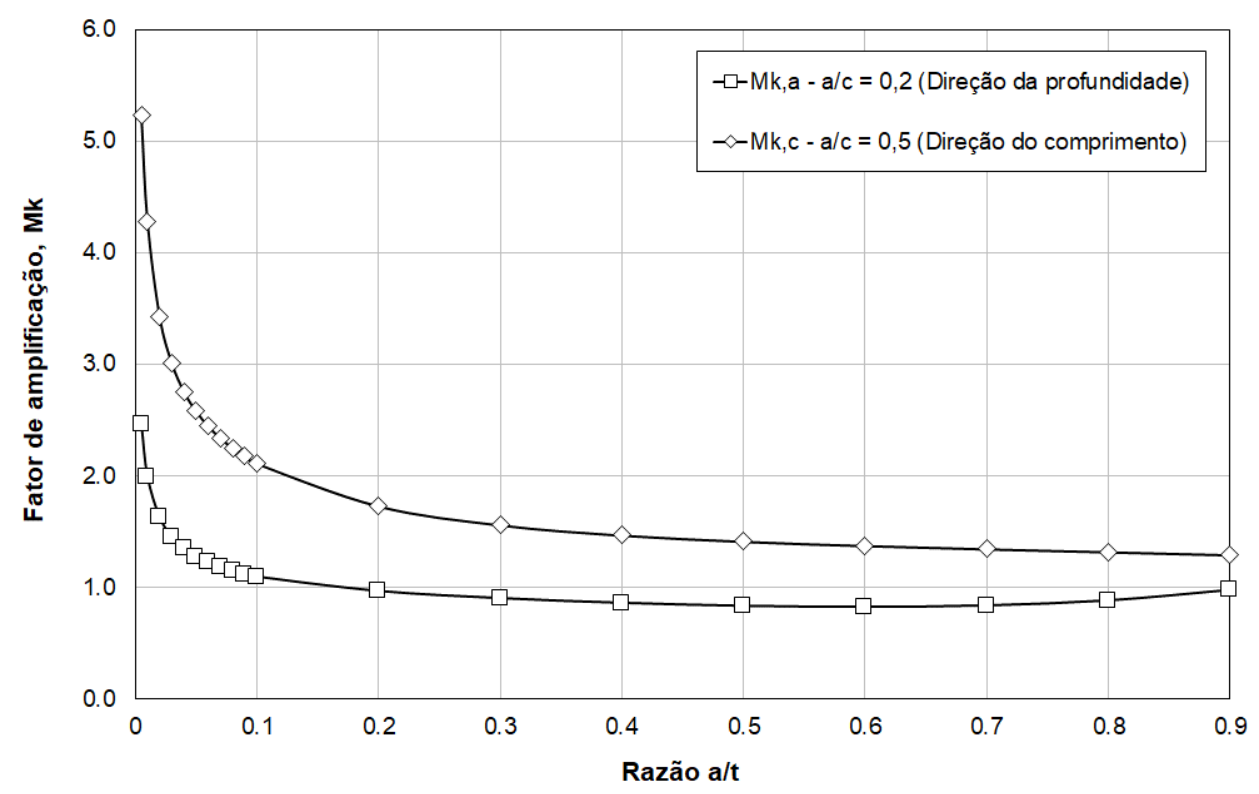

Fonte: Próprio autor.

O perfil de tensões residuais na junta soldada da roda de caçambas está sendo tratado neste trabalho como positivo (tração) e constante na direção transversal ao cordão de solda. Esta consideração tem caráter conservador e se baseia em uma das abordagens apresentadas pela norma BS 7910 [24] no estudo de propagação de trincas quando não há dados experimentais disponíveis. Nesta abordagem, pode ser considerado um nível de tensões residuais uniforme e igual ao menor valor entre os limites de escoamento do metal de base e do metal de solda. Mesmo em casos em que há alívio de tensões após a soldagem, a norma BS 7910 [24] sugere a adoção de tensões residuais transversais ao cordão de solda iguais a $20 \%$ do limite de escoamento.

A outra abordagem adotada pela norma BS 7910 [24] é referente à utilização de perfis não uniformes para a distribuição de tensões residuais ao longo da espessura da chapa. Bate et al. [66] realizaram experimentos para a determinação de tensões residuais em soldas de penetração total de juntas “T”. A Figura 4-34 ilustra os dados de tensão residual obtidos experimentalmente pelos autores. No eixo da abscissa, é representada a posição relativa ao longo da espessura, enquanto que o eixo da ordenada indica o valor das tensões residuais expresso por meio de uma proporção em relação ao limite de escoamento. 
Figura 4-34 - Dados de tensão residual obtidos experimentalmente em juntas " $\mathrm{T}$ ”.

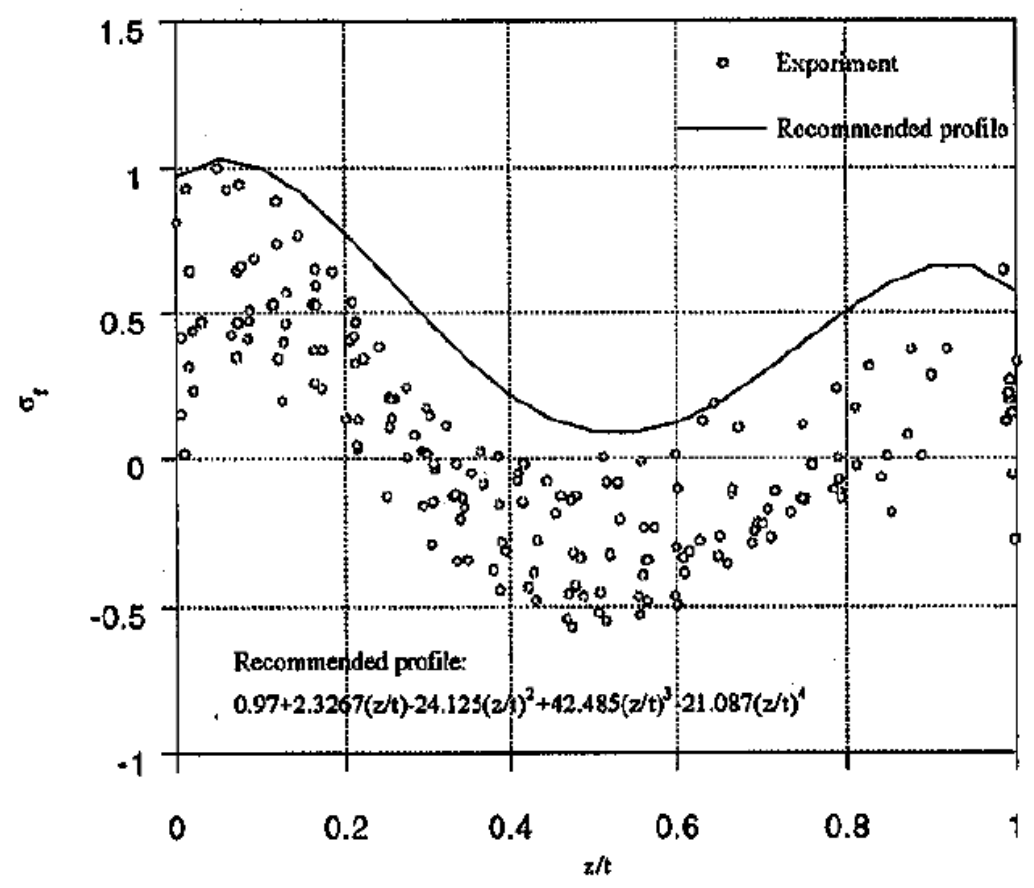

Fonte: Retirado de Bate et al. [66].

Nos dados experimentais obtidos por Bate et al. [66], observam-se tensões residuais tão elevadas quanto o limite de escoamento e também tensões residuais compressivas de até 50\% do escoamento. Embora tenham sido apresentados tais dados, Bate et al. [66] recomendam a utilização de um perfil majoritariamente trativo indicado pela linha cheia na Figura 4-34. Tal perfil também é adotado pela norma BS 7910 [24].

Especificamente no caso de rodas de caçambas, Arsić et al. [44] estudaram a ocorrência de fratura em juntas soldadas de uma roda de caçambas (veja localização das trincas na Figura 2-25). Tais autores instalaram rosetas para medição de tensões residuais em pontos próximos às soldas de partes da roda que não apresentaram falha, como ilustrado na Figura 4-35. Os resultados indicaram a ocorrência de tensões residuais transversais à solda com valores entre +196 $\mathrm{MPa}$ (ponto 2) e +300 MPa (ponto 4) na zona termicamente afetada, entre +169 MPa (ponto 5) e +334 MPa (ponto 7) na solda e entre -154 MPa (ponto 9) e +104 MPa (ponto 3) no metal de base. O limite de escoamento do aço da roda (S355J2G3) é de $355 \mathrm{MPa}$. 
Figura 4-35 - Pontos de medição de tensões residuais na roda de caçambas da escavadora SRs 1300.

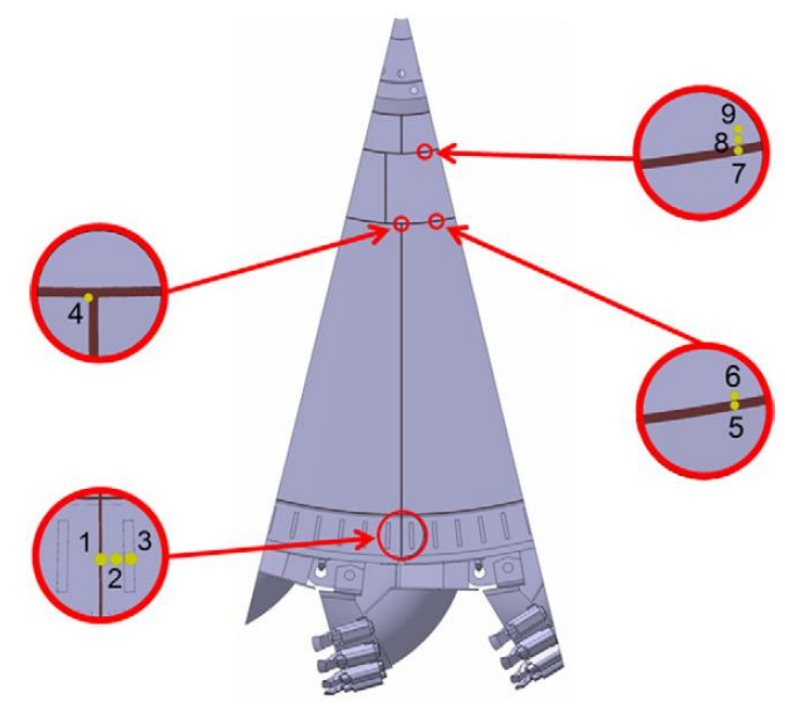

Fonte: Retirado de Arsić et al. [44].

Considerando o perfil de tensões residuais não uniformes ilustrado na Figura 4-34, realizou-se novamente a avaliação de propagação da trinca. Destaca-se que tal perfil se refere apenas ao $1^{\circ}$ estágio de propagação (trinca semielíptica). Após a espessura ser ultrapassada pela trinca, foram adotadas tensões residuais constantes de $191 \mathrm{MPa}$ ( $57 \%$ do limite de escoamento), sendo este valor obtido para uma razão unitária entre a profundidade da trinca e a espessura. A evolução do comprimento da trinca $2 c$ em função da vida em fadiga $N$ pode ser vista na Figura 4-36. A variação do fator de intensidade de tensões equivalente $K_{e q}$ em função do comprimento da trinca $2 c$ é apresentada na Figura 4-37.

Figura 4-36 - Comprimento da trinca em função da vida em fadiga considerando o perfil de tensões residuais proposto por Bate et al.

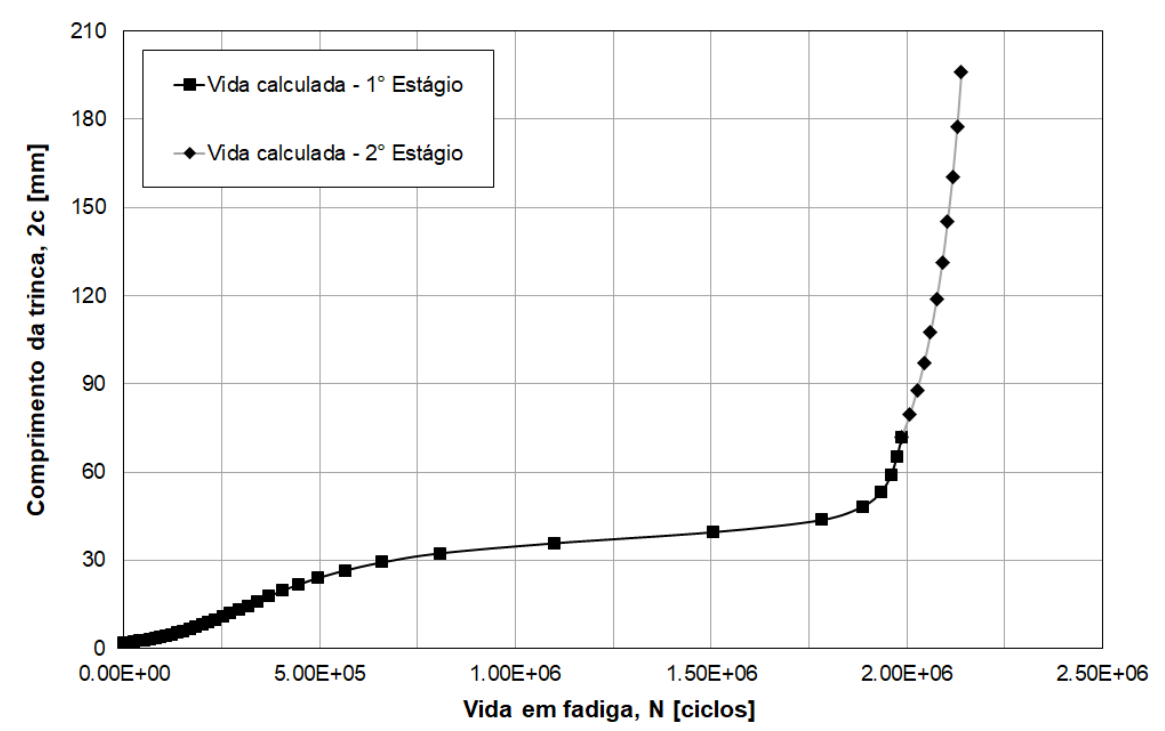

Fonte: Próprio autor. 
Figura 4-37 - Fator de intensidade de tensões equivalente em função do comprimento da trinca considerando o perfil de tensões residuais proposto por Bate $e t a l$.

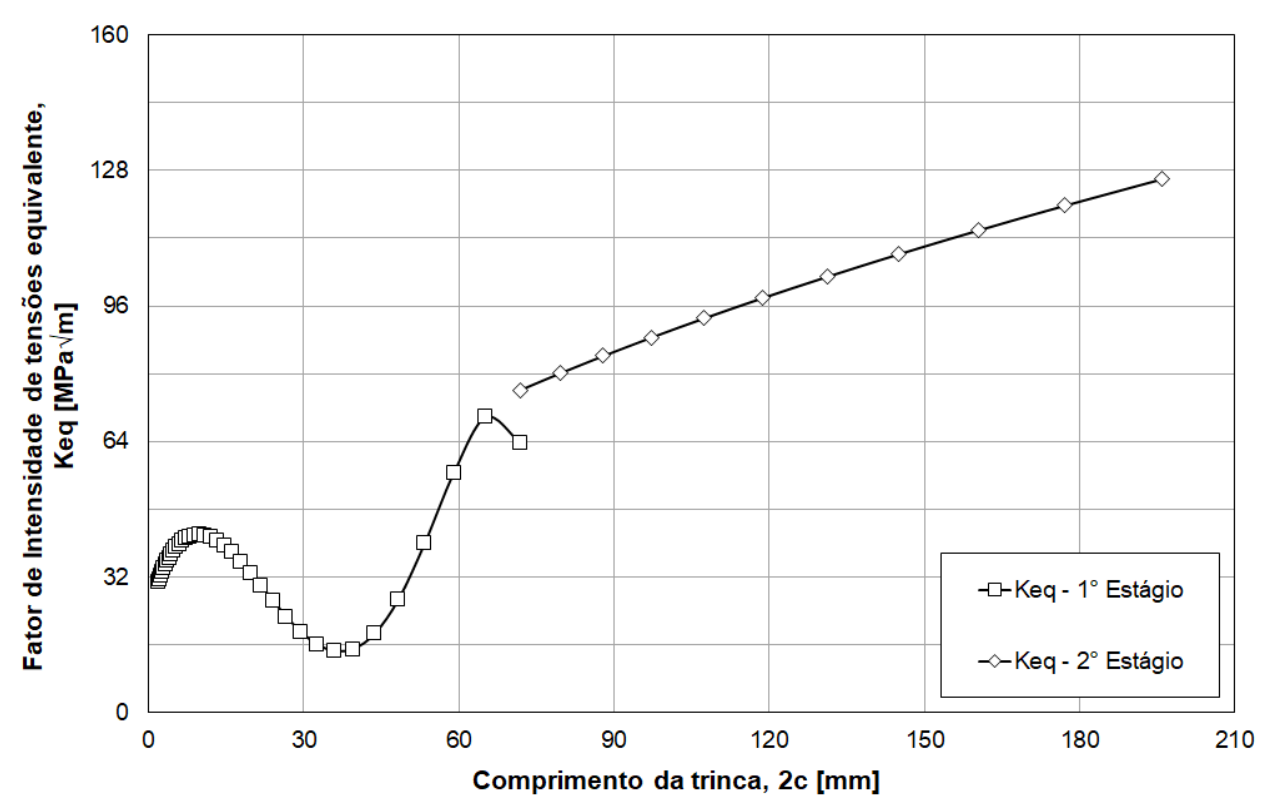

Fonte: Próprio autor.

Verifica-se que são necessários 2,14 × $10^{6}$ ciclos para que a trinca cresça até um comprimento crítico $2 c$ de $195,9 \mathrm{~mm}$, sendo atingida a tenacidade à fratura de $126 \mathrm{MPa} \sqrt{\mathrm{m}}$ para este comprimento. A vida calculada foi inferior à vida estimada até a falha da roda de caçambas $\left(2,37 \times 10^{6}\right.$ ciclos). Devido ao perfil de tensões residuais considerado, observa-se que a trinca tem um crescimento mais acentuado no início da propagação, em função da ocorrência de tensões residuais com valor próximo ao limite de escoamento do material. Novamente, a descontinuidade entre o fator de intensidade de tensões do $1^{\circ}$ e $2^{\circ}$ estágios se refere à adoção de diferentes formulações para o cálculo de $K$.

A propagação da trinca na roda de caçambas desconsiderando-se qualquer influência das tensões residuais também foi avaliada. Verificou-se que, para que a falha da junta soldada ocorresse no período de aproximadamente um ano de operação, seria necessário que a trinca tivesse um comprimento inicial de $1374,9 \mathrm{~mm}$ e fosse completamente passante pela espessura ( $3^{\circ}$ estágio) em toda a sua extensão. O comprimento crítico para que a trinca se torne instável é igual a 1809,2 mm. Tendo em vista que o cordão de solda possui um comprimento aproximado de 2600 mm, torna-se uma condição improvável que tal trinca não tenha sido detectada ao final do processo de fabricação da roda de caçambas. 
A evolução do comprimento da trinca $2 c$ em função da vida em fadiga $N$ pode ser vista na Figura 4-38. A variação do fator de intensidade de tensões equivalente $K_{e q}$ em função do comprimento da trinca $2 c$ é apresentada na Figura 4-39.

Figura 4-38 - Comprimento da trinca em função da vida em fadiga desconsiderando a ocorrência de tensões residuais.

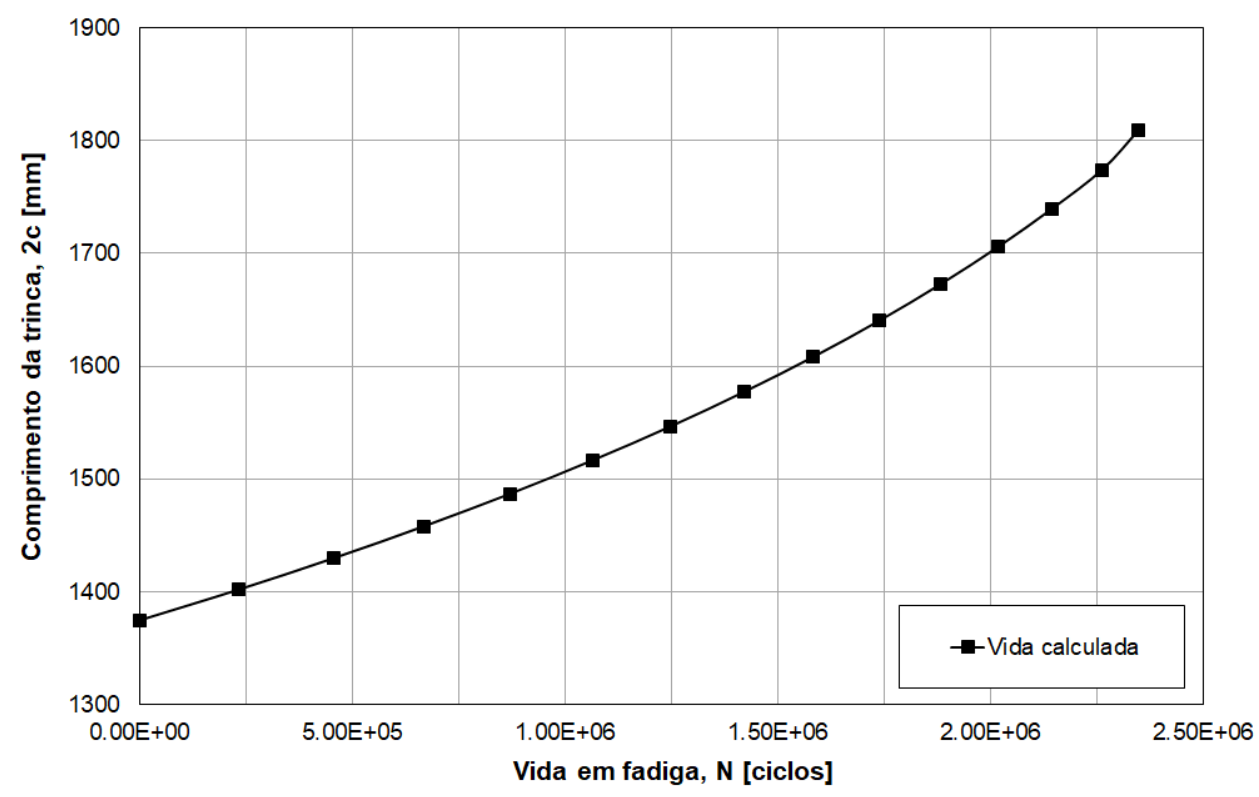

Fonte: Próprio autor.

Figura 4-39 - Fator de intensidade de tensões em função do comprimento da trinca desconsiderando a ocorrência de tensões residuais.

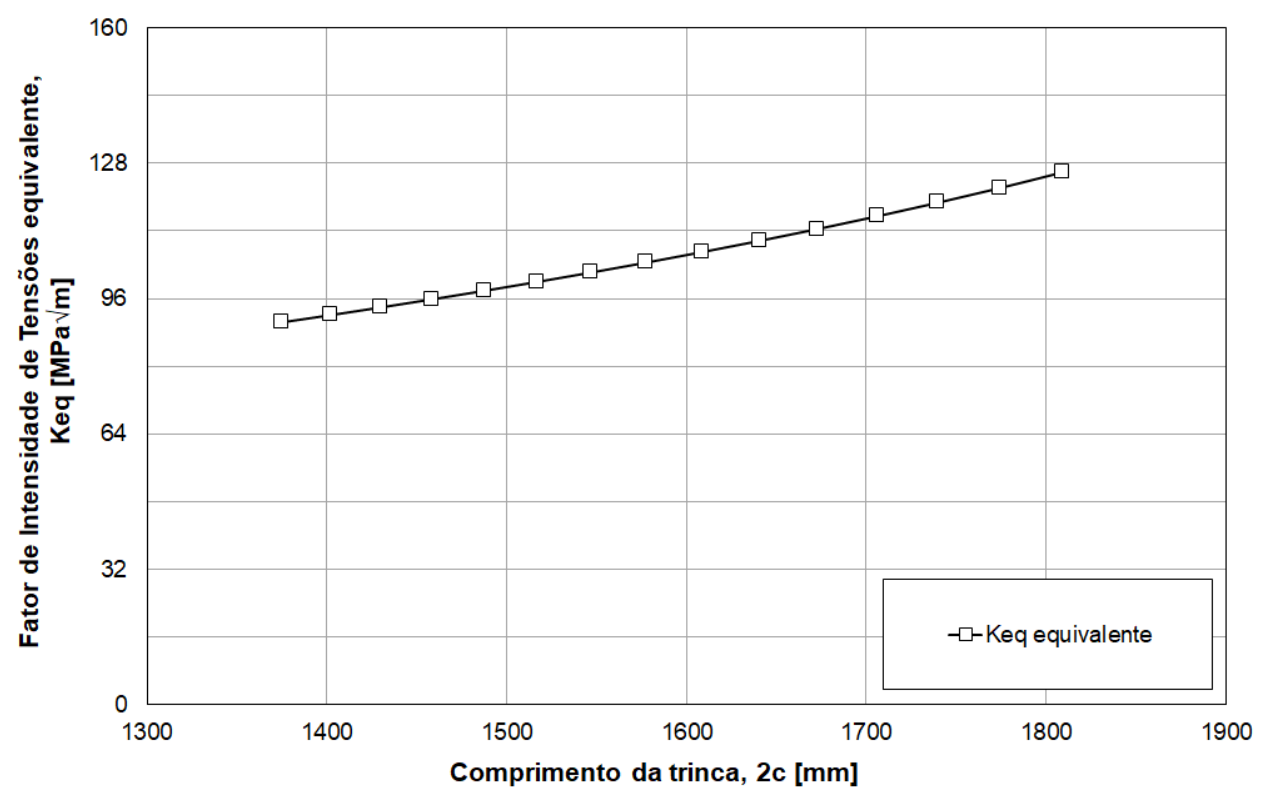

Fonte: Próprio autor. 


\subsection{Verificação conforme as recomendações do IIW}

A partir da geometria da junta soldada em estudo, verificou-se a compatibilidade da mesma e dos esforços atuantes com o detalhe de solda $n^{\circ} 415$ do IIW [42]. Este detalhe se refere a juntas cruciformes ou em "T" compostas por soldas de penetração total biseladas em "V", com potencial de falha no pé do cordão de solda. Considerando-se a realização de inspeção na solda, a classe de fadiga $F A T$ é igual a 71, e em caso contrário, é definido um valor igual a 36 para a classe FAT. Em relação ao cisalhamento, adotou-se conservadoramente FAT igual a 80 por ser a classe com menor resistência à fadiga. A Figura 4-40 ilustra a classe de fadiga adotada na análise da roda de caçambas.

Figura 4-40 - Classe de fadiga para o detalhe de solda analisado na roda de caçambas.

\begin{tabular}{l|l|l|l|l|l}
\hline No. & Structural Detail & $\begin{array}{l}\text { Description } \\
\text { (St. = steel; Al. = aluminium) }\end{array}$ & $\begin{array}{l}\text { FAT } \\
\text { St. }\end{array}$ & $\begin{array}{l}\text { FAT } \\
\text { Al. }\end{array}$ & Requirements and remarks \\
\hline 415 & $\begin{array}{l}\text { Cruciform joint or T-joint, single-sided arc or laser } \\
\text { beam welded V-butt weld, full penetration, } \\
\text { potential failure from weld toe. Full penetration } \\
\text { checked by inspection of root } \\
\text { If root is not inspected, then root crack }\end{array}$ & 71 & 25 & $\begin{array}{l}\text { Advisable to ensure that intermediate plate was } \\
\text { checked against susceptibility to lamellar tearing } \\
\text { Misalignment }<15 \% \text { of primary plate thickness in } \\
\text { cruciform joints }\end{array}$ \\
\hline
\end{tabular}

Fonte: Retirado de IIW [42].

As variações de tensões normais $\Delta \sigma_{e q, S, d}$ e cisalhantes $\Delta \tau_{e q, S, d}$ foram calculadas utilizando-se a Eq. (2.27) com base nos dados apresentados na Tabela 4-4. Para $\Delta \sigma_{e q, S, d}$, foi obtido um valor de 49,8 MPa, e para $\Delta \tau_{e q, S, d}$, obteve-se o valor de 13,9 MPa. As variações de tensões admissíveis em fadiga $\Delta \sigma_{R, d}$ e $\Delta \tau_{R, d}$ foram corrigidas para a estimativa de vida da roda de caçambas de 2,37 x $10^{6}$ ciclos. O resultado da combinação entre tensões normais e cisalhantes, realizada por meio da Eq. (2.28), é apresentado na Tabela 4-5.

Tabela 4-5 - Combinação entre tensões normais e cisalhantes.

\begin{tabular}{c|c|c|c|c|c}
\hline $\begin{array}{c}\text { Classe de } \\
\text { fadiga }\end{array}$ & $\begin{array}{c}\Delta \sigma_{\text {eq,S,d }} \\
{[\mathrm{MPa}]}\end{array}$ & $\begin{array}{c}\Delta \sigma_{\mathrm{R}, \mathrm{d}}[\mathrm{MPa}] \\
\left(\mathrm{N}=2,37 \times 10^{6}\right)\end{array}$ & $\begin{array}{c}\Delta \tau_{\mathrm{eq}, \mathrm{S}, \mathrm{d}} \\
{[\mathrm{MPa}]}\end{array}$ & $\begin{array}{c}\Delta \tau_{\mathrm{R}, \mathrm{d}}[\mathrm{MPa}] \\
\left(\mathrm{N}=2,37 \times 10^{6}\right)\end{array}$ & $\mathrm{IU}$ \\
\hline FAT 71 & 49,8 & 67,1 & 13,9 & 77,4 & 0,58 \\
\hline
\end{tabular}

Fonte: Próprio autor.

$\mathrm{Na}$ análise de fadiga, verifica-se que a junta soldada estaria aprovada no critério de tensões combinadas (IU $\leq 1)$, uma vez que os desenhos de projeto indicam a necessidade de inspeções por ultrassom na roda de caçambas (consideração da classe FAT 71). 
A Figura 4-41 apresenta a verificação de fadiga com base nas curvas S-N para se determinar a vida em fadiga. Na roda de caçambas, verifica-se que a mudança de direção das tensões principais máximas atende aos requisitos indicados pelo IIW [42], e não se observam diferenças significativas da magnitude da variação destas tensões em relação à variação de tensões normais equivalente. Desta forma, esta última foi adotada na determinação da vida em fadiga.

Figura 4-41 - Plotagem dos resultados da análise sobre a curva de resistência em fadiga.

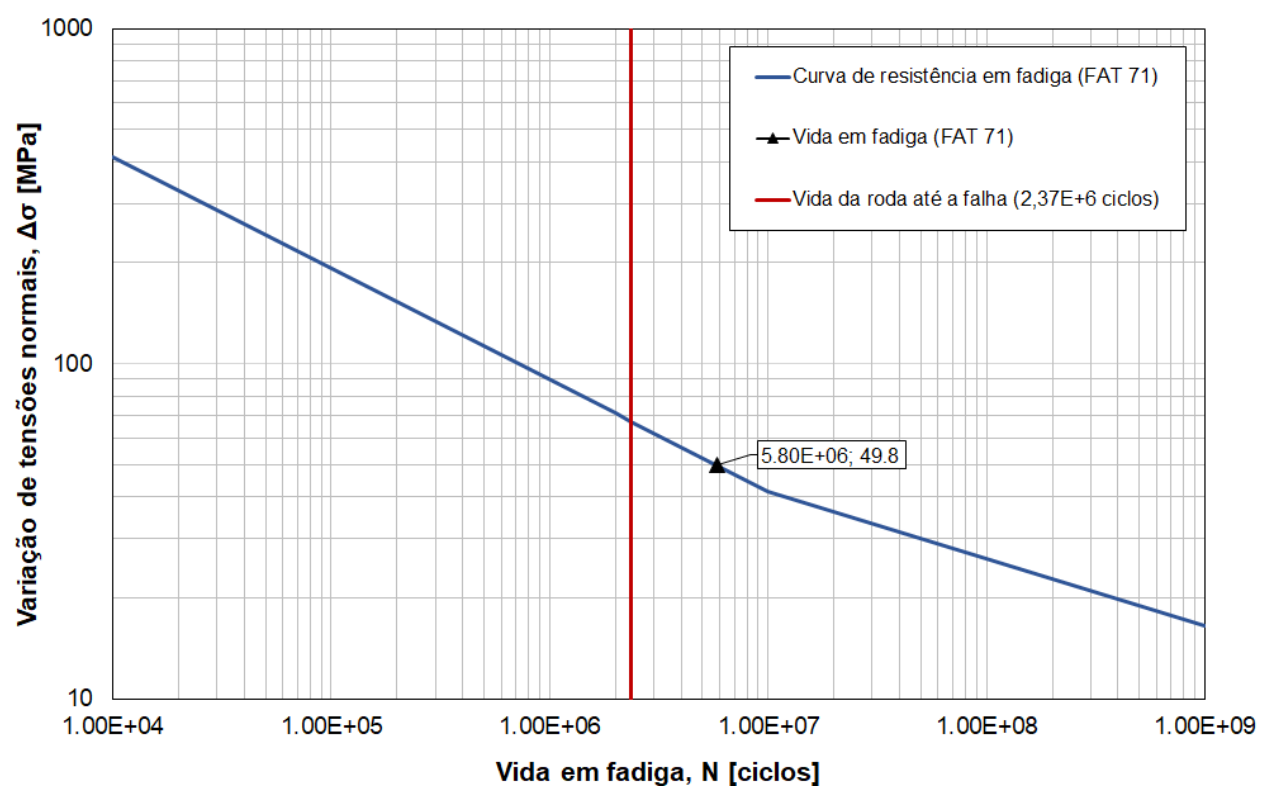

Fonte: Próprio autor.

No gráfico da Figura 4-41, observa-se que uma vida em fadiga de 5,80 x $10^{6}$ ciclos é obtida na análise, sendo este valor superior à vida de $2,37 \times 10^{6}$ ciclos até a falha da roda de caçambas. Este resultado está consonância com o indicado na Tabela 4-5. Deve-se destacar que a vida obtida com base nas recomendações do IIW [42] é relativa à ocorrência de uma trinca que proporcione a ruptura completa da seção transversal da chapa em estudo, uma vez que a definição do valor da classe de fadiga FAT adota este critério de falha.

Na Figura 4-42, é realizada a avaliação do critério de Goodman para a vida em fadiga da roda de caçambas. Dois pontos são plotados: o primeiro $(5,7 ; 24,9)$ representa o par $\left(\sigma_{m} ; \sigma_{a}\right)$ considerando-se as tensões apresentadas na Tabela 4-4. O segundo $(121,6 ; 24,9)$ representa uma extrapolação do valor de tensão residual de tração na solda necessário para alterar a tensão média de forma que a vida em fadiga de 2,37 × $10^{6}$ ciclos seja obtida, ou seja, quando o ponto de trabalho intercepta a curva de Goodman. 
Figura 4-42 - Avaliação do critério de Goodman para a vida em fadiga da roda de caçambas.

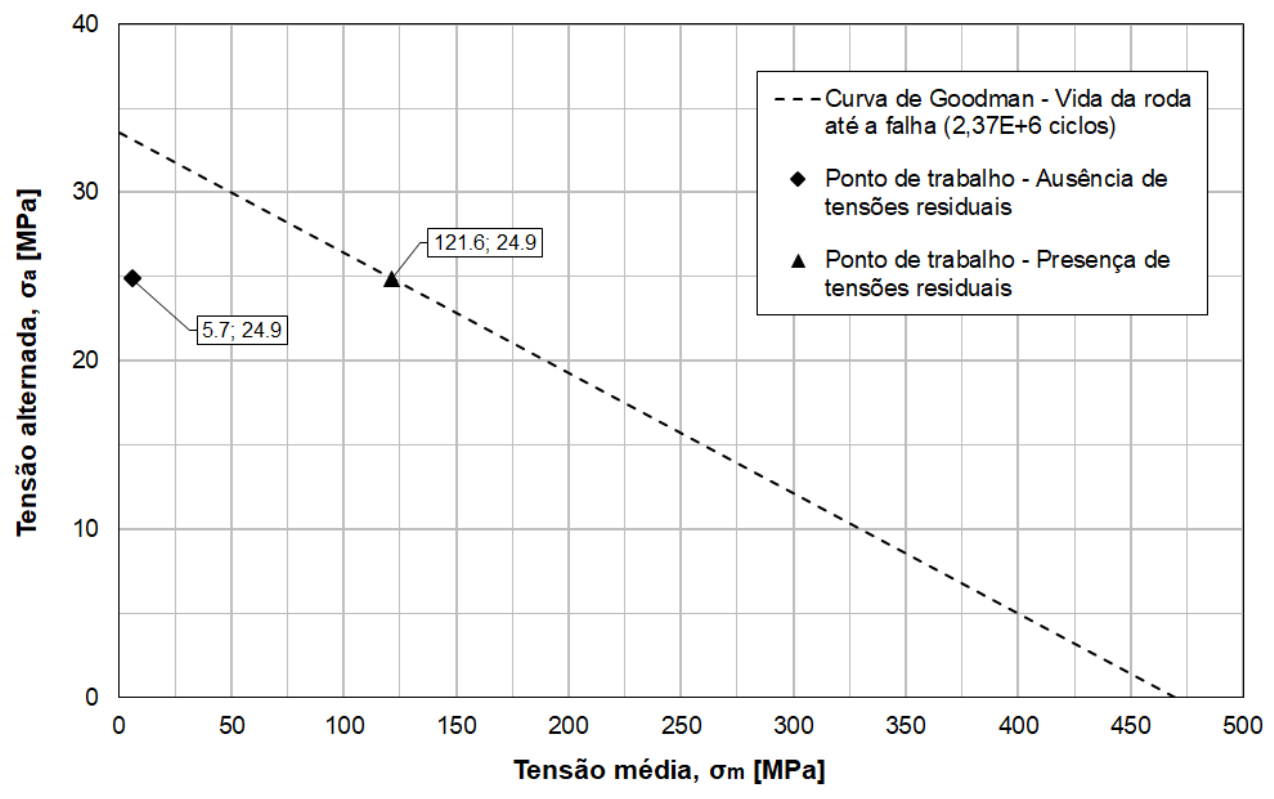

Fonte: Próprio autor.

Esta metodologia foi utilizada por Arsić et al. [44] para avaliar o efeito de tensões residuais sobre a falha por fadiga de soldas em uma roda de caçambas. Na análise deste trabalho, é possível estimar uma tensão residual de tração igual a $115,9 \mathrm{MPa}$, que representa $34,6 \%$ do limite de escoamento do aço de fabricação da roda. 


\subsection{CONCLUSÕES}

O estudo de propagação de trinca com base na Mecânica da Fratura Linear Elástica demonstrou que uma trinca inicial preexistente na estrutura, decorrente do processo de fabricação do equipamento, pode ter sido a causa da falha prematura da roda de caçambas. As tensões atuantes, obtidas no modelo de elementos de finitos da roda de caçambas, são muito inferiores ao limite de escoamento do aço de fabricação da roda, e, desta forma, não comprometeram sua integridade estrutural.

A análise permitiu verificar que uma vida coerente com a estimativa de ciclos até a falha da roda em campo pode ser obtida, considerando-se a propagação de uma trinca semielíptica com profundidade inicial de $0,5 \mathrm{~mm}$ em um campo de tensões residuais uniforme de tração de 145,7 $\mathrm{MPa}$, que representa 43,5\% do limite de escoamento do aço de fabricação do equipamento. $\mathrm{O}$ comprimento crítico obtido para a trinca é de 299,6 mm (11,5\% do comprimento do cordão de solda).

Devido à incerteza quanto à profundidade inicial da trinca, variou-se este parâmetro entre $0,1 \mathrm{~mm}$ e 1,0 mm para a propagação na direção do comprimento. Nestas condições, as máximas tensões residuais necessárias para a ocorrência da falha são iguais a 176,9 $\mathrm{MPa}$, para a profundidade inicial de $0,1 \mathrm{~mm}$. Valores de tensão superiores a este seriam suficientes para causar a propagação instável da trinca em um tempo inferior ao tempo de operação estimado para a roda de caçambas

Os resultados mostram que a presença de tensões residuais trativas é determinante para a redução da vida em fadiga do componente, uma vez que, desconsiderando-se qualquer influência das tensões residuais, seria necessário que uma trinca com comprimento inicial de 1374,9 mm estivesse presente na estrutura da roda para que a falha ocorresse. Tal condição avaliada demonstra-se improvável, em função da grande extensão da trinca estimada, e de que a mesma seria facilmente detectada após a construção da roda de caçambas. 
A consideração de um perfil de tensões residuais trativas uniforme se justifica em função das recomendações da norma BS 7910 [24], embora dados experimentais obtidos por Bate et al. [66] também apontem a ocorrência de um perfil de tensões residuais não uniforme, composto por tensões trativas da ordem do limite de escoamento do material, além de tensões compressivas com magnitude igual a $50 \%$ do limite de escoamento. Desta forma, as tensões residuais consideradas neste trabalho podem ser tratadas como tensões residuais médias em relação à variação destas tensões ao longo da espessura.

Há o indicativo de que a propagação da trinca tenha ocorrido preferencialmente na direção do comprimento, tendo em vista que é necessário um nível de tensões residuais mais baixo na direção do comprimento, em detrimento à direção da profundidade da trinca, para a obtenção de um mesmo número de ciclos. Esta hipótese está relacionada à influência das tensões cisalhantes, que proporciona a formação de um modo misto de tração e cisalhamento, e também à maior amplitude do fator de amplificação $M_{k}$ na direção do comprimento da frente da trinca.

A verificação de vida em fadiga com base nas recomendações do IIW foi realizada, e há indícios de que algum defeito de fabricação tenha permanecido na solda mesmo após a realização do ensaio por ultrassom, uma vez que a vida em fadiga obtida com base nas curvas $\mathrm{S}-\mathrm{N}$ é superior à ciclagem estimada até a falha, para um detalhe de solda semelhante à junta soldada empregada na roda de caçambas. 


\section{REFERÊNCIAS BIBLIOGRÁFICAS}

[1] Boom type Bucket Wheel Reclaimer in South Africa. Tenova. Disponível em: <http://www.tenova.com/product/reclaimers/\#boom-type-bucket-wheel-reclaimer-insouth-africa $>$. Acesso em 15/04/2017.

[2] WÖHLBIER, R. H. Stacking, blending and reclaiming of bulk materials. 1. ed. Alemanha: TransTech Publications, 1977. 856p.

[3] KOTCHERGENKO ENGENHARIA. Recuperadoras de rodas de caçambas. 2016. Acervo técnico.

[4] RUSIŃSKI, E., CZMOCHOWSKI, J., MOCZKO, P., PIETRUSIAK, D. Surface Mining Machines: Problems of Maintenance and Modernization. 1. ed. Suíça: Springer, 2017. 169p.

[5] RUSIŃSKI, E., CZMOCHOWSKI, J., ILUK, A., KOWALCZYK, M. An analysis of the causes of a BWE counterweight boom support fracture. Engineering Failure Analysis 17, p. 179-191, 2010.

[6] DANIČIĆ, D., LAZAREVIĆ, Ž., MITROVIĆ, S. Proactive approach as contribution to system of preventing fatigue failures of BWE. In: 13TH INTERNATIONAL SYMPOSIUM CONTINUOUS SURFACE MINING - ISCSM 2016, Belgrado: Sérvia. 2016.

[7] SOUZA, Roberto G. Rodas de caçambas. 2017. Acervo iconográfico.

[8] BRANCO, Carlos A.G.M., FERNANDES, Antônio A., CASTRO, Paulo M.S.T. Fadiga de estruturas soldadas. 2. ed. Lisboa: Calouste Gulbenkian, 1999. 902p.

[9] BROEK, David. Concepts of Fracture Control and Damage Tolerance Analysis. Fatigue and Fracture - ASM Handbook vol. 19, American Society for Metals, p. 1004-1025. 1996.

[10] TIMMINS, P. F. Failure Control in Process Operations. Fatigue and Fracture - ASM Handbook vol. 19, American Society for Metals, p. 1149-1188. 1996.

[11] ANDERSON, Ted. L. Fracture mechanics: Fundamentals and applications. 3. ed. Boca Raton: Taylor \& Francis, 2005. 621p. 
[12] SHANMUGHAM, S., LIAW, P. K. Detection and Monitoring of Fatigue Cracks. Fatigue and Fracture - ASM Handbook vol. 19, American Society for Metals, p. 517-552. 1996.

[13] AMERICAN SOCIETY FOR TESTING AND MATERIALS. ASTM E1823: Standard Terminology Relating to Fatigue and Fracture Testing. EUA, 2013. 25p.

[14] BANNANTINE, Julie A., COMER, Jess J., HANDROCK, James L. Fundamentals of metal fatigue analysis. 1. ed. New Jersey: Prentice-Hall, 1990. 273p.

[15] KUNA, Meinhard. Finite Elements in Fracture Mechanics: Theory - Numerics Applications. 1. ed. Holanda: Springer, 2013. 447p.

[16] TADA, Hiroshi, PARIS, Paul C., IRWIN, George R. The stress analysis of cracks handbook. 3. ed. New York: American Society of Mechanical Engineers, 2000. 694p.

[17] AMERICAN SOCIETY FOR TESTING AND MATERIALS. E399: Standard Test Method for Linear-Elastic Plane-Strain Fracture Toughness $\mathrm{K}_{\mathrm{IC}}$ of Metallic Materials. EUA, 2012. 33p.

[18] CAMPBELL, Flake C. Elements of Metallurgy and Engineering Alloys. 1.ed. Ohio: American Society for Metals, 2008. 656p.

[19] DOWLING, Norman E. Mechanical behavior of materials: Engineering methods for deformation, fracture, and fatigue - International Edition. 4. ed. Inglaterra: Pearson, 2013. 960p.

[20] RICHARD, H. A., FULLAND, M., SANDER, M. Theoretical crack path prediction. Fatigue \& Fracture of Engineering Materials \& Structures 28, p. 3-12, 2005.

[21] ERDOGAN, F., SIH, G. C. On the crack extension in plates under plane loading and transverse shear. Journal of Basic Engineering 85, p. 519-525, 1963.

[22] LEE, Y., PAN, J., HATHAWAY, R., BARKEY, M. Fatigue testing and analysis: Theory and Practice. 1. ed. Burlington: Elsevier, 2005. 417p.

[23] BARSOM, John M., ROLFE, Stanley T. Fracture and fatigue control in structures: Applications of fracture mechanics. 2. ed. New Jersey: Prentice-Hall, 1987. 628p.

[24] BRITISH STANDARDS INSTITUTION. BS 7910: Guide to methods for assessing the acceptability of flaws in metallic structures. Inglaterra, 2013. 492p. 
[25] WALKER, K. The Effect of Stress Ratio During Crack Propagation and Fatigue for 2024T3 and 7075-T6 Aluminum. Effects of Environment and Complex Load History on Fatigue Life, ASTM STP 462, American Society for Testing and Materials, p. 1-14, 1970.

[26] GROSS, Todd S., LAMPMAN, Steven. Micromechanics of Monotonic and Cyclic Crack Growth. Fatigue and Fracture - ASM Handbook, vol. 19, American Society for Metals, p. 104-148. 1996.

[27] ELBER, Wolf. The Significance of Fatigue Crack Closure. Damage Tolerance in Aircraft Structures, ASTM STP 486, American Society for Testing and Materials, p. 230-242, 1971.

[28] SCHIJVE, J. Some Formulas for the Crack Opening Stress Level. Engineering Fracture Mechanics, vol. 14, p. 461-465, 1981.

[29] KURIHARA, M., KATOH, A., KAWAHARA, M. Analysis on Fatigue Crack Growth Rates Under a Wide Range of Stress Ratios. Journey of Pressure Vessel Technology, Transactions of the ASME, vol. 108, p. 209-213, 1986.

[30] JUTLA, Tarsem. Fatigue and Fracture Control of Weldments. Fatigue and Fracture ASM Handbook, vol. 19, American Society for Metals, p. 1058-1098. 1996.

[31] CARY, Howard B., HELZER, Scott C. Modern welding technology. 6. ed. New Jersey: Pearson Prentice Hall, 2005. 715p.

[32] MILLER, Duane K. Welded Connections - A Primer for Engineers. Steel Design Guide 21. 1. ed. EUA: American Institute of Steel Construction, 2006. 152p.

[33] AMERICAN WELDING SOCIETY. Welding Handbook: Welding Science and Technology - Vol. 1. 9. ed. Miami, 2001. 985p.

[34] MARTINSSON, Johan. Fatigue Assessment of Complex Welded Steel Structures. Doctoral Thesis, Royal Institute of Technology, 2005. 34p.

[35] MADDOX, S. J. An analysis of fatigue cracks in the fillet welded joints. International Journal of Fracture, vol. 11, No. 2, p. 221-243, 1975.

[36] HOBBACHER, A. Stress intensity factors of welded joints. Engineering Fracture Mechanics, vol. 46, No. 2, p. 173-182, 1993.

[37] BOWNESS, D., LEE, M.M.K. Prediction of weld toe magnification factors for semielliptical cracks in T-butt joints. International Journal of Fatigue vol. 22(5), p. 369387, 2000. 
[38] NEWMAN, J. C., Jr., RAJU, I. S. Stress-Intensity Factor Equations for Cracks in ThreeDimensional Finite Bodies. Fracture Mechanics: Fourteenth Symposium - Volume I: Theory and Analysis, ASTM STP 791, American Society for Testing and Materials, p. I-238-I-265, 1983.

[39] MÜLlER, H. M., MÜLlER, S., MUNZ, D., NEUMANN, J. Extension of Surface Cracks During Cyclic Loading. Fracture Mechanics: Seventeenth Volume, ASTM STP 905, American Society for Testing and Materials, Philadelphia, p. 625-643, 1986.

[40] COMITÉ EUROPÉEN DE NORMALISATION. EN 1993-1-9: Eurocode 3: Design of steel structures - Part 1-9: Fatigue. Bruxelas, 2005. 37p.

[41] DET NORSKE VERITAS. DNVGL-RP-C203: Fatigue design of offshore steel structures. Noruega, 2016. 216p.

[42] HOBBACHER, A. F. Recommendations for fatigue design of welded joints and components (IIW document IIW-2259-15). 2. ed. Suíça: Springer, 2016. 150p.

[43] NIEMI, E., FRICKE, W., MADDOX, S. J. Structural hot-spot stress approach to fatigue analysis of welded components: Designer's guide. 2. ed. Singapura: Springer, 2018. 85p.

[44] ARSIĆ, M., BOŠNJAK, S., ZRNIĆ, N., SEDMAK, A., GNJATOVIĆ, N. Bucket wheel failure caused by residual stresses in welded joints. Engineering Failure Analysis 18, p. 700-712, 2011.

[45] BOŠNJAK, S., ARSIĆ, M., GNJATOVIĆ, N., MILENOVIĆ, I, ARSIĆ, D. Failure of the bucket wheel excavator buckets. Engineering Failure Analysis 84, p. 247-261, 2018.

[46] RUSIŃSKI, E., HARNATKIEWICZ, P., KOWALCZYK, M., MOCZKO, P. Examination of the causes of a bucket wheel fracture in a bucket wheel excavator. Engineering Failure Analysis 17, p. 1300-1312, 2010.

[47] BOŠNJAK, S., ARSIĆ, M., ZRNIĆ, N., RAKIN, M., PANTELIĆ, M. Bucket wheel excavator: Integrity assessment of the bucket wheel boom tie-rod welded joint. Engineering Failure Analysis 18, p. 212-222, 2011.

[48] CERNESCU, A., MARSAVINA, L., DUMITRU, I. Structural integrity assessment for a component of the bucket-wheel excavator. International Journal of Structural Integrity, vol. 5, No. 2, p. 129-140, 2014.

[49] DANIČIĆ, D., SEDMAK, S., BLAČIĆ, I. Scenario of fracture development in bucket wheel excavator. Structural Integrity and Life, vol. 13, No. 3, p. 189-196, 2003. 
[50] BROEK, David. Elementary engineering fracture mechanics. 3. ed. Holanda: Martinus Nijhoff Publishers, 1984. 469p.

[51] NX NASTRAN, Element Library Reference. Siemens, 2008.

[52] ANSYS Help - Mechanical APDL Documentation version 17.0. Disponível em: $<$ https://www.sharcnet.ca/Software/Ansys/17.0/en-us/help/ans_frac/ans_frac.html >.

Acesso em 06/08/2018.

[53] RASPER, Ludwig. The bucket wheel excavator: Development - Design - Application. 1. ed. Alemanha: TransTech Publications, 1975. 390p.

[54] INTERNATIONAL ORGANIZATION FOR STANDARDIZATION. ISO 5049: Mobile equipment for continuous handling of bulk materials - Part 1: rules for the design of steel structures. Suíça, 1994. 56p.

[55] STARDARDIZATION ADMINISTRATION OF THE PEOPLE'S REPUBLIC OF CHINA. GB/T 1591: High strength low alloy structural steels. China, 2008. 13p.

[56] STARDARDIZATION ADMINISTRATION OF THE PEOPLE'S REPUBLIC OF CHINA. GB/T 5293: Carbon steel electrodes and fluxes for submerged arc welding. China, 1999. 12p.

[57] XIONG, Y., HU, X. X. The effect of microstructures on fatigue crack growth in Q345 steel welded joint. Fatigue \& Fracture of Engineering Materials \& Structures 35, p. 500-512, 2011.

[58] ROHATGI, Ankit. WebPlotDigitizer. Version 3.8. Disponível em: $<$ https://automeris.io/WebPlotDigitizer/ >. Acesso em 26/08/2017.

[59] STEPHENS, R. I., LEE, S. G., LEE, H. W. Constant and variable amplitude fatigue behavior and fracture of $\mathrm{A} 572$ at $25^{\circ} \mathrm{C}\left(77^{\circ} \mathrm{F}\right)$ and $-45^{\circ} \mathrm{C}\left(-50^{\circ} \mathrm{F}\right)$. International Journal of Fracture 19, p. 83-98, 1982.

[60] WANG, Y., ZHOU, H., SHI, Y., CHEN, H. Study on Fracture Toughness Indices of Chinese Structural Steel and Weld Metal. International Society of Offshore and Polar Engineers, Beijing, China. p. 129-134, 2010.

[61] WANG, Y. Q., LIU, X. Y. HU, Z. W., SHI, Y. J. Experimental study on mechanical properties and fracture toughness of structural thick plate and its butt weld along thickness and at low temperatures. Fatigue \& Fracture of Engineering Materials \& Structures 36, p. 1258-1273, 2013. 
[62] BRANSEN, Marjolein. Numerical simulation of crack development for Leak-BeforeBreak applications. Master of Science Thesis, Delft University of Technology, 2016. $142 p$.

[63] HE, M.Y., HUTCHINSON, J. W. Surface crack subject to mixed mode loading. Engineering Fracture Mechanics, vol. 65, p. 1-14, 2000.

[64] NODA, N., KAGITA, M. Variations of stress intensity factors of a semi-elliptical crack subjected to mode I, II, III loading. International Journal of Pressure Vessels and Piping, vol. 81, p. 635-644, 2004.

[65] KASSIR, M. K., SIH, G. C. Three-Dimensional Stress Distribution Around an Elliptical Crack Under Arbitrary Loadings. Journal of Applied Mechanics, vol. 33, p. 601-611, 1966.

[66] BATE, S. K., GREEN, D., BUTTLE, D. A review of residual stress distributions in welded joints for the defect assessment of offshore structures. OTH 482. Inglaterra: Health and Safety Executive Books, 1997. 145p.

[67] BERZENGOLI, A., FERRETTI, C. Calculation Program for the Analysis of the Performance of Boom-Type Reclaimers. Bulk Solids Handling, vol. 6, No. 2, p. 379392, Abril, 1986.

[68] GARTNER, Karl. Bucket Wheel Excavator on Building Sites. Forden and Heben, vol. 3 e vol. 6, 1965.

[69] ANDO, K., FUJIBAYASHI, S., NAM, K. W., TAKAHASHI, M., OGURA, N. The Fatigue Life and Crack Through Thickness Behavior of a Surface-Cracked Plate (For the Case of Tensile Load). Japan Society of Mechanical Engineers International Journal, vol. 30, n 270, p. 1898-1905, 1987. 
ANEXO A

\section{A.1 Determinação das cargas atuantes na roda de caçambas}

A metodologia empregada para determinação das cargas atuantes na roda de caçambas analisada no presente trabalho se baseia no método de cálculo publicado por Himmel, W. (1963) apud Rasper [53].

Segundo Rasper [53], Himmel, W. (1963) realizou em torno de 150 experimentos no início da década de 1960 em várias escavadoras de roda de caçambas instaladas em minas de carvão na Alemanha Ocidental. Sua pesquisa mostrou boa compatibilidade entre os resultados experimentais e aqueles obtidos por meio de cálculos.

Para o cálculo das cargas atuantes, são necessários diversos parâmetros relacionados à roda de caçambas, ao material escavado e à recuperadora.

Com relação à roda de caçambas, deve-se conhecer a largura $b_{\max }$, profundidade $t_{\max } \mathrm{e}$ volume $V_{c}$ da caçamba, o número de caçambas instaladas $N_{c}$, o raio de corte da roda $R_{\text {corte }}$ (definido pela extremidade da caçamba), o fator de correção da força de corte em função da profundidade da caçamba $k_{m}$ e a rotação da roda $n_{\text {roda }}$.

A Figura A-1 ilustra as principais dimensões de uma roda de caçambas, enquanto que a Tabela A-1 apresenta os fatores de correção da força de corte em função da profundidade da caçamba. 
Figura A-1 - Principais dimensões de uma roda de caçambas.

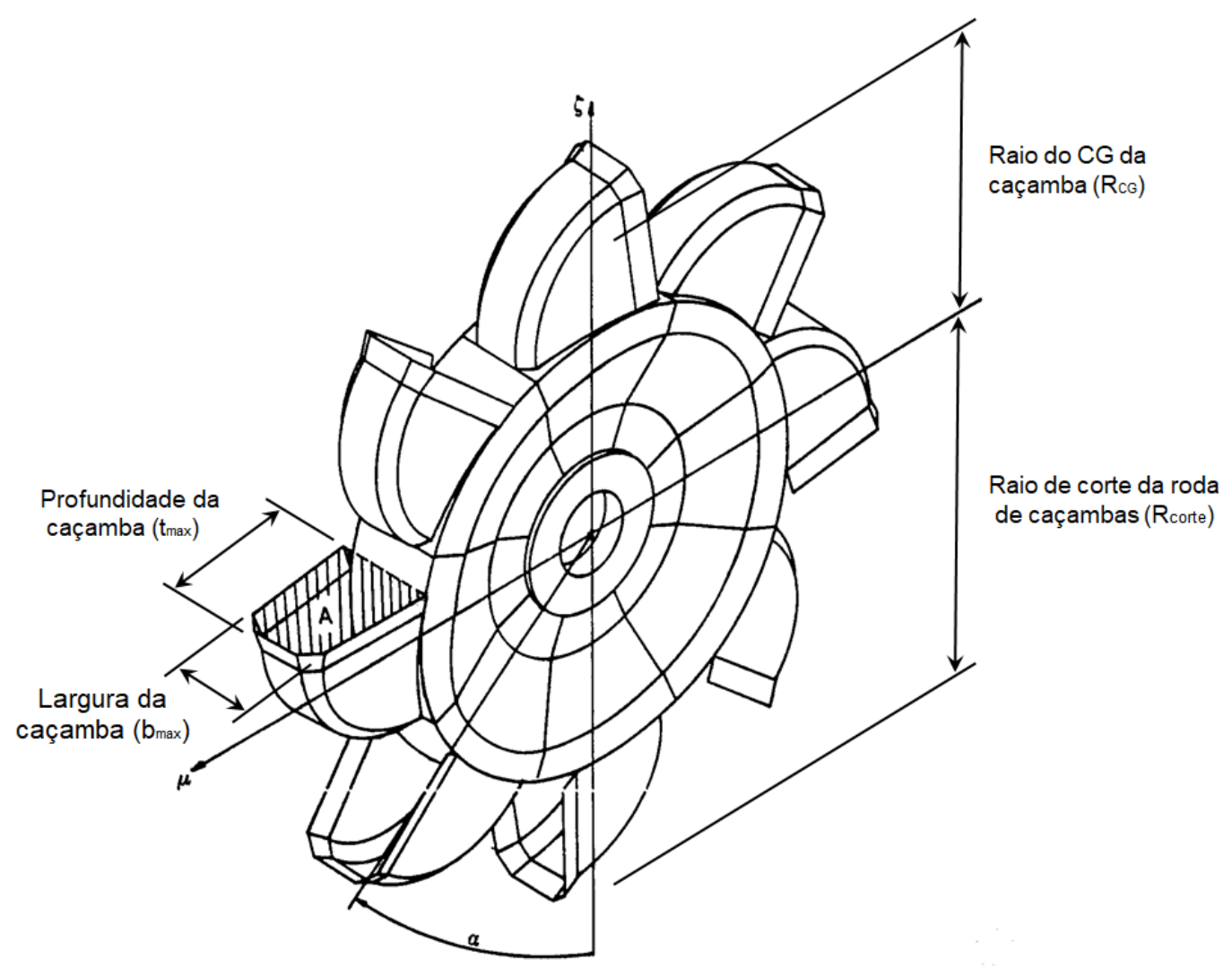

Fonte: Adaptado de Berzengoli e Ferretti [67].

Tabela A-1 - Fatores de correção da força de corte em função da profundidade da caçamba.

\begin{tabular}{c|c}
\hline$k_{m}$ & $\begin{array}{c}\text { Profundidade } d a \\
\text { caçamba, } t_{\max }[\mathrm{cm}]\end{array}$ \\
\hline 1,70 & 30 \\
\hline 1,52 & 40 \\
\hline 1,43 & 50 \\
\hline 1,37 & 60 \\
\hline 1,32 & 70 \\
\hline 1,30 & 80 \\
\hline 1,26 & 90 \\
\hline 1,24 & 100 \\
\hline
\end{tabular}

Fonte: Adaptado de Rasper [53].

Em relação ao material escavado, o peso específico $\gamma_{M}$, a força específica de corte $f_{L}$ e o fator de empolamento $f$ (taxa de expansão volumétrica do material após a escavação) são necessários para o cálculo das cargas atuantes em uma roda de caçambas. 
Dentre as propriedades do material manuseado por uma recuperadora, a força específica de corte merece maior destaque, uma vez que a força tangencial de corte é diretamente proporcional a esta propriedade. A força específica de corte representa a força necessária para escavar um determinado comprimento de material empilhado e está ligada ao grau de compactação do material durante o processo de escavação. Pode ser obtida diretamente por meio de ensaios em laboratório, ou indiretamente por meio de medições da corrente no motor de acionamento da roda de caçambas. Gartner [68] indicam valores de força específica de corte entre 20 e $40 \mathrm{kgf} / \mathrm{m}$ para minério de ferro com granulometria de até $150 \mathrm{~mm}$.

No que se refere aos dados operacionais da recuperadora, requerem-se a capacidade de material transportado $Q$, o raio de giro da lança $R_{\text {lança }}$ (medido no centro da roda de caçambas) e a velocidade angular de giro da lança $\omega_{\text {lança }}$ para o cálculo das cargas atuantes em uma roda de caçambas.

Considerando o modo de operação de uma recuperadora descrito no item 2.1, verifica-se a atuação de forças de escavação (denominadas comumente como forças de corte) nas direções tangencial e lateral à roda de caçambas, e de forças de elevação do material escavado.

\section{A.1.1 Força tangencial de corte}

A força tangencial de corte $F_{\text {corte }}$ se refere à força necessária para a escavação do material empilhado e é decorrente do movimento de rotação da roda de caçambas. Possui direção tangencial ao raio de corte definido pela extremidade da caçamba e é normal ao eixo de rotação da roda.

A seguir, são apresentadas as equações necessárias ao cálculo da força tangencial de corte com base na metodologia publicada por Himmel, W. (1963) e apresentada por Rasper [53]. 
O cálculo da velocidade tangencial de giro da lança $v_{\text {giro }}$ é dado por:

$$
v_{\text {giro }}=\omega_{\text {lança }} \cdot R_{\text {lança }}
$$

A partir da rotação e do raio de corte da roda de caçambas, pode-se determinar sua velocidade tangencial $v_{t a n}$ :

$$
v_{\text {tan }}=\frac{\pi \cdot n_{\text {roda }}}{30} \cdot R_{\text {corte }}
$$

A altura de corte $H$, ou seja, a diferença entre o ponto onde a caçamba começa a cortar a pilha e onde ela deixa a pilha, será considerada igual ao raio de corte da roda de caçambas:

$$
H=R_{\text {corte }}
$$

Uma vez que a altura de corte e o raio de corte possuem a mesma magnitude, o ângulo de corte $\varphi$ calculado será igual a $90^{\circ}$ :

$$
\varphi=\operatorname{acos}\left(\frac{R_{\text {corte }}-H}{R_{\text {corte }}}\right)=90^{\circ}
$$

A profundidade de corte $t$ deve ser calculada com base na capacidade de material transportado e está limitada à profundidade da caçamba:

$$
t=\frac{Q}{\gamma_{M} \cdot H \cdot f \cdot v_{\text {giro }}} \leq t_{\text {max }}
$$

O número de descargas por minuto $s$ realizadas pela roda de caçambas é dado por:

$$
s=n_{\text {roda }} \cdot N_{c}
$$

$\mathrm{O}$ volume requerido da caçamba $V$ depende da capacidade de material transportado e não deve ser superior ao volume da caçamba:

$$
V=\frac{Q}{\gamma \cdot s} \leq V_{c}
$$


O grau de enchimento da caçamba $\eta_{c}$ é dado pela razão entre o volume requerido e o volume da caçamba:

$$
\eta_{c}=\frac{V}{V_{c}}
$$

A área cortada $A_{\text {corte }}$ é obtida pela equação abaixo:

$$
A_{\text {corte }}=\frac{V}{f \cdot H}
$$

A partir da área cortada, calcula-se a largura de corte $b$ que é limitada à largura da caçamba:

$$
b=\frac{A_{\text {corte }}}{t} \leq b_{\text {máx }}
$$

A razão de profundidade de corte $\alpha$ é dada pelo quociente entre a profundidade de corte e a largura de corte:

$$
\alpha=\frac{t}{b}
$$

O número de caçambas participantes do corte $N$ depende do ângulo de corte e é calculado pela equação abaixo:

$$
N=N_{c} \frac{\varphi}{360^{\circ}}
$$

A razão da altura de corte $c$ pode ser calculada da seguinte forma:

$$
c=\frac{H}{R_{\text {corte }}}
$$

A determinação da força tangencial de corte $F_{\text {corte }}$ pode ser feita por meio da equação abaixo:

$$
F_{\text {corte }}=\frac{100 \cdot N_{c} \cdot f_{L}}{2 \pi} \sqrt{\frac{\alpha}{c}}\left(k_{m} \cdot c+\frac{\varphi}{\alpha}\right) \sqrt{\frac{V}{R_{\text {corte }} \cdot f}}
$$




\section{A.1.2 Força lateral de corte}

A força lateral de corte $F_{\text {lat }}$ está relacionada à resistência que a pilha de material oferece à caçamba durante o movimento de giro da lança da recuperadora. Devido à combinação do giro da lança com a rotação da roda, cada ponto localizado no raio de corte descreve uma trajetória helicoidal.

Para o cálculo da força lateral de corte, duas abordagens podem ser realizadas, devendo ser adotada a metodologia mais conservadora. A primeira é apresentada por Rasper [53], onde a proporção entre as forças lateral e tangencial de corte é dada pela razão entre a velocidade de giro da lança e a velocidade tangencial da roda de caçambas, como apresentado abaixo:

$$
F_{\text {lat }}=\frac{v_{\text {giro }}}{v_{\text {tan }}} \cdot F_{\text {corte }}
$$

A segunda abordagem se baseia no critério proposto pela norma ISO 5049-1 [54], que recomenda que a força lateral de corte pode ser tomada como $30 \%$ da força tangencial de corte:

$$
F_{\text {lat }}=0,3 \cdot F_{\text {corte }}
$$

\section{A.1.3 Força de elevação do material}

A força de elevação do material $F_{\text {elev }}$ corresponde ao peso propriamente dito de material no interior da caçamba. Conforme o método proposto por Himmel, W. (1963) apud Rasper [53], esta força pode ser determinada dividindo-se a potência necessária à elevação do material pela velocidade tangencial da roda de caçambas. Tal potência depende, entre outros fatores, da proporção $\beta$ entre a altura de elevação do material e o raio de corte da roda de caçambas.

$$
F_{\text {elev }}=\frac{0,163 \cdot \gamma_{M} \cdot s \cdot V \cdot \beta \cdot R_{\text {corte }}}{v_{\text {tan }}}
$$




\section{A.2 Memória de cálculo}

Com base na metodologia apresentada no item anterior, foi elaborada uma memória de cálculo das cargas atuantes na roda de caçambas, sendo a mesma ilustrada nas páginas a seguir. A Tabela A-2 apresenta o resumo das variáveis envolvidas nesta memória de cálculo.

Tabela A-2 - Resumo das variáveis envolvidas na memória de cálculo.

\begin{tabular}{|c|c|c|}
\hline- & Variável & Valor \\
\hline \multirow{13}{*}{ Entrada } & Número de caçambas $\left(\mathrm{N}_{\mathrm{c}}\right)$ & 9 \\
\hline & Volume total da caçamba $\left(V_{c}\right)$ & $2,24 \mathrm{~m}^{3}$ \\
\hline & Profundidade da caçamba $\left(t_{\max }\right)$ & $1,58 \mathrm{~m}$ \\
\hline & Largura da caçamba $\left(b_{\max }\right)$ & $0,88 \mathrm{~m}$ \\
\hline & Raio de corte da roda de caçambas ( $\left.\mathrm{R}_{\text {corte }}\right)$ & $5 \mathrm{~m}$ \\
\hline & Rotação da roda de caçambas ( $\mathrm{n}_{\text {roda }}$ ) & $5 \mathrm{rpm}$ \\
\hline & Parâmetro $\beta$ & 1,1 \\
\hline & Peso específico do material transportado $\left(\gamma_{\mathrm{M}}\right)$ & $2,3 \mathrm{t} / \mathrm{m}^{3}$ \\
\hline & Força específica de corte $\left(\mathrm{f}_{\mathrm{L}}\right)$ & $30 \mathrm{kgf} / \mathrm{cm}$ \\
\hline & Fator de empolamento (f) & 1 \\
\hline & Capacidade de material transportada $(\mathrm{Q})$ & $11620 \mathrm{t} / \mathrm{h}$ \\
\hline & Velocidade angular de giro da lança ( $\left.\omega_{\text {lança }}\right)$ & $39,6 \%$ min \\
\hline & Raio de giro da lança $\left(\mathrm{R}_{\text {lança }}\right)$ & $50 \mathrm{~m}$ \\
\hline \multirow{17}{*}{ Saída } & Velocidade tangencial de giro da lança (vgiro) & $0,58 \mathrm{~m} / \mathrm{s}$ \\
\hline & Velocidade tangencial da roda de caçambas $\left(\mathrm{v}_{\tan }\right)$ & $2,62 \mathrm{~m} / \mathrm{s}$ \\
\hline & Altura de corte $(\mathrm{H})$ & $5 \mathrm{~m}$ \\
\hline & Ângulo de corte $(\varphi)$ & $90^{\circ}$ \\
\hline & Profundidade de corte $(\mathrm{t})$ & $0,49 \mathrm{~m}$ \\
\hline & Número de descargas por minuto (s) & $45 / \mathrm{min}$ \\
\hline & Volume requerido da caçamba $(\mathrm{V})$ & $1,87 \mathrm{~m}^{3}$ \\
\hline & Grau de enchimento da caçamba $\left(\eta_{c}\right)$ & $83,5 \%$ \\
\hline & Área cortada $\left(\mathrm{A}_{\text {corte }}\right)$ & $0,37 \mathrm{~m}^{2}$ \\
\hline & Largura de corte (b) & $0,77 \mathrm{~m}$ \\
\hline & Razão de profundidade de corte $(\alpha)$ & 0,63 \\
\hline & Número de caçambas participantes do corte $(\mathrm{N})$ & 2,25 \\
\hline & Razão da altura de corte (c) & 1 \\
\hline & Fator de correção da força de corte $\left(\mathrm{k}_{\mathrm{m}}\right)$ & 1,43 \\
\hline & Força tangencial de corte $\left(\mathrm{F}_{\text {corte }}\right)$ & $80128 \mathrm{~N}$ \\
\hline & Força lateral de corte $\left(\mathrm{F}_{\text {lat }}\right)$ & $24038 \mathrm{~N}$ \\
\hline & Força de elevação do material $\left(\mathrm{F}_{\text {elev}}\right)$ & $66522 \mathrm{~N}$ \\
\hline
\end{tabular}

Fonte: Próprio autor. 
1) DADOS DE ENTRADA

1.1) DADOS DA RODA DE CAÇAMBAS

Número de caçambas $N_{C}:=9$

Volume total da caçamba $V_{C}:=2,24 \mathrm{~m}^{3}$

Profundidade da caçamba $t_{\max }:=1,58 \mathrm{~m}$

Largura da caçamba $b_{\max }:=0,88 \mathrm{~m}$
Raio de corte da roda de caçambas $R_{\text {corte }}:=5 \mathrm{~m}$

Rotação da roda de caçambas $\mathrm{n}_{\text {roda }}:=5 \cdot \frac{1}{m i n}$

Parâmetro $\beta:=1,1$

Nota: Valor médio conforme Rasper

1.2) DADOS DO MATERIAL TRANSPORTADO

Peso específico $Y_{M}:=2,3 \frac{t}{m^{3}}$

Força específica de corte $\mathrm{f}_{\mathrm{L}}:=30 \frac{\mathrm{kgf}}{\mathrm{cm}}$

Nota: Valor médio para o minério de ferro com granulometria de até $150 \mathrm{~mm}$ (Tabela 6-2)

Fator de empolamento $f:=1$

Nota: Considerado que o material não sofre expansão volumétrica após a escavação

\section{3) DADOS OPERACIONAIS DA RECUPERADORA}

Capacidade de material transportada $Q:=11620 \frac{t}{h r}$

Velocidade angular de giro da lança $\omega_{\text {lança }}:=39,6 \frac{\text { deg }}{\mathrm{min}}$

Raio de giro da lança R $R_{\text {lança }}:=50 \mathrm{~m}$

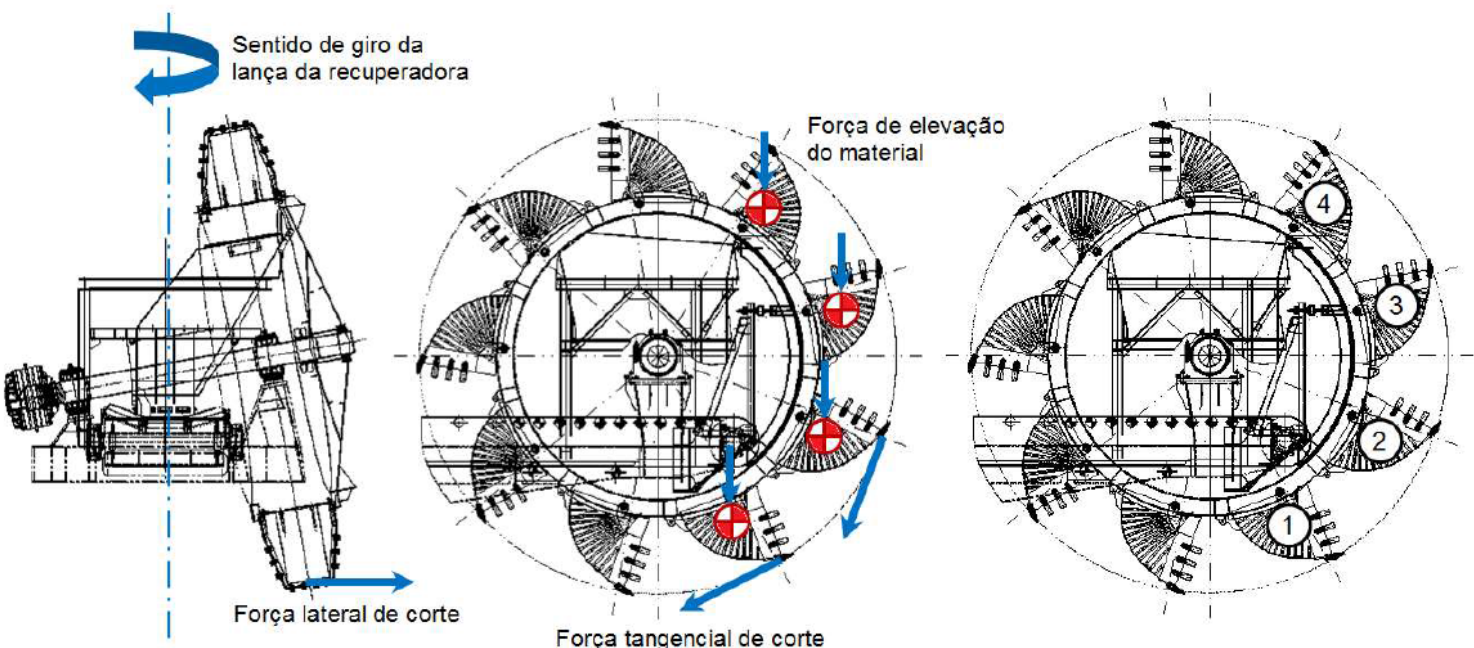




\section{2) DETERMINAÇÃO DAS FORÇAS ATUANTES}

\section{1) CÁLCULO DA FORÇA TANGENCIAL DE CORTE}

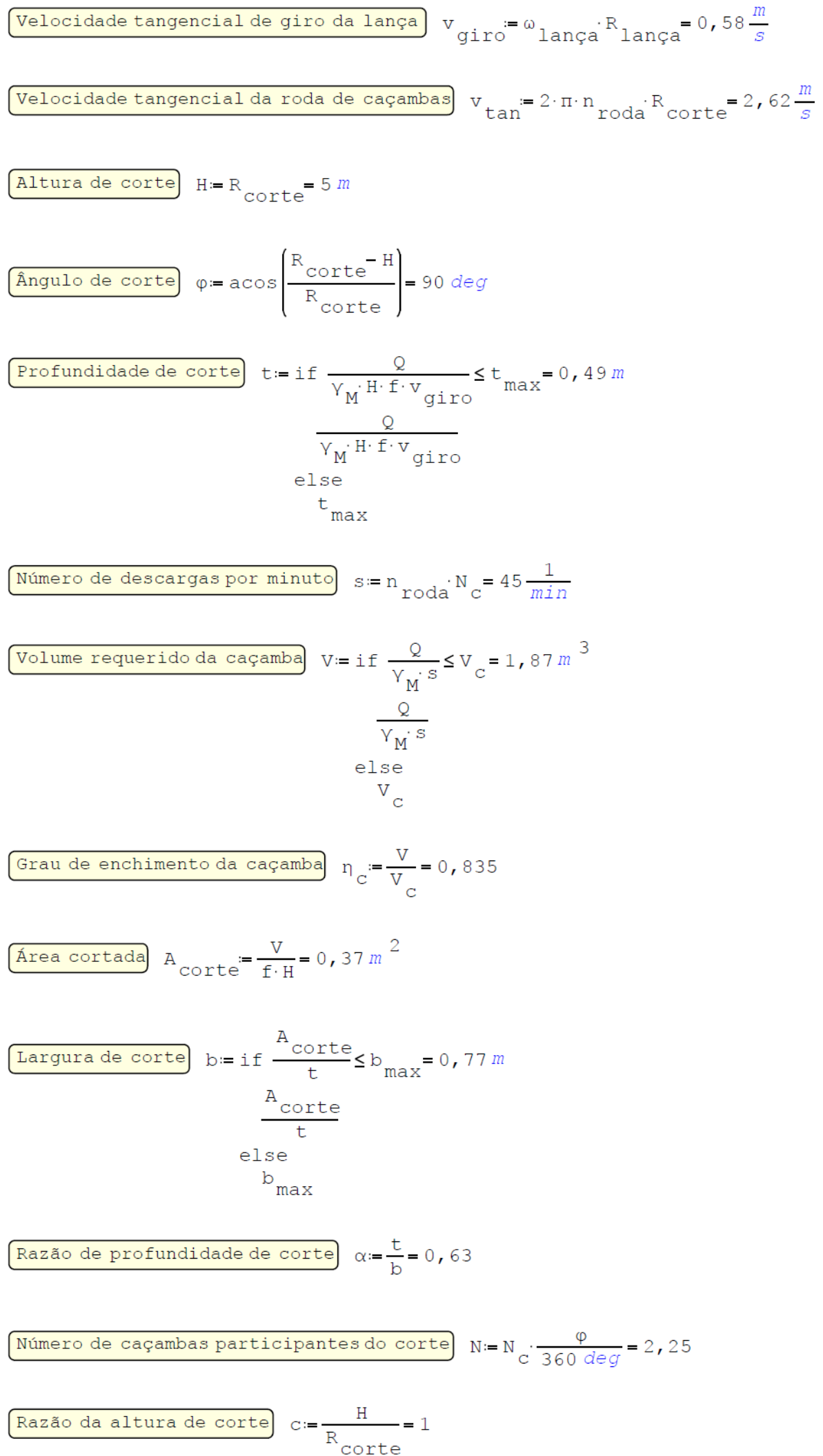


Fator de correção da força de corte

$k_{m}:=4,36 \cdot 10^{-8} \cdot\left(\frac{\mathrm{t}}{\mathrm{cm}}\right)^{4}-1,35 \cdot 10^{-5} \cdot\left(\frac{\mathrm{t}}{\mathrm{cm}}\right)^{3}+0,00157 \cdot\left(\frac{\mathrm{t}}{\mathrm{cm}}\right)^{2}-0,0853 \cdot \frac{\mathrm{t}}{\mathrm{cm}}+3,1713=1,43$

Nota: Equação para o parâmetrok ${ }_{m}$ é a regressão com base na Tabela A-1

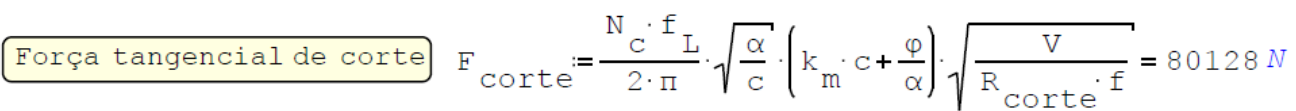

Distribuição por caçamba - Força tangencial de corte

$\mathrm{F}_{\text {Corte_caçambai }}=50 \%$ F $\operatorname{corte}=40064 \mathrm{~N} \quad$ F corte_caçambaj $=0 \mathrm{~N}$

$\mathrm{F}_{\text {corte_caçamba2 }}=50 \% \cdot \mathrm{F}_{\text {corte }}=40064 \mathrm{~N} \quad \mathrm{~F}_{\text {Corte_caçamba }}=0 \mathrm{~N}$

F corte_caçamba $=\left[\begin{array}{l}\text { F } \text { corte_caçambal } \\ \text { F } \text { corte_caçamba } \\ \text { F } \text { corte_caçamba } \\ \text { F } \text { corte_caçamba }\end{array}\right]=\left[\begin{array}{c}40064 \\ 40064 \\ 0 \\ 0\end{array}\right] N$

\section{2) CÁLCULO DA FORÇA LATERAL DE CORTE}

Força lateral de corte $F_{\text {lat }}:=$ if $\frac{\mathrm{V}_{\text {giro }}}{\mathrm{v}_{\text {tan }}} \mathrm{F}_{\text {corte }} \geq 0,3 \cdot \mathrm{F}_{\text {corte }}=24038 \mathrm{~N}$

$$
\begin{aligned}
& \frac{{ }_{\text {giro }}}{V_{\text {tan }}} F_{\text {corte }} \\
& \text { else } \\
& 0,3 \cdot F_{\text {corte }}
\end{aligned}
$$

Distribuição por caçamba - Força lateral de corte

$$
\begin{aligned}
& \mathrm{F}_{\text {lat_caçambai }}=50 \% \mathrm{~F}_{\text {lat }}=12019,2 \mathrm{~N} \quad \mathrm{~F}_{\text {lat_caçamba }}=0 \mathrm{~N} \\
& \mathrm{~F}_{\text {lat_caçamba }}=50 \% \text { F }{ }_{\text {lat }}=12019,2 \mathrm{~N} \quad \mathrm{~F}_{\text {lat_caçamba }}=0 \mathrm{~N} \\
& \text { Flat_caçamba }=\left[\begin{array}{l}
\text { Flat_caçamba } \\
\text { Flat_caçambał } \\
\text { Flat_caçambał } \\
\text { Flat_caçambal }
\end{array}\right]=\left[\begin{array}{c}
12019,2 \\
12019,2 \\
0 \\
0
\end{array}\right] N
\end{aligned}
$$


Força de elevação do material $F_{\text {elev }}:=\frac{Y_{M} \cdot \mathrm{S} \cdot \mathrm{V} \cdot \beta \cdot \mathrm{R}_{\text {Corte }}}{\mathrm{V}_{\tan }} \cdot 9,81 \frac{\mathrm{m}}{\mathrm{s}^{2}}=66522 \mathrm{~N}$

Distribuição por caçamba - Força de elevação do material

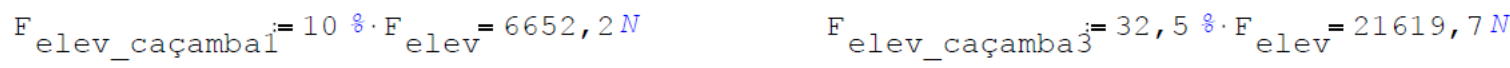

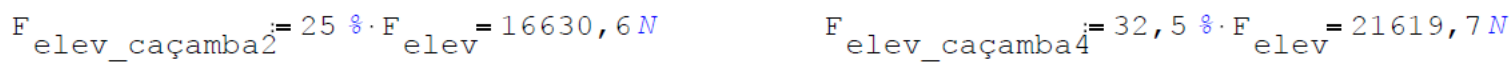

$$
\begin{aligned}
& \text { Felev_caçamba }:=\left[\begin{array}{l}
\text { F elev_caçambal } \\
\text { F elev_caçambą } \\
\text { F elev_caçambał } \\
\text { F elev_caçambal }
\end{array}\right]=\left[\begin{array}{r}
6652,2 \\
16630,6 \\
21619,7 \\
21619,7
\end{array}\right] N
\end{aligned}
$$




\section{ANEXO B}

\section{B.1 Formulação do Fator de Intensidade de Tensões de uma trinca semielíptica}

A Figura B-1 ilustra as definições geométricas para uma trinca semielíptica.

Figura B-1 - Definições geométricas para uma trinca semielíptica.

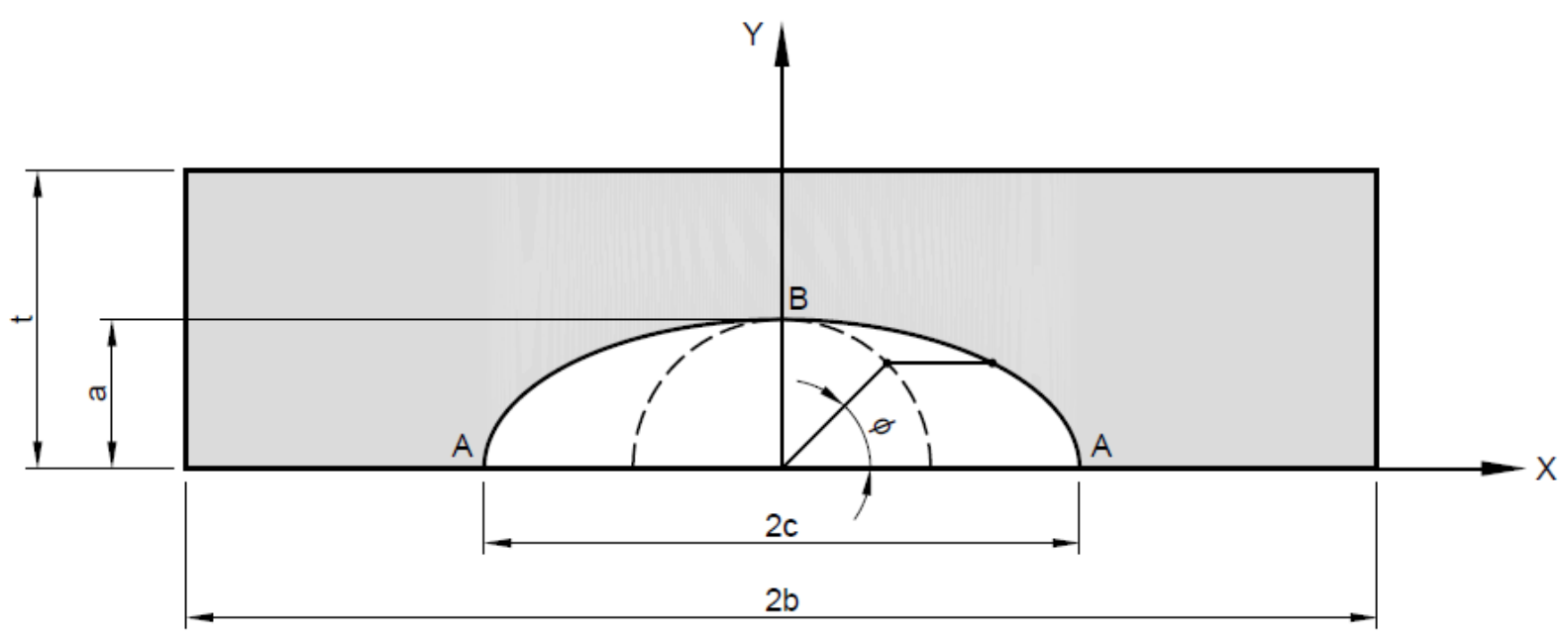

Fonte: Adaptado de Newman e Raju [38].

\section{B.1.1 Propagação sob tração (Modo I)}

A formulação do fator de intensidade de tensões para uma trinca semielíptica sob tração foi obtida em Newman e Raju [38].

Considerando os limites $0 \leq a / c \leq 2, c / b<0,5$ e $0 \leq \Phi \leq \pi$ e a razão $a / t$ que satisfaça a Eq. (B.1). o fator de intensidade de tensões para o modo I pode ser calculado pela Eq. (B.2).

$$
\begin{gathered}
\frac{a}{t}<1,25\left(\frac{a}{c}+0,6\right) \text { para } 0 \leq \frac{a}{c} \leq 0,2 \\
\frac{a}{t} \leq 1 \text { para } 0,2 \leq \frac{a}{c} \leq \infty \\
K_{I}=\sigma \sqrt{\frac{\pi a}{Q}} \cdot F_{S}\left(\frac{a}{c}, \frac{a}{t}, \frac{c}{b}, \phi\right)
\end{gathered}
$$


Destaca-se que todas as equações a seguir consideram uma proporção $a / c \leq 1$. O fator de forma $Q$ para uma trinca elíptica é aproximado por:

$$
Q=1+1,464\left(\frac{a}{c}\right)^{1,65}
$$

A função $F_{s}$ pode ser calculada conforme equação abaixo:

$$
F_{s}=\left[M_{1}+M_{2}\left(\frac{a}{t}\right)^{2}+M_{3}\left(\frac{a}{t}\right)^{4}\right] g f_{\phi} f_{w}
$$

Os coeficientes $M_{1}, M_{2}, M_{3}$ e $g$ são calculados conforme as equações abaixo:

$$
\begin{aligned}
& M_{1}=1,13-0,09\left(\frac{a}{c}\right) \\
& M_{2}=-0,54+\frac{0,89}{0,2+\frac{a}{c}} \\
& M_{3}=0,5-\frac{1}{0,65+\frac{a}{c}}+14\left(1-\frac{a}{c}\right)^{24} \\
& g=1+\left[0,1+0,35\left(\frac{a}{t}\right)^{2}\right](1-\operatorname{sen} \phi)^{2}
\end{aligned}
$$

O fator que considera a variação do fator de intensidade de tensões com o ângulo $\Phi$ (veja indicação na Figura B-1) é calculado como:

$$
f_{\phi}=\left[\left(\frac{a}{c}\right)^{2} \cos ^{2} \phi+\operatorname{sen}^{2} \phi\right]^{1 / 4}
$$

O fator de correção para uma geometria de largura finita é dado por:

$$
f_{w}=\left[\sec \left(\frac{\pi c}{2 b} \sqrt{\frac{a}{t}}\right)\right]^{1 / 2}
$$


Da Figura B-2 à Figura B-4, são apresentadas as regressões obtidas a partir dos dados obtidos numericamente para o fator de intensidade de tensões para trincas semielípticas sob tração na geometria da roda de caçambas.

Figura B-2 - Regressões polinomiais para $K$ normalizado numérico - Trinca semielíptica sob tração com razão $\mathrm{a} / \mathrm{c}$ igual a 0,2 .

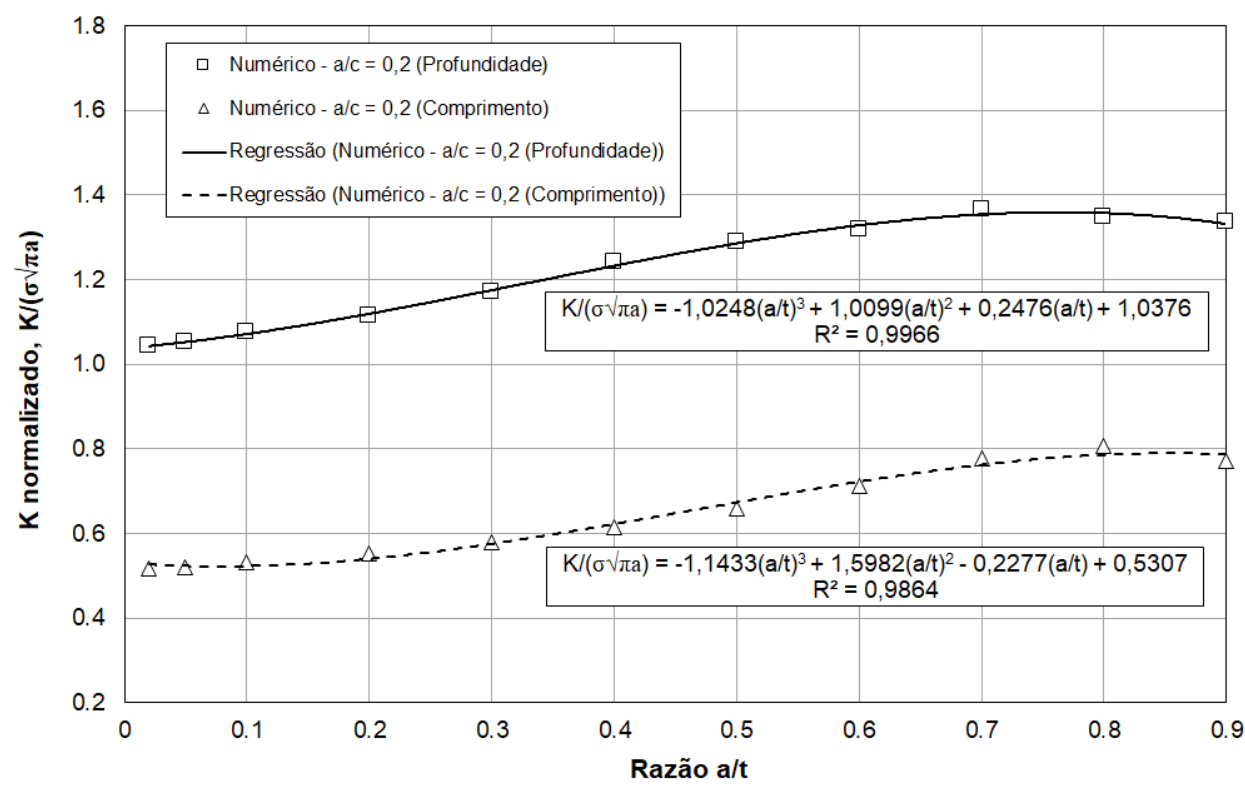

Fonte: Próprio autor.

Figura B-3 - Regressões polinomiais para $K$ normalizado numérico - Trinca semielíptica sob tração com razão $\mathrm{a} / \mathrm{c}$ igual a 0,5 .

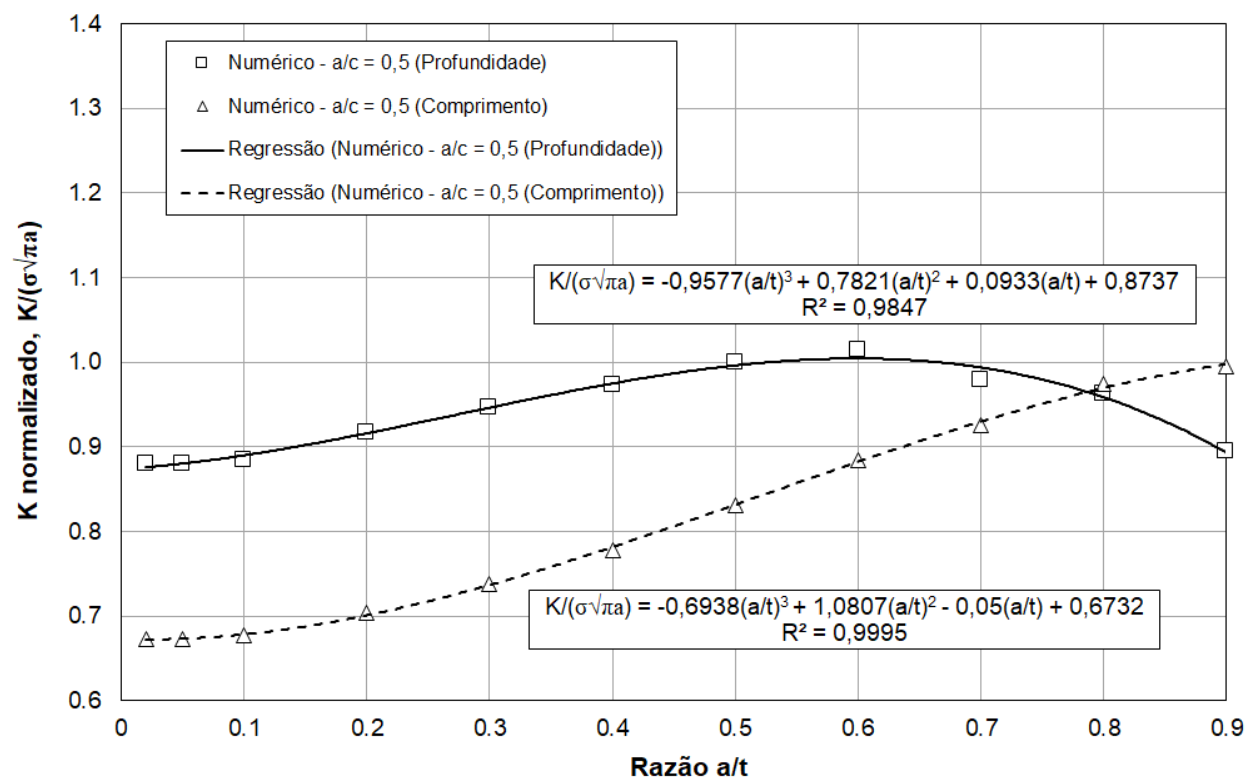

Fonte: Próprio autor. 
Figura B-4 - Regressões polinomiais para $K$ normalizado numérico - Trinca semielíptica sob tração com razão a/c igual a 1,0 .

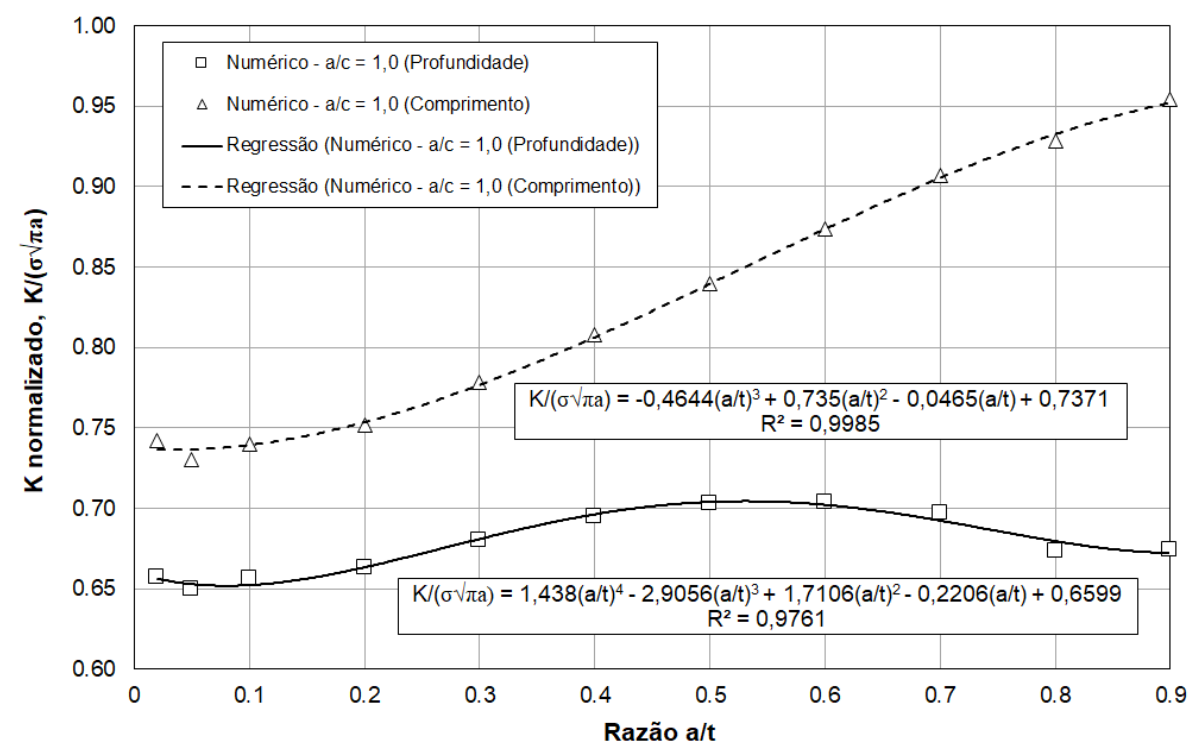

Fonte: Próprio autor.

\section{B.1.2 Propagação sob cisalhamento (Modo II)}

Da Figura B-5 à Figura B-7, são apresentadas as regressões obtidas a partir dos dados obtidos numericamente para o fator de intensidade de tensões para trincas semielípticas sob cisalhamento na geometria da roda de caçambas.

Figura B-5 - Regressões polinomiais para $K$ normalizado numérico - Trinca semielíptica sob cisalhamento com razão a/c igual a 0,2 .

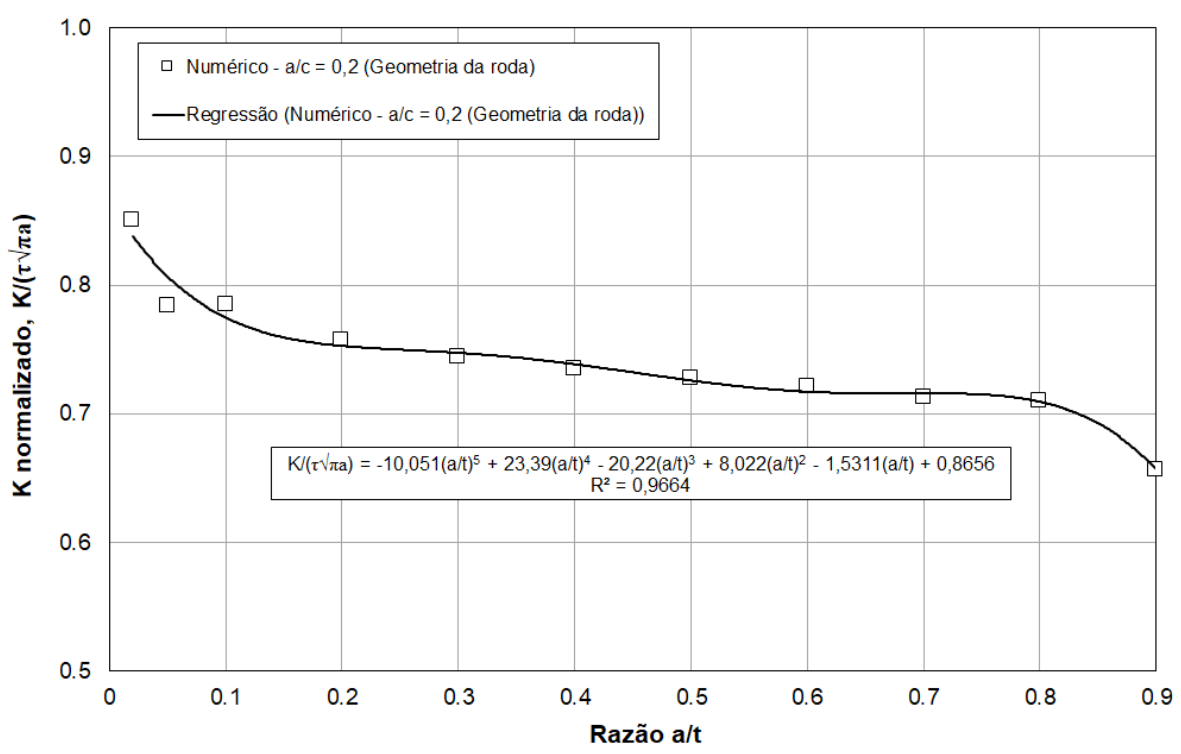

Fonte: Próprio autor. 
Figura B-6 - Regressões polinomiais para $K$ normalizado numérico - Trinca semielíptica sob cisalhamento com razão a/c igual a 0,5 .

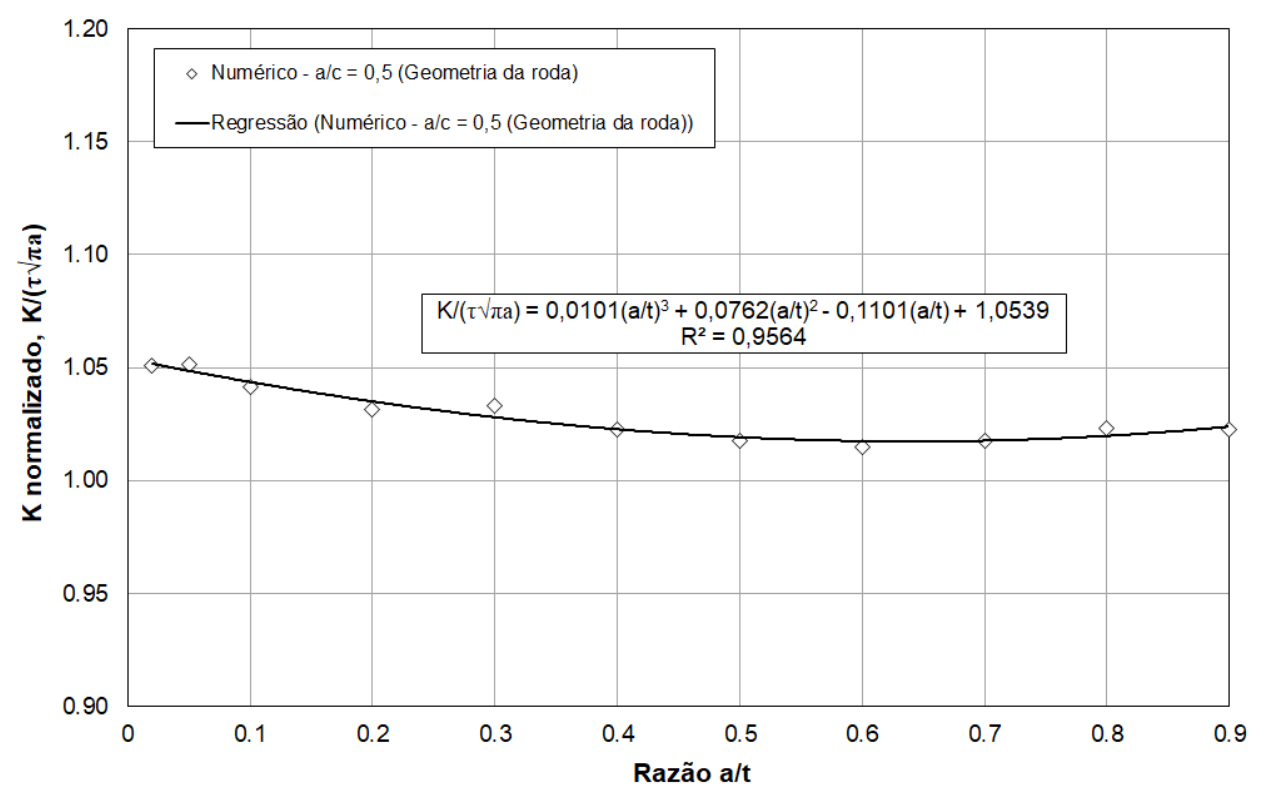

Fonte: Próprio autor.

Figura B-7 - Regressões polinomiais para $K$ normalizado numérico - Trinca semielíptica sob cisalhamento com razão a/c igual a 1,0 .

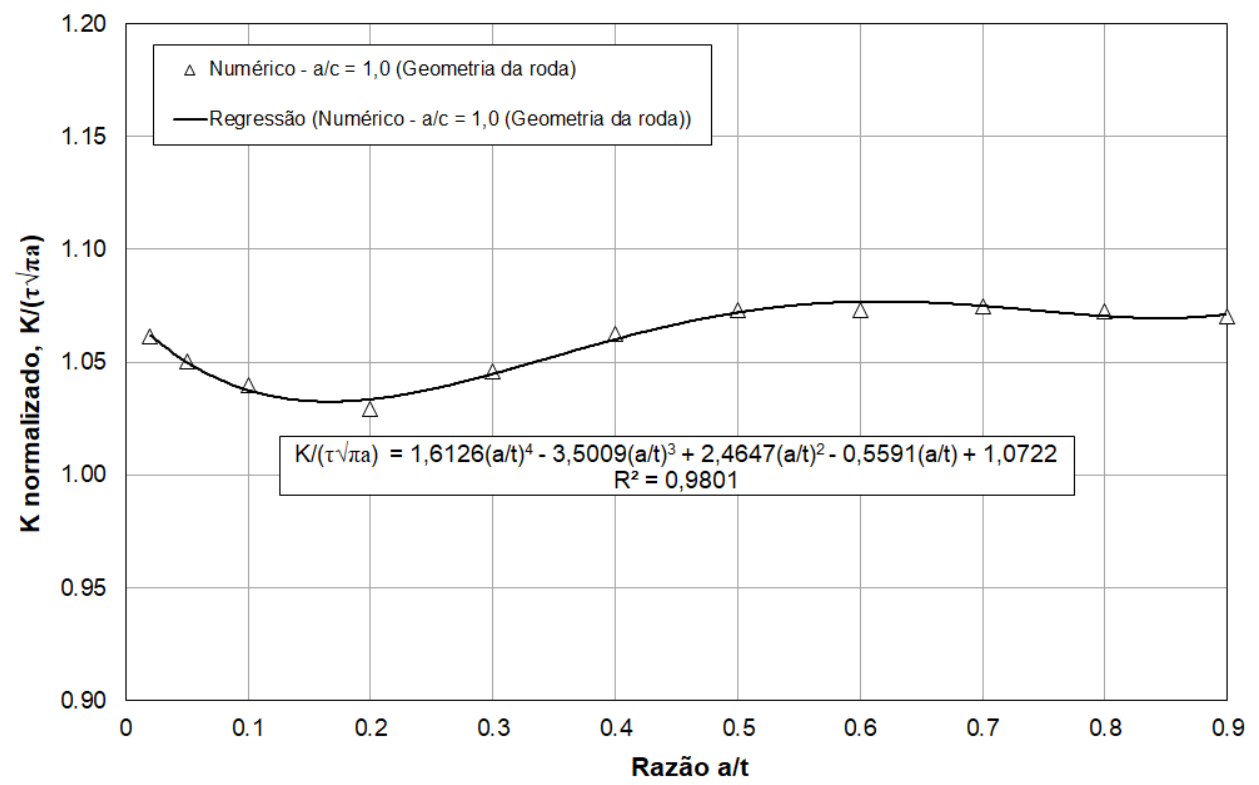

Fonte: Próprio autor. 


\section{B.2 Trinca passante pela espessura}

A formulação do fator de intensidade de tensões para uma trinca passante pela espessura foi obtida em Tada et al. [16]. A Figura B-8 ilustra as definições geométricas para este tipo de trinca.

Figura B-8 - Definições geométricas para uma trinca passante pela espessura.

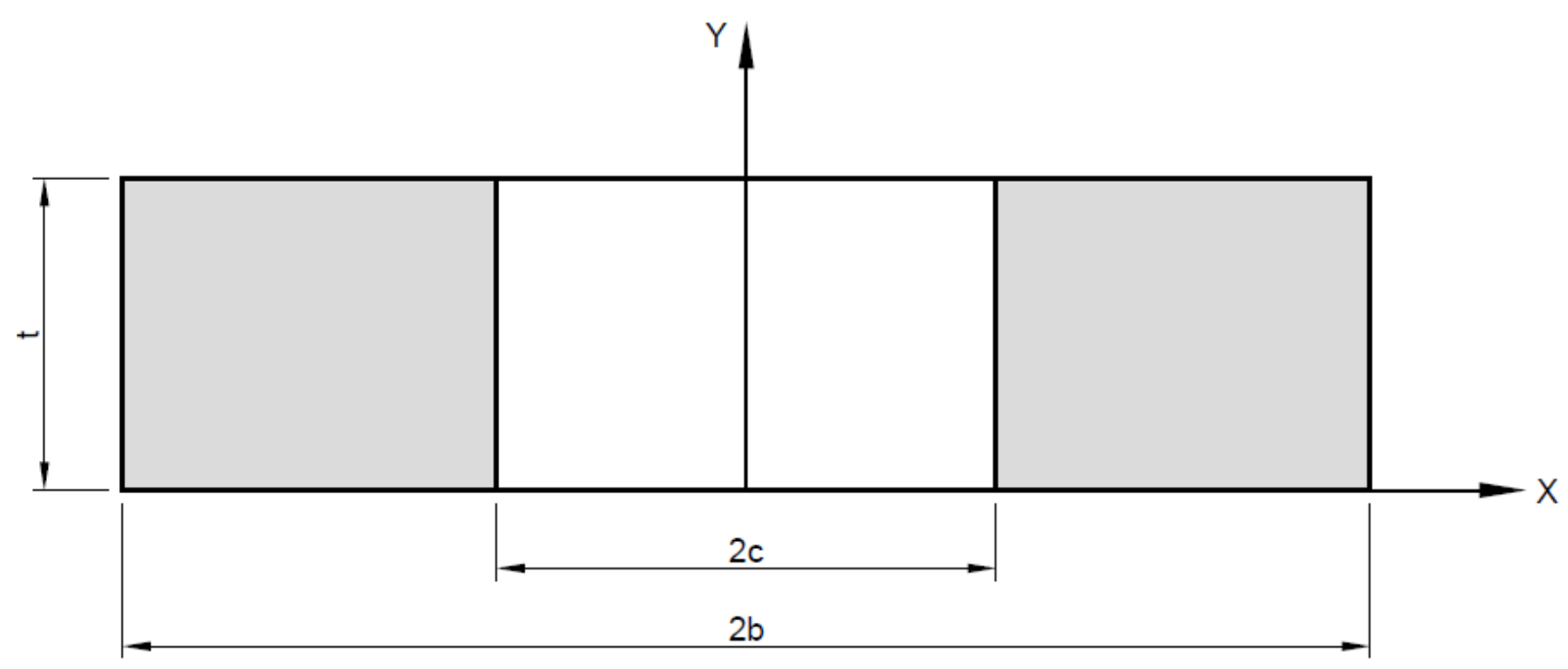

Fonte: Adaptado de Tada et al. [16].

Os fatores de intensidade de tensões para os modos I e II são dados pelas equações abaixo:

$$
\begin{aligned}
& K_{I}=\sigma \sqrt{\pi c} \cdot F(c / b) \\
& K_{I I}=\tau \sqrt{\pi c} \cdot F(c / b)
\end{aligned}
$$

O fator de forma utilizado na formulação é dado por:

$$
F(c / b)=\left(1-0,025\left(\frac{c}{b}\right)^{2}+0,06\left(\frac{c}{b}\right)^{4}\right) \sqrt{\sec \left(\frac{\pi c}{2 b}\right)}
$$




\section{B.3 Trinca semielíptica através da espessura}

A formulação do fator de intensidade de tensões para uma trinca semielíptica através da espessura foi obtida utilizando a mesma formulação para trincas passantes apresentada no item B.2. A Figura B-9 ilustra as definições geométricas para este tipo de trinca.

Figura B-9 - Definições geométricas para uma trinca semielíptica através da espessura.

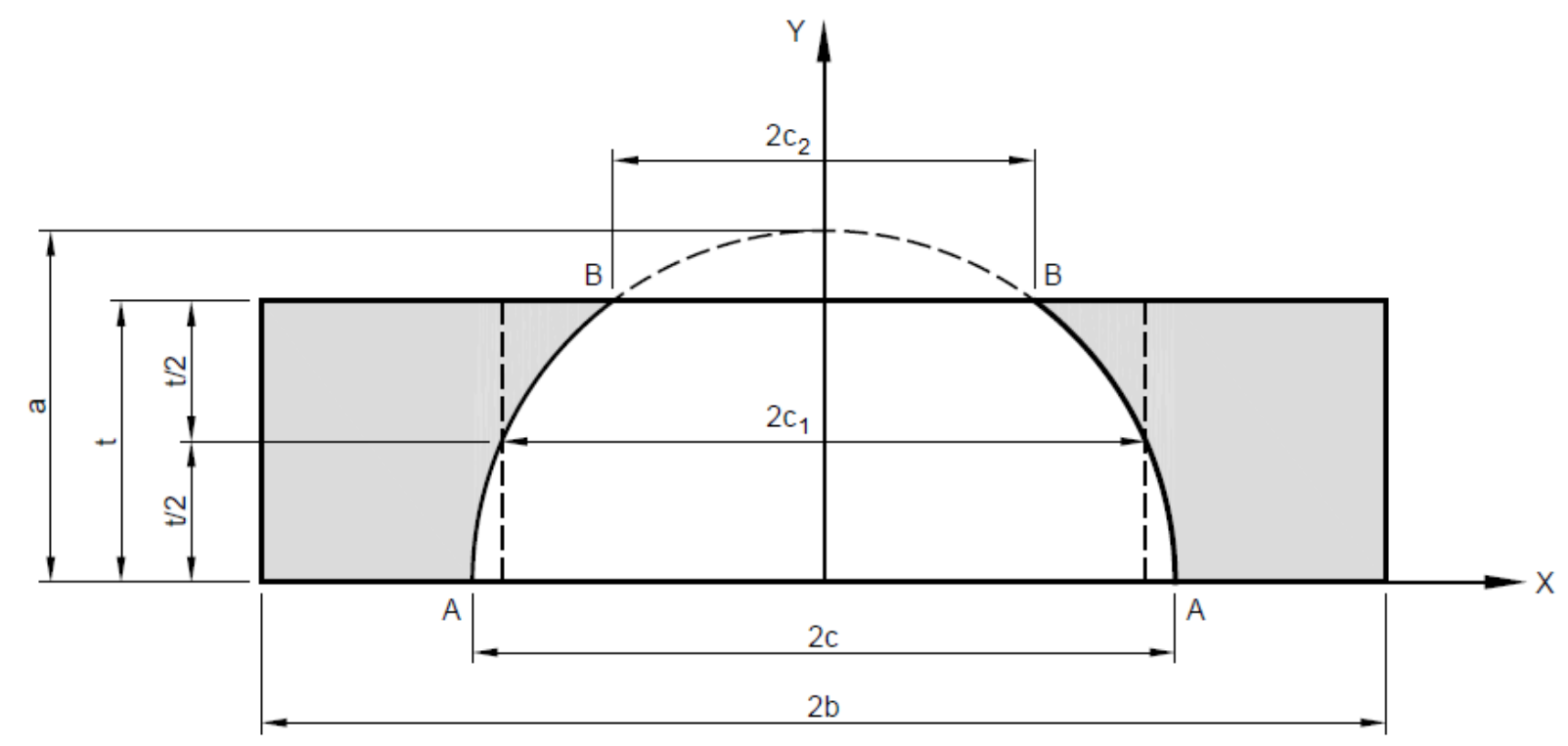

Fonte: Adaptado de Ando et al. [69].

A partir das dimensões $a$ e $c$ da trinca, pode-se determinar as dimensões $c_{1}$ e $c_{2}$ da Figura B-9:

$$
\begin{aligned}
& c_{1}=0.5 \sqrt{3 c^{2}+c_{2}^{2}} \\
& c_{2}=c \sqrt{1-\left(\frac{t}{a}\right)^{2}}
\end{aligned}
$$

O fator de intensidade de tensões para o modo I nos pontos A e B indicados na Figura B-9 podem ser calculados conforme as equações (B.16) e (B.17), respectivamente.

$$
\begin{aligned}
& K_{I}^{A}=\sigma \sqrt{\pi c} \cdot F(c / b) \\
& K_{I}^{B}=\sigma \sqrt{\pi c_{2}} \cdot F\left(c_{2} / b\right)
\end{aligned}
$$


Os fatores de forma para uma trinca semielíptica através da espessura são dados por:

$$
\begin{aligned}
& F(c / b)=\left(1-0,025\left(\frac{c}{b}\right)^{2}+0,06\left(\frac{c}{b}\right)^{4}\right) \sqrt{\sec \left(\frac{\pi c}{2 b}\right)} \\
& F\left(c_{2} / b\right)=\left(1-0,025\left(\frac{c_{2}}{b}\right)^{2}+0,06\left(\frac{c_{2}}{b}\right)^{4}\right) \sqrt{\sec \left(\frac{\pi c_{2}}{2 b}\right)}
\end{aligned}
$$

Para a determinação do fator de intensidade de tensões para o modo II, deve-se utilizar as equações (B.16) e (B.17) substituindo-se a tensão normal $\sigma$ pela tensão cisalhante $\tau$. 


\section{ANEXO C}

\section{C.1 Formulação do Fator de Amplificação $M_{k}$}

As equações para o cálculo do Fator de Amplificação $M_{k}$ do Fator de Intensidade de Tensões $K$ são apresentadas neste capítulo. A formulação foi obtida em Bowness e Lee [37], que realizaram um estudo detalhado utilizando a modelagem em elementos finitos de juntas de penetração total em $\mathrm{T}$ contendo trinca semielípticas, sendo incluso este estudo na norma BS 7910 [24]. Regressões múltiplas foram realizadas para a obtenção do melhor ajuste de curva para as soluções encontradas. A Figura C-1 ilustra o modelo computacional utilizado por Bowness e Lee [37] para a obtenção do fator de amplificação $M_{k}$.

Figura C-1 - Modelo computacional utilizado para a obtenção do fator $\mathrm{M}_{\mathrm{k}}$.

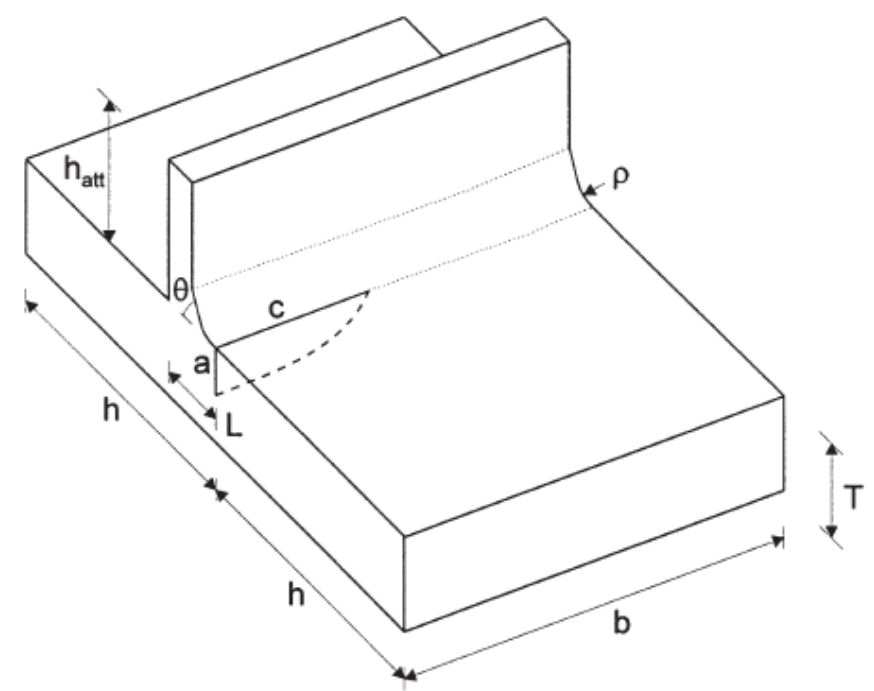

Fonte: Retirado de Bowness e Lee [37].

Uma vez que as equações apresentadas por Bowness e Lee [37] foram empregadas neste trabalho em um caso específico de dimensões do cordão de solda na estrutura da roda de caçambas (razão entre a largura do pé do cordão $L$ e a espessura da chapa $t^{(3)}$ igual a 2 e ângulo do cordão de solda $\theta$ igual a $45^{\circ}$ ), simplificações na formulação foram realizadas para redução do número de equações utilizadas. Destaca-se que as equações de $M_{k}$ são aplicáveis dentro dos seguintes limites:

\footnotetext{
${ }^{3}$ Ambas as nomenclaturas “ $t$ ” e " $T$ ” representam a espessura da chapa soldada. A nomenclatura " $t$ ” será adotada na formulação do $M_{k}$ em coerência com os demais capítulos deste trabalho.
} 


$$
M_{k} \text { válido } \rightarrow\left\{\begin{array}{c}
0,005 \leq a / t \leq 0,9 \\
0,1 \leq a / c \leq 1,0 \\
0,5 \leq L / t \leq 2,75
\end{array}\right.
$$

As equações a seguir, apresentam o cálculo do fator de amplificação $M_{k}$ para a direção de profundidade da trinca semielíptica.

$$
M_{k, a}=f_{1}\left(\frac{a}{t}, \frac{a}{c}\right)+f_{2}\left(\frac{a}{t}\right)+f_{3}\left(\frac{a}{t}\right)
$$

Onde:

$$
\begin{gathered}
f_{1}\left(\frac{a}{t}, \frac{a}{c}\right)=0,43358\left(\frac{a}{t}\right)^{\left\{g_{1}+\left[g_{2}\left(\frac{a}{t}\right)\right]^{g_{3}}\right\}}+0,93163 \cdot \exp \left[\left(\frac{a}{t}\right)^{-0,050966}\right]+g_{4} \\
f_{2}\left(\frac{a}{t}\right)=-0,21521\left[1-\left(\frac{a}{t}\right)\right]^{176,4199}+2,8141\left(\frac{a}{t}\right)^{0,1074\left(\frac{a}{t}\right)} \\
f_{3}\left(\frac{a}{t}\right)=0,33994\left(\frac{a}{t}\right)^{-0,35109}+1,9493\left(\frac{a}{t}\right)^{0,23003}+0,64582\left(\frac{a}{t}\right)^{2}-1,0814\left(\frac{a}{t}\right) \\
-11,07633
\end{gathered}
$$

Onde:

$$
\begin{aligned}
& g_{1}=-1,0343\left(\frac{a}{c}\right)^{2}-0,15657\left(\frac{a}{c}\right)+1,3409 \\
& g_{2}=1,3218\left(\frac{a}{c}\right)^{-0,61153} \\
& g_{3}=-0,87238\left(\frac{a}{c}\right)+1,2788 \\
& g_{4}=-0,4619\left(\frac{a}{c}\right)^{3}+0,6709\left(\frac{a}{c}\right)^{2}-0,37571\left(\frac{a}{c}\right)+4,6511
\end{aligned}
$$


As equações a seguir, apresentam o cálculo do fator de amplificação $M_{k}$ para a direção do comprimento da trinca semielíptica.

$$
M_{k, c}=f_{1}\left(\frac{a}{t}, \frac{c}{a}\right) \cdot f_{2}\left(\frac{a}{t}, \frac{a}{c}\right) \cdot f_{3}\left(\frac{a}{t}, \frac{a}{c}\right)
$$

Onde:

$$
\begin{aligned}
& f_{1}\left(\frac{a}{t}, \frac{c}{a}\right)=g_{1}\left(\frac{a}{t}\right)^{g_{2}}+g_{3}\left[1-\left(\frac{a}{t}\right)\right]^{g_{4}} \\
& f_{2}\left(\frac{a}{t}, \frac{a}{c}\right)=\left[-0,28639\left(\frac{a}{c}\right)^{2}+0,35411\left(\frac{a}{c}\right)+1,643\right]\left(\frac{a}{t}\right)^{g_{5}}+0,2745\left[1-\left(\frac{a}{t}\right)\right]^{g_{6}} \\
& f_{3}\left(\frac{a}{t}, \frac{a}{c}\right)=-1,9018\left(\frac{a}{t}\right)^{0,7543}+0,85122 \cdot \exp \left[\left(\frac{a}{t}\right)^{g_{7}}\right]
\end{aligned}
$$

Onde:

$$
\begin{aligned}
& g_{1}=0,0078157\left(\frac{c}{a}\right)^{2}-0,070664\left(\frac{c}{a}\right)+1.8508 \\
& g_{2}=-0,000424\left(\frac{c}{a}\right)^{2}+0,01065\left(\frac{c}{a}\right)-0,28878 \\
& g_{3}=-0,01864\left(\frac{c}{a}\right)^{2}+0,24311\left(\frac{c}{a}\right)-1,7644 \\
& g_{4}=-0,00504\left(\frac{c}{a}\right)^{2}+0,10514\left(\frac{c}{a}\right)+1,0503 \\
& g_{5}=-0,25473\left(\frac{a}{c}\right)^{2}+0,40928\left(\frac{a}{c}\right)+0,0021892 \\
& g_{6}=37,423\left(\frac{a}{c}\right)^{2}-15,741\left(\frac{a}{c}\right)+64,903 \\
& g_{7}=-0,011411\left(\frac{a}{c}\right)^{2}-0,00437\left(\frac{a}{c}\right)+0,51732
\end{aligned}
$$

